\title{
Konsequenzen der Expression des Ether à go-go Kaliumkanals
}

\author{
Dissertation \\ zur Erlangung des Doktorgrades \\ der Mathematisch-Naturwissenschaftlichen Fakultäten \\ der Georg-August-Universität zu Göttingen
}

vorgelegt von

Claudia Weber

aus Wolfenbüttel

Göttingen 2006 
D7

Referent: Prof. Dr. Rüdiger Hardeland

Korreferent: Prof. Dr. Andreas Stumpner

Tag der mündlichen Prüfung: Donnerstag, 6. Juli 2006 


\section{Inhaltsverzeichnis}

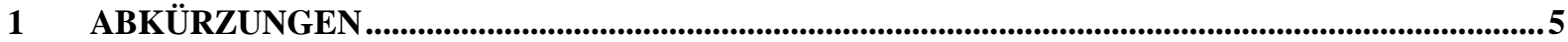

2 EINLEITUNG ..............................................................................................................................................

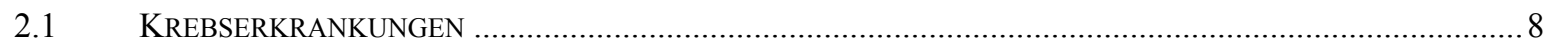

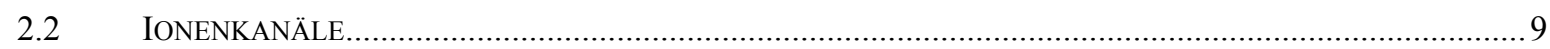

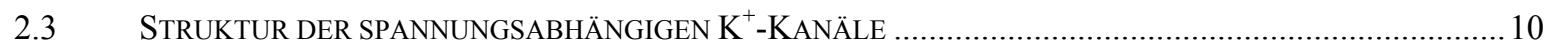

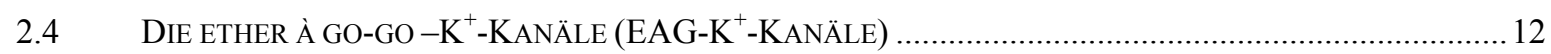

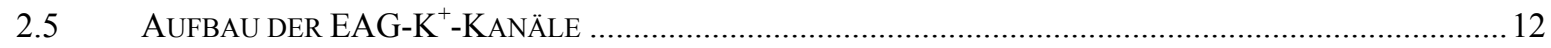

2.6 ELEKTROPHYSIOLOGISCHE MERKMALE DER EAG-K ${ }^{+}$-KANÄLE ......................................................... 14

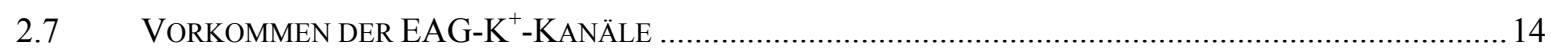

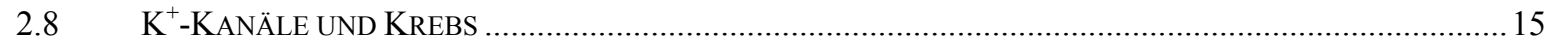

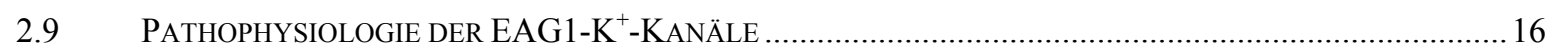

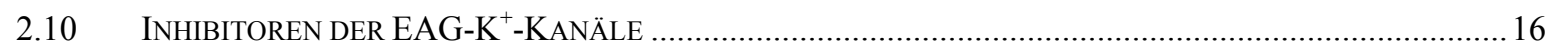

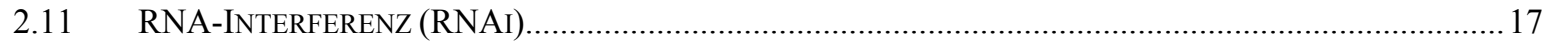

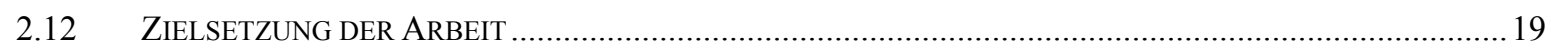

3 MATERIAL UND METHODEN ...........................................................................................................20

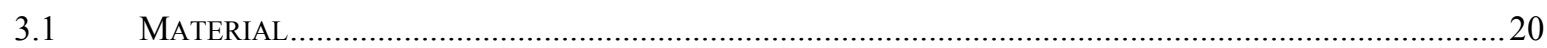

3.1.1 Bakterienstämme, Zelllinien und Versuchstiere ....................................................................20

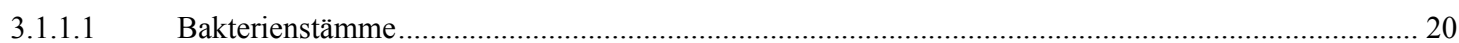

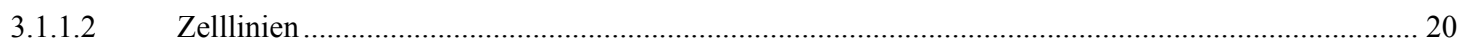

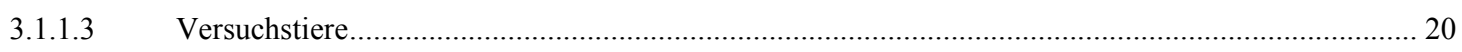

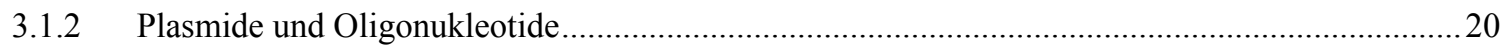

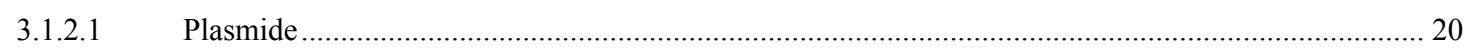

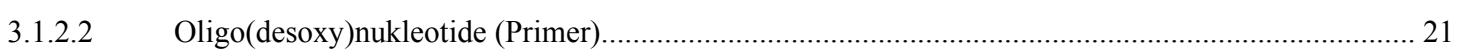

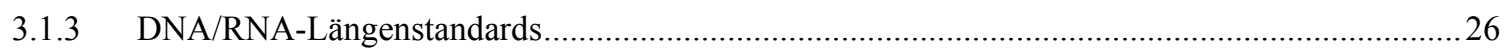

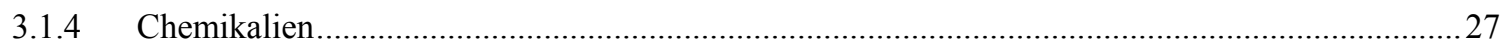

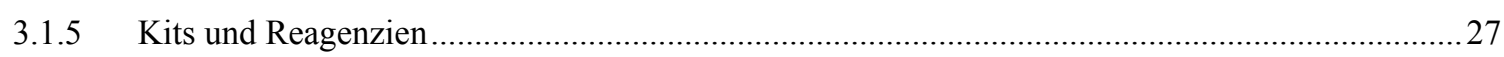

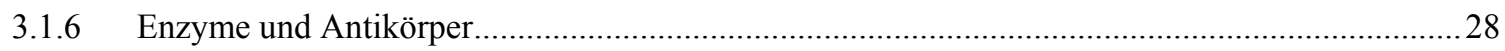

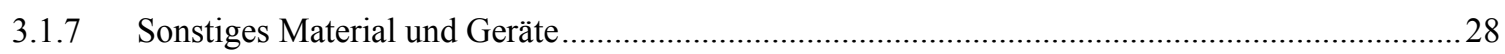

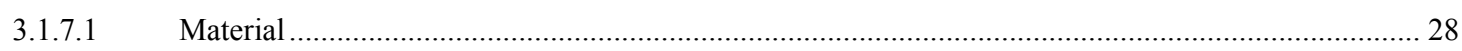

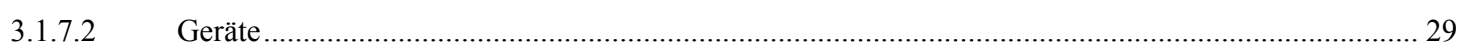

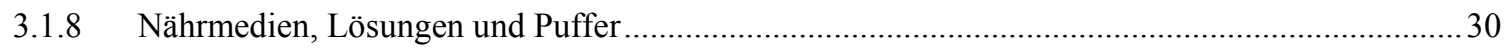

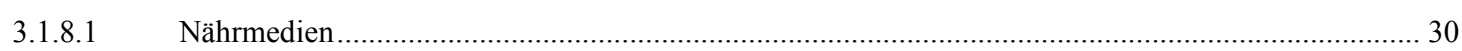

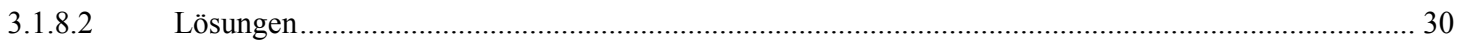

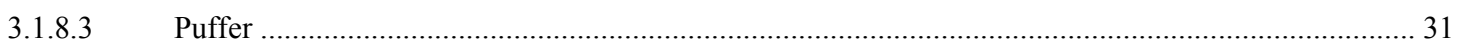

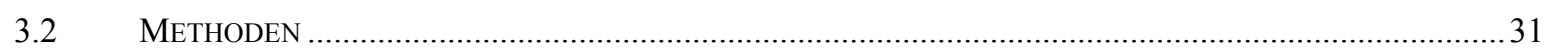

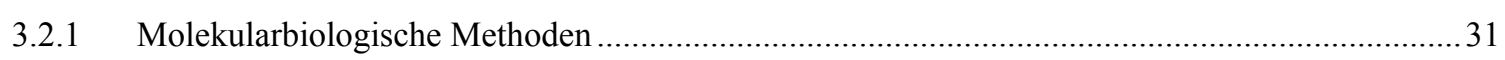

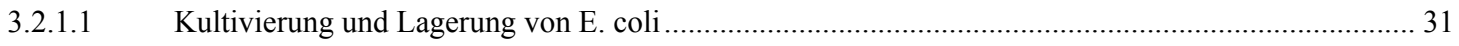

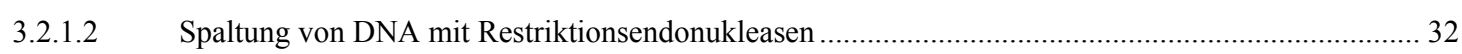

3.2.1.3 Ligation doppelsträngiger DNA ………............................................................................. 32 


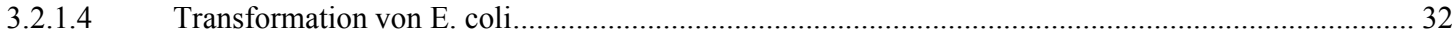

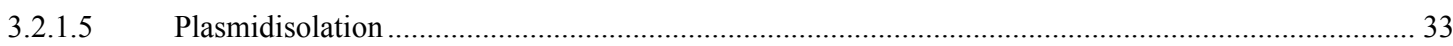

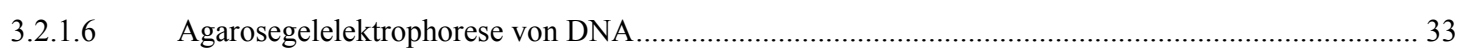

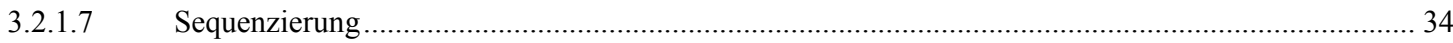

3.2.1.8 Vorbereitung des Material zur RNA-Isolation ............................................................................ 34

3.2.1.9 RNA-Isolation aus fettigem Gewebe (Qiazol) ............................................................................. 34

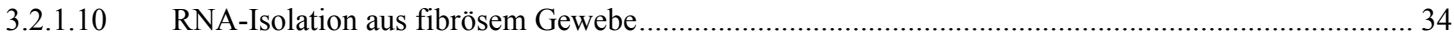

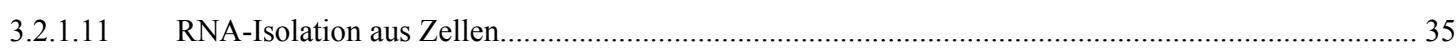

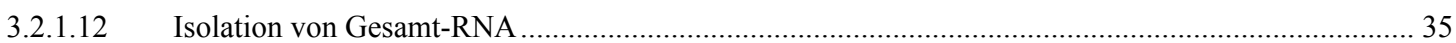

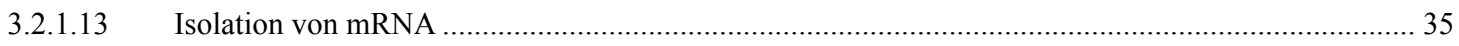

3.2.1.14 Auftrennung von RNA in Formaldehydgel und Agarose/Ethidiumbromidgel ................................ 36

3.2.1.15 Konzentrationsbestimmung von RNA, DNA und Oligonukleotiden ................................................ 36

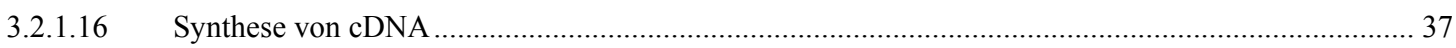

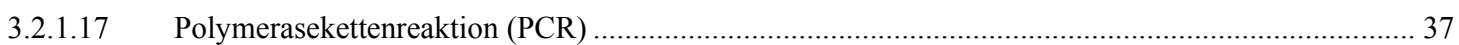

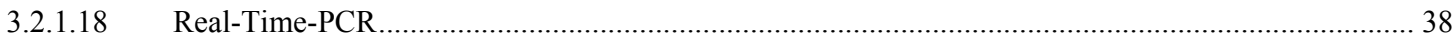

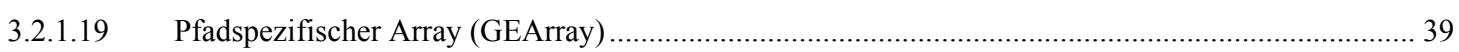

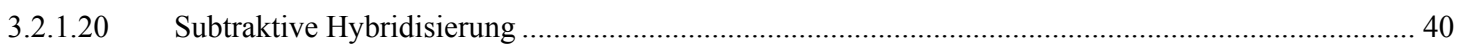

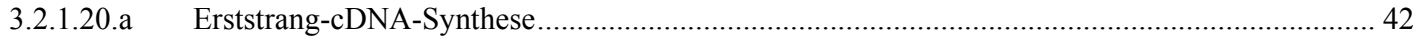

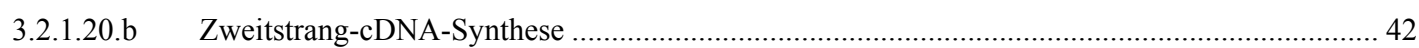

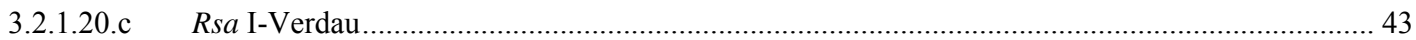

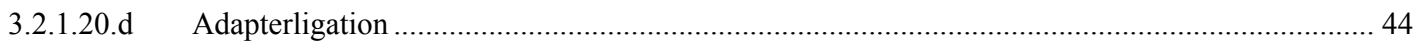

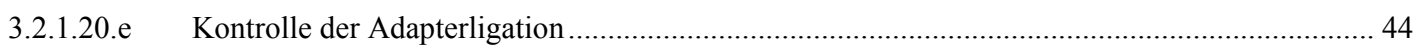

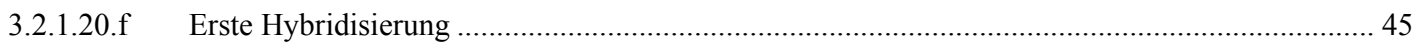

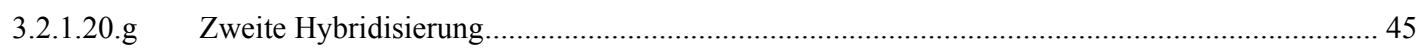

3.2.1.20.h Erste PCR-Amplifikation .................................................................................................... 45

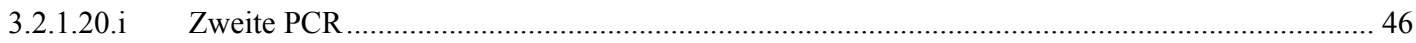

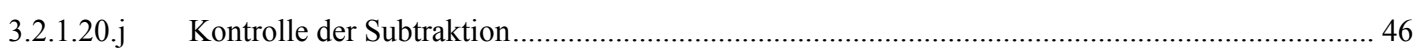

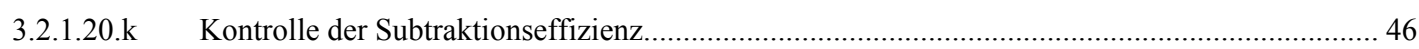

3.2.1.20.1 Klonierung der subtrahierten PCR-Fragmente ....................................................................... 47

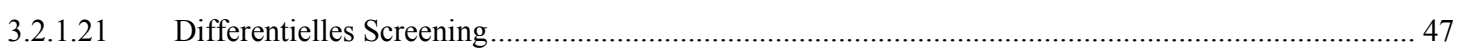

3.2.1.21.a Amplifizierung der cDNA-Fragmente aus der Bibliothek ..................................................... 48

3.2.1.21.b Aufbringen der potentiell differentiellen Klone auf Membranen ............................................ 48

3.2.1.21.c Herstellung der radioaktiv markierten subtrahierten Sonden ................................................... 49

3.2.1.21.d Herstellung der radioaktiv markierten EAG1a-Sonde ............................................................. 49

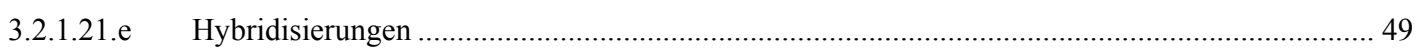

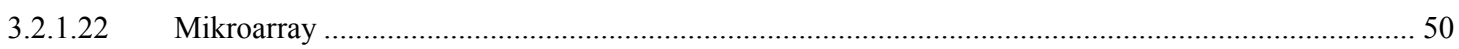

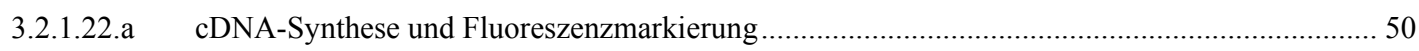

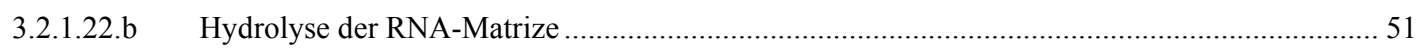

3.2.1.22.c Aufreinigung der markierten cDNA ....................................................................................... 51

3.2.1.22.d Agarosegelanalyse der markierten cDNA .............................................................................. 51

3.2.1.22.e Hybridisierung der markierten cDNA.................................................................................... 51

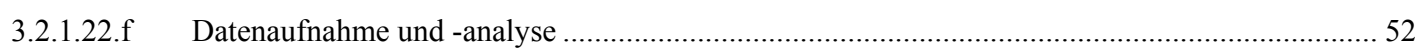

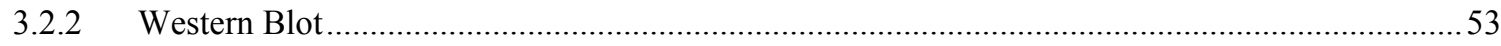

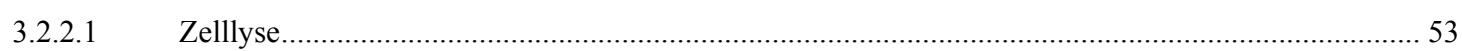

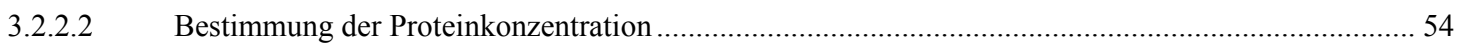

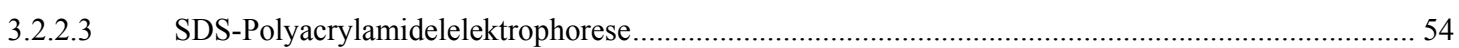




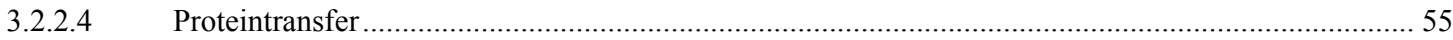

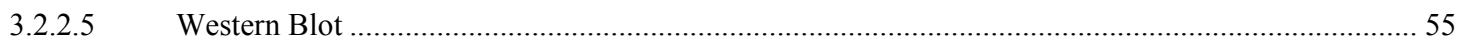

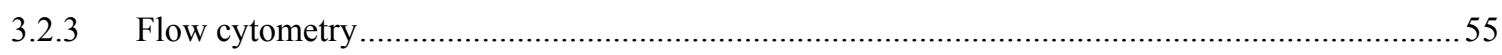

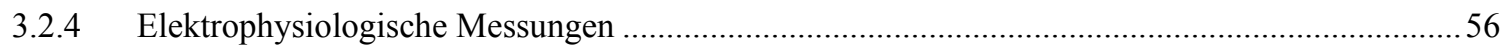

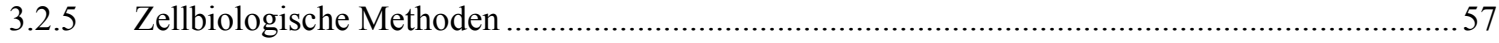

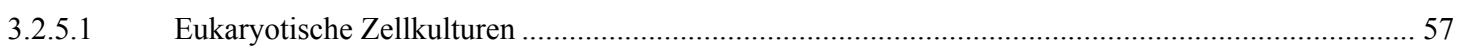

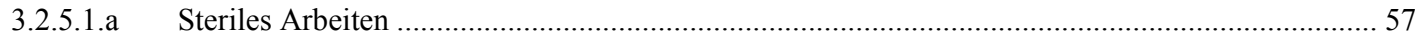

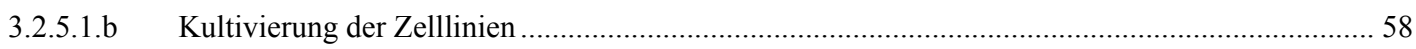

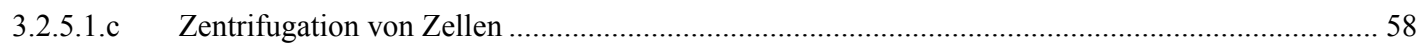

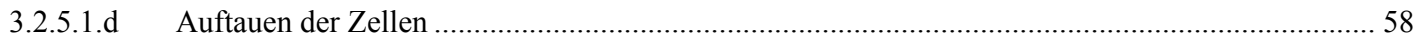

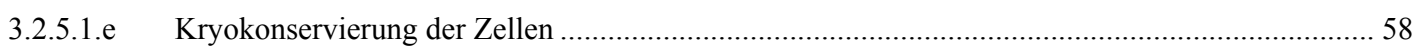

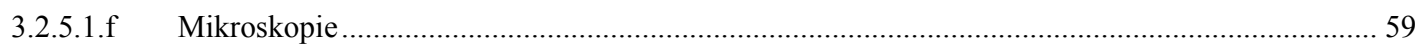

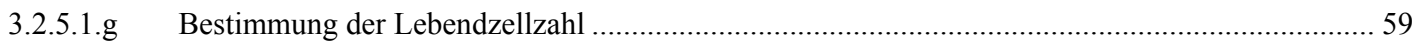

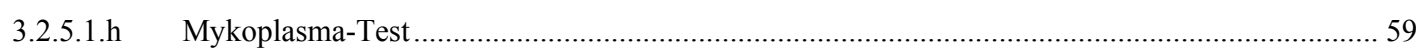

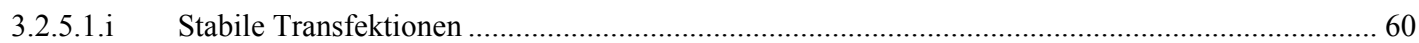

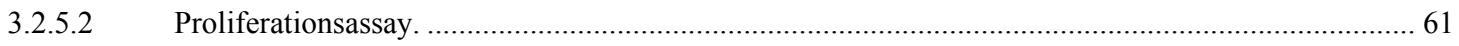

3.2.5.3 Matrixmetalloproteinase-2 (MMP-2) Aktivitätsassay ….................................................................. 61

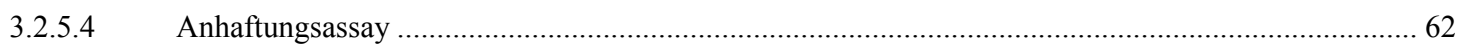

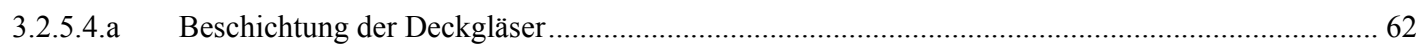

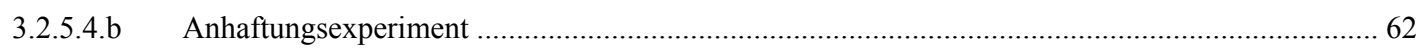

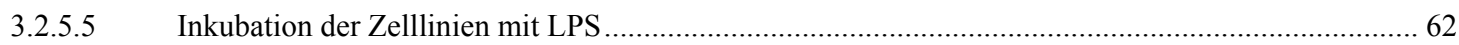

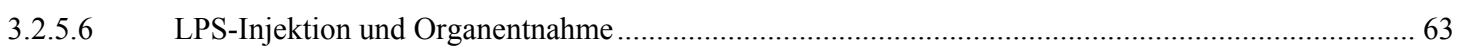

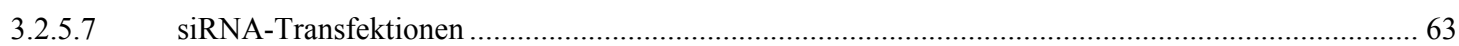

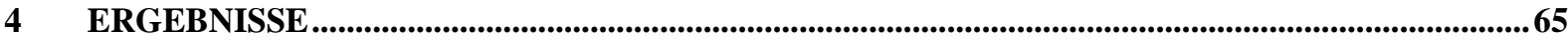

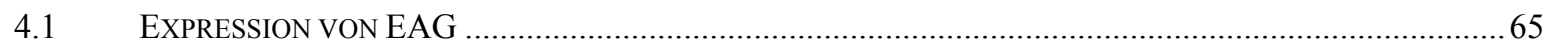

4.1.1 EAG1- und EAG2-Expression im Gehirn und peripheren Geweben der Maus und Ratte ............65

4.1.2 Auslösung differentieller EAG-Expression durch Lipopolysacchariden (LPS) .........................66

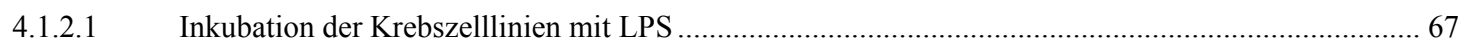

4.1.2.2 Intraperitoneale Injektion von LPS in Mäuse veränderte die EAG-Expression in einigen Organen,

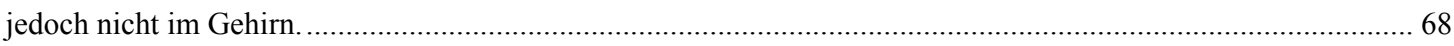

4.1.3 Herstellung und Charakterisierung EAG1a-transfizierter Zellen ............................................. 70

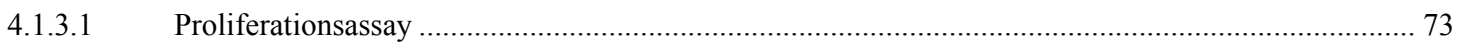

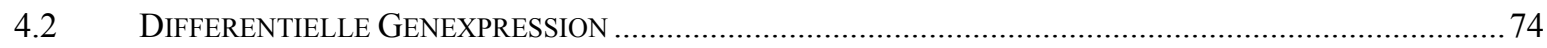

4.2.1 Differentielle Expression in transfizierten HEK-Zellen ..................................................... 74

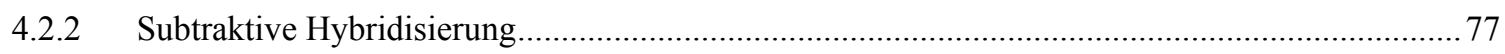

4.2.2.1 hGAPDH ist in hEAG1a-und pTracer-transfizierten HEK-Zellen differentiell exprimiert ................. 78

4.2.2.2 Differentielles Screening der Klone aus der Vorwärts- und Rückwärtssubtraktion ............................ 79

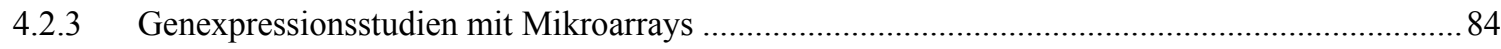

4.2.3.1 Behandlung von natürlich exprimierenden Krebszelllinien mit Astemizol verringert die Proliferation

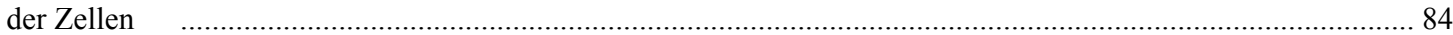

4.2.3.2 Differentielle Genexpression in Astemizol, Norastemizol und DMSO behandelten MDA-MB435S-

Zellen

4.2.4 Expression einiger in Krebs involvierter Gene unter Astemizolbehandlung ............................89

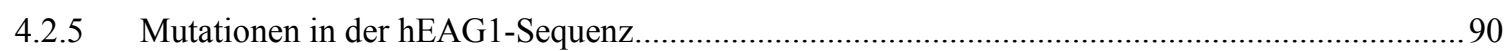


4.2.6 HEK-hEAG1a- und hG440S-Zellen zeigen einen veränderten Phänotyp ................................ 92

4.2.6.1 HEK-hEAG1a- und HEK-hG440S-Zellen weisen ein geringeres Haftungsvermögen auf verschiedenen extrazellulären Matrixproteinen auf.

4.2.6.2 Die Integrin $\beta 1$-Untereinheit ist in den kanalhaltigen Zellen nicht differentiell exprimiert ............... 94

4.2.6.3 Differentielle Expression von Fibronektin ............................................................................. 95

4.2.6.4 hEAG1a-haltige HEK-Zellen produzieren weniger MMP2-RNA und scheiden weniger MMP2-

Protein aus

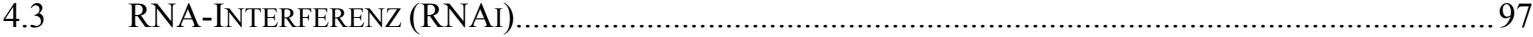

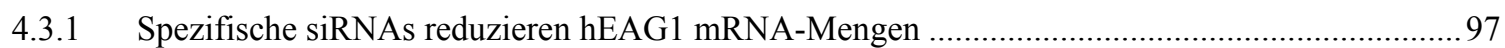

4.3.2 Die Reduktion von hEAG1a durch EAG-siRNAs ist spezifisch .......................................... 100

4.3.3 hEAG1-siRNAs lösen keine unspezifischen Antworten der Zelle aus ..................................... 101

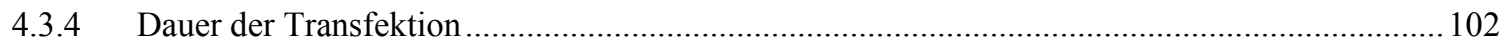

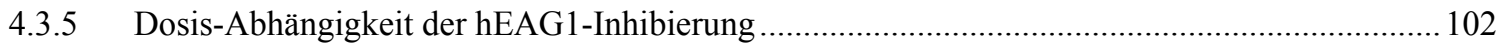

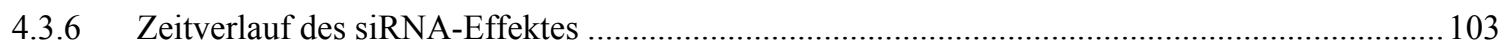

4.3.7 Die Stilllegung von hEAG1 mit siRNAs reduziert die Proliferation von Tumorzelllinien ......... 105

4.3.8 Behandlung der transfizierten HEK-, MDA-MB435S- und Daoy-Zellen mit hEAG1-siRNAs erhöht die RNA-Menge des Zinkfingertranskriptionsfaktors MAZ ....................................................... 106

4.3.9 Die Transkription der durch hMAZ regulierten Protoonkogene hc-Myc und hTERT wird durch

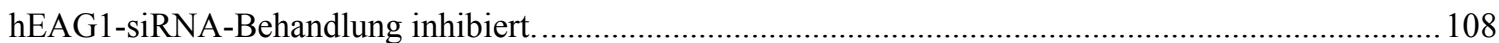

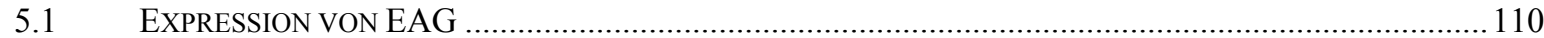

5.1.1 Expression von EAG in Ratten und Mäusen ..................................................................... 110

5.1.2 Induktion oder Repression von EAG durch Auslösung einer sterilen Entzündung mit LPS ....... 112

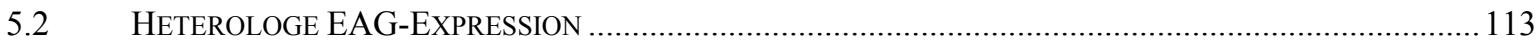

5.2.1 hEAG1a-haltige HEK-Zellen zeigten eine verminderte Proliferation ..................................... 114

5.2.2 Differentielle Matrix-Metalloproteinaseproduktion der hEAG1a-haltigen Zellen .................... 115

5.2.3 hEAG1a-haltige HEK-Zellen haften schlechter auf Plastik und extrazellulären

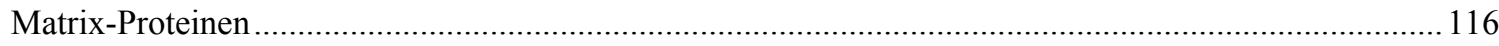

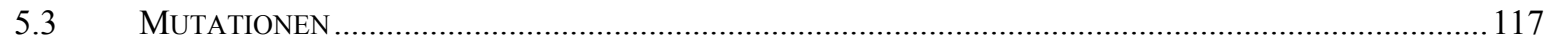

5.4 IDENTIFIKATION DIFFERENTIELL EXPRIMIERTER GENE IN TRANSFIZIERTEN HEK-ZELLEN .............. 118

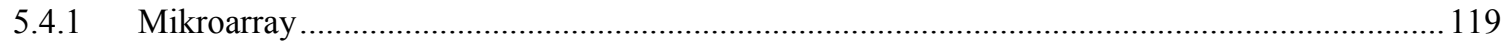

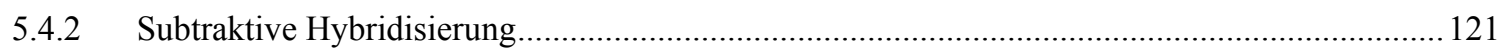

5.4.2.1 Das Haushaltsgen GAPDH war in den verglichenen Zelllinien differentiell exprimiert .................. 122

5.4.2.2 Zwei Gene, RACK1 und MAZ, sind in kanalhaltigen Zellen differentiell exprimiert ...................... 123

5.5 HEAG1 WIRD EFFIZIENT UND HOCHSPEZIFISCH DURCH ANTI-EAG1-SIRNAS GEHEMMT ................ 124

5.6 DIE EXPRESSION VON MAZ UND ZWEI SEINER ZIELGENE WERDEN DURCH HEAG1 MODULIERT ...... 127

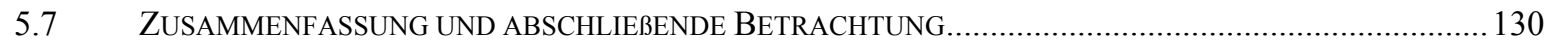




\section{Abkürzungen}

A

$\mathrm{Abb}$

ATP

bp

BSA

bzw.

${ }^{\circ} \mathrm{C}$

C

ca.

cDNA

$\mathrm{Ci}$

CTP

dATP

dCTP

DEPC

DMSO

DNA

DNase

dNTP

ds

EAG

E. coli

EDTA

Fam

FCS

$\mathrm{g}$

$\times \mathrm{g}$

G

GAPDH

$\mathrm{h}$

$\mathrm{K}^{+}$-Kanäle
Adenin

Abbildung

Adenosintriphosphat

Basenpaar

engl.: bovine serum albumin

beziehungsweise

Grad Zelsius

Cytosin

zirka

komplementäre (engl.: copy) DNA

Curie

Cytosintriphosphat

Desoxyadenosintriphosphat

Desoxycytidintriphosphat

Diethyl Pyrocarbonat

Dimethylsulfoxid

Desoxy-Ribonukleinsäure

Desoxyribonuklease

Desoxy-Nukleotid

doppelsträngig

ether à go-go

Escherichia coli

Ethylendiamintetraessigsäure

Carboxyfluorescin

Fötales Kälberserum

Gramm

Vielfaches der Erdbeschleunigung $\left(9.81 \mathrm{~m} / \mathrm{s}^{2}\right)$

Guanin

Glycerinaldehyd-3-Phosphat-Dehydrogenase

Stunde

Kaliumkanäle 
$\mathrm{kb}$

$\mathrm{kDa}$

IPTG

1

lacZ

LB

LPS

M

$\mathrm{mM}$

$\mathrm{mm}$

mg

$\min$

$\mathrm{ml}$

$\mu \mathrm{g}$

$\mu 1$

MOPS

mRNA

miRNA

OD

p. A.

PBS

PCR

$\mathrm{pH}$

RISC

RNA

RNase

RNAi

RT

S

S

SDS

SDS-PAGE
Kilobasen

Kilodalton

Isopropyl- $\beta$-D-thiogalactopyranosid

Liter

lacZ-Gen kodierend für die $\beta$-Galaktosidase

Luria-Bertani (Medium)

Lipopolysaccharide

molar, Molarität

millimolar

Millimeter

Milligramm

Minute

Milliliter

Mikrogramm

Mikroliter

3-(N-Morpholino)-Propansulfonsäure

Boten-Ribonukleinsäure (engl::messenger RNA)

microRNA

Optische Dichte

zur Analyse

Phosphat-gepufferte Saline

Polymerasekettenreaktion

negativer dekadischer Logarithmus der

Protonenkonzentration

RNA induced silencing complex

Ribonukleinsäure

Ribonuklease

RNA-Interferenz

Raumtemperatur

Transmembransegment

Sekunde

Natriumdodecylsulfat

SDS-Polyakrylamidgelelektrophorese 


\section{SEM}

siRNA

SSC

Taq-Polymerase

TBE

TE

TEMED

$\mathrm{T}$

Tamra

Tris

U

UV

u. a.

V

$\mathrm{v} / \mathrm{w}$

$\mathrm{v} / \mathrm{v}$

Vol

X-Gal

z. B.
Standardfehler

small interfering RNA

Natriumcitrat-Puffer

DNA-Polymerase aus Thermus aquaticus

Tris-Borat-Puffer

Tris-EDTA-Puffer

$\mathrm{N}, \mathrm{N}, \mathrm{N}^{\prime}$ N'-Tetramethylethylendiamin

Thymidin

Carboxytetramethylrhodamin

Trishydroxymethylaminoethan

Einheit für Enzymaktivität (engl.: unit)

ultraviolettes Licht

unter anderem

Volt

Volumen pro Gewicht

Volumen pro Volumen

Volumen

Substrat der $\beta$-Galaktosidase

zum Beispiel

Die Benennung der einzelnen Aminosäuren erfolgte nach dem Ein-Buchstaben-Code 


\section{Einleitung}

\subsection{Krebserkrankungen}

Krebszellen weisen zwei von normalen Zellen abweichende Hauptmerkmale auf, die Fähigkeit, sich unkontrolliert zu vermehren und das sie umgebende Gewebe zu infiltrieren (Invasion). Trifft ersteres zu, spricht man von gutartigen (benignen), trifft beides zu, von bösartigen (malignen) Tumoren. Den der Invasion häufig folgende Vorgang der Auswanderung und Bildung neuer Tumore in einem anderen Gewebe des Körpers nennt man Metastasierung. Die meisten Krebsarten entstehen aus einer einzigen transformierten Zelle, in der sich vererbliche Veränderungen ereignet haben, die der Zelle die Fähigkeit verleihen, schneller und ungehemmt auch unter suboptimalen Bedingungen zu proliferieren. Diese Veränderungen können verschiedener Art sein. So können sie Punktmutationen, Insertionen und Deletionen von Gensequenzen oder Abnormalitäten ganzer Chromosomen darstellen (Russo et al., 1998). Dabei wird entweder ein stimulatorisches Gen (Protoonkogen) hyperaktiviert (Onkogen) oder ein inhibitorisches Gen (Tumorsuppressorgen) inaktiviert. Solche Gene, die Krebs erzeugen, wenn sie von Mutationen betroffen werden, kodieren für Wachstumsfaktoren und deren Rezeptoren, Proteine der Signaltransduktionskaskaden und Transkriptionsfaktoren und im Falle der Metastasierung auch Proteasen und Zelladhäsionsproteine (Bashyam, 2002). Teilweise werden auch verschiedene Spleißvarianten des gleichen Gens in Krebsgewebe und normalen Gewebe exprimiert (Agrawal und Eng, 2006). Es häufen sich in den letzten Jahren die Hinweise darauf, dass auch Ionenkanäle als Proto-Onkogene fungieren können (Abdul und Hoosein, 2002a; Abdul und Hoosein, 2002b; Fraser et al., 2003; Preussat et al., 2003). Normalerweise ist jedoch eine einzige Mutation nicht ausreichend, um Krebs hervorzurufen. Es bedarf sukzessiver Runden von Mutationen und Selektion, dass sich Zellen mit einem leicht gestörten Phänotyp zu einem bösartigen, metastasierenden Tumor entwickeln (Hahn und Weinberg, 2002). Die Metastasierung erfolgt in mehreren Schritten. Die Krebszellen müssen sich von ihren Nachbarzellen ablösen, das Ursprungsgewebe durch die Basalmembran verlassen und dabei andere Gewebe durchqueren, um zu Blut- oder Lymphgefäßen zu kommen. Um in die Zirkulation zu gelangen, müssen sie durch die Basalmembran und die Endothelauskleidung wandern, den Transport durch Blut und Lymphe überleben und an anderer Stelle des Körpers an die Gefäßwände anhaften, sie durchqueren und in der neuen Umgebung proliferieren. Der gesamte Vorgang der 
Metastasenbildung unterliegt daher einer strengen zeitlichen und örtlichen Regulation von Anheftung, Ablösung und proteolytischen Prozessen. Es verwundert daher nicht, dass die beteiligten Proteine (Matrixmetalloproteinasen, Extrazelluläre Matrixproteine, Integrine) auf mehreren Ebenen der Expression und Funktion reguliert werden und in enger Wechselwirkung miteinander stehen (Ludwig et al., 2005). Während fast aller Vorgänge der Zellentartung kommt es zu Änderungen der Genexpression, entweder als primäre Ursache oder als sekundäre Folge von erblichen Veränderungen, die sich als Änderungen in den oben erläuterten physiologischen Funktionen äußern.

\subsection{Ionenkanäle}

Zellen müssen mit ihrer Umgebung kommunizieren um zu überleben. Während hydrophobe Moleküle wie Gase und kleine polare Moleküle wie Wasser durch die hydrophobe Zellmembran diffundieren können, stellt eben diese Membran eine Barriere für die meisten polaren oder geladenen Stoffe dar. Daher haben sich im Laufe der Evolution Strukturen entwickelt, die einen Austausch von Stoffen und Informationen durch die Membran gewährleisten. Diese teilen sich in drei Gruppen auf: Zelloberflächenrezeptoren, Transporter und Ionenkanäle. Rezeptoren leiten durch Bindung eines Liganden ein Signal an eine Transduktionskaskade im Zellinneren weiter, die gewöhnlich im Zellkern eine Expressionsänderung eines oder mehrerer Gene bewirkt. Sowohl Transporter als auch Ionenkanäle sind in den Transport von Ionen über die Membran involviert, wobei die Transporter unter Energieverbrauch die Ionen auch entgegen dem elektrochemischen Gradienten bewegen können, während Ionenkanäle Ionen mit dem Gradienten transportieren. Ionenkanäle werden nach ihrer Selektivität für verschiedene Ionen Natrium-( $\left.\mathrm{Na}^{+}\right)$, Kalium$\left(\mathrm{K}^{+}\right)$, Kalzium- $\left(\mathrm{Ca}^{2+}\right)$ und Chloridkanäle $\left(\mathrm{Cl}^{-}\right)$benannt. $\mathrm{K}^{+}$-Kanäle bilden die größte Gruppe und sind meist tetramere, in biologische Membranen eingebettete Makromoleküle (Coetzee et al., 1999). Sie sind an einer Vielzahl physiologischer Funktionen und in fast allen Zelltypen aller Organismen an der Entstehung und Aufrechterhaltung des Membranpotentials beteiligt (Miller, 2000).

Die Einteilung der $\mathrm{K}^{+}$-Kanäle in Familien basiert auf der primären Aminosäuresequenz der porenbildenden $\alpha$-Untereinheiten. Drei Gruppen mit zwei (2TM/1P-Kanäle), vier (4TM/2PKanäle) und sechs (6TM/1P-Kanäle) membrandurchspannenden Segmenten sind bekannt. Zu der ersten Gruppe zählen die einwärtsgleichrichtenden $\mathrm{K}^{+}$-Kanäle (Kir, inward rectifier) mit 
nur zwei membrandurchspannenden $\alpha$-Helices (TM) und einer Porenregion (P) (Abb. 1). In der zweiten Gruppe, die die Leckstrom-Kanäle TWIK, TREK, TASK und TRAAK beinhaltet, sind $\mathrm{K}^{+}$-Kanäle mit vier Transmembrandomänen und zwei Porenregionen zusammengefasst, die als Dimere assemblieren (Coetzee et al., 1999). Die dritte Familie bilden die spannungsabhängigen $\mathrm{K}^{+}$-Kanäle $\quad(\mathrm{Kv}$ - und KCNQ-Kanäle), die aus sechs Transmembrandomänen und einer Porenregion aufgebaut sind und durch Depolarisierung aktiviert werden. In diese Gruppe gehören die shaker-verwandten Kanäle, die ether à go-go(EAG) verwandten Kanäle und die $\mathrm{Ca}^{2+}$-abhängigen $\mathrm{K}^{+}$-Kanäle.
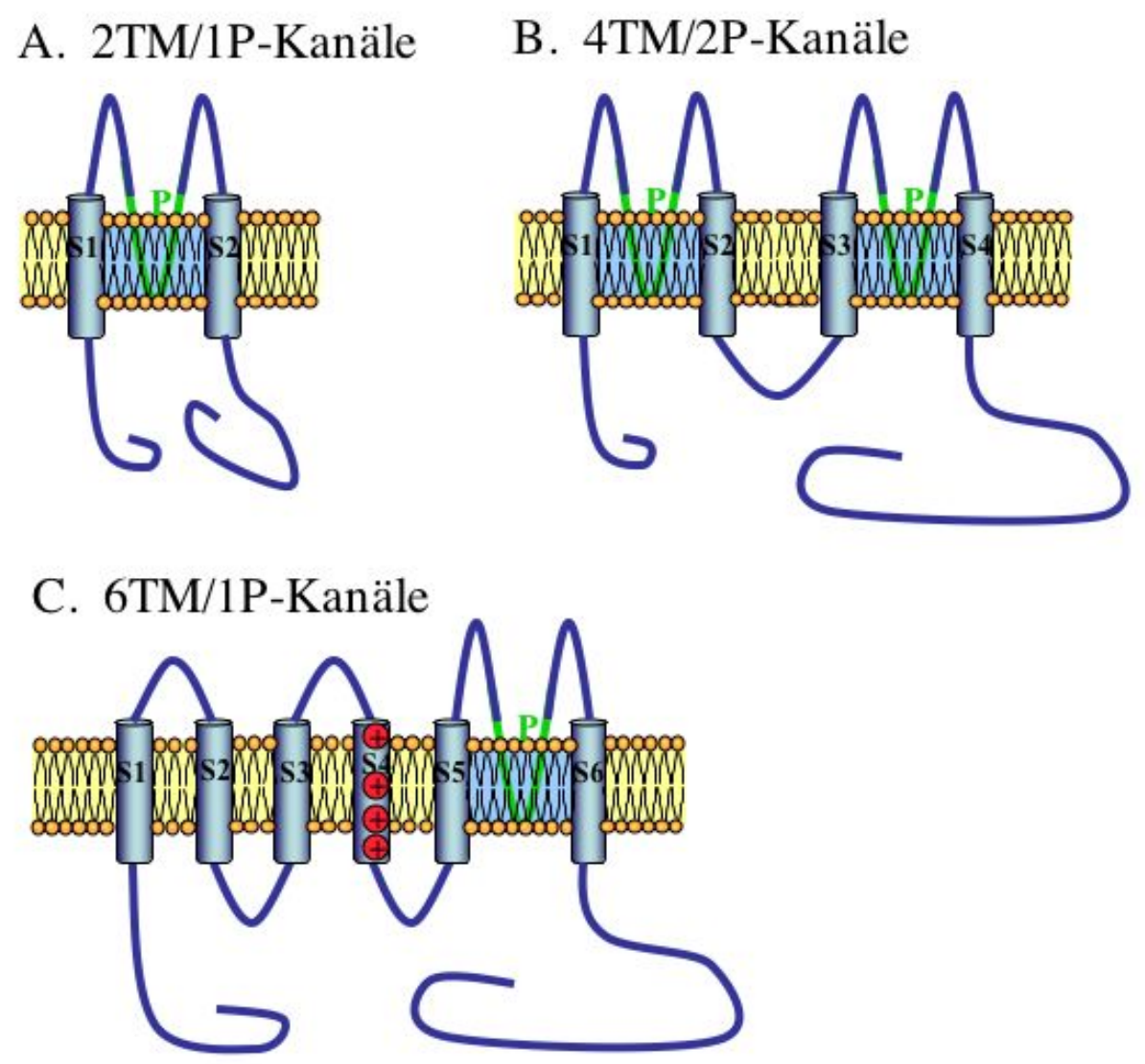

Abb. 1: Schematische Darstellung der Strukturmerkmale der verschiedenen $\mathbf{K}^{+}$-Kanalfamilien. A: 2TM/1P-Kanal; B: 4TM/2P-Kanal; C: 6TM/1P-Kanal. TM Transmembrandomäne, P Porendomäne, S Transmembransegment 1-6.

\subsection{Struktur der spannungsabhängigen $\mathrm{K}^{+}$-Kanäle}

Spannungsabhängige $\mathrm{K}^{+}$-Kanäle öffnen sich, wenn die Membran depolarisiert wird. Damit erlauben sie den Ionen mit Diffusionsgeschwindigkeit passiv entlang ihres elektrochemischen Gradienten durchzufließen. Es wird deutlich, das $\mathrm{K}^{+}$-Kanäle zwei prinzipielle Funktionselemente besitzen: den Spannungssensor und die Ionen-selektive Pore. 
Spannungsabhängige $\mathrm{K}^{+}$-Kanäle bestehen aus vier Untereinheiten, die eine zentrale ionenpermeable Pore umschließen. Jede Untereinheit ist aus sechs $\alpha$-Helices (S1-S6) mit intrazellulären N- und C-Termini aufgebaut. Die ersten vier Transmembranhelices (S1-S4) bilden den Spannungssensor, während die letzten beiden (S5-S6) zusammen mit einer dazwischen liegenden, in die Membran zurückgefalteten Schleife die Pore auskleiden. Die Pore enthält neben einer kurzen $\alpha$-Helix das charakteristische, bei $\mathrm{K}^{+}$-Kanälen hochkonservierte Sequenzmotiv (TVGYG) und wirkt als Selektivitätsfilter (Sands et al., 2005) (Abb. 2).

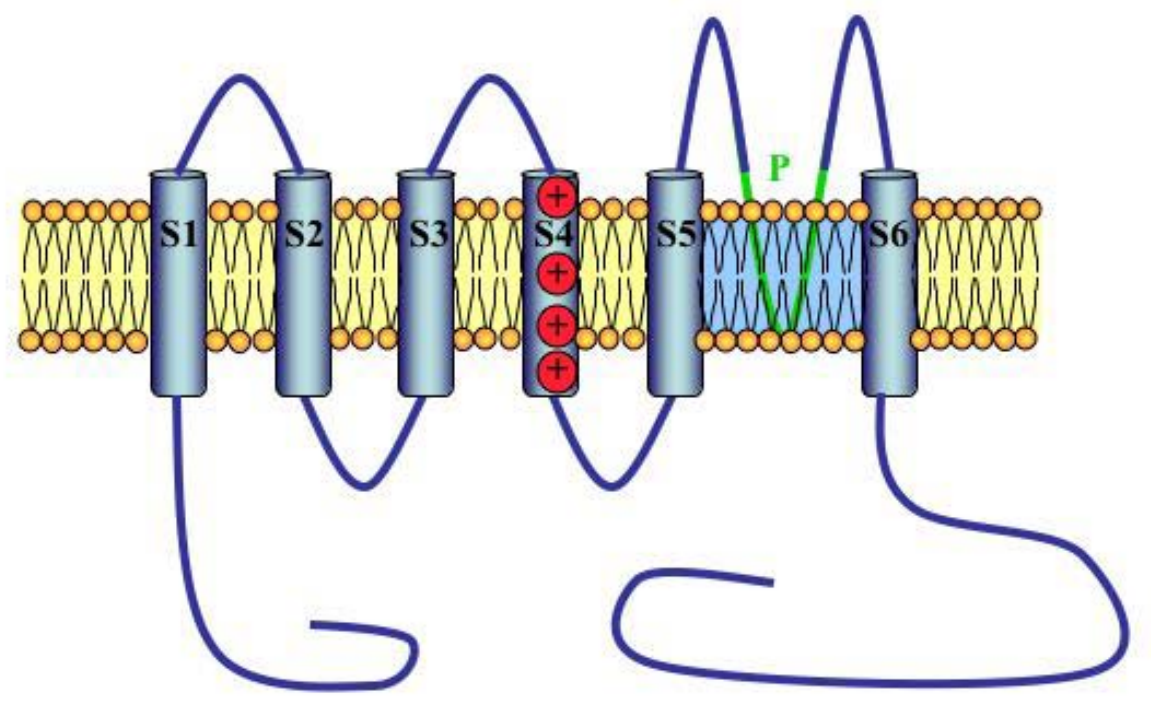

Abb. 2: Schematische Darstellung der Strukturmerkmale spannungsabhängiger $\mathbf{K}^{+}$-Kanäle. TM Transmembrandomäne, $\mathrm{P}$ Porendomäne, $\mathrm{S}$ Transmembransegment 1-6. Die roten Kreise mit Pluszeichen deuten die positiv geladenen Aminosäuren des Spannungssensors an.

Die S4-Helix mit ihrer regelmäßigen Abfolge von positiv geladenen Aminosäuren ist verantwortlich für die Spannungsmessung. Sie vermittelt auf Depolarisation hin durch Eigenbewegung eine Konformationänderung des Kanals, die zur Öffnung der Pore führt und als gating current elektrophysiologisch gemessen werden kann. Viele $\mathrm{K}^{+}$-Kanäle werden von akzessorischen $\beta$-Untereinheiten, die selbst keine Pore bilden und sehr unterschiedliche Strukturen haben, durch Beeinflussung der Faltung, durch den Transport zur Plasmamembran oder Aktivierung bzw. Inaktivierung reguliert (Trimmer, 1998). 


\subsection{Die ether à go-go -K ${ }^{+}$-Kanäle (EAG-K ${ }^{+}$-Kanäle)}

Kanäle der EAG-Familie wurden zuerst durch Mutationen in Genen in Drosophila melanogaster entdeckt (Kaplan und Trout, 1969), die den Fliegen einen hyper-erregbaren Phänotyp verliehen, und zählen zu den spannungsgesteuerten Kaliumkanälen. Die EAGFamilie gliedert sich basierend auf Sequenzhomologien in drei Untergruppen: ether à go-go (EAG), eag-related gene (ERG) und eag-like (ELK) $\mathrm{K}^{+}$-Kanäle (Warmke und Ganetzki, 1994). Vier Untereinheiten, die aus je sechs Transmembranregionen, einem kurzen NTerminus und einem relativ langen C-Terminus bestehen, bilden den funktionellen Kanal. Die Tetramerisierung wird durch ein Motiv im C-Terminus vermittelt, der sogenannten tetramerisierenden coiled-coil Domäne (TCC-Domäne) (Jenke et al., 2003).

\subsection{Aufbau der EAG-K ${ }^{+}$-Kanäle}

Die EAG-Kanäle weisen im Vergleich zu den anderen spannungsgesteuerten Kaliumkanälen einige Besonderheiten auf. Zum einen befindet sich im intrazellulär gelegenen N-Terminus neben mehreren putativen Bindungsstellen für Kinasen eine PAS-Domäne (Per-Arnt-Sim) (Morais Cabral et al., 1998), die beim gating-Prozess (Ju und Wray, 2006) eine Rolle spielt. Zum anderen besitzen sie einen ungewöhnlich langen, vermutlich intrazellulären C-Terminus mit verschiedenen Sequenzmotiven (Abb. 3). Diese sind eventuell wichtig für die Funktion bzw. die Regulation von EAG. So findet man dort neben Bindungsstellen für verschiedene Kinasen, für zyklische Nukleotide (cNBD) und Calmodulin (CaM) auch ein zweiteiliges Kerntransportsignal (NLS, nuclear localisation signal) und die für die Tetramerisierung der $\alpha$-Untereinheiten notwendige CAD bzw. TCC-Domäne (Jenke et al., 2003; Ludwig et al., 1997), die ein endoplasmatisches Retentionssignal maskiert (Kupershmidt et al., 2002; Shikano und Li, 2003) (Abb. 3). Inaktivierung dieser Retentionssignalerkennungssequenz RXR im menschlichen EAG1-Kanal durch Mutationen führt zur Erhöhung der Plasmamembranexpression des Kanals im heterologen Expressionssystem (Jenke et al., 2003). Calmodulin ist in der Lage, die Kaliumströme in einer $\mathrm{Ca}^{2+}$-abhängigen Weise $\mathrm{zu}$ vermindern (Schönherr et al., 2000). Weiterhin konnten, nachdem eine Bindungsstelle für den MPF (mitosis promoting factor) im C-Terminus von EAG1 gefunden wurde, EAG1-Ströme fast vollständig durch Progesteron oder MPF unterdrückt werden (Bruggemann et al., 1997). 

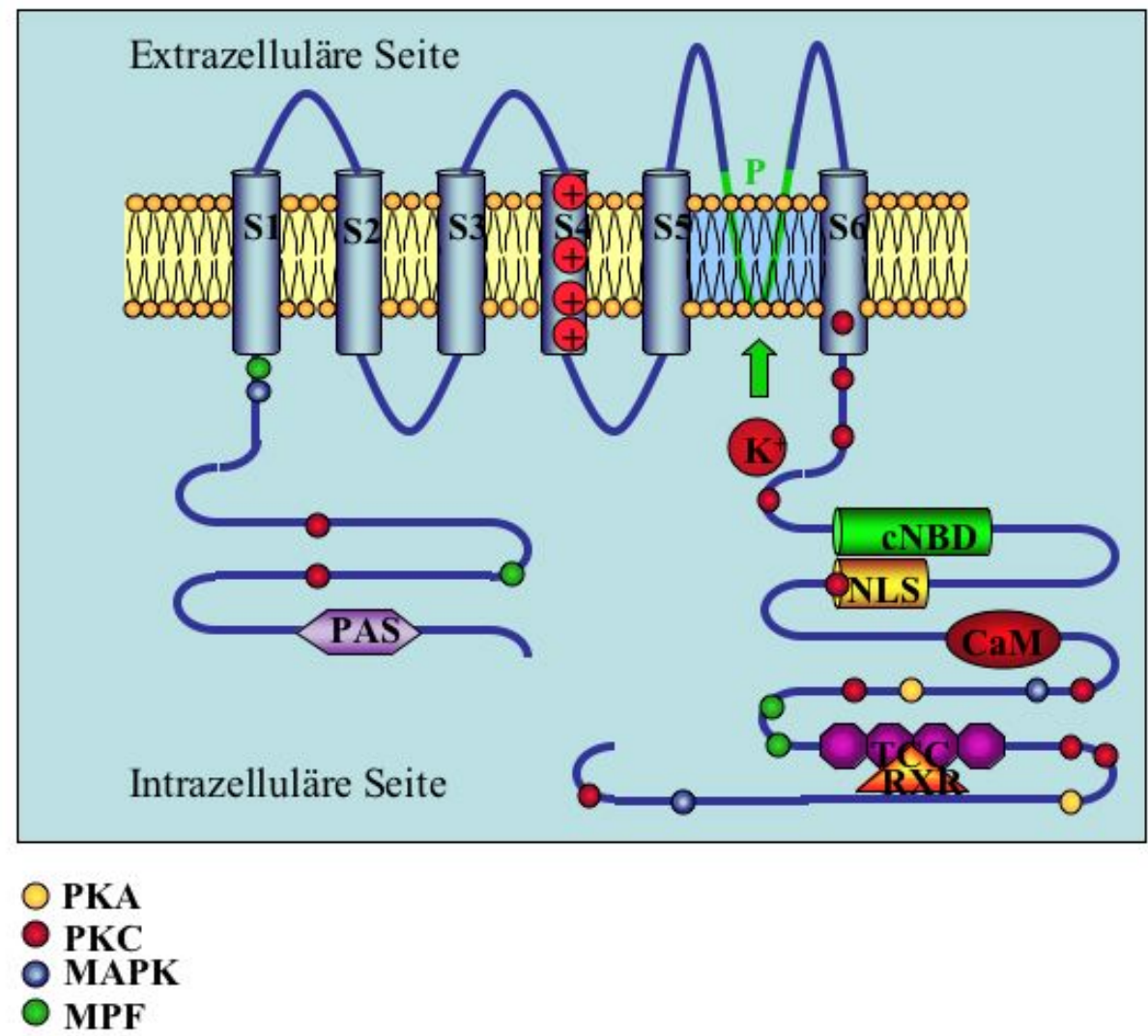

Abb. 3: Schematische Darstellung der Strukturmerkmale und Domänen des EAG1-Kanals. PAS: Per-Arndt-Sim-Domäne, cNBD: Bindedomäne für zyklische Nukleotide, NLS: Kernlokalisationsdomäne, CaM: Calmodulinbindungsstelle, TCC: Tetramerisierungsdomäne, RXR: Endoplasmatisches Retentionssignal, PKA: Phosphorylierungstelle für die Proteinkinase A, PKC: Phosphorylierungstelle für die Proteinkinase C, MAPK: Phosphorylierungsstelle für die Mitogenaktivierte Proteinkinase, MPF: Phosphorylierungsstelle für den Mitosis-Promoting-Faktor.

In der Literatur sind zwei weitere Bindungspartner von EAG beschrieben, ein Protein namens Epsin, welches als Two-Hybrid-Interaktionspartner gefunden wurde und hauptsächlich bei der Endozytose eine Rolle spielt (Piros et al., 1999) und KCR1, eine neue akzessorische Untereinheit, die die Aktivierung des Ratten-EAG-Kanals beschleunigt (Hoshi et al., 1998; Marrion, 1997; Mathie und Watkins, 1997). Weiterhin assoziert der EAG-Kanal der Maus mit der $\beta$-Untereinheit Hyperkinetic (Wilson et al., 1998), wodurch die Stromamplitude wie auch das gating und die Modulation durch Progesteron beeinflusst werden. Außerdem bildet EAG komplexe Interaktionen mit Proteinen des Zytoskeletts aus, die die Kanaleigenschaften stark beeinflussen (Camacho et al., 2000). 


\subsection{Elektrophysiologische Merkmale der EAG-K ${ }^{+}$-Kanäle}

Die EAG-Kanäle aus Säugetieren zeichnen sich durch langsame Aktivierung und fehlende Fähigkeit zur Inaktivierung bei fortgesetzter Depolarisation aus. Zudem zeigen EAG-Kanäle eine starke Abhängigkeit der Aktivierungskinetik vom Vorpulspotential („Cole-Moore-Shift“) (Ludwig et al., 1994) (Abb. 4), von der extrazellulären Magnesiumkonzentration und vom extrazellulären $\mathrm{pH}-\mathrm{Wert}$ (Terlau et al., 1996).

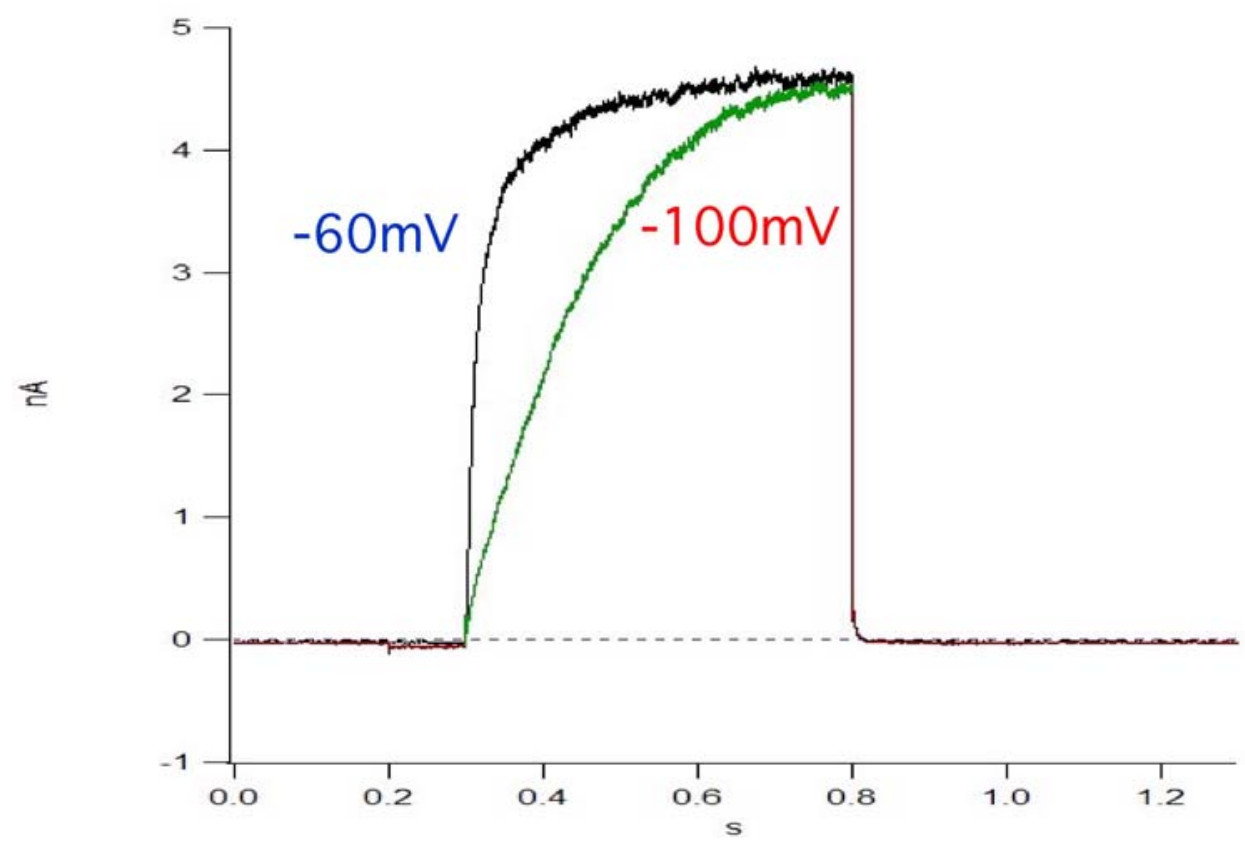

Abb. 4: Darstellung des Cole-Moore-Shifts. Die schwarze Linie entspricht einem Vorpulspotential von $-60 \mathrm{mV}$, die grüne von $-100 \mathrm{mV}$.

Die Aktivierung des Kanals ist umso langsamer, je hyperpolarisierter das Startmembranpotential ist. Diese spezielle Eigenschaft hat zur Folge, dass die Charakteristik des EAG-Stroms einer bestimmten Zelle nicht nur vom aktuellen Stimulus abhängig ist, sondern auch durch das durchschnittliche Membranpotential vor dem Reiz mitbestimmt wird.

\subsection{Vorkommen der EAG-K ${ }^{+}$-Kanäle}

EAG $\mathrm{K}^{+}$-Kanäle wurden zuerst in Drosophila melanogaster und in einer Mausgehirn-cDNABibliothek (Warmke und Ganetzki, 1994) entdeckt und aus menschlichen Myoblasten kloniert (Occhiodoro et al., 1998). Der prototypische Kanal (EAG1) wird in den meisten Gehirnregionen exprimiert, wo zwei alternative Spleißvarianten (EAG1a und EAG1b) aufgefunden wurden (Pardo et al., 1999). Wenig später wurde ein zweiter EAG-Kanaltyp, 
EAG2, im Menschen entdeckt, der vermutlich in zwei Spleißvarianten exprimiert wird (Ju und Wray, 2006; Schönherr et al., 2002). Im Menschen findet man den EAG-Kanal außer in reproduktivem Gewebe (Hoden, Uterus) hauptsächlich im Gehirn (Patt et al., 2004). Dot BlotExperimente zeigten im Cortex, im Cerebellum, in der Amygdala, im Hippocampus, Nucleus caudatus, Putamen, frontalen, occipitalen und temporalen Lappen ein positives Signal für EAG1, während der Thalamus, die Substantia nigra und die Medulla oblongata wie auch Herz, Leber, Niere, Lunge, Milz, und Thymus negativ waren (Pardo et al., 1999). Im Rattenhirn war eine ausgeprägte Expression von EAG1 im Cortex, im Hippocampus, im Cerebellum, im Nucleus caudatus, im Putamen, in der Amygdala, im Hypothalamus und im Bulbus olfactorius nachweisbar. Im Gegensatz dazu war die Expression von EAG2 etwas begrenzter, so konnten größere Mengen ausschließlich im Cortex, Thalamus und im Bulbus olfactorius mittels in situ Hybridisierung gefunden werden. Hier konnte EAG2 in Gliazellen detektiert werden (Saganich et al., 2001). Trotz der Anstrengungen mehrerer Arbeitsgruppen bleibt bis dato ungewiss, ob EAG in Nagetieren auch in Geweben außerhalb des Gehirns exprimiert wird, wie und ob die Expression induziert werden kann, ob weitere Spleißvarianten oder Mutationen vorhanden sind und welche physiologische Funktion EAG im Gehirn ausführt. Diese Anstrengungen führten jedoch zur Entdeckung einiger interessanter Aspekte des Kanals: Sein nahezu ausschließliche Vorkommen von EAG1 außerhalb des Gehirns in tumorösem Gewebe und sein onkogenes Potential (Pardo et al., 1999).

\section{$2.8 \mathrm{~K}^{+}$-Kanäle und Krebs}

Es sind eine Reihe von Ionenkanälen gefunden worden, die von verschiedenen Tumortypen exprimiert wurden und zu der Entstehung von Tumoren und einem veränderten Phänotyp führten (Mu et al., 2003; Pei et al., 2003). Kv1.3 ist wohl der am Besten beschriebene Kanal, der auf seinen Einfluss auf die Proliferation untersucht wurde (Abdul und Hoosein, 2002a; Abdul und Hoosein, 2002b; Chittajallu et al., 2002; Fraser et al., 2003; Mu et al., 2003; Pei et al., 2003; Preussat et al., 2003). Zwei weitere Kanäle gehören zur EAG-Familie, EAG1 (Kv10.1) und HERG (Kv11.1). HERG wurde in Proben von klinischen Tumoren und Tumorzelllinien gefunden (Bianchi et al., 1998; Cherubini et al., 2000), wo vermutet wird, dass es Unterschiede in der Verteilung der Spleißvarianten in normalem und Tumorgewebe gibt (Crociani et al., 2003). 


\subsection{Pathophysiologie der EAG1-K ${ }^{+}$-Kanäle}

Der zweite Kanal aus der EAG-Familie, EAG1, wurde in einigen Krebszelllinien nachgewiesen, nicht jedoch in Gewebe, aus dem die Zellen ursprünglich entnommen wurden (Pardo et al., 1999). Außerdem wurde das EAG1-Protein in $75 \%$ der Tumorgewebe aus verschiedenen Organen entdeckt (Queiroz et al., 2006; Hemmerlein et al., 2006). Dies ist besonders bedeutend, wenn man berücksichtigt, dass das korrespondierende gesunde Gewebe in fast allen Fällen negativ für EAG1 getestet wurde. EAG-Überexpression in heterologen Systemen führte zu einem transformierten Phänotyp mit erhöhter Proliferationsrate, Verlust der Kontaktinhibierung und der Fähigkeit, größere und aggressivere Tumore als Kontrollzellen $\mathrm{zu}$ erzeugen, wenn die Zellen subkutan in SCID- (severe combined immunodeficient) Mäuse implantiert wurden (Pardo et al., 1999). Die Ursachen für diese transformierenden Eigenschaften und die zugrunde liegenden molekularen Mechanismen sind noch gänzlich unerforscht.

\subsection{Inhibitoren der EAG-K ${ }^{+}$-Kanäle}

Diese Ergebnisse lassen vermuten, dass der EAG-Kanal nicht nur transformierende Eigenschaften besitzt und wertvoll für die Diagnose und Prognose von Krebserkrankungen in Patienten sein könnte, sondern möglicherweise sogar bei der Entstehung oder Progression von Krebs eine Rolle spielt. Daher ist die Suche nach Inhibitoren ein unerlässlicher Schritt im Prozess der Therapieentwicklung und zur Aufklärung der molekularen Mechanismen der transformierenden Eigenschaften von EAG. Bis heute wurde noch kein spezifischer Inhibitor für die EAG-Kanäle gefunden. Während sowohl über das trizyklische Antidepressivum Imipramin und das Anti-Histaminikum Astemizol (Abb. 5) beschrieben ist, dass sie den EAG-Kanal im heterologen Expressionssystem (HEK293-Zelllinie) blocken können, fehlt ihnen jedoch die erforderliche Spezifität für die Anwendung in endogen exprimierenden Zellen, da sie gleichzeitig unspezifisch viele andere Kationenkanäle inhibieren (GarcíaFerreiro et al., 2004). 
Astemizol

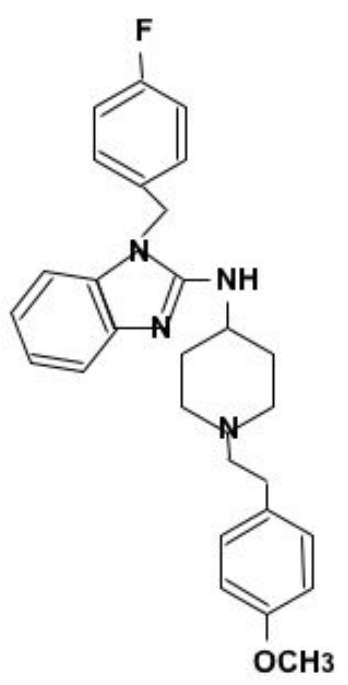

Norastemizol<smiles>Fc1ccc(Cn2c(NC3CCNCC3)nc3ccccc32)cc1</smiles>

Abb. 5: Strukturformeln von Astemizol und Norastemizol. Beides sind Antihistaminika, Astemizol blockiert den EAG1-Kanal jedoch stärker als Norastemizol (García-Ferreiro et al., 2004).

\subsection{RNA-Interferenz (RNAi)}

Die small interfering (si) RNA-Technologie stellt ein gänzlich neues Werkzeug zur hochspezifischen effektiven Untersuchung und Bekämpfung der molekularen Determinanten, die für die Entstehung und Progression von Krankheiten wie Krebs verantwortlich sind. Diese Methode erfährt seit ihrer Entdeckung weit verbreitete Anwendung sowohl in vitro als auch in vivo. Das Phänomen der RNA-Interferenz (RNAi) wurde zuerst in Pflanzen und Caenorhabditis elegans entdeckt, als die Stilllegung von Genen auf Exposition von Zellen mit langer doppelsträngiger RNA (dsRNA) hin beobachtet wurde (Novina und Sharp, 2004). Die RNAi dient der Zelle als Verteidigungsstrategie gegen virale Nukleinsäuren und endogene transponierbare Genelemente (Wang und Barr, 2005). Seitdem konnte mit dieser Methode eine Anzahl von verschiedenen Genen aus Neuronen und Zelllinien unterschiedlichen Ursprungs aus einer Vielzahl an Wirbeltieren und wirbellosen Tieren stillgelegt werden (Holen und Mobbs, 2004). RNAi wird durch dsRNA ausgelöst und führt zu einem Abbau von homologen einzelsträngigen mRNA-Sequenzen. Der zugrunde liegende Mechanismus ist ein Abbau der langen doppelsträngigen RNA in kleine, 21-Nukleotide lange, einzelsträngige RNA-Stücke durch ein Enzym namens Dicer. Diese Stücke bilden 19-Nukleotide lange Duplexe mit 2-Nukleotiden langen Überhängen an den Enden, die im Zytosol an einen 
Ribonukleinkomplex namens RISC (RNA-induced silencing complex) binden. Mit dem RISCKomplex ist eine Nuklease assoziert, die durch den Gegenstrang der siRNA geleitet die ZielRNA spaltet (Hutvagner und Zamore, 2002). Dieser Abbau der mRNA resultiert in einer Reduktion der Expression des kodierten Proteins und damit in einer Stilllegung der Genexpression. Studien über einen Vergleich von RNAi mit der traditionellen antisenseStrategie deuten an, dass die RNA-Interferenz die effektivere Methode von beiden ist (Vickers et al., 2003). Verschiedene Ansätze sind bekannt, wie die siRNA in die Zellen eingeführt werden kann. Entweder werden chemisch synthetisierte siRNAs verwendet oder neuerdings auch kurze RNAs mit Haarschleifen, die von Plasmid- oder Virus-basierten Vektoren aus exprimiert werden und durch RISC im Zytoplasma zu funktionellen siRNAs prozessiert werden (Huppi et al., 2005). Obwohl die meisten Studien in vitro durchgeführt wurden, berichten einige neuere Studien über in vivo Stilllegung von Genen durch Injektion von synthetisch hergestellten siRNAs (McCaffrey et al., 2002) oder Expression der siRNAs von Plasmiden oder viralen Vektoren in Mäusen (McCaffrey et al., 2002; Rubinson et al., 2003). Das Hauptproblem bei der Interferenzmethode stellt das Auftreten von unspezifischen Effekten dar, die entweder durch die siRNA selbst (zum Beispiel durch Wirkung als MikroRNA) oder durch die Interferonantwort der Zelle, einer globalen Stressantwort der Zelle auf die Aufnahme von dsRNA, hervorgerufen werden (Eckstein, 2005; Huppi et al., 2005). Anfangs nahm man an, dass die kurzen siRNAs nicht in der Lage sind, diese Interferonantwort oder andere unspezische Effekte auszulösen (Bantounas et al., 2004; Sledz und Williams, 2004), neuere Studien jedoch zeigen, dass dies sehr wohl der Fall ist (Persengiev et al., 2004). Daher ist es nötig, eine Zahl von unabhängigen Kontrollexperimenten durchzuführen, um das Risiko von unspezifischen Effekten zu minimieren. Es wird von einem Gremium von Experten vorgeschlagen, beobachtete Effekte mit mehreren gegen das gleiche Gen gerichteten siRNA-Spezies zu verifizieren, verschiedene Negativkontrollen durchzuführen und die Effekte auf unterschiedlichen Ebenen der Genexpression qualitativ und quantitativ zu untersuchen (Editorial, 2003).

Die RNAi-Methode eignet sich, wenn die oben genannten Hinweise berücksichtigt werden sehr gut dafür, Gene stillzulegen, für deren Expressionsprodukte es keine spezifischen Hemmstoffe gibt, so wie es für den EAG-Kanal der Fall ist. Daher wurde in dieser Arbeit untersucht, ob eine Stilllegung von hEAG1 durch RNAi geeignet ist, um die Tumorbildenden Eigenschaften in vitro zu hemmen. 


\subsection{Zielsetzung der Arbeit}

Die EAG-Kanäle sind noch größtenteils unerforscht. Ihre Funktion und molekularen Mechanismen im Gehirn und in ektopisch EAG-exprimierenden Krebszellen und Zelllinien sind gänzlich unbekannt. Weiterhin sind weder die Bedingungen, die zu ihrer Expression führen, noch eine Möglichkeit, wie sie spezifisch gehemmt werden können, beschrieben.

Unser Labor konnte zeigen, dass der menschliche EAG1-Kanal onkogenes Potential aufweist, wenn er heterolog in CHO- (chinese hamster ovary) oder 3T3-Zellen (Mausfibroblastenzelllinie) exprimiert wird (Pardo et al., 1999). Die molekularen Mechanismen, die diesem Phänomen in menschlichen Zellen zugrunde liegen, sollten in dieser Arbeit untersucht werden. Hierzu sollte mit verschiedenen Methoden das Genexpressionsprofil von Zellen mit funktionsfähigem im Vergleich $\mathrm{zu}$ Zellen ohne funktionsfähigem EAG1-Kanal erstellt werden. Weiterhin sollte überprüft werden, ob es sich bei dem transformierenden EAG1 um die Variante handelt, die auch im Gehirn exprimiert wird oder ob Mutationen vorhanden sind, die das heterogene physiologische Verhalten von EAG1 erklären könnten.

Das Hauptziel dieser Arbeit war es, Bedingungen für eine Expressionsänderung von EAG1 in Krebszellen und im Gehirn zu finden, um erste mögliche Ansatzpunkte für die Aufklärung der physiologischen Rolle des Kanals im Gehirn als auch seiner pathophysiologischen Relevanz in Tumorzellen und die Entwicklung von Krebstherapeutika zu erhalten, da für EAG vor dieser Arbeit keine spezifischen Inhibitoren bekannt waren. 


\section{Material und Methoden}

\subsection{Material}

\subsubsection{Bakterienstämme, Zelllinien und Versuchstiere}

\subsubsection{Bakterienstämme}

E. coli JM109 High Efficiency Competent Cells (Promega)

[recA1, endA1, gyrA96, thi, hsdR17 (rK-, mK+), relA1, supE44, $\Delta$ (lac-proAB), [F', traD36, proAB, lacIqZ $\Delta \mathrm{M} 15]]$

\subsubsection{Zelllinien}

Die Zelllinien (HEK293, MDA-MB435S, Daoy, HT-1080, Hs633t, TE-671, A204, IGR-39, IPC298, HeLa, MCF-7, SHSY-5Y) wurden bei der Deutschen Sammlung für Mikroorganismen und Zelllinien (DSMZ), der American Tissue and Cell Culture Collection (ATCC) oder der European Collection of Cell Cultures (ECACC) bestellt.

\subsubsection{Versuchstiere}

Es wurden als Versuchstiere 10 Wochen alte männliche Mäuse des Stammes C57BL/6N (Charles River, Sulzfeld, D) mit einem Körpergewicht von 25 - 30 g verwendet.

Die in dieser Arbeit verwendeten adulten männlichen Ratten gehörten dem Stamm Wistar an.

\subsubsection{Plasmide und Oligonukleotide}

\subsubsection{Plasmide}

\section{pTracer-Vektor (Invitrogen)}

Für die Transfektionen der Zellinien wurde der pTracer-CMV-Vektor der Firma Invitrogen verwendet. Die Herstellung des hEAG1-haltigen Plasmids wurde in der Literatur beschrieben (Pardo et al., 1999). 


\section{pcDNA3-Vektor (Invitrogen)}

Für die Transfektionen der Zellinien wurde der pcDNA3-CMV-Vektor der Firma Invitrogen verwendet. Die Herstellung des hEAG1-haltigen Plasmids wurde in der Literatur beschrieben (Pardo et al., 1999).

\section{pGEM-T-Vektor (Promega)}

PCR-Fragmente wurden in dieser Arbeit ausschließlich in den T/A-Klonierungsvektor pGEM-T der Firma Promega ligiert, der eine Blau-Weiß-Selektion erlaubt und eine Ampicillin-Resistenz vermittelt.

\subsubsection{Oligo(desoxy)nukleotide (Primer)}

\begin{tabular}{|c|c|c|}
\hline Primername & Zielgen & Primersequenz \\
\hline 855 & \multirow{2}{*}{$\begin{array}{l}\text { Menschlicher Ether à go-go- } \\
\text { Kanal Typ } 1\end{array}$} & CGCATGAACTACCTGAAGACG \\
\hline 861 & & TCTGTGGATGGGGCGATGTTC \\
\hline $\begin{array}{l}\text { Mycoplasma Plus }{ }^{\mathrm{TM}} \\
\text { PCR Primer }\end{array}$ & rRNA des Genus Mycoplasma & $?$ \\
\hline hColl-IVa-UP & \multirow[t]{2}{*}{ Menschliches Kollagen IVa } & GGACCCCCGGGAGAAATAGG \\
\hline hColl-IVa-LP & & TGAGCCGCAAGTCGAAATAAAAC \\
\hline hITG- $\beta 1-U P$ & \multirow[t]{2}{*}{ Menschliches Integrin $\beta 1$} & ATGGCTTAATTTGTGGAGGA \\
\hline hITG- $\beta 1-L P$ & & ATTTTCACCCGTGTCCCATTT \\
\hline hEAG1a-UP & \multirow{3}{*}{$\begin{array}{l}\text { Menschlicher Ether à go-go- } \\
\text { Kanal Typ 1a }\end{array}$} & TCTGTCCTGTTTGCCATATGATGT \\
\hline hEAG1a-P & & $\begin{array}{l}\text { 5'-Fam-AACGTGGA(Tamra-C6-Amino } \\
\text { dT)GAGGGCATCAGCAGCCT- 3' }\end{array}$ \\
\hline hEAGla-LP & & CGGAGCAGCCGGACAA \\
\hline hEAG2-UP & \multirow{3}{*}{$\begin{array}{l}\text { Menschlicher Ether à go-go- } \\
\text { Kanal Typ } 2\end{array}$} & CCCTCTGCTTTGTGGTGTCAG \\
\hline hEAG2-P & & $\begin{array}{l}\text { 5'-Fam-CCCTTCCC(Tamra-C6-Amino } \\
\text { dT)AAAATAGCCACCACCTCA -3' }\end{array}$ \\
\hline hEAG2-LP & & CGGACGTTCGCACATGC \\
\hline hTFR1-UP & \multirow{3}{*}{$\begin{array}{l}\text { Menschlicher } \\
\text { Transferrinrezeptor } 1\end{array}$} & GACTTTGGATCGGTTGGTGC \\
\hline hTFR1-P & & $\begin{array}{l}\text { 5'-Joe-TGAATGGCTAGAGGGA(Tamra } \\
\text { dT)ACCTTTCGTCCC-3' }\end{array}$ \\
\hline hTFR1-LP & & CCAAGAAC GCTTTATCCAGAT \\
\hline hGAPDH-UP & \multirow{3}{*}{$\begin{array}{l}\text { Menschliche Glyzerinaldehyd-3- } \\
\text { phosphat Dehydrogenase }\end{array}$} & CCACATCGCTCAGACACCAT \\
\hline hGAPDH-P & & $\begin{array}{l}\text { AATACGACCAAATCCGTTGACTCCGACC } \\
\mathrm{T}\end{array}$ \\
\hline hGAPDH-LP & & ACCAGAGTTAAAAGCAGCCCTG \\
\hline
\end{tabular}




\begin{tabular}{|c|c|c|}
\hline hblk-UP & \multirow{3}{*}{$\begin{array}{l}\text { Menschliche B-Lymphozyten- } \\
\text { spezifische Tyrosinkinase }\end{array}$} & CACCTGGATGAAGACAAGCA \\
\hline hblk-P & & TGGTTCTTTAGATCACAGGGTCGGAAG \\
\hline hblk-LP & & TAGACCATCCCCCTTCTTAG \\
\hline hc-src-UP & \multirow{3}{*}{$\begin{array}{l}\text { Menschliches Zelluläres rous } \\
\text { sarcoma } \\
\text { Virus Onkogen }\end{array}$} & AGGGCGGGCTCTACATCGTCAC \\
\hline hc-src-P & & CTCCTCAAGTTCTCGCTAGATGTCTG \\
\hline hc-src-LP & & ATTGCGGGCAGCCAGGTCTC \\
\hline hPAI-1-UP & \multirow{3}{*}{$\begin{array}{l}\text { Menschlicher } \\
\text { Plasminogenaktivator-Inhibitor } \\
\text { Typ } 1\end{array}$} & CTGTCTCTGTGCCCATGATGGC \\
\hline hPAI-1-P & & $\begin{array}{l}\text { ACTATACTGAGTTCACCACGCCCGATGG } \\
\text { C }\end{array}$ \\
\hline hPAI-1-LP & & GTGGTAGGGCAGTTCCAGGATG \\
\hline hMMP2-UP & \multirow{3}{*}{$\begin{array}{l}\text { Menschliche } \\
\text { Matrixmetalloproteinase-2 }\end{array}$} & ACTGCGGTTTTCTCGAATCCAT \\
\hline hMMP2-P & & CGCTGGGAGCATGGCGATGGATAC \\
\hline hMMP2-LP & & AGTCCGTCCTTACCGTCAAAGG \\
\hline hMMP9-UP & \multirow{3}{*}{$\begin{array}{l}\text { Menschliche } \\
\text { Matrixmetalloproteinase-9 }\end{array}$} & TTCACTCGCGTGTACAGCCG \\
\hline hMMP9-P & & AGTTTGGTGTCGCGGAGCACGG \\
\hline hMMP9-LP & & CAACTCGTCATCGTCGAAATGG \\
\hline hVAP-C-UP & \multirow{3}{*}{$\begin{array}{l}\text { Menschliches Vesikel- } \\
\text { assoziiertes Membraneprotein- } \\
\text { assoziiertes Protein C }\end{array}$} & AAGGTGGAGCAGGTCCTGAGC \\
\hline hVAP-C-P & & CCGCAGCACGAGCTCAAATTCCGA \\
\hline hVAP-C-LP & & GTCGGGTTGCCAAGCTTTAGG \\
\hline hCUTL1-UP & \multirow{3}{*}{$\begin{array}{l}\text { Menschliches CCAAT- } \\
\text { displacement Protein }\end{array}$} & CAGTCCAGAAAGCGGCTTATC \\
\hline hCUTL1-P & & AGAACACTCCAGAGGATTTGCGCA \\
\hline hCUTL1-LP & & CCTTGGAAACTCTTCAGCAGC \\
\hline hRACK1-UP & \multirow{3}{*}{$\begin{array}{l}\text { Menschlicher Rezeptor für } \\
\text { aktivierte Proteinkinase C }\end{array}$} & CCAGTTTGCCCTCTCAGGCTC \\
\hline hRACK1-P & & ATCTCACAACGGGCACCACCACGAG \\
\hline hRACK1-LP & & GCACATCCTTGGTATGGCCCA \\
\hline hMAZ-UP & \multirow{3}{*}{$\begin{array}{l}\text { Menschliches Myc-assoziiertes } \\
\text { Zinkfingerprotein }\end{array}$} & CACTCAACAGAACGGCCCTT \\
\hline hMAZ-P & & CCACGAAGGATCGGCTGCGG \\
\hline hMAZ-LP & & GGCACTTTCTCCTCGTGTCGTA \\
\hline hPIK3R3-UP & \multirow{3}{*}{$\begin{array}{l}\text { Menschliche } \\
\text { Phospatidylinositol-3-kinase, } \\
\text { regulatorische Untereinheit } 3\end{array}$} & CAGACTGGAGGGAGGTGATG \\
\hline hPIK3R3-P & & ATCCTCCAGCTCTTCCACCAAAGCC \\
\hline hPIK3R3-LP & & GAACTGCTGAAGTCATTGGCT \\
\hline hEEF1A1-UP & \multirow{3}{*}{$\begin{array}{l}\text { Menschlicher Eukariotischer } \\
\text { Translationselongationsfactor } 1\end{array}$} & TATCATTGATGCCCCAGGAC \\
\hline hEEF1A1-P & & CAGGGACATCTCAGGCTGACTGTGC \\
\hline hEEF1A1-LP & & TCACCAACACCAGCAGCAAC \\
\hline hUBE1-UP & \multirow{3}{*}{$\begin{array}{l}\text { Menschliches Ubiquitin- } \\
\text { activierendes Enzyme } 1\end{array}$} & CTGCCTACACTGGACCCCTCG \\
\hline hUBE1-P & & AAGCTGGTGGTGGCAGACACGCGG \\
\hline hUBE1-LP & & CAGAAGAGCTGCCCAAACAGG \\
\hline hBRCA1-UP & Brustkrebsgen & GCTCAGGGCTATCCTCTCAGAGT \\
\hline
\end{tabular}




\begin{tabular}{|c|c|c|}
\hline hBRCA1-P & Typ 1 & $\begin{array}{l}\text { CATTTTAACCACTCAGCAGAGGGATACC } \\
\text { A }\end{array}$ \\
\hline hBRCA1-LP & & TTCTAGTTCAGCCATTTCCTGCT \\
\hline hGADD45 $\alpha-U P$ & \multirow{3}{*}{$\begin{array}{l}\text { Menschliches Wachstumsarrest- } \\
\text { und DNA-Beschädigung- } \\
\text { induzierbares Gen } 45 \alpha\end{array}$} & AGGAATTCTCGGCTGGAGAGC \\
\hline hGADD45 $\alpha-P$ & & AAGACCGAAAGGATGGATAAGGTGGG \\
\hline hGADD45 $\alpha-L P$ & & GAGCACTTCCTCCAGGGCAT \\
\hline hSpry2-UP & \multirow{3}{*}{$\begin{array}{l}\text { Menschliches Sprouty Homolog } \\
2\end{array}$} & CTGTCCAGATCCATAAGCACGG \\
\hline hSpry2-P & & CTCAGGGTCGCGGAGCAGTACGAG \\
\hline hSpry2-LP & & CTGTTCAGAGGAGCTGCTGCTG \\
\hline hPRKAR1A-UP & \multirow{3}{*}{$\begin{array}{l}\text { Menschliche c-AMP-abhängige } \\
\text { Proteinkinase, regulatorische } \\
\text { Untereinheit } 1 \alpha\end{array}$} & TTTAGCCAAAGCCATTGAAAA \\
\hline hPRKAR1A-P & & $\begin{array}{l}\text { TGATAATGAGAGAAGTGATATTTTTGAT } \\
\text { GCC }\end{array}$ \\
\hline hPRKAR1A-LP & & CTGCGATAAAGGAGACCGAAAA \\
\hline hPCQAP-UP & \multirow{3}{*}{$\begin{array}{l}\text { Menschliches PC2 Glutamin/Q- } \\
\text { reich-assoziiertes Protein }\end{array}$} & CAGGCTCATTATCCATTTTCG \\
\hline hPCQAP-P & & $\begin{array}{l}\text { ACATTCATAACAAGAAATCTCAAGCTTC } \\
\text { CG TC }\end{array}$ \\
\hline hPCQAP-LP & & CTCTGGAGTGCATTCATAGGATC \\
\hline hKRT23-UP & \multirow[t]{3}{*}{ Menschliches Keratin 23} & AACTGAAGCGCACATTCCAGG \\
\hline hKRT23-P & & $\begin{array}{l}\text { CCTGCAGACACAGTACAGCACGAAATCT } \\
\text { GC } \\
\text { TTT }\end{array}$ \\
\hline hKRT23-LP & & GTACCGAGACTGGGTCTCGGA \\
\hline hFLJ20337-UP & \multirow[t]{3}{*}{$?$} & TTCCCAGGGAGGTTCGACCTATA \\
\hline hFLJ20337-P & & TCCTGTCGGGCTATCTCCCAGCAAACAC \\
\hline hFLJ20337-LP & & AGCCAAAATATTCCTCCCGCTTC \\
\hline hFLJ32800-UP & \multirow[t]{3}{*}{$?$} & AAACTCAGAATGTTGTCACCAA \\
\hline hFLJ32800-P & & $\begin{array}{l}\text { AAAGAAGATGAAGTACAGGCCATTGCCA } \\
\text { C }\end{array}$ \\
\hline hFLJ32800-LP & & TTTACTACGATTTGTGCCTGC \\
\hline hCTNNA1-UP & \multirow[t]{3}{*}{ Menschliches Catenin $\alpha 1$} & CAGATGCTGTCGATGACATTACT \\
\hline hCTNNA1-P & & \begin{tabular}{|l} 
CTTGGCTGTCTCAGAGAATCACATTTTG \\
\end{tabular} \\
\hline hCTNNA1-LP & & GCAATGACACATTTGTTCACAT \\
\hline hZNF236-UP & \multirow{3}{*}{$\begin{array}{l}\text { Menschliches Zinkfinger-Protein } \\
236\end{array}$} & TGGAATCGATGCTGCCA \\
\hline hZNF236-P & & $\begin{array}{l}\text { AATAACATTACGTTGCAGATTGATCCAA } \\
\text { GC }\end{array}$ \\
\hline hZNF236-LP & & AGCCAATAGGTTGCCCTGC \\
\hline hVASP-UP & \multirow{3}{*}{$\begin{array}{l}\text { Menschliches Vasodilator- } \\
\text { stimuliertes Phosphoprotein }\end{array}$} & CTCCAGTGATTACTCGGACCTA \\
\hline hVASP-P & & AGAGGGTGAAACAGGAGCTTCTGGAA \\
\hline hVASP-LP & & TCTTTCACTTTCTGCAATTCC T \\
\hline
\end{tabular}




\begin{tabular}{|c|c|c|}
\hline hHSD17B7-UP & \multirow{3}{*}{$\begin{array}{l}\text { Menschliche 17 } \beta \text { - } \\
\text { Hydroxysteroiddehydrogenase } \\
\text { Typ } 7\end{array}$} & GGCTTTGAACAGGAACTTCA \\
\hline hHSD17B7-P & & CCAGCAGGGTCTCTATTCCAA TG \\
\hline hHSD17B7-LP & & TGGTCAATGCTGTACCTGGA \\
\hline hFLJ10901-UP & \multirow[t]{3}{*}{$?$} & ACGATGGTCAGAAACTCAGAA T \\
\hline hFLJ10901-P & & $\begin{array}{l}\text { CCAAAGTGAAAAAAGAAGATGAAGTAC } \\
\text { AGG }\end{array}$ \\
\hline hFLJ10901-LP & & TTCTCAATTAGGGTGGCAATG \\
\hline hFLJ31795-UP & \multirow[t]{3}{*}{$?$} & GTTTGTGTGCTGTGGAGATCG \\
\hline hFLJ31795-P & & CCCCTGTGCAAGTCTTTGTACCTGAAA \\
\hline hFLJ31795-LP & & CACCTGGCTGATGATCTCTCCT \\
\hline hAMPD2-UP & \multirow{3}{*}{$\begin{array}{l}\text { Menschliche } \\
\text { Adenosinemonophosphatdeamin } \\
\text { ase-2 }\end{array}$} & GAATCTCACGGCCTACGACCT \\
\hline hAMPD2-P & & TGGATGTGCATGCGGACAGGAAC \\
\hline hAMPD2-LP & & AACTTGTCAAAGCGATGGAAAG \\
\hline hSIGLEC8-UP & \multirow{3}{*}{$\begin{array}{l}\text { Menschliches Sialsäure- } \\
\text { bindendes Ig-ähnliches Lectin } 8\end{array}$} & GACAGGTGTGACCACGACCAGT \\
\hline hSIGLEC8-P & & CCGCCTCGATGTGTCCTACCCTCCT \\
\hline hSIGLEC8-LP & & CCTTGGAAGACAGTCATGGTCAA \\
\hline hEAG1-UP & \multirow{2}{*}{$\begin{array}{l}\text { Menschlicher Ether à go-go- } \\
\text { Kanal Typ } 1\end{array}$} & TTCCTGCTGTCGTAAGAAGCC \\
\hline hEAG1-LP & & CTGAAAGTGCAAAGAAATAAAACCAC \\
\hline hEAG2-UP & \multirow{2}{*}{$\begin{array}{l}\text { Menschlicher Ether à go-go- } \\
\text { Kanal Typ } 1\end{array}$} & GTGGTTCTTTGTGAAAATTGCTCC \\
\hline hEAG2-LP & & CACGATGCTATCAACAACCAGC \\
\hline hEAG3-UP & \multirow{2}{*}{$\begin{array}{l}\text { Menschlicher Ether à go-go- } \\
\text { Kanal Typ } 1\end{array}$} & AGCAAGAGGCACCAAAGACTCC \\
\hline hEAG3-LP & & GCTCCATATTCAATGTAGTGGTCCAG \\
\hline hEAG4a-UP & \multirow{2}{*}{$\begin{array}{l}\text { Menschlicher Ether à go-go- } \\
\text { Kanal Typ 1a }\end{array}$} & CTAAAAGTTGTCCGGCTGCTCC \\
\hline hEAG4a-LP & & GGAAAATAGTCGTCACATTCCCG \\
\hline hEAG4b-UP & \multirow{2}{*}{$\begin{array}{l}\text { Menschlicher Ether à go-go- } \\
\text { Kanal Typ } 1\end{array}$} & TTCTGACCCCAAACTTATCCGC \\
\hline hEAG4b-LP & & CATTGTGAAATACAACGAGGAGATGT \\
\hline hEAG5-UP & \multirow{2}{*}{$\begin{array}{l}\text { Menschlicher Ether à go-go- } \\
\text { Kanal Typ } 1\end{array}$} & CATTGTGAAATACAACGAGGAGATGT \\
\hline hEAG5-LP & & CTTTTCCTAGAATGGCCACCAC \\
\hline hEAG6-UP & \multirow{2}{*}{$\begin{array}{l}\text { Menschlicher Ether à go-go- } \\
\text { Kanal Typ } 1\end{array}$} & GTTCCAGACGGTGCACTGTG \\
\hline hEAG6-LP & & CTGTCGGAATCTCTGGAAGAGG \\
\hline hEAG7-UP & \multirow{2}{*}{$\begin{array}{l}\text { Menschlicher Ether à go-go- } \\
\text { Kanal Typ } 1\end{array}$} & GATCAGCGATGTGAAACGTGAA \\
\hline hEAG7-LP & & CATCGACTCAGCCTTGGACAC \\
\hline hEAG8-UP & \multirow{2}{*}{$\begin{array}{l}\text { Menschlicher Ether à go-go- } \\
\text { Kanal Typ } 1\end{array}$} & TCAAAGATGCTTGCGGGAAGA \\
\hline hEAG8-LP & & CAGCTGGCTCCAAAAATGTCTC \\
\hline hEAG9-UP & \multirow{2}{*}{$\begin{array}{l}\text { Menschlicher Ether à go-go- } \\
\text { Kanal Typ } 1\end{array}$} & GATGGAGACACTTCCCGAGAGG \\
\hline hEAG9-LP & & GGTGACGGCAGGGTTGGA \\
\hline hc-Myc-UP & \multirow{3}{*}{$\begin{array}{l}\text { Menschliches zelluläres Myc } \\
\text { (Vogel-Myelozytomatosis- } \\
\text { Viren-Homolog) }\end{array}$} & CAGCTGCTTAGACGCTGGATTT \\
\hline hc-Myc-P & & AGCAGCCTCCCGCGACGATGC \\
\hline hc-Myc-LP & & TTCCTGTTGGTGAAGCTAACGT \\
\hline
\end{tabular}




\begin{tabular}{|c|c|c|}
\hline hTERT-UP & \multirow{3}{*}{$\begin{array}{l}\text { Reverse Transkriptase der } \\
\text { menschlichen Telomerase }\end{array}$} & GACATGGAGAACAAGCTGTTTG \\
\hline hTERT-P & & CGGGCTGCTCCTGCGTTTG \\
\hline hTERT-LP & & TGTCACCAACAAGAAATCATCC \\
\hline hPDK1-UP & \multirow{3}{*}{$\begin{array}{l}\text { Pyruvatdehydrogenasekinase } \\
\text { Isoenzym } 1\end{array}$} & ATTCAAGTTCATGTCACGCTGGG \\
\hline hPDK1-P & & $\begin{array}{l}\text { TGAGGATTTGACTGTGAAGATGAGTGAC } \\
\text { CGA }\end{array}$ \\
\hline hPDK1-LP & & TTTCCTCAAAGGAACGCCACCT \\
\hline HFibro-UP & \multirow[t]{3}{*}{ Menschliches Fibronektin } & GGACCAGGACCAACAAAAA \\
\hline HFibro-P & & GCAGTAACCAACATTGATCGCCCT \\
\hline HFibro-LP & & ATCAGTGAATGCCAGTCCTT \\
\hline $\mathrm{Na} 21$ & Primer 1 & TGTAGCGTGAAGACGACAGAA \\
\hline St19 & Nested Primer St19 & AGGGCGTGGTGCGGAGGGCGGT \\
\hline Not1 & Nested Primer Not1 & AGCGTGGTCGCGGCCGAGGT \\
\hline 5'-GAPDH (Clontech) & \multirow{2}{*}{$\begin{array}{l}\text { Menschliche Glyzerinaldehyd-3- } \\
\text { phosphat Dehydrogenase }\end{array}$} & ACCACAGTCCATGCCATCAC \\
\hline 3'-GAPDH (Clontech) & & TCCACCACCCTGTTGCTGTA \\
\hline rEAG1a-UP & \multirow{3}{*}{$\begin{array}{l}\text { Ratten Ether à go-go-Kanal Typ } \\
\text { 1a }\end{array}$} & TCACTCCTGTTTGCCATATGACG \\
\hline rEAG1a-P & & AACAGGCTGCTGATGCCCTCATCCAC \\
\hline rEAG1a-LP & & GAGACGGAGCAGCCGCAC \\
\hline rEAG1b-UP & \multirow{3}{*}{$\begin{array}{l}\text { Ratten Ether à go-go-Kanal Typ } \\
1 \mathrm{~b}\end{array}$} & GGGAAGATTGGTTTTGCTGATC \\
\hline rEAG1b-P & & AGGCTGCTGATGCCCTGACTCTCTCTCC \\
\hline rEAG1b-LP & & CAGCCGCACGACTTTCAGA \\
\hline rEAG2-UP & \multirow{3}{*}{$\begin{array}{l}\text { Ratten Ether à go-go-Kanal Typ } \\
2\end{array}$} & TTGTGTCAACGTGGTCAATGTCA \\
\hline rEAG2-P & & AGATGGAGAGGACCTTCTCTGTGTCG \\
\hline rEAG2-LP & & CGGTTCAGATGAACACAGATGTC \\
\hline rTFR-UP & \multirow{3}{*}{$\begin{array}{l}\text { Ratten Transferrin-Rezeptor Typ } \\
1\end{array}$} & TGCCAGCTGGACTGCAGG \\
\hline rTFR-P & & $\begin{array}{l}\text { 5'-Joe-AGATGAAAGG(Tamra-C6-Amino } \\
\text { dT)ACCCCTCCAGCCACTCAGT-3' }\end{array}$ \\
\hline rTFR-LP & & $\begin{array}{l}\text { GATTAATGTAAGTGAAAGCCTTTAGATG } \\
\text { C }\end{array}$ \\
\hline mEAG1-UP & \multirow[t]{3}{*}{ Maus Ether à go-go-Kanal Typ 1} & AAGGAAGCTACCCTTGCACAGT \\
\hline mEAG1-P & & CCTTGACCTACTGTGACCTGCACGTGAT \\
\hline mEAG1-LP & & AATTCTAGCACTTTCTGAAGGGC \\
\hline mEAG2-UP & \multirow[t]{3}{*}{ Maus Ether à go-go-Kanal Typ 2} & AAACAGAGACAGTCCACAAGCA \\
\hline mEAG2-P & & TGCTTCAGCTGGGATCAGACATCCTTC \\
\hline mEAG2-LP & & TGCTTCAGCTGGGATCAGACATCCTTC \\
\hline mTFR1-UP & \multirow{3}{*}{$\begin{array}{l}\text { Maus Transferrin-Rezeptor Typ } \\
1\end{array}$} & AATAAATTCCCCGTTGTTGAGG \\
\hline mTFR1-P & & $\begin{array}{l}\text { CACTCTTTGGACATGCTCATCTAGGAACT } \\
\text { GG }\end{array}$ \\
\hline mTFR1-LP & & TATTTCCAATCACTGGGAGAGG \\
\hline
\end{tabular}




\begin{tabular}{|c|c|}
\hline mIL1 $\beta$-UP & CCACCTCAATGGACAGAATATC \\
\hline mIL1 $\beta-P$ & $\begin{array}{l}\text { ACCAACAAGTGATATTCTCCATGAGCTT } \\
\text { TGTAC }\end{array}$ \\
\hline mIL1 $\beta-L P$ & ATTTTGTCGTTGCTTGGTTCTC \\
\hline yCHS1-UP & GGAACTCTAGGACGTCACCGA \\
\hline yCHS1-P & TGCAGATCAGGAAGCTAGGCCCATT \\
\hline yCHS1-LP & GCTATTCATGTTATTGTTGGGTTG \\
\hline Mycocont-UP & GGGAGCAAACAGGATTAGATACCCT \\
\hline Mycocont-LP & TGCACCATCTGTCACTCTGTTAAC \\
\hline
\end{tabular}

Tab. 1: Auflistung der in dieser Arbeit verwendeten Oligonukleotide. Fam und Joe: Fluoreszenzfarbstoffe, Tamra: Quencher. Alle Real-Time-PCR-Sonden waren, sofern nicht anders in der Tabelle angegeben, am 5'-Ende mit dem Fluoreszenzfarbstoff Fam und am 3'-Ende mit dem Quencher Tamra versehen. Von den Oligonukleotiden für die Real-Time-PCR wurde ein Spektrum gefahren, um zu überprüfen, ob sich in den Proben größere Mengen an Salzen oder uneingebautem Fluoreszenzfarbstoff befinden. Außerdem wurden die amplifizierten Real-Time-PCR-Produkte der Oligonukleotide auf Agarose/Ethidiumbromidgele aufgetragen, um nachzuweisen, dass nur ein einziges Amplifikationsprodukt hergestellt wurde.

\subsubsection{DNA/RNA-Längenstandards}

\section{1kb+-Leiter (Invitrogen)}

Dieser DNA-Marker umfaßt 20 Banden der Größe 100 - 500 bp in 100 bp-Schritten, 650 bp, 850 bp, 1000 bp, 1650 bp, 2000-120000 bp in 1000bp-Schritten.

\section{0bp-Leiter (Invitrogen)}

Dieser DNA-Marker umfaßt 16 Banden der Größe 100 - 1500 bp in 100 bp-Schritten und 2072 bp.

\subsection{4-9.5 kb RNA-Leiter (Invitrogen)}

Dieser RNA-Marker (RM) umfaßt 6 Banden von 0.24, 1.35, 2.37, 4.40, 7.46 und $9.49 \mathrm{~kb}$ Größe. 


\subsubsection{Chemikalien}

Alle Chemikalien, bis auf die an der jeweiligen Stelle angegebenen, stammten von der Firma Merck, Fluka oder Sigma

\subsubsection{Kits und Reagenzien}

Gelextraktion

Plasmid-Isolation

PCR

PCR

Sequenzierungs-Kit

Hybridisierungslösung

Markierung von DNA

MMP2-Aktivitätassay

Kit für subtraktive Hybridisierung

Kit für differentielles Screening
Mikroarray-Kit

NucleoSpin Extract, Macherey \& Nagel

NucleoSpin Plasmid, Macherey \& Nagel

PCR reagent system, Invitrogen

TaqMan $^{\mathrm{TM}}$ Core Kit PCR reagent system

AmpliTaq FS 1/4 Big Dye Terminator,

Applied Biosystems

ExpressHyb Hybridization Solution, BD

Biosciences-Clontech

Rediprime DNA Labeling System, Amersham

Biosciences

Matrix Metalloproteinase-2 (MMP-2) Biotrak Activity assay System, Amersham

Biosciences

BD PCR-Select ${ }^{\mathrm{TM}}$ cDNA Subtraction Kit, BD

Biosciences-Clontech

PCR-Select Differential Screening Kit, BD

Biosciences-Clontech

GEArray ${ }^{\mathrm{TM} K I T} \quad$ PATHWAY-SPECIFIC

GENE EXPRESSION PROFILING

SYSTEM, SuperArray Inc.

Kit zur Messung von metabolischer Aktivität AlamarBlue, Biosource

Transfektionreagenzien

FuGENE 6, Roche

Oligofectamine, Invitrogen

Lipofectamine, Invitrogen

$[\alpha-32 \mathrm{P}] \mathrm{dCTP}(3000 \mathrm{Ci} / \mathrm{mmol})$ 


\subsubsection{Enzyme und Antikörper}

cDNA-Erststrangsynthese

Ribonukleaseinhibitor

Taq-Polymerase,

Anti-EAG1-Antikörper

mAb-33

$\mathrm{mAb}-62$

Sekundärer Antikörper
MMLV-Reverse Transcriptase, Promega

RNasin Ribonuclease Inhibitor, Promega

Invitrogen

Polyklonaler Kaninchen-Antikörper gegen den C-Terminus von rEAG1 gerichtet

Monoklonaler Maus-Antikörper gegen den C-

Terminus von hEAG1 gerichtet.

Monoklonaler Maus-Antikörper gegen die Porenregion von hEAG1 gerichtet.

Polyklonaler Esel-Antikörper gegen Kaninchen gerichtet und Rettich-Peroxidase konjugiert

Die Restriktionsenzyme stammten von den Firmen New England Biolabs (NEB), Pharmacia oder Roche.

\subsubsection{Sonstiges Material und Geräte}

\subsubsection{Material}

Chromatographie-Papier 3MM

Sterilfilter $0.22 \mu \mathrm{m}$ Millex-GS

Sterilfilter Stericup $125 \mathrm{ml}$ und $500 \mathrm{ml}$

Nitrozellulosemembranen Hybond ${ }^{\mathrm{TM}} \mathrm{ECL}^{\mathrm{TM}}$

Nitrocellulosemembrane

Mikrotiterplatten 6-Well

96-Well, TTP

Reaktionsgefäße $0.5 \mathrm{ml}$ PCR-Gefäße

1.5 und $2 \mathrm{ml} \mathrm{Gefäße}$

Röntgenfilme X-Omat Blue XB-1

Zellkulturflaschen
Whatman

Millipore

Millipore

Amersham Pharmacia biotech

Sarstedt

Renner

Biozym

Eppendorf

Kodak

Sarstedt 
Zellkulturschalen verschiedene Größen Nunc

Sonden-Aufreinigungssäulen MicroSpin ${ }^{\mathrm{TM}}$ G- Amersham Biosciences

50 Columns

\subsubsection{Geräte}

Bilddokumentation Cybertech CS-1

Cybertech

Crosslinker UV Stratalinker 1800

Stratagene

Mikrotiterplatten-Leser Wallac 1420 Victor2

Wallac

Phosphoimager BAS 1500 Fujix

Raytest

Szintillationszähler LS 6000LL

Beckman Coulter

Thermodrucker SEIKO precision VP-1200

Seiko

Zentrifugen XL-90

Beckman

5415 C (Tischzentrifuge)

Eppendorf

5402 (Kühlzentrifuge)

Eppendorf

Entwicklungsmaschine Curix 60

AGFA

Fluoreszenzmikroskop Axioskop

Zeiss

Vortex-Gerät

Schütt Labortechnik

PAGE-Apparatur Mini-PROTEAN II gel

BIO-RAD Laboratories

system

Patch-clamp Verstärker EPC9

HEKA Electronic

Photometer

Eppendorf

Gerät zur Herstellung von Pipetten HEKA

HEKA Electronic

PIP5

PCR-Geräte TRIO-Thermoblock ${ }^{\mathrm{TM}}$

Biometra

ABI 7700 sequence analyzer

Applied Biosystems

Mastercycler gradient

Eppendorf

Verstärker Turbo TEC-10CD amplifier

NPI-Elektronik 


\subsubsection{Nährmedien, Lösungen und Puffer}

Alle Nährmedien, Lösungen und Puffer wurden aus voll entsalztem und sterilem Wasser (Arium 611, Sartorius) hergestellt. Zur Sterilfiltration wurden $150 \mathrm{ml}$ oder $500 \mathrm{ml}$ Zelluloseacetatfilter $(0.2 \mu \mathrm{m})$ verwendet.

\subsubsection{Nährmedien}

Das LB-Medium (10 g Bacto $®$-tryptone, $5 \mathrm{~g}$ Bacto $®$-yeast extract, $5 \mathrm{~g} \mathrm{NaCl}, \mathrm{pH} 7.0)$ wurden 20 min bei $120^{\circ} \mathrm{C}$ und 1 atm autoklaviert. Antibiotika wurden den flüssigen Medien erst kurz vor Gebrauch zugefügt, den festen Medien (LB-Medium, $15 \mathrm{~g}$ Agar/l) nachdem sie auf $45{ }^{\circ} \mathrm{C}$ abgekühlt waren. Ampicillin (Amp) wurde in einer Endkonzentration von $100 \mu \mathrm{g} / \mathrm{ml}$ eingesetzt. Zum Nachweis der $\beta$-Galaktosidase-Aktivität von Transformanten wurden LBAmp-Platten vor dem Ausplattieren der Zellen mit $20 \mu l 50$ mg/ml X-Gal-Lösung und $100 \mu \mathrm{l}$ 100mM IPTG ausgestrichen. Die Platten wurden anschließend 30 min im Brutschrank bei 37 ${ }^{\circ} \mathrm{C}$ inkubiert, um das Lösungsmittel zu verdampfen.

Zur Herstellung des SOC-Mediums wurden $2 \mathrm{~g}$ Bacto Rtryptone, $0.5 \mathrm{~g}$ Bacto ${ }^{\circledR}$-yeast extract, $1 \mathrm{ml} 1 \mathrm{M} \mathrm{NaCl}$ und $0.25 \mathrm{ml} 1 \mathrm{M} \mathrm{KCl}$ in $97 \mathrm{ml}$ Wasser gegeben, der $\mathrm{pH}$ auf 7.0 eingestellt und autoklaviert. Nach dem Abkühlen wurden $1 \mathrm{ml}$ sterilfiltrierte $2 \mathrm{M} \mathrm{Mg}^{2+}$-Lösung (20.33 g $\mathrm{MgCl}_{2} \bullet 6 \mathrm{H}_{2} \mathrm{O}$ und $24.65 \mathrm{~g} \mathrm{MgSO}_{4} \bullet 7 \mathrm{H} 20$ in $100 \mathrm{ml} \mathrm{H} 2 \mathrm{O}$, sterilfiltriert) und $1 \mathrm{ml} 2 \mathrm{M}$ sterilfiltrierte Glucose zugegeben.

Alle Zellkulturmedien wurden von der Firma Invitrogen bezogen.

\subsubsection{Lösungen}

Ampicillinlösung

Ethidiumbromid-Lösung

IPTG-Lösung

X-Gal-Lösung
$10 \mathrm{mg} / \mathrm{ml}$ in Wasser, sterilfiltriert

$10 \mathrm{mg} / \mathrm{ml}$ Ethidiumbromid in Wasser

0.1 M IPTG in Wasser, sterilfiltriert

$50 \mathrm{mg} / \mathrm{ml} \mathrm{X-Gal} \mathrm{in} \mathrm{N,} \mathrm{N'-dimethylformamid}$ 


\subsubsection{Puffer}

PBS

$136 \mathrm{mM} \mathrm{NaCl}, 2.7 \mathrm{mM} \quad \mathrm{KCl}, 8 \mathrm{mM}$ $\mathrm{Na}_{2} \mathrm{HPO}_{4}, 1.5 \mathrm{mM} \mathrm{Kh}_{2} \mathrm{PO}_{4}$

TBS

$20 \mathrm{mM}$ Tris, $150 \mathrm{mM} \mathrm{NaCl}, \mathrm{pH} 7.5$

MOPS-Puffer $(10 \times)$

200

$\mathrm{mM}$

3-(N-Morpholino)-

Propansulfonsäure, $50 \mathrm{mM}$ Natriumacetat, 10 mM EDTA, pH7.0

DNA-Probenpuffer $(5 \times)$

$20 \%$ Ficoll 400, 100 mM EDTA (pH 8.0), $0.25 \%$ Bromphenolblau, $0.25 \%$ Xylencyanol

SSC-Puffer $(20 \times)$

$3 \mathrm{M} \mathrm{NaCl}, 0.3 \mathrm{M}$ Natriumcitrat, $\mathrm{pH} 7.0$

TBE-Puffer $(10 \mathrm{x})$

$890 \mathrm{mM}$ Tris, $890 \mathrm{mM}$ Borsäure, $20 \mathrm{mM}$ EDTA, pH 8.0

TE-Puffer

10 mM Tris-HCl, 1mM EDTA, $\mathrm{pH} 7.5$ oder $\mathrm{pH} 8.0$

Spezielle Lösungen, Puffer und Reaktionszusätze werden im Rahmen der entsprechenden Methoden aufgeführt.

\subsection{Methoden}

\subsubsection{Molekularbiologische Methoden}

\subsubsection{Kultivierung und Lagerung von E. coli}

Die Bakterien wurden in LB-Amp-Medium angezogen und bei $37{ }^{\circ} \mathrm{C}$ bei $200-250$ upm geschüttelt (Innova 4430-Schüttelinkubator). Zur dauerhaften Lagerung der Bakterien bei -80 
${ }^{\circ} \mathrm{C}$ wurden Glyzerinkulturen angelegt. Dazu wurden Übernachtkulturen im gleichen Verhältnis (v/v) mit steriler 30 \% Glyzerinlösung verdünnt.

\subsubsection{Spaltung von DNA mit Restriktionsendonukleasen}

Restriktionsendonukleasen vom Typ II (Xba I, Kpn I, Pme I) wurden benutzt, um DNA an definierten Stellen der Sequenz zu schneiden. Sie wurden in glyzerinhaltigem Puffer bei -20 ${ }^{\circ} \mathrm{C}$ gelagert. Plasmide wurden mit 5U Enzym pro $\mu \mathrm{g}$ DNA in einem Volumen von $20 \mu \mathrm{l}$ für 1$2 \mathrm{~h}$ bei $37{ }^{\circ} \mathrm{C}$ in dem empfohlenen Puffer mit bzw. ohne Zugabe von BSA in einer Endkonzentration von $100 \mu \mathrm{g} / \mu \mathrm{l}$ inkubiert. Die Reaktion wurde durch Zugabe von $10 \mathrm{mM}$ EDTA $\mathrm{pH} \quad 8$ beendet und vollständig in einem präparativen $0.8 \%$ Agarose/Ethidiumbromidgel in $1 / 5$ Volumen $5 \times$ Gelbeladungspuffer aufgetrennt. Die erwünschten Banden der Fragmente wurden ausgeschnitten und die DNA mittels des Nucleospin Extract (Macherey \& Nagel) gereinigt.

\subsubsection{Ligation doppelsträngiger DNA}

Doppelsträngige PCR-Produkte wurden in den doppelsträngigen DNA-Vektor pGEM-T aus dem pGEM-T Vector System (Promega) ligiert. Dazu wurde ein molares Vektor: InsertVerhältnis von 1: 1 bis 1: 3 gewählt. Die Ligation erfolgte im $2 \times$ Rapid Ligation Buffer, 50 ng Vektor und 3 Weiss-Units in einem Reaktionsvolumen von $10 \mu \mathrm{l}$ über Nacht bei $4{ }^{\circ} \mathrm{C}$.

\subsubsection{Transformation von E. coli}

Die kompetenten Zellen (JM109) wurden auf Eis aufgetaut und $50 \mu$ lavon mit $3 \mu$ l Ligationsansatz für 20 min auf Eis inkubiert. Danach wurden die Zellen einem 1-minütigen Hitzeschock bei $42{ }^{\circ} \mathrm{C}$ unterworfen und dann sofort für 2 min auf Eis gestellt. Es wurden 950 $\mu \mathrm{l}$ SOC-Medium $\mathrm{zu}$ den Zellen gegeben und $1.5 \mathrm{~h}$ bei $37{ }^{\circ} \mathrm{C}$ und 150 upm inkubiert. Schließlich wurden die Zellen in $100 \mu 1$ Aliquots auf LB-Amp-IPTG-X-Gal-Platten ausgestrichen und über Nacht bei $37^{\circ} \mathrm{C}$ im Brutschrank inkubiert. 


\subsubsection{Plasmidisolation}

Die Plasmidisolation erfolgte nach dem Prinzip der alkalischen SDS-Lyse (Birnboim und Doly, 1979) und Aufreinigung der DNA durch eine Silikamembran unter Verwendung des NucleoSpin $\circledast$ Plasmid Kits der Firma Macherey \& Nagel. In dem ersten Schritt erfolgte eine alkalische Lyse der Bakterien mit nachfolgender Neutralisation zur Herstellung adäquater Bindungsbedingungen an die Silikamembran und danach ein Waschschritt mit dem auf $50{ }^{\circ} \mathrm{C}$ erwärmten Puffer AW, um Nukleasen aus Bakterienstämmen (JM109) mit hohem Nukleasegehalt zu entfernen. Ein weiterer Waschschritt mit ethanolhaltigem A4 und Elution unter Niedrigsalzbedingungen mit sterilem Wasser folgten. Die so gewonnene DNA ist qualitativ für den Verdau mit Restriktionsenzymen, für Transformationen, Ligationen und Sequenzierreaktionen geeignet.

\subsubsection{Agarosegelelektrophorese von DNA}

Diese Art der Gelelektrophorese wurde zur analytischen und präparativen Auftrennung von DNA-Fragmenten angewendet. In der vorliegenden Arbeit wurden 1 - $2 \%$ Agarosegele verwendet. Die Agarose wurde in TBE-Puffer, der $0.4 \mu \mathrm{g} / \mathrm{ml}$ Ethidiumbromid enthielt, unter Kochen gelöst und nach Abkühlen auf $50{ }^{\circ} \mathrm{C}$ in eine Flachbettgelapparatur mit einem drüberhängenden Taschenformer der erforderlichen Größe gegossen. Nach Verfestigung des Geles konnte der Kamm vorsichtig herausgelöst und das Gel in eine mit TBE-Puffer gefüllte Elektrophoresekammer transferiert werden. Die DNA-Proben wurden mit 1/5 Volumen an Gelbeladungspuffer versetzt und in die Geltaschen pipettiert. Der Einlauf in das Gel wurde bei einer Feldstärke von $6 \mathrm{~V} / \mathrm{cm}$ und die anschließende Trennung bei $11-12 \mathrm{~V} / \mathrm{cm}$ durchgeführt. Die DNA-Banden wurden unter UV-Licht im GelDoc EQ-System (Bio-Rad) sichtbar gemacht und aufgenommen.

TBE: 25 mM Tris, 25 mM Borsäure, 2 mM EDTA, pH 8.3

Gelbeladungspuffer: $25 \%$ Glyzerin in TBE-Puffer, $0.04 \%(\mathrm{w} / \mathrm{v})$ Bromphenolblau, $0.04 \%$ Xylencyanolblau. 


\subsubsection{Sequenzierung}

Die Sequenzierung erfolgte unter Verwendung des AmpliTaq FS 1/4 Big Dye TerminatorKits der Firma Applied Biosystems. $4 \mu \mathrm{l}$ des Terminator Ready Mix wurden mit $0.2 \mu \mathrm{g}$ DNA und 3.2 pmol Oligonukleotid in einem Volumen von $20 \mu \mathrm{l}$ gemischt. Diese Reaktion wurde mit 25 Zyklen $\left(30 \mathrm{~s} 96{ }^{\circ} \mathrm{C}, 15 \mathrm{~s}\right.$ bei $50{ }^{\circ} \mathrm{C}$ und $4 \mathrm{~min}$ bei $\left.60{ }^{\circ} \mathrm{C}\right)$ im Thermozykler durchgeführt. Die amplifizierte DNA wurde durch Zugabe von $2 \mu$ l Natriumazetat (3M pH 4.6) und $50 \mu 195 \%$ Ethanol für 10 min auf Eis gefällt und 15 min bei $14000 \times$ g zentrifugiert, mit $70 \%$ Ethanol gewaschen, getrocknet und auf einem Sequenziergel zur Bestimmung der Sequenz aufgetrennt.

\subsubsection{Vorbereitung des Material zur RNA-Isolation}

Die Organe und Hirnregionen wurden mit dem TissueLyser der Firma Qiagen in Buffer RLT bzw. Qiazol (Qiagen) zerkleinert. Bei dieser Methode werden die Gewebestücke durch eine im Reaktionsgefäß befindliche Metallkugel durch starkes Schütteln zerschlagen.

\subsubsection{RNA-Isolation aus fettigem Gewebe (Qiazol)}

Bei Verwendung von Qiazol wurden die homogenisierten Proben 5 min bei RT inkubiert und dann 1/5 Volumen Chloroform zugegeben, $15 \mathrm{~s}$ gevortext, 3 min bei RT inkubiert und 15 min bei $4{ }^{\circ} \mathrm{C}$ und $12000 \times$ g zentrifugiert. Die obere wässrige Phase wurde abgenommen, mit 1/2 Volumen Isopropanol versetzt und $10 \mathrm{~min}$ bei RT inkubiert. Darauf folgte ein Zentrifugationsschritt bei $4{ }^{\circ} \mathrm{C}$ und $12000 \times$ g. Der Überstand wurde abgenommen, das Pellet mit $1 \mathrm{ml} 75 \%$ Ethanol versetzt und 5 min bei $4{ }^{\circ} \mathrm{C}$ und $7500 \times \mathrm{g}$ zentrifugiert. Dann wurde das Pellet getrocknet, in RNase-freiem Wasser aufgenommen, Buffer RLT (mit 1 \% $\beta$ Mercaptoethanol) zugefügt, die RNA durch eine QIAshredder-Säule homogenisiert und mit dem RNeasy Mini bzw. Midi isoliert.

\subsubsection{RNA-Isolation aus fibrösem Gewebe}

Das in Buffer RLT zerkleinerte Gewebe wurde mit RNase-freiem Wasser auf $890 \mu \mathrm{l}$ aufgefüllt, mit $10 \mu$ Proteinase K-Lösung versetzt, 10 min bei $55^{\circ} \mathrm{C}$ inkubiert und 3 min bei 
$10000 \times \mathrm{g}$ bei RT zentrifugiert. Der Überstand wurde in ein neues Reaktionsgefäß pipettiert, mit 0.5 Volumen Ethanol versetzt und mit dem RNeasy Mini bzw. Midi Kit weiterverarbeitet.

\subsubsection{RNA-Isolation aus Zellen}

Zur Isolation von Gesamt-RNA aus Zellen wurden 5 Mio. Zellen mit Buffer RLT(mit $1 \% \beta$ Mercaptoethanol) der Firma Qiagen versetzt und durch Zentrifugation in einer QIAshredderSäule homogenisiert.

\subsubsection{Isolation von Gesamt-RNA}

Das vorbereitete Zell- oder Gewebelysat wurde mit gleichem Volumen an $70 \%$ Ethanol versetzt, zur Bindung auf die Säule (Mini oder Midi-Säule) pipettiert und bei $8000 \times \mathrm{g}$ bzw. $5000 \times$ g zentrifugiert. Darauf folgten ein Waschschritt mit 500 $\mu 1$ bzw. 2 ml RW1-Puffer und die Inkubation der an die Säule gebundenen RNA mit DNAse I in RDD-Puffer $(12.5 \%$ DNAseI in $160 \mu \mathrm{l}$ bzw. $320 \mu \mathrm{l}$ RDD-Puffer) bei $37^{\circ} \mathrm{C}$ für $30 \mathrm{~min}$ zur Zerstörung von kontaminierender DNA. Die RNA wurde einmal mit $500 \mu$ bzw. 2 ml RW1- und zweimal mit $500 \mu \mathrm{l}$ bzw. $2 \mathrm{ml}$ RPE-Puffer gewaschen, mit $50 \mu \mathrm{l}$ bzw. $200 \mu 1$ DEPC-Wasser eluiert und bis zur Weiterverwendung bei $-80{ }^{\circ} \mathrm{C}$ gelagert.

\subsubsection{Isolation von mRNA}

Zur Isolation von mRNA wurde der FastTrack 2.0 Kit von der Firma Invitrogen verwendet. Diese Methode beruht auf der selektiven Bindung von mRNA an Oligo(dT)-Zellulose unter Hochsalzbedingungen. Die Zellulose wird nach Bindung der mRNA in eine Mikrozentrifugensäule überführt, mehrfach mit einem Niedrigsalzpuffer gewaschen, um ribosomale RNA zu entfernen und eluiert.

Die Zellen wurden mit PBS gewaschen und pelletiert. Das Zellpellett wurde in $15 \mathrm{ml}$ Lysispuffer resuspendiert und viermal durch eine 18 - 21-gauge Nadel aufgezogen, um die genomische DNA zu scheren. Das Lysat wurde 45 min bei $45^{\circ} \mathrm{C}$ inkubiert, um Proteine und RNasen $\mathrm{zu}$ verdauen, und $5 \mathrm{~min}$ bei $4000 \times \mathrm{g}$ zentrifugiert, um unlösliches Material $\mathrm{zu}$ entfernen. Danach wurde die NaCl-Konzentration auf 0.5 M eingestellt und erneut viermal durch eine 18 - 21-gauge Nadel aufgezogen. Nach der Zugabe der Oligo(dT)-Zellulose und einem 2 min Quellvorgang wurde die Mischung 30 min unter leichtem Schütteln inkubiert, 
bei Raumtemperatur 5 min bei $3000 \times \mathrm{g}$ zentrifugiert und der Überstand vorsichtig abgenommen. Nun folgten zwei Waschschritte mit je $20 \mathrm{ml}$ Bindungspuffer und vier Schritte mit $10 \mathrm{ml}$ Niedrigsalzwaschpuffer. Die Oligo(dT)-Zellulose wurde in Niedrigsalzwaschpuffer in eine Zentrifugensäule überführt, bei $5000 \times \mathrm{g} 10$ s lang zentrifugiert und viermal mit $500 \mu \mathrm{l}$ Niedrigsalzwaschpuffer gewaschen bis der durchgelaufene Puffer eine OD260 von $<0.05$ aufwies. Die mRNA wurde zweimal mit $200 \mu$ l Elutionpuffer eluiert, mit 0.15 Volumen $2 \mathrm{M}$ Natriumazetat und 2.5 Volumen $100 \%$ Ethanol auf Trockeneis gefällt und nach Auftauen bei $16000 \times \mathrm{g} 15 \mathrm{~min}$ zentrifugiert und in $50 \mu \mathrm{l}$ Elutionspuffer aufgenommen. Anschließend wurde zusätzlich eine RNA-Isolation samt DNAse I-Verdau mit dem RNeasy Mini Kit (Qiagen) vorgenommen, um kontaminierende DNA zu entfernen.

\subsubsection{Auftrennung von RNA in Formaldehydgel und Agarose/Ethidiumbromidgel}

Bei der Auftrennung von RNA in einem Agarosegel ist es nötig, dass zuerst die Gelkammern und Taschenformer mit $3 \% \mathrm{H}_{2} \mathrm{O}_{2}$ RNAse-frei gemacht werden. Zur Herstellung eines $1 \%$ Formaldehyd-Agarose-Geles wurden $1 \mathrm{~g}$ Agarose mit $88 \mathrm{ml}$ DEPC-Wasser aufgekocht, auf $60{ }^{\circ} \mathrm{C}$ abgekühlt, dann mit $10 \mathrm{ml} 10$ x MOPS-Puffer und $1.8 \mathrm{ml} 37 \%$ Formaldehyd versetzt und in die Gelkammer gegossen. Die gewünschte Menge an RNA wurde mit DEPC-Wasser auf ein Volumen von $4.5 \mu \mathrm{l}$ gebracht, mit $2 \mu \mathrm{l} 10 \times$ MOPS-Puffer und $3.5 \mu 137 \%$ Formaldehyd gemischt, $15 \mathrm{~min}$ bei $65^{\circ} \mathrm{C}$ denaturiert und bis zum Auftragen auf Eis aufbewahrt. Die 0.24 - 9.5 Kb-RNA-Leiter $(1 \mu \mathrm{g} / \mu \mathrm{l})$ wurde ebenso behandelt. Die Proben wurden dann nach Zugabe von $2 \mu 15 \times$ Probenbeladungspuffer und $0.5 \mu \mathrm{l} 1 \mathrm{mg} / \mathrm{ml}$ Ethidiumbromid für $2 \mathrm{~h}$ in $1 \times$ MOPS-Puffer aufgetrennt. Alle so analysierten RNA-Spezies zeigten keine Abbauprodukte und das erforderliche Verhältnis von 28S und 18S RNA bei 4.5 und $1.9 \mathrm{~kb}$ von $1.5-2.5$ : 1 .

\subsubsection{Konzentrationsbestimmung von RNA, DNA und Oligonukleotiden}

Die Optische Dichte (OD) von RNA, DNA oder Oligonukleotiden wurde in geeigneter Verdünnung in einem Spektrophotometer bestimmt. Für RNA wurde dabei als Berechnungsfaktor $40 \mathrm{mg} / \mathrm{l}$, für DNA $50 \mathrm{mg} / \mathrm{l}$ und für Oligonukleotide $30 \mathrm{mg} / \mathrm{l}$ verwendet. 


\subsubsection{Synthese von cDNA}

Für die Synthese der cDNA wurden Enzyme und Puffer der Firma Promega verwendet und geringe Mengen in vitro-transkribierte Chitinsynthetase 1-RNA aus Hefe (yCHS1) zur cDNA-Synthesereaktion zugefügt, um die Effizienz der reversen Transkription zu überprüfen und eventuelle differentielle Expression von Haushaltsgenen abzuschätzen. $5 \mu \mathrm{g}$ RNA wurde mit $5 \mu \mathrm{l} 0.5 \mu \mathrm{g} / \mu \mathrm{l}$ OdT12-18-Oligo-dT-Primern und $4 \times 10^{-9} \mu \mathrm{g} / \mu \mathrm{l}$ yCHS1-RNA versetzt und mit DEPC-Wasser auf $25 \mu \mathrm{l}$ aufgefüllt. Diese Mischung wurde $8 \mathrm{~min}$ auf $70{ }^{\circ} \mathrm{C}$ im Thermozykler erhitzt und auf Eis schockgekühlt, um die Sekundärstrukturen der RNA zu zerstören. Dann wurde das Puffergemisch hinzugefügt (10 $\mu 15 \times$ MMLV-RT-Puffer, dNTPs, RNasin, MMLV-RT, DEPC-Wasser), die reverse Transkription für $1 \mathrm{~h}$ bei $42{ }^{\circ} \mathrm{C}$ im Thermozykler durchgeführt und die reverse Transkriptase 15 min bei $70{ }^{\circ} \mathrm{C}$ inaktiviert. Zur Langzeitaufbewahrung wurde die cDNA bei $-20{ }^{\circ} \mathrm{C}$ gelagert.

\subsubsection{Polymerasekettenreaktion (PCR)}

Die Polymerasekettenreaktion dient der enzymatischen in vitro Amplifikation spezifischer DNA-Fragmente und besteht aus aufeinanderfolgenden Amplifikationszyklen, die jeweils durch drei Phasen unterschiedlicher Temperatur gekennzeichnet sind (Mullis und Faloona, 1987; Saiki et al., 1988). In der ersten Phase, der Denaturierungsphase, wird eine doppelsträngige DNA-Matrize bei einer Temperatur von $94{ }^{\circ} \mathrm{C}$ in eine sekundärstrukturfreie Einzelstrang-DNA überführt. In der zweiten Phase, die Anlagerungsphase (annealing) genannt wird, wird durch Temperatursenkung auf $50-68{ }^{\circ} \mathrm{C}$ dafür gesorgt, dass sich spezifische Oligodesoxynukleotide (Primer), die jeweils in entgegengesetzter Orientierung die Zielregion der Duplex-DNA flankieren, anlagern und in der Extentionsphase durch eine thermostabile DNA-Polymerase bei $72^{\circ} \mathrm{C}$ in $5^{\prime} \rightarrow 3^{\prime}$-Richtung komplementär zur Zielregion verlängert werden können. In aufeinanderfolgenden Amplifikationsrunden kommt es damit zur exponentiellen Anreicherung der durch die beiden Primer flankierten Ziel-DNA-Sequenz. Um eine spezifische Amplifikation zu gewährleisten, dürfen sich die Primer nur wenig in den $\mathrm{T}_{\mathrm{m}}$-werten unterscheiden und dürfen keine komplementären Sequenzen beinhalten, um die Ausbildung von Sekundärstrukturen zu vermeiden. Für die Synthese der PCR-Produkte wurde Taq-Polymerase der Firma Invitrogen und die jeweils mitgelieferten Puffer verwendet. Die PCR-Reaktionen wurden in dünnwandigen 0.5 ml-PCR-Reaktionsgefäßen in $50 \mu 1$ Ansätzen durchgeführt. 
Die einzelnen Komponenten wurden für $50 \mu$-Reaktionen $2.5 \mu 110$ x Puffer, $1.5 \mu 1 \mathrm{MgCl}_{2}$ (50 mM), $1 \mu \mathrm{l}$ dNTPs $(10 \mathrm{mM}), 1.25 \mu$ Primer $1(10 \mu \mathrm{M}), 1.25 \mu 1$ Primer $2(10 \mu \mathrm{M}), 100$ $200 \mathrm{ng}$ zu amplifizierende DNA eingesetzt, auf $49.75 \mu \mathrm{l}$ mit autoklaviertem Wasser aufgefüllt und nach $3 \mathrm{~min}$ bei $95^{\circ} \mathrm{C} 0.25 \mu \mathrm{l}$ Taq-Polymerase zugegeben.

Allen PCR-Reaktionen war ein Denaturierungsschritt von $94{ }^{\circ} \mathrm{C} 3 \mathrm{~min}$ zur Zerstörung der Sekundärstrukturen vorgeschaltet. Erst nach diesem Schritt wurde die Taq-Polymerase zugefügt (hot start). Für die Reaktionen wurden PCR-Geräte der Firma Biometra (TRIO Thermoblock) und der Firma Eppendorf (Mastercycler gradient) mit Deckelheizung und folgendem PCR-Profil verwendet: hot start: $94{ }^{\circ} \mathrm{C} 3 \mathrm{~min}$, Denaturierung: $94{ }^{\circ} \mathrm{C} 1 \mathrm{~min}$, Anheftung: $\mathrm{X}{ }^{\circ} \mathrm{C} 45 \mathrm{~s}$ (abhängig von dem Tm-Wert des Primer), Amplifikation: $72{ }^{\circ} \mathrm{C} 1$ min/1000 bp-Fragmentgröße, Auffüllreaktion: $72{ }^{\circ} \mathrm{C} 10 \mathrm{~min}$ (Auffüllreaktion eventuell unvollendeter Synthese). Die Denaturierungs-, Anheftungs- und Amplifikationsphase wurden zyklisch mit einer vom Gen abhängigen Anzahl von Wiederholungen durchgeführt.

\subsubsection{Real-Time-PCR}

Zusätzlich zu den zwei der zu amplifizierenden Sequenz komplementären Primern, die in jeder normalen PCR benutzt werden, wird bei dieser Form der Real-Time-PCR eine ebenfalls komplementäre fluoreszenzmarkierte Sonde verwendet, die die Detektion während des PCRLaufs ermöglicht und zwischen den unmarkierten Primern liegt. Am 5'-Ende der Sonde befindet sich ein Fluoreszenzfarbstoff (FAM oder JOE), dessen Fluoreszenz von dem am 3'Ende befindlichen Quencher (TAMRA) in der intakten Sonde unterdrückt wird. Wird nun der an den gleichen Strang bindende normale Primer verlängert, spaltet die 5'-3'Nukleaseaktivität der speziellen Taq-Polymerase die Sonde und trennt damit den Fluoreszenzfarbstoff und den Quencher. Die dabei entstehende Fluoreszenz wird gemessen.

Real-Time-PCR wurde in mehreren Replikaten mit 100 ng cDNA im $10 \mu$ Volumen mit dem two step TaqMan Core Kit von der Firma Applied Biosystems in dem ABI 7700 sequence analyzer (Perkin Elmer) durchgeführt. Die PCR-Bedingungen waren: 2 min $50^{\circ} \mathrm{C} ; 15$ min 94 ${ }^{\circ} \mathrm{C}$; $15 \mathrm{~s} 94{ }^{\circ} \mathrm{C}, 15 \mathrm{~s} 56{ }^{\circ} \mathrm{C}$, und $1 \mathrm{~min} 60{ }^{\circ} \mathrm{C}$ (40 Zyklen). Die Kopienzahl pro eingesetztem Volumen der Probe wurde mit Hilfe einer Kalibrierkurve bestimmt, die mit Plasmidstandards bekannter Konzentration erstellt wurde. Die resultierenden Konzentrationen wurden auf die Menge des Haushaltsgens, den humanen Transferrinrezeptor Typ 1, standardisiert, nachdem die gleichverteilte Effizienz der cDNA-Synthese durch Real-Time-PCR einer extern zur cDNA-Synthesereaktion zugefügten RNA, der Chitinsynthetase 1 aus Hefe, überprüft wurde. 
Die Graphen stellen diese standardisierten Werte dar, die weiterhin auf die jeweilige Kontrolle normalisiert und als Mittelwerte mit Standardfehler dargestellt wurden. Die Anzahl der Wiederholungen wurde entweder direkt über den jeweiligen Säulen in der Abbildung oder in der Legende beschrieben (z. B. $n=6)$.

\subsubsection{Pfadspezifischer Array (GEArray)}

Mit Expressionsarrays ist es möglich, vergleichende Genexpressionsprofile zweier oder mehrerer RNA-Populationen, die aus unterschiedlichen experimentellen Bedingungen isoliert wurden, zu erstellen.

Pfadspezifische Expressionsarrays bestehen aus einer positiv geladenen Nylonmembran, auf die spezifische cDNA-Fragmente für bestimmte Gene des jeweiligen Pfades aufgetupft sind und mit denen radioaktiv markierte Sonden, die aus unterschiedlichen Versuchsbedingungen stammen, hybridisiert werden. In dieser Arbeit wurden GEArrays (SuperArray INC) des Typs Cancer/Oncogenesis-II, Cancer/Metastasis-I, Cancer/Angiogenesis-II und Integrin zum Vergleich des Expressionsprofils von hEAG1a-transfizierten HEK293-Zellen mit WildtypHEK293-Zellen verwendet. Zuerst wurde in einem Schritt aus den RNA-Proben der unterschiedlichen experimentellen Bedingungen mit für die aufgetupften 23 Gene (und die zwei Haushaltsgene Gene $\beta$-Aktin und GAPDH) spezifischen Primern cDNA hergestellt und mit $[\alpha-32 P]-d C T P$ markiert. Im zweiten Schritt wurden die markierten cDNAs mit den Arrays hybridisiert.

Für jede RNA-Probe wurden $5 \mu \mathrm{g}$ RNA mit $2 \mu \mathrm{l}$ GEAprimer Mix (Buffer A) versetzt, mit RNAse-freiem Wasser auf $20 \mu \mathrm{l}$ aufgefüllt und 2 min bei $70{ }^{\circ} \mathrm{C}$ inkubiert. Danach wurde diese Mischung auf $42{ }^{\circ} \mathrm{C}$ gehalten bis $8 \mu 15 \times$ GEAlabeling Buffer (Buffer B), $5 \mu 1$ [ $\alpha$-32P]dCTP $(10 \mathrm{mCi} / \mathrm{ml}), 1 \mu \mathrm{l}$ Rase-Inhibitor, $2 \mu \mathrm{l}$ MMLV reverse Transkriptase (50 units/ $\mu \mathrm{l}$ ) und $4 \mu \mathrm{l}$ RNase-freies Wasser zugefügt wurden und die Markierungsreaktion 25 min bei $42{ }^{\circ} \mathrm{C}$ weitergeführt wurde. Nach dem Abstoppen der Reaktion mit $5 \mu 10 \times$ Stop Solution (Buffer C) wurden $5 \mu 110 \times$ Denaturation Solution (Buffer D) zugegeben und bei $68^{\circ} \mathrm{C}$ für $20 \mathrm{~min}$ inkubiert. Dann wurden $50 \mu 12 \times$ Neutralization Buffer (Buffer E) zugefügt und weitere 10 min bei $68^{\circ} \mathrm{C}$ inkubiert, bevor sie für 5 min auf $94{ }^{\circ} \mathrm{C}$ erhitzt und dann auf Eis gekühlt wurde. Die Arrays wurden mit $10 \mathrm{ml}$ Hybridisierungslösung (GEAhyb Hybridization Solution mit $100 \mu \mathrm{g}$ Hitze-denaturierter sheared salmon sperm DNA bei $68^{\circ} \mathrm{C}$ für $2 \mathrm{~h}$ prähybridisiert. Die markierten Sonden wurden nun in $5 \mathrm{ml}$ Hybridisierungslösung (GEAhyb Hybridization Solution mit $100 \mu \mathrm{g}$ Hitze-denaturierter sheared salmon sperm DNA zu den prähybridisierten 
Arrays gegeben und über Nacht bei $68{ }^{\circ} \mathrm{C}$ unter ständiger Bewegung hybridisiert. Am nächsten Tag folgten zwei 20-minütige Waschschritte mit $50 \mathrm{ml} 2 \times$ SSC und 1\% SDS und zwei mit $50 \mathrm{ml} 0.1 \times \mathrm{SSC}$ und $0.5 \%$ SDS bei $68^{\circ} \mathrm{C}$. Schließlich wurden die Membranen in Klarsichtfolie verpackt, beide Membranen gemeinsam auf einer Phospho-Imager-Platte exponiert, die Signale detektiert und quantifiziert. Für die Auswertung wurden die Signalintensitäten auf die Intensität des Haushaltsgens GAPDH standardisiert.

\subsubsection{Subtraktive Hybridisierung}

Die subtraktive Hybridisierung hat sich als eine wirkungsvolle Methode zum Vergleich des Expressionsprofils zweier Zellpopulationen erwiesen, die verschiedenen experimentellen Bedingungen unterworfen wurden oder anderweitig unterschiedliche Populationen darstellen Der BD PCR-Select TM cDNA Subtraction Kit von Clontech stellt eine Weiterentwicklung der traditionellen subtraktiven Hybridisierung dar, dadurch dass er die Identifikation seltener RNA-Spezies erlaubt und die Amplifikation von nicht differentiellen Genen durch Suppressions-PCR unterdrückt. Die mRNA, die die differentiell exprimierten Transkripte enthält, wird als Tester bezeichnet, die Referenz-mRNA als Driver. Mit dieser Subtraktionsrichtung, die man Vorwärtssubtraktion nennt, können Gene gefunden werden, die im Tester höher als im Driver exprimiert werden. Um im Tester herunterregulierte Gene zu entdecken, muss die Subtraktion auch in Gegenrichtung durchgeführt werden, also mit dem Tester der Vorwärtsreaktion als Driver für die Rückwärtssubtraktion und umgekehrt.

Die Methode besteht aus einer Reihe sukzessiver Schritte, die mit der Isolation von mRNA aus den unterschiedlich behandelten Zellpopulationen, der Herstellung doppelsträngiger cDNA, einem Verdau mit dem blunt-end-Restriktionsenzym Rsa I und der Ligation zweier unterschiedlicher Adaptoren an zwei Proben der gleichen Tester-RNA beginnt. Dann erfolgen zwei Runden von Hybridisierungen, die die Bildung von doppelsträngigen Spezies der differentiell exprimierten cDNAs mit den zwei verschiedenen Adaptoren an den Enden und einer nachfolgenden Anreicherung dieser durch zwei aufeinanderfolgende PCR-Reaktionen erlaubt (Abb. 6). Diese angereicherte cDNA-Bibliothek wird dann in Sequenziervektoren kloniert und dient als Material für das nachfolgende differentielle Screening. 


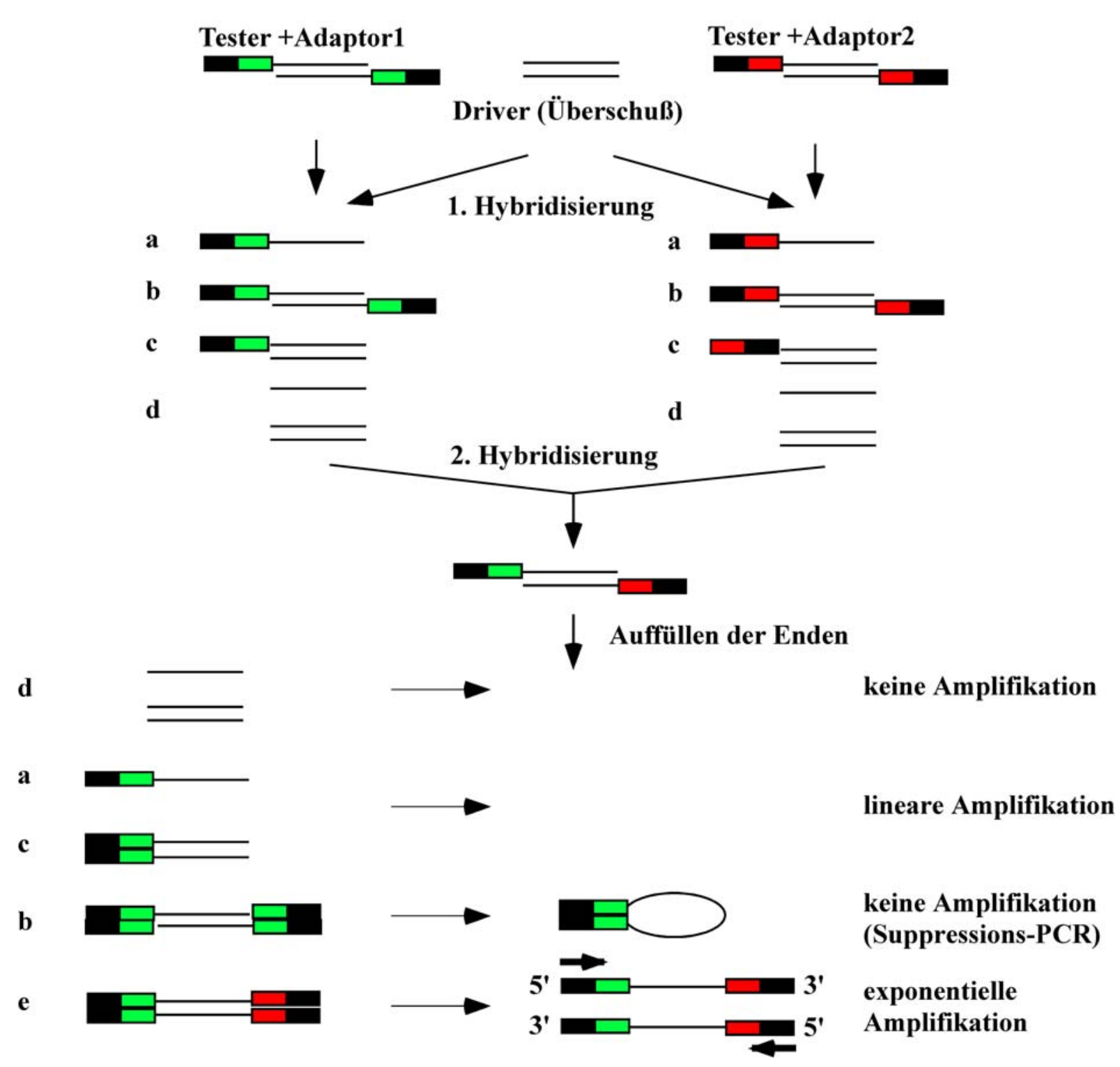

Abb. 6: Schematische Darstellung der Schritte der subtraktiven Hybridisierung. Die TestermRNA wurde aufgeteilt und mit den zwei verschiedenen Adaptoren ligiert. Nach der 1. Hybridisierung mit dem Driver entstanden die Moleküle a-d. Die zwei Hybridisierungen mit den verschiedenen Adaptoren wurden vereinigt und die Enden aufgefüllt. Dabei enstanden doppelsträngige Moleküle mit den verschiedenen Adaptoren an den Enden, die durch PCR mit Primern für die konstante Region der Adaptoren angreichert wurden. Moleküle mit dem gleichen Adapter an den Enden konnten auf Grund von intramolekularer Schleifenbildung nicht amplifiziert werden (Suppressions-PCR).

In dieser Arbeit wurden human embryonic kidney 293 (HEK293)-Zellen verwendet, die polyklonal und stabil mit hEAG1a im pTracer-Vektor (Invitrogen) (Tester-Population der Vorwärtssubtraktion) und nur mit pTracer-Vektor (Driver der Vorwärtssubtraktion) transfiziert waren. Durch diesen Versuchsaufbau wurden einige Modifikationen zum Clontech-Protokoll notwendig. Zum einen wurden zum jeweiligen Driver das Rsa I-verdaute Plasmid zugesetzt, das für die Transfektion der jeweiligen Tester-Zellen verwendet wurde, 
um das Auftreten von EAG1a- und GFP-Klonen beim nachgeschalteten differentiellen Screening zu unterdrücken. Zum anderen wurden nicht die Clontech-Adaptoren benutzt, da diese den T7-Promotor enthalten, der sowohl im transkribierten Bereich des Transfektionsplasmids (pTracer) als auch des Sequenzierungsvektors (pGEM-T) vorkommt und daher zu Subtraktions- und Sequenzierproblemen geführt hätte. Die stattdessen verwendeten Adaptoren wurden mit Na21St19 und Na21Not1 bezeichnet und die entprechenden Primer1 und Nested Primer mit Na21 bzw. St19 und Not1. Weiterhin wurden bei dem nachfolgenden differentiellen Screening die der Sequenz dieser Adaptoren entsprechenden Oligonukleotide zugesetzt, um die unspezifische Hybridisierung der Sonden zu unterdrücken. Die Subtraktion wurde von der Firma Euregene durchgeführt. Bei der Durchführung der Subtraktion wurde nach dem Protokoll von Clontech verfahren, außer bei den Schritten, die als Abweichungen vom Protokoll an jeweiliger Stelle beschrieben werden.

\subsubsection{0.a Erststrang-cDNA-Synthese}

Zweimal $2 \mu \mathrm{g}$ Poly A+ RNA in $2-4 \mu \mathrm{l}$ Volumen von Tester und Driver wurden nach Qualitätskontrolle der mRNA-Isolation für zwei Erststrangsynthesen pro Probe zu $1 \mu 1$ cDNA-Synthesis Primer $(10 \mu \mathrm{M})$ gegeben, auf je $10 \mu$ l Endvolumen mit RNAse-freiem Wasser aufgefüllt. und 2 min bei $70{ }^{\circ} \mathrm{C}$ im Thermozykler inkubiert. Nachfolgend wurden die Reaktionsmischungen auf Eis gekühlt, pro Reaktion $2 \mu l 5 \times$ First-Strand Buffer, $1 \mu l d N T P$ Mix (10mM), $1 \mu \mathrm{l}$ RNAse-freies Wasser und AMV Reverse Transcriptase (20 units/ $\mu \mathrm{l}$ ) zugegeben und für $1.5 \mathrm{~h}$ bei $42{ }^{\circ} \mathrm{C}$ inkubiert.

\subsubsection{0.b Zweitstrang-cDNA-Synthese}

Die beiden Tester-Erststrang-Reaktionen und die beiden Driver-Erststrang-Reaktionen wurden jeweils vereinigt, um genug Ausgangsmaterial für Vorwärts- und Rückwärtssubtraktion und für das nachfolgende differentielle Screening herzustellen. Die Zweitstrangsynthese erfolgte sodann im doppelten Volumen der im Clontech-Protokoll angegebenen Mengen. Es wurden $96.8 \mu \mathrm{l}$ RNAse-freies Wasser, $32 \mu \mathrm{l} 5 \times$ Second-Strand Buffer, $3.2 \mu \mathrm{d}$ dNTP Mix und $8 \mu 120 \times$ Second-Strand Enzyme Cocktail zu der vereinigten Erststrangreaktion gegeben und $2 \mathrm{~h} \mathrm{im} 16{ }^{\circ} \mathrm{C}$ Wasserbad inkubiert. Danach wurden $2 \mu \mathrm{T}$ T- 
Polymerase zugemischt und die Reaktion für 30 min bei $16{ }^{\circ} \mathrm{C}$ ins Wasserbad gestellt. Die Beendigung der Zweitstrangsynthese erfolgte im Gegensatz zum Protokoll nur mit $8 \mu 120 \times$ EDTA (0.2 M) ohne $1 \mathrm{mg} / \mathrm{ml}$ Glykogen, da Glykogen und jegliche andere kopräzipitierende Reagenzien die Viskosität der DNA-Lösung erhöhen und dadurch die späteren DNAHybridisierungsreaktionen stören können. Die cDNA wurde mit $200 \mu \mathrm{l}$ Phenol: Chloroform: Isoamylalkohol (25:24:1) versetzt, durchmischt, $10 \mathrm{~min}$ bei $16000 \times \mathrm{g}$ zentrifugiert, um die Phasen zu trennen, und die obere wässrige Phase abgenommen. Mit dieser wässrigen Phase wurde der Extraktionsschritt ein zweites Mal durchgeführt, zu der Lösung $80 \mu 14 \mathrm{M}$ Ammoniumazetat und $600 \mu 195 \%$ Ethanol zugesetzt und 20 min bei Raumtemperatur und $16000 \times$ g zentrifugiert. Der Überstand wurde verworfen, das Pellet mit $1 \mathrm{ml} 80$ \% Ethanol überschichtet und 10 min bei $16000 \times$ g zentrifugiert. Nachdem der Überstand abgenommen wurde, wurde das Pellet 10 min getrocknet und in $100 \mu$ sterilem Wasser aufgenommen. $6 \mu 1$ dieser Lösung wurden zur späteren Kontrolle des Rsa I-Verdaus abgefüllt und aufbewahrt.

\subsubsection{0.c Rsa I-Verdau}

Dieser Schritt wurde mit doppelten Mengen und Volumina der Protokollangaben durchgeführt. $87 \mu \mathrm{l}$ der doppelsträngigen cDNA , $10 \mu \mathrm{l} 10 \times$ Rsa I Restriction Buffer und $3 \mu 1$ Rsa I (10 units/ $\mu \mathrm{l})$ wurden gemischt, $1.5 \mathrm{~h}$ bei $37{ }^{\circ} \mathrm{C}$ inkubiert und, nachdem $5 \mu \mathrm{l}$ der Mischung zum Testen der Effizienz des Rsa I-Verdaus abgenommen wurden, wurde auch hier die Reaktion mit $5 \mu 120$ x EDTA (0.2 M) ohne Glykogen beendet. Die Extraktion erfolgte mit $100 \mu$ Phenol: Chloroform: Isoamylalkohol (25: 24: 1) und 10 min Zentrifugation bei 16000 $\times$ g. Für den 2. Extraktionsschritt wurde stattdessen $100 \mu$ l Chloroform: Isoamylalkohol verwendet, zu der Lösung $50 \mu \mathrm{l} 4 \mathrm{M}$ Ammoniumazetat und $375 \mu 195 \%$ Ethanol zugesetzt und 10 min bei Raumtemperatur und $16000 \times \mathrm{g}$ zentrifugiert. Der Überstand wurde verworfen, das Pellet mit $400 \mu 180 \%$ Ethanol überschichtet und 10 min bei $16000 \times \mathrm{g}$ zentrifugiert. Nachdem der Überstand abgenommen wurde, wurde das Pellet $10 \mathrm{~min}$ getrocknet und in $11 \mu \mathrm{l}$ sterilem Wasser aufgenommen. Zur Überprüfung der Effizienz des Rsa I-Verdaus wurden $2.5 \mu 1$ der unverdauten cDNA und $5 \mu 1$ der Rsa I-verdauten cDNA auf einem $1 \%$ Agarose/Ethidiumbromidgel in $1 \times$ TBE-Puffer aufgetrennt. Es konnte die erwartete Größenverschiebung von $0.5 \mathrm{~kb}-10 \mathrm{~kb} \mathrm{zu} 0.1 \mathrm{~kb}-2 \mathrm{~kb}$ beobachtet werden, die einen erfolgreichen Verdau kennzeichnet. 
500 ng der Vektoren pTracer und pTracer-hEAG1a wurden einem genauso gearteten Rsa IVerdau unterworfen und später zu der entsprechenden Rsa I-verdauten Driver cDNA gegeben.

\subsubsection{0.d Adapterligation}

Zur Herstellung der Tester-Verdünnung wurden je $1 \mu$ Rsa I-verdaute Tester-cDNA sowohl für die Vorwärts- als auch die Rückwärtssubtraktion mit $5 \mu$ sterilem Wasser gemischt. Von diesen Verdünnungen wurden jeweils $2 \mu \mathrm{l}$ für die Ligation an die Adaptoren zu $2 \mu l$ Adapter Na21St19 bzw. $2 \mu \mathrm{l} \mathrm{Na21Not1} \mathrm{in} \mathrm{getrennte} \mathrm{Reaktionsgefäße} \mathrm{gegeben} \mathrm{und} \mathrm{zusätzlich} 6 \mu 1$ Master Mix (3 $\mu 1$ steriles Wasser, $2 \mu 15$ × Ligation Buffer, $1 \mu 1$ T4 DNA Ligase (400 units/ $\mu 1$ pro Reaktion) zugefügt . Von diesen $10 \mu \mathrm{l}$ wurden jeweils $2 \mu \mathrm{l}$ von den Ligationsansätzen mit den zwei verschiedenen Adaptoren zusammenpipettiert, um später als unsubtrahierte TesterKontrolle für die Vorwärts- und Rückwärtssubtraktion zu dienen, und ebenso wie die TesterAnsätze über Nacht bei $16^{\circ} \mathrm{C}$ inkubiert. Die Proben wurden zur Beendigung der Reaktion mit $1 \mu 10.2 \mathrm{M}$ EDTA versetzt und 5 min auf $72{ }^{\circ} \mathrm{C}$ erhitzt, um die Ligase zu inaktivieren. Von den unsubtrahierten Tester-Kontrollen wurde $1 \mu$ abgenommen und auf $1 \mathrm{ml}$ mit sterilem Wasser aufgefüllt, um später als Kontrolle für die Effizienz der Subtraktion zu dienen.

\subsubsection{0.e Kontrolle der Adapterligation}

Die an die verschiedenen Adaptoren ligierten Tester wurden zur Kontrolle der Ligationseffizienz sowohl mit hGAPDH 3' und 5'-Primern als auch mit GAPDH-3' und Na21-Primern in getrennten PCR-Reaktionen gefahren. Die dabei entstehenden Banden mit GAPDH-3'/Na21 sollten in ihrer Signalintensität im $2 \%$ Agarose/Ethidiumbromidgel mindestens ein viertel der Signalintensität der Banden mit GAPDH-3'/5 aufweisen.

Dazu wurden $1 \mu \mathrm{l}$ 1: 200 verdünnter Adapter-ligierter Tester und $1 \mu \mathrm{l}$ des jeweiligen Vorwärts- oder Rückwärtsprimer mit $22 \mu \mathrm{l}$ eines gemisches aus $18.5 \mu \mathrm{l}$ sterilem Wasser, 2.5 $\mu 110 \times$ PCR Reaction Buffer, $0.5 \mu \mathrm{l}$ dNTP Mix (10mM) und $0.5 \mu 150 \times$ BD Advantage cDNA Polymerase gemischt, mit $50 \mu \mathrm{l}$ Öl überschichtet und für 5 min auf $75^{\circ} \mathrm{C}$ erhitzt. Das PCRProfil war folgendes: $94{ }^{\circ} \mathrm{C}$ für $30 \mathrm{~s}, 94{ }^{\circ} \mathrm{C} 10 \mathrm{~s}, 65^{\circ} \mathrm{C} 30 \mathrm{~s} 68^{\circ} \mathrm{C} 2.5 \mathrm{~min}$ für 20 Zyklen. Die 
Signalintensität der großen Banden entsprach mindestens ein viertel der Signalintensität der kleinen Banden. Die Adapterligation war daher effizient.

\subsubsection{0.f Erste Hybridisierung}

$1.5 \mu \mathrm{Rsa}$ I-verdaute Driver cDNA, die $500 \mathrm{ng}$ des jeweiligen Tester-Plasmids enthielten, wurden in getrennten Reaktionsgefäßen mit $1.5 \mu \mathrm{l}$ der an Na21St19 oder Na21Not1 ligierten Tester und $1 \mu 14 \times$ Hybridization Buffer gemischt und, nachdem sie mit einem Tropfen Öl überschichtet wurden, für $1.5 \mathrm{~min}$ auf $98{ }^{\circ} \mathrm{C}$ erhitzt. Darauf folgte eine 8 -stündige Hybridisierung bei $68^{\circ} \mathrm{C}$.

\subsubsection{0.g Zweite Hybridisierung}

Die zwei Reaktionen des gleichen Testers, der an verschiedene Adaptoren ligiert wurde, wurden vereinigt, $1 \mu$ frisch in $1 \mu \mathrm{l} 4 \times$ Hybridization Buffer und $2 \mu$ l sterilem Wasser denaturierter Driver so hinzugefügt, dass sich die zwei Tester-Reaktionen gleichzeitig und nur in der Gegenwart von frisch denaturiertem Driver vermischten und bei $68{ }^{\circ} \mathrm{C}$ über Nacht inkubiert. Es wurden am nächsten Tag $200 \mu$ Dilution Buffer zugegeben und das Gemisch für 7 min auf $68^{\circ} \mathrm{C}$ erhitzt.

\subsubsection{0.h Erste PCR-Amplifikation}

In dieser PCR werden nur doppelsträngige cDNAs selektiv exponentiell amplifiziert, die zwei verschiedene Adaptoren an den Enden besitzen, da bei gleichen Adaptoren am Ende das Phänomen der Suppression auftritt, bei dem die Adaptersequenzen aneinander binden und zwischen sich Haarnadelschleifen ausbilden.

$1 \mu l$ der cDNA aus der zweiten Vorwärts- und Rückwärts-Hybridisierung und der unsubtrahierten Tester-Kontrolle wurden aliquotiert, mit $24 \mu \mathrm{l}$ einer Mischung aus $19.5 \mathrm{ml}$ sterilem Wasser, $2.5 \mu \mathrm{l} 10 \times$ PCR Reaction Buffer, $0.5 \mu \mathrm{l}$ dNTP Mix (10 mM), $1 \mu \mathrm{l} \mathrm{Na21-}$ Primer $(10 \mu \mathrm{M})$ und $0.5 \mu 150 \times B D$ Advantage cDNA Polymerase Mix versetzt und mit $50 \mu 1$ Mineralöl überschichtet. Die Reaktionsmischung wurde für $5 \mathrm{~min}$ auf $75{ }^{\circ} \mathrm{C}$ erhitzt, um die fehlenden Stücke der Adaptersequenzen aufzufüllen, 25 s auf $94{ }^{\circ} \mathrm{C}$ erhitzt und dann 27 Zyklen von $30 \mathrm{~s} 94{ }^{\circ} \mathrm{C}, 30 \mathrm{~s} 66^{\circ} \mathrm{C}$ und $1.5 \min 72{ }^{\circ} \mathrm{C}$ unterworfen. 


\subsubsection{0.i Zweite PCR}

Die zweite PCR-Runde dient zur Anreicherung von differentiell exprimierten Sequenzen und zur Unterdrückung von Hintergrundsignal.

Es wurde $3 \mu \mathrm{l}$ dieser ersten PCR-Reaktion mit $27 \mu$ sterilem Wasser verdünnt und $1 \mu \mathrm{l}$ davon mit $24 \mu \mathrm{l}$ einer Mischung aus $18.5 \mu \mathrm{l}, 2.5 \mu 110 \times$ PCR Reaction Ruffer, $0.5 \mu 1$ dNTP Mix (10 $\mathrm{mM}), 1 \mu \mathrm{l} \mathrm{St19-Primer}(10 \mu \mathrm{M}), 1 \mu \mathrm{l}$ Not1-Primer $(10 \mu \mathrm{M})$ und $0.5 \mu \mathrm{l} 50 \times B D$ Advantage cDNA Polymerase Mix versetzt. Nachdem die Reaktion mit einem Tropfen Öl überschichtet wurde, wurden $11 \mathrm{Zyklen}$ von $10 \mathrm{~s} 94{ }^{\circ} \mathrm{C}, 30 \mathrm{~s} 68^{\circ} \mathrm{C}$ und $1.5 \mathrm{~min} 72{ }^{\circ} \mathrm{C}$ gefahren.

\subsubsection{0.j Kontrolle der Subtraktion}

$8 \mu$ von der ersten und der zweiten PCR wurden nebeneinander in einem $2 \%$ Agarose/Ethidiumbromidgel aufgetrennt. Im Vergleich zu der unsubtrahierten cDNA kann man das Auftauchen von blassen Banden sowohl in der ersten, aber deutlicher in der zweiten PCR erkennen. Diese entsprechen stark differentiell exprimierten Genen.

\subsubsection{0.k Kontrolle der Subtraktionseffizienz}

Zur Kontrolle der Subtraktionseffizenz verwendet man üblicherweise ein Gen, das in der Tester- und Driver-Probe gleichstark exprimiert wird und daher im Verlaufe der Hybridisierungen heraussubtrahiert wird sowie ein Gen, was bekanntermaßen differentiell exprimiert wird. Meistens handelt es sich bei dem konstant exprimierten Gen um ein Haushaltsgen. In dieser Arbeit wurden sowohl hGAPDH als auch hTFR1 verwendet. Leider war kein differentiell exprimiertes Gen im Vorfeld bekannt, dass man als Positivkontrolle hätte nutzen können. Durch die Notwendigkeit, den Driver mit Transfektionsplasmid zu versetzen, wurde die Nutzung von EAG1a als Positivkontrolle in der PCR unmöglich.

Die subtrahierten und unsubtrahierten sekundären PCR-Produkte wurden 10-fach in sterilem Wasser verdünnt, und davon äquivalente Konzentrationen, nachdem mittels einer AgaroseGelelektrophorese die relative Konzentration semiquantitativ bestimmt wurde, in einer PCRReaktion mit $1.2 \mu$ l GAPDH-3' bzw. hTFR1-3'-Primer und $1.2 \mu$ l GAPDH-5' bzw. hTFR15'-Primer, einem entsprechenden Volumen sterilen Wassers, $3 \mu 110 \times$ PCR Reaction Buffer, 
$0.6 \mu \mathrm{l} d N T P$ Mix $(10 \mathrm{mM})$ und $0.6 \mu \mathrm{l} 50 \times$ BD Advantage cDNA Polymerase Mix eingesetzt. Nachdem die Reaktionen mit einem Tropfen Mineralöl überschichtet worden waren, wurde folgendes PCR-Programm durchgeführt: $94{ }^{\circ} \mathrm{C} 30 \mathrm{~s}, 60{ }^{\circ} \mathrm{C} 30 \mathrm{~s}, 68{ }^{\circ} \mathrm{C} 2$ min für 18 Zyklen. Nach 18 Zyklen and dann alle 5 Zyklen wurden $5 \mu$ aus der Reaktion entnommen und nach Beendigung der PCR nach 43 Zyklen auf ein $2 \%$ Agarose/Ethidiumbromidgel aufgetragen. Der Vergleich von hTFR1-Banden vor und nach der Subtraktion zeigte eine, wenn auch in Vorwärts- und Rückwärtssubtraktion nicht ganz identische Reduktion von hTFR1. GAPDH jedoch konnte in der Rückwärtssubtraktion nicht reduziert werden, während die Vorwärtssubtraktion sehr effizient verringert war. GAPDH ist ein Schlüsselenzym aus der Glykolyse und setzt Glyzerinaldehyd-3-phosphat in 1, 3-Bisphosphoglyzerat um. Es wird allgemein als konstantes Haushaltsgen betrachtet und als solches als Kontrolle für differentielle RNA-und Protein-Produktion in Northern Blotting, Real-Time-PCR und Western Blot verwendet. Neuere Studien jedoch machen deutlich, dass auch Haushaltsgene unter bestimmten Bedingungen differentiell exprimiert sein können (Valenti et al., 2006). Die differentielle Expression von „nicht differentiellen“ Haushaltsgenen in der Embryonalentwicklung ist beschrieben (Prime et al., 2000).

Die Beobachtungen deuten darauf hin, dass GAPDH in den zwei Zelltypen differentiell exprimiert wird und als „Negativkontrolle“ für die Subtraktion und als Haushaltsgen für weitere Studien ungeeignet war.

\subsection{Klonierung der subtrahierten PCR-Fragmente}

Die Produkte der zweiten PCR-Reaktion konnten direkt unter Verwendung eines T/Abasierten Klonierungssystems (Promega) in Sequenziervektoren ligiert (pGEM-T), in hochkompetente E. coli-Bakterien des Stammes JM109 transformiert und diese auf Ampicillinagar nach Blau-Weiß-Selektion ausplattiert werden. Die entstehenden weißen Kolonien beinhalteten Vektor mit cDNA-Fragment, die blauen nur Vektor ohne Insert.

\subsubsection{Differentielles Screening}

Es gibt zwei verschiedene Ansätze, um die durch Klonierung in Sequenziervektoren erhaltenen Bibliotheken nach positiven Klonen durchzusehen. Man kann Erststrang-cDNA markieren und hybridisiert diese dann mit den subtrahierten Bibliotheken. Sie sollte nur mit 
der Vorwärtssubtraktion und nicht mit der Rückwärtsreaktion ein positives Signal geben. Diese Methode hat allerdings den Nachteil, dass nur hochexprimierte differentielle mRNAs ( $>0.2 \%$ der Gesamt-cDNA) detektiert werden können. Daher wurde in dieser Arbeit die zweite Möglichkeit zum Durchsuchen der Bibliothek durchgeführt, bei der die zweite PCRReaktion sowohl der Vorwärts- als auch der Rückwärtssubtraktion als Sonde markiert wird und für die Hybridisierung mit der subtrahierten Bibliothek verwendet wird. Klone aus der Vorwärtssubtraktion sollten nur mit der markierten Vorwärtssonde und nicht mit der Rückwärtssonde ein positives Signal geben, während Klone aus der Rückwärtssubtraktion nur mit der Rückwärtssonde und nicht mit der Vorwärtssonde hybridisieren sollten. Zusätzlich zu diesen Hybridisierungen wurden die Klone aus der Vorwärtssubtraktion noch mit einer hEAG1a-Sonde hybridisiert, um die differentiellen EAG1a-Klone zu identifizieren und vor der Sequenzierung zu verwerfen.

\subsubsection{1.a Amplifizierung der cDNA-Fragmente aus der Bibliothek}

Die weißen Kolonien aus der Blau-Weiß-Selektion, die die potentiell differentiellen cDNAFragmente enthielten, wurden zum Animpfen von $200 \mu$ l Schüttelkulturen in LB-AmpMedium im 96-Well-Maßstab verwendet. Mit $1 \mu$ dieser Kultur wurde eine PCR-Reaktion in $2 \mu 110 \times$ PCR Reaction Buffer, $0.6 \mu$ Nested Primer St19, $0.6 \mu 1$ Nested Primer Not1, $0.4 \mu 1$ dNTP Mix (10 mM), $15.2 \mu$ sterilen Wasser und 50 × PCR Enzyme Mix im 96-Well-Maßstab durchgeführt. Das verwendete PCR-Profil war folgendes: $94{ }^{\circ} \mathrm{C} 30 \mathrm{~s}, 95{ }^{\circ} \mathrm{C} 10 \mathrm{~s}, 68{ }^{\circ} \mathrm{C} 3$ min. Einige der so entstandenen PCR-Fragmente wurden als Kontrolle für die Durchführung der PCR in einem Volumen von $5 \mu$ auf einem Agarose/Ethidiumbromidgel aufgetrennt. Die Banden lagen wie erwartet im Größenbereich von 100 - 800 bp.

\subsubsection{1.b Aufbringen der potentiell differentiellen Klone auf Membranen}

$5 \mu \mathrm{l}$ jeder PCR-Reaktion wurde mit $5 \mu \mathrm{l} 0.6 \mathrm{~N} \mathrm{NaOH}$ versetzt, um die Fragmente zu denaturieren, und $1 \mu \mathrm{l}$ auf eine Nylon-Membran aufgetupft. Die Blots wurden dann in $0.5 \mathrm{M}$ Tris-HCL ( $\mathrm{pH}$ 7.5) für 4 min neutralisiert, mit sterilem Wasser gewaschen und unter $120 \mathrm{~mJ}$ im UV Stratalinker (Stratagene) durch UV-Bestrahlung kovalent an die Membran gebunden. 


\subsubsection{1.c Herstellung der radioaktiv markierten subtrahierten Sonden}

In getrennten Reaktionsgefäßen wurden $3 \mu \mathrm{l}$ der zweiten PCR der Vorwärts- und Rückwärtssubtraktion mit $6 \mu \mathrm{l}$ sterilem Wasser versetzt, 8 min bei $95{ }^{\circ} \mathrm{C}$ denaturiert und, nachdem das Gemisch auf Eis abgekühlt war, mit $3 \mu 1$ Reaction Buffer (-dCTP), $2 \mu 1$ Random Primer Mix, $5 \mu \mathrm{l}[\alpha-32 \mathrm{P}] \mathrm{dCTP}(50 \mu \mathrm{Ci}, 3000 \mathrm{Ci} / \mathrm{mmol})$ und $1 \mu \mathrm{l}$ Klenow Enzyme (exo-) gemischt. Die Reaktion wurde 30 min bei $37^{\circ} \mathrm{C}$ inkubiert und die Reaktion durch Zugabe von $5 \mu \mathrm{l}$ Stop Solution beendet. Die uneingebauten Nukleotide wurden nachfolgend mit CHROMA SPIN-100-Säulen abgetrennt und die Aktivität der Sonden bestimmt.

\subsubsection{1.d Herstellung der radioaktiv markierten EAG1a-Sonde}

Das pTracer-hEAG1-Transfektionsplasmid wurde mit Xba I/Kpn I bzw. Pme I verdaut, das Fragment, das die Sequenz für hEAG1a enthielt, nach Auftrennung aus dem Agarosegel ausgeschnitten, durch Gelextraktion mit dem Nucleospin Extract Kit (Macherey \& Nagel) gereinigt und $35 \mathrm{ng}$ davon nachfolgend wie die subtrahierten Sonden markiert und aufgereinigt.

\subsubsection{1.e Hybridisierungen}

$50 \mu \mathrm{l} 20 \times \mathrm{SSC}$ und $50 \mu \mathrm{l}$ Blocking Solution $(10 \mathrm{mg} / \mathrm{ml}$ Sheared salmon sperm DNA, 0.3 mg/ml Oligonukleotide den Sequenzen der Nested Primern St19 und Not1 entsprechend) wurden für $5 \mathrm{~min}$ gekocht, auf Eis gekühlt und mit $5 \mathrm{ml}$ Hybridisierungslösung vereinigt. Diese Prähybridisierungsmischung wurde 60 min bei $72{ }^{\circ} \mathrm{C}$ mit den Membranen hybridisiert. Die radioaktiv markierten Sonden $(107 \mathrm{cpm})$ wurden mit $50 \mu 120 \times \mathrm{SSC}$ und $50 \mu \mathrm{l}$ Blocking Solution $(10 \mathrm{mg} / \mathrm{ml}$ Sheared salmon sperm DNA, $0.3 \mathrm{mg} / \mathrm{ml}$ Oligonukleotide den Sequenzen der Nested Primer St19 und Not1 entsprechend) wurden für 5 min gekocht, auf Eis gekühlt, $\mathrm{zu}$ dem Prähybridisierungsgemisch gegeben und bei $72{ }^{\circ} \mathrm{C}$ und ständiger Bewegung über Nacht hybridisiert. Die Waschschritte erfolgten $4 \times 20$ min bei $68{ }^{\circ} \mathrm{C}$ mit niedrigstringentem Puffer $(2 \times \mathrm{SSC} / 0.5 \% \mathrm{SDS})$ und $2 \times 20 \mathrm{~min}$ bei $68^{\circ} \mathrm{c}$ mit hochstringentem Puffer $(0.2 \times$ SSC/0.5 \% SDS). Die Membranen wurden nachfolgend in Klarsichtfolie verpackt und auf Phosphoimager-Platten für verschiedene Zeiten exponiert. 
Die scheinbar positiven Klone, die nicht hEAG1a entsprachen, wurden nachfolgend sequenziert und die Sequenzen mit Hilfe des BLAST Programms mit bekannten Genen aus Genbanken verglichen. Die identifizierten Gene wurden dann mittels Real-Time-PCR auf differentielle Expression überprüft.

\subsubsection{Mikroarray}

2000 MDA-MB435S-Zellen, 1500 IGR-39 Zellen und 1500 IPC298-Zellen wurden pro Vertiefung der 96-Well-Platten in $200 \mu \mathrm{l}$ Medium mit $10 \%$ oder $0.5 \%$ FCS ausgesät und mit $500 \mathrm{nM}$ Astemizol oder Norastemizol versetzt. Die Proliferation wurde über 6 bis 7 Tage mit dem AlamarBlue Assay von der Firma Biosource verfolgt. Die MDA-MB435S-Zelllinie wurde für die Mikroarraystudie ausgewählt, da sie einen signifikanten Proliferationsunterschied zwischen den Astemizol- und den Norastemizol-behandelten Zellen unter FCS-haltigen Bedingungen zeigte.

cDNA-Mikroarrays werden routinemäßig für Transkriptomanalysen von verschiedenen Zelltypen, Entwicklungsstadien, Krankheitszuständen und Zellen, die verschiedenen exogenen Reagenzien oder Behandlungen ausgesetzt wurden, verwendet und ermöglichen eine simultane Untersuchung der Expression einer nahezu unbegrenzten Zahl von Genen (Schena et al., 1995). Vor der Durchführung der Arrays in 3 Wiederholungen (3 verschiedene Kultivierungen der Zellen mit den Reagenzien) wurde die Qualität der RNA überprüft. Die zu vergleichenden RNA-Spezies wurden simultan in cDNA umgeschrieben und jeweils entweder mit Cy-3 oder Cy-5-dUTP markiert. Nach der Hydrolyse der RNA-Matrize, Aufreinigung und Trocknung der markierten cDNA wurde sie mit Membranen hybridisiert, die die 15657 aufgetupften zu untersuchenden Gene enthielten.

\subsubsection{2.a cDNA-Synthese und Fluoreszenzmarkierung}

Es wurden $25 \mu \mathrm{g}$ Gesamt-RNA aus mit Astemizol (500 nM, 7 Tage), Norastemizol (500 nM, 7Tage) und Medium/DMSO (7Tage) behandelten MDA-MB435S-Zellen pro Array eingesetzt und zunächst simultan in cDNA umgeschrieben und jeweils entweder mit Cy-3 oder Cy-5dUTP markiert. Dazu wurde die entsprechende Menge RNA mit $3 \mu \mathrm{g}$ Random/Anchored Oligo-dT-Primer versetzt, mit DEPC-Wasser auf $10 \mu \mathrm{l}$ aufgefüllt, $5 \mathrm{~min}$ auf $70^{\circ} \mathrm{C}$ erhitzt, 10 min bei RT inkubiert und danach 2 min auf Eis gekühlt. Dann wurden pro Reaktion im 
Dunkeln $4 \mu l 5 \times R T$-Buffer (Invitrogen), $2 \mu 10.1 \mathrm{M}$ DTT (Invitrogen), $1 \mu 11 \mathrm{mM} \mathrm{Cy3-oder}$ Cy5-dUTP, $0.5 \mu$ l Niedrig-dT dNTP Mischung (25 mM dATP, dGTP, dCTP und $10 \mathrm{mM}$

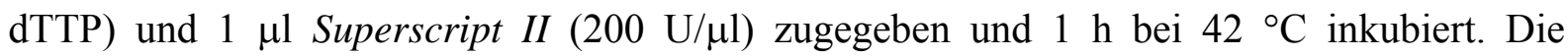
Inkubation wurde nach erneuter Zugabe von $1 \mu$ Superscript II (200 U/ $\mu \mathrm{l})$ um $1 \mathrm{~h}$ verlängert und mit $4 \mu 10.5$ M EDTA beendet.

\subsubsection{2.b Hydrolyse der RNA-Matrize}

Um die RNA-Matrize zu hydrolysieren, wurden $2 \mu 12.5 \mathrm{M} \mathrm{NaOH}$ zugefügt, 15 min bei $37{ }^{\circ} \mathrm{C}$ inkubiert und mit $10 \mu 1$ 2M HEPES-Säure (pH 5.5) neutralisiert.

\subsubsection{2.c Aufreinigung der markierten cDNA}

Vor der Aufreinigung wurde die markierte cDNA auf $500 \mu 1$ mit DEPC-Wasser aufgefüllt, in eine Microcon YM-30 purification column (Millipore) überführt und $12 \mathrm{~min}$ bei $14000 \times \mathrm{g}$ zentrifugiert. Darauf folgten zwei Waschschritte mit $500 \mu 1$ DEPC-Wasser. Die Säule wurde umgedreht in ein neues Reaktionsgefäß überführt und 3 min bei 1000 x g zentrifugiert, um die markierte Probe zu sammeln. Weitere $20 \mu l$ wurden auf die Säule gegeben und wie oben damit verfahren. Das Endvolumen der gereinigten cDNA wurde auf $50 \mu$ l gebracht.

\subsubsection{2.d Agarosegelanalyse der markierten cDNA}

Die markierte cDNA wurde in einem $1 \%$ Agarosegel ohne Ethidiumbromid in einem FL88000 Fuji Scanner (Fuji) analysiert, um den Farbstoffeinbau zu überprüfen. Nachfolgend wurde das Gel mit Ethidiumbromid gefärbt, um die Integrität der cDNA zu kontrollieren.

\subsubsection{2.e Hybridisierung der markierten cDNA}

Nach der Aufreinigung wurden die cDNAs in einem Vakuumkonzentrator konzentriert und zu jedem Reaktionsgefäß $10 \mu \mathrm{g}$ Poly-d(A) (Invitrogen), $20 \mu \mathrm{g}$ Human Cot-1 DNA (Invitrogen), $10 \mu \mathrm{g}$ Salmon sperm DNA und $75 \mu \mathrm{l}$ Hybridisierungspuffer (50\% Deionisiertes Formamid, 5 
mM EDTA, $1 \%$ Denhardts, $0.5 \%$ SDS, auf $10 \mathrm{ml}$ mit sterilem Wasser aufgefüllt) gegeben und die Cy3- und Cy5 markierten unterschiedlichen cDNAs für die differentielle Hybridisierung zusammengemischt. Die Mischungen wurden 5 min bei $95{ }^{\circ} \mathrm{C}$ denaturiert und das Gemisch 20 min bei $42{ }^{\circ} \mathrm{C}$ inkubiert, um die Bindung der Blockierungsreagenzien (Polyd(A), human Cot-1 DNA, Salmon sperm DNA) an die repetetiven Sequenzen der Ziel-cDNAs zu ermöglichen. $80 \mu \mathrm{l}$ Hybridisierungsmischung, die jeweils zwei verschiedene Cy3- bzw. Cy5-markierte cDNAs enthielt, wurde auf den Array gegeben, mit einem $24 \times 40 \mathrm{~mm}$ Deckglas (Menzel-Glaser, D) Luftblasen-frei abgedeckt und in einer feuchten Kammer im 42 ${ }^{\circ} \mathrm{C}$ Wasserbad für $18 \mathrm{~h}$ im Dunkeln inkubiert. Am nächsten Tag wurden die Arrays $2 \times 10$ min bei RT mit $0.2 \times \mathrm{SSC} / 0.1 \% \mathrm{SDS}$ und $2 \times 10$ min mit $0.2 \times \mathrm{SSC}$ gewaschen und durch Zentrifugation bei $200 \mathrm{x}$ g für 10 min getrocknet.

\subsubsection{2.f Datenaufnahme und -analyse}

Die Fluoreszenzbilder wurden mit einem Affymetrix 428 Scanner (Affymetrix) mit entsprechender Verstärkung durch den Photomultiplier so aufgenommen, das die höchste Signalintensität ohne Sättigung erreicht wurde. Ein 16 bit TIFF-Bild wurde für jeden Kanal für die nachfolgende Analyse erstellt. Für die Bildanalyse wurde die AIDA-Software (Raytest) verwendet, wobei das Zentrum jedes Fleckens manuell plaziert und mit einer zweidimensionalen Gaussverteilung um dieses Zentrum herum quantifiziert wurde. Die erhaltenen Werte für drei biologische Replikate (drei verschiedene Kultivierungen der Zellen mit den Reagenzien) wurden simultan normalisiert, um die Schwankungen zwischen den Experimenten zu eliminieren. Dazu wurde zunächst der lokale Hintergrund jedes Spots von der Intensität des Spots abgezogen, für jedes Experiment der Median des Signals berechnet $\left(\operatorname{med}_{\mathrm{j}}\right)$, ein Faktor aus $\mathrm{med}_{\mathrm{ref}} /$ med $_{\mathrm{j}}$ berechnet, wobei med $_{\mathrm{ref}}$ der globale Median ist, der aus den durchschnittlichen Signalintensitätswerten aller Experimente erhalten wurde. Mit diesem Faktor wurde das Signal der einzelnen cDNAs multipliziert und der statistischen Analyse unterworfen (Adjaye et al., 2004)

Um die differentielle Expression der Gene abzuschätzen wurden drei verschiedene statistische Tests angewendet. Der Student's t-test setzt eine Normalverteilung und eine gleiche Varianz der Messwerte voraus, während der Welch-test von verschiedenen Varianzen ausgeht. Der Wilcoxon's rank sum test ist Verteilungs-frei. 
Die putativ signifikant differentiell exprimierten Gene wurden in vier Klassen eingeordenet. Die erste Klasse enthielt Gene, die in den Astemizol-behandelten größere oder kleinere Signale als in den Norastemizol-behandelten Zellen zeigten, wobei Norastemizol-behandelte nicht verschieden von den DMSO-behandelten Zellen waren. $(A>N=D ; A<N=D)$. Bei diesen handelt es sich dann um Gene, die durch Inhibierung von EAG1 differentiell exprimiert werden. Die zweite Klasse umfasst Gene, die in Astemizol-behandelten größere oder kleinere Signale als in den Norastemizol-behandelten Zellen zeigten, wobei die DMSObehandelten Zellen größere bzw. kleinere Werte als die Norastemizol-behandelten Zellen aufwiesen $(A>D>N$; A $<$ D $<$ N). Dieser Fall tritt auf, wenn Astemizol und Norastemizol gegenläufige Effekte auslösen, z. B. wenn Norastemizol über ein bestimmtes Protein die Expression eines Gens in die eine Richtung änderten, während durch Inhibierung von EAG1 mit Astemizol die Expression des Gens in die andere Richtung geändert wurde. Die dritte Klasse beinhaltet Gene, die in den Astemizol-behandelten größere oder kleinere Signale als in den Norastemizol-behandelten Zellen zeigten, wobei Norastemizol-behandelte größere oder kleinere Signale als die DMSO-behandelten Zellen zeigten $(A>N>D ; A<N<D)$. Hierbei treten gleichgerichtete Effekte von Astemizol und Norastemizol auf, bei denen es sich um eine Wirkung der Reagenzien auf sowohl EAG1 als auch andere Gene handeln kann. In die vierte Klasse schließlich gehören Gene, bei denen die Astemizol-behandelten und Norastemizol-behandelten Zellen gleiche Signale zeigten, die verschieden zu den Signalen der DMSO-behandelten Zellen waren $(\mathrm{A}=\mathrm{N}>\mathrm{D} ; \mathrm{A}=\mathrm{N}<\mathrm{D})$ und deren differentielle Expression nicht durch Inhibierung von EAG1 hervorgerufen worden sein konnte. Hier wurden andere Gene beeinflusst. Als Auswahlkriterium wurde ein mindestens 1.5-facher signifikanter Signalunterschied zwischen Astemizol- und Norastemizol-bzw. DMSObehandelten Zellen verwendet, wobei mindestens eine der 3 Proben eine signifikante Expressionsmenge aufweisen sollte (Bgtag $>0.90$, Bgtag = background tag, der prozentuale Anteil der Hintergrundspots, die eine Signalintensität aufweisen, die kleiner als die des Genspots sind).

\subsubsection{Western Blot}

\subsubsection{Zelllyse}

Die Kulturen wurden mit PBS gewaschen, mit 1\% SDS und Proteaseinhibitortabletten (Roche) in PBS lysiert und durch 10-maliges Aufziehen in eine 23-gauge Injektionsnadel 
homogenisiert und die DNA durch Ultraschallbehandlung zerkleinert. Das Lysat wurde 10 min bei $16100 \times$ g zum Pelletieren von Zelltrümmern zentrifugiert.

\subsubsection{Bestimmung der Proteinkonzentration}

Die Proteinkonzentration wurde mit dem Bio-Rad Protein Assay (Bio-Rad) im Vergleich zu einer Kalibrierreihe bestimmt. Dazu wurden verschiedene Konzentrationen der zu bestimmenden Proteinlösung mit sterilem Wasser auf $800 \mu$ l aufgefüllt, mit $200 \mu$ BioRadReagenz versetzt, 5 min bei RT inkubiert und bei $595 \mathrm{~nm}$ in einem Spektrophotometer gemessen.

\subsubsection{SDS-Polyacrylamidelelektrophorese}

Die denaturierende Polyacrylamidelektrophorese (SDS-PAGE) ermöglicht die Auftrennung von Proteinen nach ihren Molekularmassen. In dieser Arbeit wurde ein diskontinuierliches Gel verwendet, das aus einem $4 \%$ Sammelgel mit pH 6.8 und einem 5 - $15 \%$ Trenngel mit pH 8.8 bestand. Das Sammelgel fokussiert die in die Geltaschen geladenen Proteine in eine Bande, die dann nach dem Übertritt in das Trenngel entsprechend der Molekularmassen aufgetrennt werden. Für ein $8 \times 10 \times 0.1 \mathrm{~cm}$ Gel werden für $10 \mathrm{ml}$ Trenngel $5-15 \%$ Acrylamid: Bisacrylamid (37.5: 1), $1 \times$ Trennpuffer, $0.1 \%$ APS und $0.1 \%$ TEMED in Wasser, für $5 \mathrm{ml}$ Sammelgel 4 \% Acrylamid: Bisacrylamid (37.5: 1), $1 \times$ Sammelpuffer, 0.1 $\%$ APS und $0.1 \%$ TEMED in Wasser benötigt. Das Trenngel wurde zwischen die Glasscheiben gegossen, mit Isobutanol überschichtet und bei RT polymerisieren gelassen. Nach der Entfernung des Isobutanols und einem Waschschritt mit sterilem Wasser wurde das Sammelgel in die Apparatur gegossen und der Probenkamm eingesetzt. Nach 30 min war das Sammelgel polymerisiert. Die Proben (30 $\mu$ g Protein) wurden mit $5 \times$ Laemmli-Probenpuffer versetzt, bei $95{ }^{\circ} \mathrm{C} 5$ min gekocht und in die Taschen eines $10 \%$ Gels geladen und zusammen mit farbigen Molekulargewichtsmarkern bei $50-80 \mathrm{~mA} / 40 \mathrm{~cm}^{2} 2 \mathrm{~h}$ aufgetrennt.

Trennpuffer $(4 \times): 1.5 \mathrm{M}$ Tris- $\mathrm{HCl} \mathrm{pH} 8.8,0.4 \%$ SDS.

Sammelpuffer $(4 \times)$ : 0.5 M Tris-HCl pH 6.8, 0.4\% SDS.

Laemmli-Probenpuffer $(5 \times): 0.625$ M Tris-HCl pH 6.8, $10 \%$ SDS, $16.75 \% \quad \%$ Mercaptoethanol 45 \% Glyzerin, $0.025 \%$ Bromphenolblau.

Laufpuffer $(10 \times)$ : $1.92 \mathrm{M}$ Glycin, $0.25 \mathrm{M}$ Tris-HCl pH 8.8, 1\% SDS. 
Ammoniumperoxodisulfat (APS): $10 \%$ in Wasser.

\subsubsection{Proteintransfer}

Nach der Auftrennung durch SDS-PAGE wurden die Proteine bei pH 10 elektrophoretisch auf eine Nitrozellulosemembran transferiert. Der berechnete isoelektrische Punkt von EAG1 liegt nahe dem $\mathrm{pH}-$ Wert der üblicherweise verwendeten Transferpuffer ( $\mathrm{pH} 8.0)$, daher wurde im Fall von EAG der Transfer bei $\mathrm{pH} 10$ durchgeführt. Dazu wurden das Gel, die Nitrozellulosemembran Hybond ECL (Amersham) und vier Blätter Whatman ${ }^{\mathrm{TM}}$ Papier auf Gelgröße zugeschnitten, 20 min in Transferpuffer äquilibriert. Dann wurden ein Schwamm, 2 Blätter Whatman-Papier, das Gel, die Membran, noch zwei Blätter Whatman-Papier und ein zweiter Schwamm aufeinandergestapelt und, durch eine Plastikkassette zusammengehalten, in den Puffertank getaucht. Der Transfer wurde bei $250 \mathrm{~mA}$ in $4 \mathrm{~h}$ durchgeführt.

Transferpuffer: 25 mM Tris, 192 mM Glycin, $0.1 \%$ SDS, $10 \%$ Methanol, pH 10.0 mit 5N $\mathrm{NaOH}$.

\subsubsection{Western Blot}

Die Membranen wurden mit $2 \%$ Kasein (Roche) $1 \mathrm{~h}$ geblockt, um unspezifische Bindung zu vermeiden, 2 h mit dem polyklonalen Anti-EAG1-Antikörper in $1 \%$ Kasein inkubiert (Napp et al., 2005) und $3 \times 10 \mathrm{~min}$ mit TBST gewaschen. Die Inkubation mit dem Peroxidasegekoppelten Anti-Kaninchen-Antikörper (Amersham Biosciences) erfolgte für $1 \mathrm{~h}$ in $1 \%$ Kasein, gefolgt von $3 \times 10 \mathrm{~min}$ mit TBST-Waschschritten. Die Proteine wurden durch Chemilumineszenz sichtbar gemacht (ECL Kit; Perking Elmer Life Sciences) und durch 1 30 min Exposition auf einem autoradiographischen Film in einer lichtdichten Filmkassette in der Dunkelkammer detektiert.

TBST: Tris-buffered saline mit $0.05 \%$ Tween 20

\subsubsection{Flow cytometry}

Nach der Behandlung mit den siRNAs wurden die Zellen in 6-Well-Platten ausgesät, nach 24 $\mathrm{h}$ bis $144 \mathrm{~h}$ trypsiniert und in einer Mischung aus $0.1 \%$ Saponin, zwei monoklonalen Anti- 
EAG1-Antikörpern (mAb-33 und mAb-62), die direkt mit Quantum Dots (QD) markiert waren, in PBS für $2 \mathrm{~h}$ auf Eis inkubiert. Dann wurden die Zellen $2 \times$ mit PBS/0.1 \% Saponin gewaschen und im BD FACSAria ${ }^{\mathrm{TM}}$ flow cytometer (Becton Dickinson) gemessen. Die Quantum Dots wurden bei 488nm angeregt und die Fluoreszenz mit einem LP556 dichroic and BP660/20-Filter detektiert. Messfenster für lebensfähige Zellen wurden unter Verwendung von Propidiumiodid etabliert und der Mittelwert für die Fluoreszenzintensität nach Ausschluss von toten Zellen ermittelt.

\subsubsection{Elektrophysiologische Messungen}

hEAG1a-transfizierte HEK293-Zellen wurden auf mehreren mit Poly-L-Lysin beschichtete Glasdeckgläschen in Petrischalen ausgesät und über Nacht inkubiert, damit sie anhaften konnten. Diese Zellen wurden dann für $4 \mathrm{~h}$ mit siRNAs inkubiert und nach $24 \mathrm{~h}$ oder $72 \mathrm{~h}$ elektrophysiologisch gemessen.

Die elektrophysiologischen Messungen wurden in der whole-cell Konfiguration der patchclamp-Technik (Hamill et al., 1981) gemessen, wobei ein EPC9-Verstärker und die pulse software (HEKA) verwendet wurde. Die Ströme wurden mit $10 \mathrm{KHz}$ gefiltert und mit $50 \mathrm{KHz}$ digitalisiert. patch-Pipetten wurden aus Corning \#0010 glass (World Precision Instruments) so gezogen, dass sie Widerstände von 1 - $2 \mathrm{M} \Omega$ aufwiesen, wenn sie mit der internen Flüssigkeit gefüllt wurden. Um den Serienwiderstand abzuschätzen, wurde die automatische Kapazitätskompensation des Verstärkers verwendet und auf $85 \%$ kompensiert. Unter diesen Bedingungen waren die heterologen EAG1a-Ströme robust genug, um endogene Ströme fast vollständig zu maskieren. (García-Ferreiro et al., 2004). Für die Identifikation von EAG1Strömen wurde die Zelle vom Haltepotential auf ein Vorpulspotential -60 bzw. -100 mV gebracht und für $1.5 \mathrm{~s}$ gehalten. Danach wurde ein Testpuls gegeben, der die Zelle auf +40 $\mathrm{mV}$ oder $+50 \mathrm{mV}$ depolarisierte. Die Aktivierung des Kanals verläuft langsamer bei einem Vorpulspotential von $-100 \mathrm{mV}$ als bei einem Vorpulspotential von $-60 \mathrm{mV}$, eine Eigenschaft, die für die Identifikation von EAG ausgenutzt wird und die als Cole-Moore-Shift bezeichnet wird (Ludwig et al., 1994; Terlau et al., 1996). 350 und $450 \mathrm{~ms}$ nach dem Start der Depolarisation wurden die mittleren steady state Ströme gemessen, von denen die Stromamplitude zwischen 7 und 13 ms nach dem Start der Depolarisation abgezogen wurde, da jegliche schnellaktivierenden endogenen Ströme, die zur Basislinie beitragen und schon während der ersten 13 ms nach Start der Depolarisation messbar waren, nicht durch Eag1 
hervorgerufen worden sein können. Die resultierenden Ströme wurden durch die gemessene Kapazität der Zelle geteilt, um die Stromdichte zu erhalten.

Interne Flüssigkeit: $100 \mathrm{mM} \mathrm{KCl,} 45 \mathrm{mM}$ NMDG, 5 mM BAPTA, $10 \mathrm{mM}$ HEPES, $5 \mathrm{mM}$ EGTA, $1 \mathrm{mM} \mathrm{MgCl}$, $\mathrm{pH} 7.4$ mit $\mathrm{KOH}$.

Badflüssigkeit: $160 \mathrm{mM} \mathrm{NaCl}, 2 \mathrm{mM} \mathrm{CaCl}, 1 \mathrm{mM}, 2 \mathrm{mM} \mathrm{MgCl} 2,2.5 \mathrm{mM} \mathrm{KCl}, 8 \mathrm{mM}$ Glucose, 10 mM HEPES, pH 7.4 mit NaOH.

\subsubsection{Zellbiologische Methoden}

\subsubsection{Eukaryotische Zellkulturen}

\subsubsection{1.a Steriles Arbeiten}

Beim Arbeiten in der Zellkultur wurde grundsätzlich auf sterile Bedingungen geachtet. Es wurden ausschließlich autoklavierte oder sterilfiltrierte Lösungen verwendet und alle Gegenstände, die in direkte Berührung mit den Zellen kommen, nur unter der Sterilbank geöffnet, autoklaviert, sterilfiltriert und abgeflammt. Die Sterilbank LaminAirß HBB 2448 (Heraeus) wurde vor Beginn und nach Beendigung des Arbeitens mit $70 \%$ Ethanol ausgewischt und für $1 \mathrm{~h}$ mit UV-Licht bestrahlt. Handschuhe und Flaschen wurden vor Gebrauch mit $70 \%$ Ethanol gereinigt. Im Gegensatz zu den üblichen Vorschriften zur Kultivierung von Zelllinien wurde auf die Zugabe von Antibiotika gegen Bakterien und Pilze gänzlich verzichtet, um eventuelle Kontaminationen sofort zu bemerken. Dafür wurden die Zellen und das umgebende Medium vor jedem Splitten unter hoher Vergrößerung begutachtet und bei Verdacht auf Kontamination durch sichtbare Bakterien und Pilze sofort entsorgt. Zusätzlich wurden routinemäßig einmal im Monat bzw. vor jedem Experiment alle Zelllinien auf Mycoplasmenkontamination überprüft. So sollte verhindert werden, dass latente Infektionen das Wachstum und die Genexpression der Zellen veränderten. (Razin et al., 1998). Alle Zelllinien wurden gemäß den Vorschriften der Hersteller propagiert und im Inkubator (Hera Cell 240, Heraeus) bei $37^{\circ} \mathrm{C}, 5 \% \mathrm{CO}_{2}$ und $95 \%$ Luftfeuchtigkeit in Kultur gehalten. 


\subsubsection{1.b Kultivierung der Zelllinien}

Die Zelllinien (HEK293, MDA-MB435S, Daoy, HT-1080, Hs633t, TE-671, A204, IGR-39, IPC298, HeLa, MCF-7, SHSY-5Y) wurden bei der Deutschen Sammlung für Mikroorganismen und Zelllinien (DSMZ), der American Tissue and Cell Culture Collection (ATCC) oder der European Collection of Cell Cultures (ECACC) bestellt. Alle Zelllinien wurden gemäß den Vorschriften der Hersteller propagiert und im Inkubator bei $37{ }^{\circ} \mathrm{C}, 5 \%$ CO2 und $95 \%$ Lufteuchtigkeit in Kultur gehalten.

Die Zelllinien wurden 2 - 3-mal pro Woche gesplittet, wofür sie einmal mit $10 \mathrm{ml}$ PBS gewaschen wurden und für 2 min bei $37{ }^{\circ} \mathrm{C}$ mit $1-2 \mathrm{ml}$ Trypsin/EDTA inkubiert wurden. Sodann wurden sie unter Zugabe von $10 \mathrm{ml}$ Medium durch wiederholtes Pipettieren vereinzelt und in neue Flaschen mit Medium überführt.

\subsubsection{1.c Zentrifugation von Zellen}

Alle Zentrifugationsschritte in der Zellkultur wurden mit einer Zentrifuge der Firma Beckmann bei $150 \times$ g für 2 min zentrifugiert. Der Überstand konnte anschließend vorsichtig abgesaugt und die Zellen in Medium resuspendiert werden.

\subsubsection{1.d Auftauen der Zellen}

Die Zelllinien wurden im Wasserbad bei $37{ }^{\circ} \mathrm{C}$ aufgetaut, in das vom Hersteller jeweils angegebene Medium ohne Zugabe von Antibiotika überführt und zum Anhaften im Brutschrank inkubiert. Nach $6 \mathrm{~h}$ wurde das Medium gewechselt und gegebenenfalls Selektionsantibiotika hinzugefügt.

\subsubsection{1.e Kryokonservierung der Zellen}

Zum Einfrieren wurden die Zellen einmal mit PBS gewaschen, in $10 \mathrm{ml}$ Medium aufgenommen und für 2 min bei $200 \times$ g zentrifugiert. Das Zellpellet wurde in $250 \mu 1$ Medium resuspendiert, $250 \mu \mathrm{l}$ Einfriermedium (50\% normales Medium, $25 \%$ FCS, $25 \%$ DMSO) zugefügt und in Kryoröhrchen überführt. Die Kryoröhrchen wurden dann über Nacht in Isopropanol bei $-80^{\circ} \mathrm{C}$ eingefroren und zur Langzeitaufbewarung in flüssigem Stickstoff gelagert. 


\subsubsection{1.f Mikroskopie}

Die Zellen wurden morphologisch unter einem Mikroskop der Firma Zeiss des Typs Axioskop sowohl unter Hellfeld als auch Fluoreszenzmikroskopie beurteilt und die Lebendzellzahl bestimmt.

\subsubsection{1.g Bestimmung der Lebendzellzahl}

Für die Lebendzellzahlbestimmung wurde eine Neubauer-Zählkammer mit $0.0025 \mathrm{~mm} 2$ und einer Tiefe von $0.1 \mathrm{~mm}$ verwendet. $50 \mu \mathrm{l}$ der zu zählenden Zellen wurden mit dem gleichen Volumen 0.4 \% Trypan-Blau-Lösung vermischt, 5 min bei Raumtemperatur inkubiert und unter dem Mikroskop gezählt. Die blau gefärbten Zellen entsprachen toten Zellen. Bei jeder Zellzählung lag der Anteil an toten Zellen unter $5 \%$. Tote Zellen wurden bei der Lebendzellzahlbestimmung nicht berücksichtigt. Es wurden jeweils vier Großquadrate der Zählkammer ausgewertet. Die Zellzahl berechnet sich wie folgt:

\section{Zellzahl in 4 Großquadraten $/ 4 \times$ Verdünnungsfaktor $\times 104=$ Zellzahl $/ \mathrm{ml}$}

\subsubsection{1.h Mykoplasma-Test}

Oberflächenstrukturen von Bakterien können Zellen dazu anregen, Gene zu induzieren oder zu reprimieren. Daher wurden die Zellen immer unter dem Mikroskop bei 1600-facher Vergrößerung begutachtet, um eventuelle Kontamination mit Zellwand-haltigen Bakterien oder Pilzen zu detektieren. Diese visuelle Begutachtung war nicht für die Zellwand-losen Mykoplasmen möglich, da sie unter dem Mikroskop selbst bei stärkster Vergrößerung nicht sichtbar waren. Um zu überprüfen, ob die Zellkulturen Mykoplasmen-frei waren, wurde daher routinemäßig der PCR-Test Mycoplasma Plus ${ }^{T M}$ PCR Primer Set von der Firma Stratagene und ein weiteres Primer-Paar, dass spezifisch Sequenzen aus der 16S ribosomalen RNA des Genus Mycoplasma amplifiziert (Van Kuppeveld et al., 1994a; Van Kuppeveld et al., 1994b), verwendet. 
Überstände von nahezu konfluent mit Zellen bewachsenen Zellkulturflaschen wurden dazu steril abgenommen, bei $97{ }^{\circ} \mathrm{C} 10$ min inkubiert und dann mit 1/10 Volumen StrataClean Resin versetzt. Auf diesem Harz wurden phenolische Gruppen immobilisiert, um kontaminierende Proteine von den Proben abzutrennen. Die Proben wurden 1 min bei 16100 $\times \mathrm{g}$ zentrifugiert, der Überstand abgenommen und $5 \mu \mathrm{l}$ davon in einer PCR-Reaktion mit 45 $\mu \mathrm{l}$ einer Mischung aus $5 \mu 110$ x PCR-Puffer, $1.5 \mu \mathrm{lggl}_{2}(50 \mathrm{mM}), 1 \mu \mathrm{dNTPs}(10 \mathrm{mM}), 2$ $\mu 1$ Mycoplasma Primer Mix (Statagene) bzw Mycocont-Primer Mix (Siehe Tab. 1) (10 $\mu \mathrm{M})$, $0.4 \mu \mathrm{l}$ Taq-Polymerase und $35.1 \mu \mathrm{l}$ autoklaviertes UV-bestrahltes entmineralisiertes Wasser versetzt. Das PCR-Profil war wie folgt: $2 \min 94^{\circ} \mathrm{C}, 2 \min 50^{\circ} \mathrm{C}, 2 \min 72^{\circ} \mathrm{C}$ für 1 Zyklus; $1 \min 94{ }^{\circ} \mathrm{C}, 1 \min 50{ }^{\circ} \mathrm{C}, 2 \min 72{ }^{\circ} \mathrm{C}$ für 37 Zyklen; 10 min $72{ }^{\circ} \mathrm{C}$ für den Mycoplasma Plus ${ }^{T M}$ PCR Primer Set und 3 min $94{ }^{\circ} \mathrm{C}$ für 1 Zyklus, 1 min $94{ }^{\circ} \mathrm{C}, 45 \mathrm{~s} 55{ }^{\circ} \mathrm{C}, 1 \min 72{ }^{\circ} \mathrm{C}$ für 37 Zyklen; 10 min $72{ }^{\circ} \mathrm{C}$ für die Mycocont-Primer. Die Produkte wurden auf einem Agarose/Ethidiumbromid-Gel aufgetrennt. Als Kontrolle wurden immer die positive (874 bp) und die interne Kontrolle (1000 bp) aus dem Mycoplasma Plus ${ }^{T M}$ PCR Primer Set mitgeführt. Banden von 874 bp Größe in den Proben mit Stratagene-Primern und Banden von 280 bp Größe in den Proben mit Mycocont-Primern deuteten Kontamination mit Mykoplasmen an. Diese Zelllinien wurden sofort verworfen. In der Etablierungsphase dieses Mykoplasmatests wurde mit positiven Proben der im Stratagene-Protokoll empfohlene Sau3A-Verdau durchgeführt und die kontaminierenden Mykoplasmen als Mycoplasma arginini identifiziert.

\subsubsection{1.i Stabile Transfektionen}

Die Zellen wurden am Tag vor der Transfektion so gesplittet, dass sie am Tag der Transfektion vereinzelt waren. Als Transfektionsreagenz wurde Fugene 6 Transfection reagent (Roche) verwendet, das ein nicht-liposomales Multikomponenten-Reagenz mit geringer Zelltoxizität darstellt. Es bildet Komplexe mit DNA und transportiert sie in Zellen. Die Transfektionen wurden in 6er-Well-Platten durchgeführt. Dazu wurden $97 \mu$ l serumfreies Medium, $3 \mu$ Fugene 6 Transfection reagent und 1-2 $\mu$ g Plasmid-DNA in dieser Reihenfolge in ein Reaktionsgefäß pipettiert und 30 min bei RT inkubiert, damit sich der Komplex aus DNA und Tranfektionsreagenz bilden kann. Die Mischung wurde dann tropfenweise in das Kulturmedium mit Zellen gegeben. Nach $5 \mathrm{~h}$ Inkubation bei $37{ }^{\circ} \mathrm{C}$ wurde das Medium gewechselt. Die Zellen durften nun zwei Tage wachsen und wurden unter dem Fluoreszenzmikroskop auf grüne GFP-Fluoreszenz begutachtet, bevor frisches Medium mit 
dem Selektionsantibiotikum Zeozin $(300 \mu \mathrm{g} / \mathrm{ml})$ zugegeben wurde. Über einen Zeitraum von drei Wochen wurde das Selektionsmedium zweimal wöchentlich gewechselt.

\subsubsection{Proliferationsassay.}

Die Proliferation wurde durch die Fähigkeit von metabolisch aktiven Zellen, entweder Resazurin $\mathrm{zu}$ dem fluoreszierenden Resorufin (Alamar Blue, Biosource) oder Tetrazoliumsalze zu farbigem Formazan (MTT, Roche) zu reduzieren, gemessen. Es ist generell akzeptiert, dass die metabolische Aktivität von Zellen als Maß für die Zellzahl und damit für die Proliferation verwendet werden kann, wenn sich die zu vergleichenden Zellen nicht durch grundsätzlich unterschiedliche metabolische Aktivität auszeichnen, die schon zum Startzeitpunkt des Versuchs zu beobachetn wäre. siRNA-behandelte Zellen und Kontrollzellen wurden trypsiniert und 1000 - 2500 Zellen (abhängig von der Zellinie) pro Vertiefung in $200 \mu \mathrm{l}$ in 96-Well-Platten ausplattiert. Um die metabolische Aktivität zu messen, wurden $20 \mu$ Alamar Blue oder MTT Reagenz in jede Vertiefung gegeben und die Platten für 2 - $4 \mathrm{~h}$ in den Inkubator zurückgestellt. Die Extinktion wurde in einem 1420 Victor2 Multilabel Counter (Wallac) bei $570 \mathrm{~nm}$ und die Fluoreszenz unter Anregung bei 544 $\mathrm{nm}$ bei $590 \mathrm{~nm}$ gemessen.

\subsubsection{Matrixmetalloproteinase-2 (MMP-2) Aktivitätsassay}

Zur Bestimmung der aktiven bzw. totalen Menge an sekretierten MMP-2 in Zellüberständen wurde der Biotrak ${ }^{T M} M M P-2$ Activity Assay von der Firma Amersham Biosciences verwendet. Das Prinzip dieses Assays beruht auf der spezifischen Spaltung einer Vorform eines Detektionsenzymes durch MMP-2, das dann seinerseits ein chromogenes Peptidsubstrat umsetzt, welches bei $405 \mathrm{~nm}$ im Spektrophotometer gemessen werden kann. Dazu wird zuerst die im Zellüberstand enthaltene MMP-2 durch in 96-Well-Platten immobilisierte Anti-MMP2-Antikörper gebunden.

Die Menge an MMP-2 wird mit Hilfe von Standards bekannter Konzentration bestimmt. Dabei kann man durch Verwendung des nativen Zellüberstandes im Vergleich zu künstlich durch p-Aminophenylmercuric acetate (APMA) aktivierten Überständen die Menge an endogener Aktivität und Gesamtmenge an Proteinase bestimmen.

$100 \mu 130$ x konzentrierte Überstände von hEAG1a-transfizierten und Wildtyp-HEK293Zellen wurden über Nacht in den mit Anti-MMP-2-Antikörper beschichteten Vertiefungen bei 
$2-8{ }^{\circ} \mathrm{C}$ inkubiert, am nächsten Tag viermal mit $300 \mu 1$ Wash Buffer gewaschen und mit $50 \mu 1$ APMA bzw. $50 \mu$ Assay Buffer und $50 \mu$ l Detection Reagent versetzt. Sofort nach Zugabe wurde die Anfangsaktivität bei $405 \mathrm{~nm}$ bestimmt, dann die Platte für $4 \mathrm{~h}$ bei $37^{\circ} \mathrm{C}$ inkubiert, erneut bei $405 \mathrm{~nm}$ gelesen und die Menge an MMP-2 durch Vergleich mit einer Standardreihe ermittelt.

\subsubsection{Anhaftungsassay}

\subsubsection{4.a Beschichtung der Deckgläser}

96-Well-Mikrotiterplatten wurden für die Beschichtung mit Kollagen IV (20 $\mu \mathrm{g} / \mathrm{ml})$, Fibronektin $(20 \mu \mathrm{g} / \mathrm{ml})$ Laminin $(10 \mathrm{mg} / \mathrm{ml})$ Gelatine $(10 \%)$, Poly-L-Lysin $(100 \mu \mathrm{g} / \mathrm{ml})$ und Protamin $(1 \%)$ in PBS $1.5 \mathrm{~h}$ bei $37^{\circ} \mathrm{C}$ inkubiert und über Nacht bei $4{ }^{\circ} \mathrm{C}$ aufbewahrt. Am nächsten Tag wurden sie mit PBS gewaschen, bevor die Zellen ausgesät wurden.

\subsubsection{4.b Anhaftungsexperiment}

15000 Zellen pro Vertiefung der 96-Well-Platten wurden nach Blockierung von unspezifischen Bindungsstellen mit $10 \mathrm{mg} / \mathrm{ml}$ Hitze-inaktiviertem BSA $\left(10 \mathrm{~min} 85^{\circ} \mathrm{C}\right)$ und nachfolgendem PBS-Waschschritt in den beschichteten Vertiefungen ausplattiert und $30 \mathrm{~min}$ bei $37{ }^{\circ} \mathrm{C}$ zur Anhaftung inkubiert. Dann wurde ein definiertes Schüttelprogramm mit den Platten durchgeführt (kreisförmiges Schütteln, $5 \mathrm{~mm}$ Durchmesser, $5 \mathrm{~s}$ ), einmal mit PBS gewaschen und die angehafteten Zellen mit $5 \%$ Glutaraldehyd in PBS 20 min fixiert. Nach der Fixierung wurden die Zellen mit PBS gewaschen und $1 \mathrm{~h}$ mit $0.1 \%$ Kristallviolettlösung in PBS bei RT angefärbt. Danach wurden sie $3 \times$ mit PBS gewaschen und der gebundene Farbstoff in $100 \mu 110 \%$ Essigsäure durch Schütteln (10 min 200 upm) gelöst und in einem 1420 Victor2 Multilabel Counter (Wallac) bei $570 \mathrm{~nm}$ gemessen.

\subsubsection{Inkubation der Zelllinien mit LPS}

Die Zelllinien MDA-MB435S, IPC298 und IGR-39 wurden $24 \mathrm{~h}$ bei $37^{\circ} \mathrm{C}$ mit $10 \mu \mathrm{g} / \mathrm{ml} \mathrm{LPS}$ im jeweiligen Kulturmedium inkubiert. 


\subsubsection{LPS-Injektion und Organentnahme}

Für die Organentnahmen wurden 10 Wochen alte männliche Mäuse des Stammes C57BL/6N (Charles River) mit einem Körpergewicht von 25 - 30 g verwendet. Diese Tiere wurden einzeln in Standard-Käfigen $(22 \mathrm{~cm} \times 16 \mathrm{~cm} \times 13 \mathrm{~cm}$, Länge $\times$ Breite $\times$ Höhe $)$ gehalten, die an eine eigene Luftversorgung angeschlossen waren und sich in dem Sterilbereich des Tierhauses befanden, gehalten. Die Käfige waren in einem Raum untergebracht, in dem ein künstlicher Tag-Nacht-Zyklus (12 h/ 12 h) aufrechterhalten wurde (Beginn des Tag-Zyklus um 6.00 Uhr). Die Tiere wurden nach Lieferung 2 Wochen unter konstanten Bedingungen in ihren Käfigen gehalten und hatten freien Zugang zum Standard-Futter und Wasser. Die Käfigeinstreu wurde wöchentlich gewechselt. Die Haltung und die experimentelle Behandlung der Tiere erfolgten in verschiedenen Räumen. Alle Experimentalbedingungen entsprachen den Richtlinien der Gesellschaft für Labortierwissenschaft Deutschland. Die in dieser Arbeit verwendeten adulten männlichen Ratten gehörten dem Stamm Wistar an. Für die Versuche lag eine Genehmigung der Bezirksregierung Braunschweig (Aktenzeichen: 33.42502/02-02.05) vor.

Die Mäuse wurden mit LPS in PBS (100 $\mu \mathrm{g}$ pro Maus) oder PBS injiziert, nach $12 \mathrm{~h}$ durch Genickbruch getötet, die Organe und das Gehirn entnommen und sofort in RNALater Buffer (Ambion) überführt, um die RNA vor Abbau zu schützen. Die verschiedenen Gehirnregionen wurden in RNAse-freier Umgebung auf einer RNase-freien Metallplatte über Trockeneis präpariert.

\subsubsection{7 siRNA-Transfektionen}

Vier verschiedene siRNAs wurden unter Verwendung des HiPerformance siRNA Design Algorithm von der Firma Qiagen gegen die Sequenzen mit den Nummern NM_172362 and NM_172376 (EAG1 und EAG2) entworfen. Dieser Algorithmus verwendet einen neuronalen Netzwerk-Ansatz, um die siRNAs herzustellen und verwirft diejenigen Sequenzen, die große Ähnlichkeit zu Regionen von anderen Genen aufweisen (Huesken et al., 2005). Gebiete der Sequenzen mit bekannten single nucleotide polymorphisms (SNP) wurden vermieden. Die Herstellung von mehreren funktionalen siRNAs gegen EAG1 erlaubt die unabhängige Bestätigung der phänotypischen Effekte (Huppi et al., 2005). Da bisher nur EAG1a in Bezug auf Zellproliferation untersucht wurde, wurden keine Anstrengungen unternommen, siRNA zu entwerfen, die zwischen den zwei Spleißvarianten von EAG1 unterscheiden. Die siRNAs 
(1-100nM) wurden mit Oligofectamine, Lipofectamine (Invitrogen) oder Dharamacon Transfection Reagent 2 (Dharmacon) als Transfektionsreagenzien in OptiMEM Medium (Invitrogen) in die Zellen transfiziert. Die Zellen wurden dazu am Tag zuvor gesplittet und ausplattiert. Folgende siRNA wurden in dieser Arbeit verwendet:

SiRNAs gegen hEAG1 mit NM_172362 als Zielsequenz: Kv10.1 Nukleotide 1509-1529; Kv10.1-1 Nukleotide 236-256; Kv10.1-2 Nukleotide 863-883; Kv10.1-3 Nukleotide 17931813; Kv10.1-4 Nukleotide 1022-1042; siRNAs gegen hEAG2 mit NM_172376 als Zielsequenz: Kv10.2-1 Nukleotide 378-398; Kv10.2-2 Nukleotide 678-698; Kv10.2-3 Nukleotide 1524-1544; Kv10.2-4 Nukleotide 837-857; Als negative Kontrollen wurden siRNAs mit der umgekehrten, jedoch nicht komplementären Sequenz von Kv10.1 (revKv10.1) und Kv10.1-3 (revKv10.1-3) verwendet. Diese RNAs besitzen die gleiche Basenzusammensetzung und -abfolge, so dass sie die ähnlichste Struktur zu den funktionalen siRNAs aufweisen. Der Sinnstrang der zwei hybridisierten siRNA-Duplexe wurde mit zwei Desoxythymidinnukleotiden an den 3'-Enden modifiziert und der Gegensinnstrang mit den der Sequenz entsprechenden Desoxynukleotiden, um die siRNAs gegen Abbau zu stabilisieren (Elbashir et al., 2001). Alle siRNAs wurden von der Firma Qiagen synthetisiert und vor Gebrauch hybridisiert. Eine Ausnahme stellt die kommerzielle Negativkontrolle (Negative Control \#1) und die menschliche GAPDH siRNA (human GAPDH siRNA) (Ambion) dar, die als Negativ- bzw. Positivkontrolle verwendet wurden. Die Zellen wurden 4 $\mathrm{h}$ bis $24 \mathrm{~h}$ mit den siRNA vermischt, mit dem Transfektionsreagenz in OptiMEM-Medium inkubiert und $\mathrm{zu}$ verschiedenen Zeitpunkten nach dem Start der Transfektion für die Experimente geerntet. Als Kontrollen wurden Zellen verwendet, die nur mit OptiMEM und Oligofectamine, Lipofectamine oder Dharmacon Transfection Reagent 2 behandelt wurden. 


\section{Ergebnisse}

\subsection{Expression von EAG}

\subsubsection{EAG1- und EAG2-Expression im Gehirn und peripheren Geweben der Maus und Ratte}

Die Expression von rEAG1 und rEAG2 im Zentralnervensystem, den Augen, der Lunge und den Hoden der Ratte wurde in der Literatur beschrieben (Ludwig et al., 1994; Napp, 2003). Vor dieser Arbeit gab es jedoch noch keine Studien, die das Vorhandensein von EAG außerhalb dieser Organe und des Gehirns beschrieben. Die Expression von EAG in Mausund Rattenorganen und Mausgehirn wurde mittels Real-Time-PCR überprüft und substanzielle Expressionsmengen in verschiedenen Organen außer der Leber detektiert, die vergleichbar mit den Expressionsmengen von EAG in EAG-positiven Zelllinien waren (Tab.2).

\begin{tabular}{|c|c|c|c|c|}
\hline Organ & $\begin{array}{l}\text { rEAG1a-RNA-Konzentration } \\
\left(10^{4} \mathrm{~K} / \mu \mathrm{l}\right)\end{array}$ & $\mathbf{n}$ & $\begin{array}{l}\text { rEAG2-RNA-Konzentration } \\
\left(10^{4} \mathrm{~K} / \mu \mathrm{l}\right)\end{array}$ & $\mathbf{n}$ \\
\hline Hoden & $9.26 \pm 0.39$ & 3 & $5.43 \pm 0.37$ & 3 \\
\hline Nieren & $1.12 \pm 0.11$ & 3 & $0.19 \pm 0.15$ & 3 \\
\hline Lunge & $1.98 \pm 0.13$ & 3 & $0.07 \pm 0.03$ & 3 \\
\hline Milz & $3.03 \pm 0.47$ & 3 & $0.06 \pm 0.01$ & 3 \\
\hline Thymus & $2.03 \pm 0.17$ & 3 & $0.16 \pm 0.04$ & 3 \\
\hline Leber & $0.02 \pm 0.004$ & 3 & $0.04 \pm 0.005$ & 3 \\
\hline
\end{tabular}

Tab. 2: rEAG1a- und rEAG2-RNA-Konzentration in Organen der Ratte. Aufgeführt ist die RNA-Konzentration in Kopien pro Volumen $(K / \mu 1)$ mit Standardfehler (SEM). $n=3$.

In der Ratte wurde substanzielle rEAGla-Expression in Hoden, Nieren, Lunge, Milz und Thymus gefunden, während die Leber rEAG1a-negativ war. rEAG2-RNA konnte in den Hoden, den Nieren, Lunge und Thymus detektiert werden. Geringe Mengen befanden sich auch in Milz und Leber. 


\begin{tabular}{lllll}
\hline $\begin{array}{l}\text { Organ } \\
\text { Gehirnregion }\end{array}$ & $\begin{array}{c}\text { oder } \\
\text { mEAG1a-RNA- } \\
\text { Konzentration }\left(\mathbf{1 0}^{\mathbf{4}} \mathbf{K} / \mu \mathbf{l}\right)\end{array}$ & $\mathbf{n}$ & $\begin{array}{l}\text { mEAG2-RNA- } \\
\text { Konzentration }(\mathbf{1 0} \mathbf{K} / \mu \mathbf{l})\end{array}$ & $\mathbf{n}$ \\
\hline Hippocampus & $5.01 \pm 0.31$ & 42 & n. b. & 12 \\
Hypothalamus & $9.39 \pm 0.90$ & 12 & $3.14 \pm 0.31$ & 3 \\
Bulbus olfactorius & $16.47 \pm 1.87$ & 15 & $0.004 \pm 0.00$ & \\
Lunge & $4.96 \pm 0.50$ & 42 & n. b. & \\
Hoden & $1.50 \pm 0.41$ & 3 & n. b. & \\
Thymus & $1.27 \pm 0.14$ & 42 & n. b. & 42 \\
Milz & $0.51 \pm 0.09$ & 42 & n. b. & \\
Herz & $0.13 \pm 0.01$ & 42 & $0.002 \pm 0.00$ & \\
\hline
\end{tabular}

Tab. 3: mEAG1- und mEAG2-RNA-Konzentration in Organen und Gehirnregionen der Maus. Aufgeführt ist die RNA-Konzentration in Kopien pro Volumen $(\mathrm{K} / \mu \mathrm{l})$ mit Standardfehler (SEM). $\mathrm{n}$. b.: nicht bestimmt.

In der Maus wurde mEAG1-RNA wie schon aus der Literatur bekannt in Hippocampus, Hypothalamus und dem Bulbus olfactorius exprimiert. Zusätzlich konnte in dieser Arbeit EAG1a-Expression in Hoden, Lunge, Thymus, Milz und Herz beobachtet werden. mEAG2 war im Hypothalamus detektierbar, während es im Bulbus olfactorius und im Herz nur geringfügig exprimiert waren (Tab. 3). Die mEAG1-Expression im Herz der Maus war überraschend, da für den Menschen keine hEAG1-Expression im Herz gefunden wurde (Pardo et al., 1999). Dagegen steht es im Einklang mit Veröffentlichungen des Vorkommens dieser Kanäle in der Ratte (Ludwig et al., 2000).

\subsubsection{Auslösung differentieller EAG-Expression durch Lipopolysacchariden (LPS)}

Die Expression von mEAG in der Maus außerhalb des Gehirns war vor dieser Arbeit noch nicht beschrieben. Ebenso ist noch unbekannt, ob und wie die mEAG-Expression induziert oder reprimiert werden kann und welche Funktion mEAG im Gehirn und peripheren Geweben ausübt. Stress beeinflusst in vielfacher Weise die Expression von Genen im Gehirn (Mansi et al., 1998). In der Vergangenheit wurde für viele Rezeptoren und Ionenkanäle festgestellt, dass die Modulation ihrer Expression während Entzündungsreaktionen über ähnliche Wege wie ihre Modulation durch Streß erfolgt (Gerth et al., 2005; Radulovic et al., 2000; Rivest et al., 1995). Daher wurde in dieser Arbeit die Modulation der mEAG- 
Expression durch Lipopolysaccharide (LPS), mit denen sterile Entzündungen ausgelöst werden können, untersucht.

\subsubsection{Inkubation der Krebszelllinien mit LPS}

Um festzustellen, ob es sich bei einem möglichen Einfluss von LPS auf die hEAG1Expression um einen direkten Effekt von LPS über LPS-Rezeptoren auf der Zelloberfläche handelt, wurde zunächst die Modulation der hEAG1-Expression in vitro in natürlich hEAG1exprimierenden Zelllinien untersucht. MDA-MB435S (Brustkrebszelllinie), IGR-39 und IPC298-Zellen (Melanomzelllinien) wurden mit LPS inkubiert und die Expression von hEAG1a mit Real-Time-PCR überprüft. Es konnte beobachtet werden, dass die hEAG1aRNA-Menge in allen Zelllinien signifikant durch LPS vermindert wurde (Abb. 7).

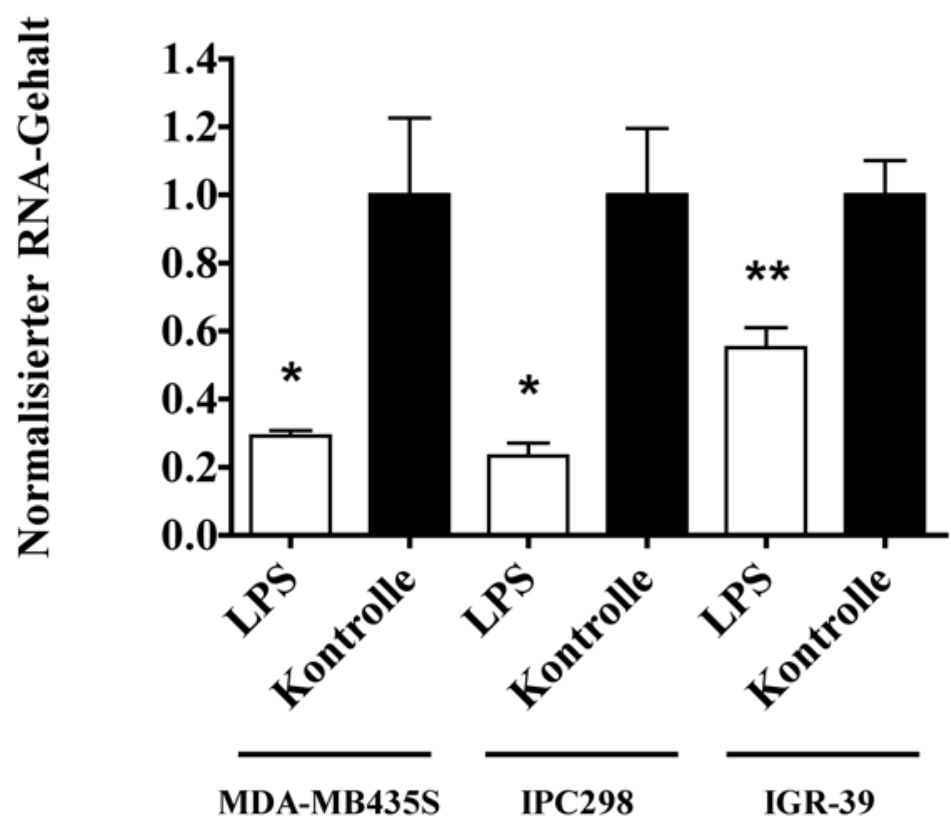

Abb. 7: Inhibierung der hEAG1a-Expression durch Behandlung der Zelllinien MDA-MB435S $(\mathbf{n}=3)$, IPC296 $(\mathbf{n}=3)$ und IGR-39 $(\mathbf{n}=\mathbf{6})$ mit LPS. Dargestellt ist der auf die Kontrolle der jeweiligen Zelllinie normalisierte RNA-Gehalt. ${ }^{*}=\mathrm{p}<0.05, * *=\mathrm{p}<0.01$.

In MDA-MB435S-Zellen war die Expression um $70.77 \pm 16.99 \%$, in IPC298-Zellen um $76.76 \pm 19.83 \%$ und in IGR-39-Zellen um $44.89 \pm 11.70 \%$ reduziert. 


\subsubsection{Intraperitoneale Injektion von LPS in Mäuse veränderte die EAG-Expression in einigen Organen, jedoch nicht im Gehirn.}

Die C57BL/6N-Mäuse wurden mit $100 \mu \mathrm{g}$ LPS in PBS oder nur PBS injiziert, $12 \mathrm{~h}$ später getötet und die Organe und das Gehirn entnommen. Die Expression von mEAG wurde mittels Real-Time-PCR überprüft. Im Hippocampus, Hypothalamus, Bulbus olfactorius, in der Lunge und in den Hoden konnte keine signifikante Änderung der mEAG1-Expression beobachtet werden, während in Herz (Abb. 8C) und Thymus (Abb. 8B) die Expression signifikant um $795.2 \pm 51.57$ \% bzw. um $474.6 \pm 80.08$ \% erhöht und in der Milz (Abb. 8A) um $56.42 \pm$ 17.69 \% vermindert war. Gleichzeitig wurden die RNA-Mengen für Interleukin1 $\beta$ (mIL1 $\beta$ ) in den verschiedenen Organen und Gehirnregionen als Kontrolle für die aktive Wirkung und Verteilung von LPS bzw. seinen Mediatoren überprüft (Abb. 8A-C, Abb. 9A-C, Abb. 10A, B).

A

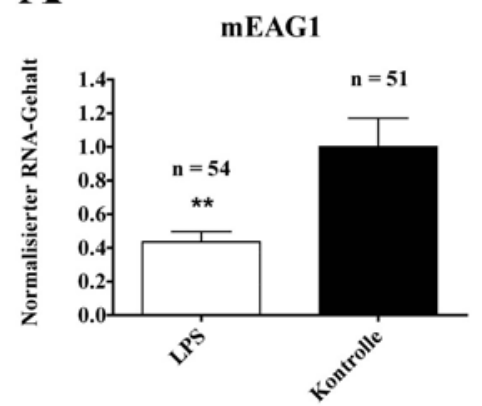

B

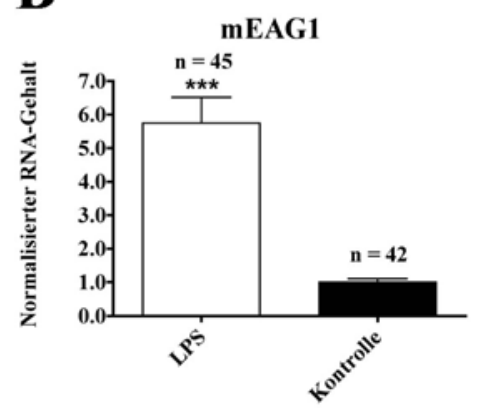

C

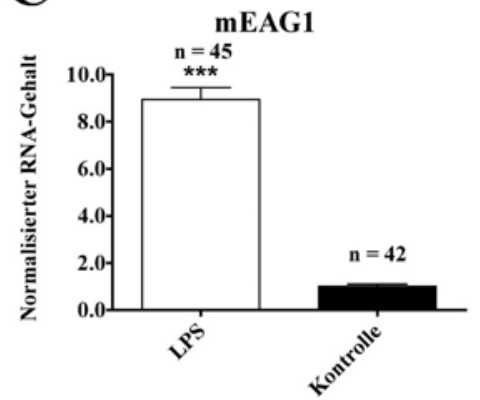

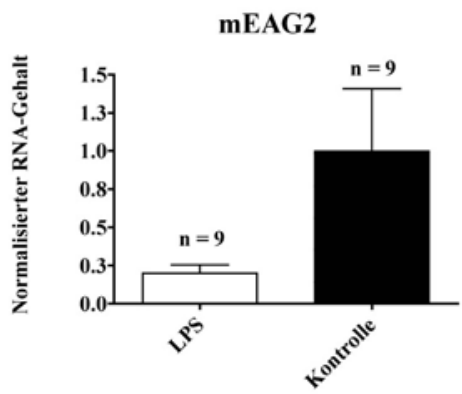
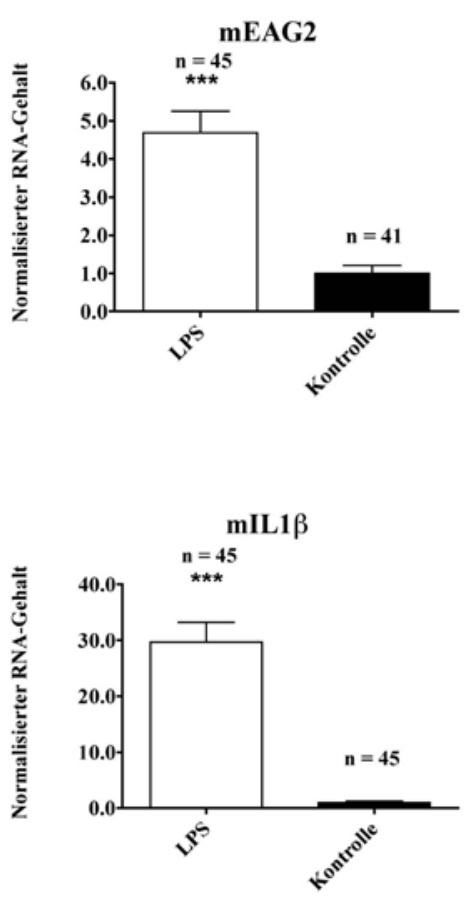
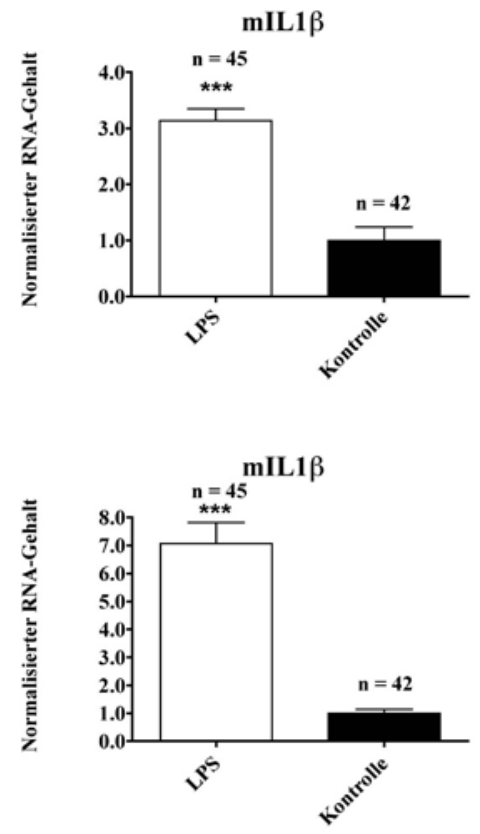

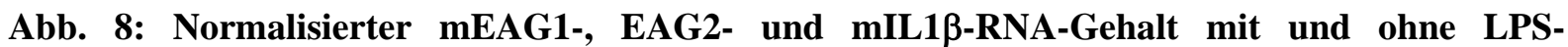
Behandlung der Mäuse. A: Milz, B: Thymus, C: Herz $(* *=p<0.01$, *** $=p<0.001)$. 
In allen Gehirnteilen und Organen konnte, eine signifikante Erhöhung der mIL1 $\beta$-RNAMenge notiert werden (Yao et al., 2005).

Es konnte auch beobachtet werden, dass die mEAG2-RNA-Menge bei LPS-Injektion im Thymus (Abb. 8B) signifikant um 369.0 $\pm 62.63 \%$ erhöht und in Hypothalamus (Abb. 9A), in der Lunge (Abb. 10A) und in der Milz (Abb. 8A) nicht verändert war.

A

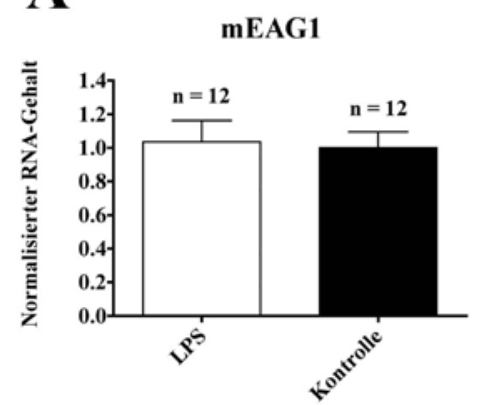

B

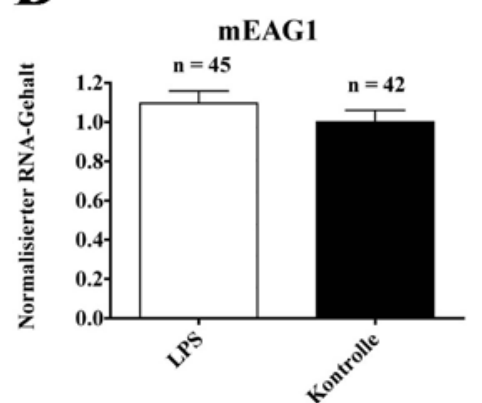

C

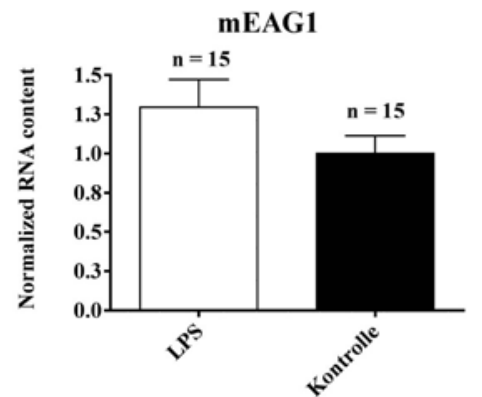

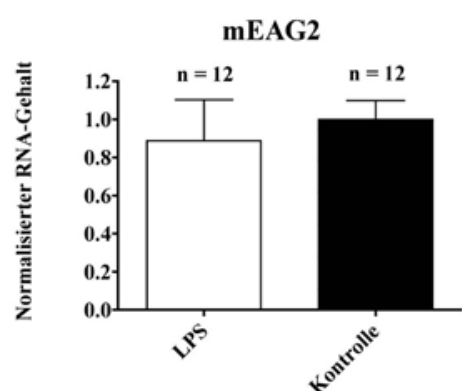
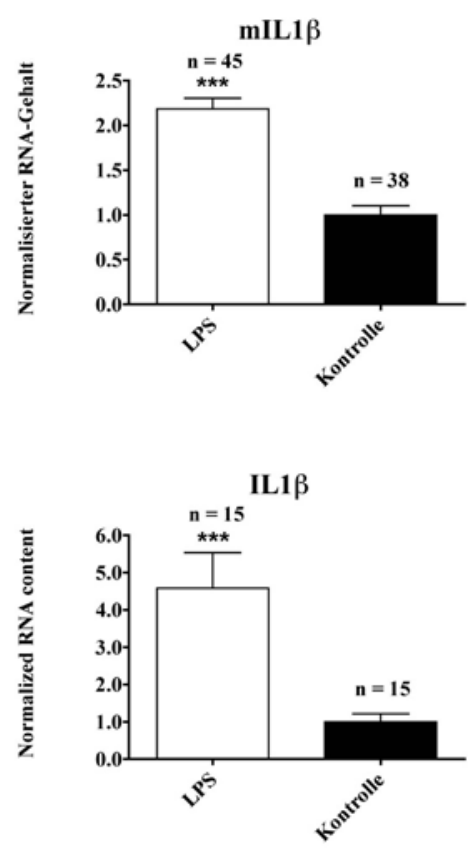

Abb. 9: Normalisierter mEAG1-, mEAG2- und mIL1 $\beta$-RNA-Gehalt mit und ohne LPSBehandlung der Mäuse. A: Hypothalamus, B: Hippocampus, C: Bulbus olfactorius $(* * *=p<$ $0.001)$. 
A
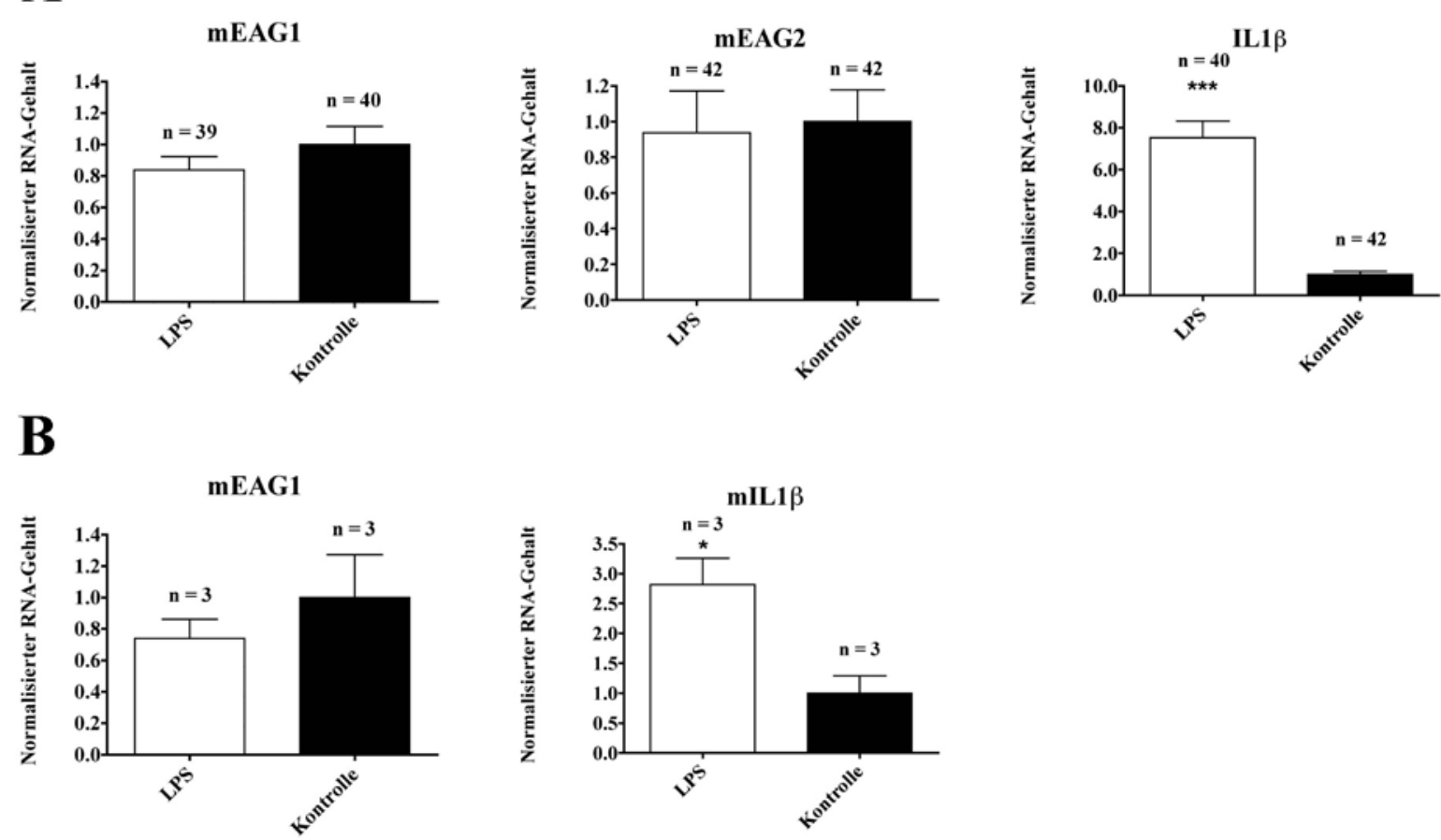

Abb. 10: Normalisierter mEAG1-, mEAG2- und mIL1 $\beta-R N A-G e h a l t$ mit und ohne LPSBehandlung der Mäuse. A: Lunge, B: Testis $(*=p<0.05, * *=p<0.01, * * *=p<0.001)$.

\subsubsection{Herstellung und Charakterisierung EAG1a-transfizierter Zellen}

In bisher veröffentlichten Studien zur physiologischen Funktion des EAG-Kanals wurde Ratten-EAG1(rEAG1) oder menschliches EAG1a (hEAG1) in CHO-Zellen (Hamster) oder 3T3-Zellen (Maus) transfiziert. In diesen Zellen wurden die Konsequenzen der EAG1aExpression für die Proliferation, Kontaktinhibition, das Wachstum in halbfestem Medium und die Tumorprogression in vivo im Tumorprogressionsmodell in SCID-Mäusen untersucht (Pardo et al., 1999). Bei diesem Ansatz handelt es sich um einen „Interspezies-Transfer“, da rEAG1 in eine Hamster- oder Mauszelllinie oder hEAG1 in eine Hamsterzelllinie eingebracht wurden. Eine Aufgabe dieser Arbeit war daher, das Verhalten des menschlichen EAG1Kanals zunächst in menschlichen Zelllinien (HEK293) zu beobachten. Dieses System beschreibt damit eher den pathologischen Fall der EAG1-Expression beim krebserkrankten Menschen. Bei den HEK293-Zellen handelt es sich um eine durch Adenovirusimmortalisierte Zelllinie (Graham et al., 1977), die im Gegensatz zu den CHO-Zellen keinen hohen Grad an Malignität besitzt und keine Metastasen bildet (Yang et al., 1999). Hierdurch sollten die potentiell transformierenden Eigenschaften des EAG1-Kanals in möglichst „normalen“ Zellen ohne den Einfluss von schon vorhandenen transformierenden Mutationen als Modell für ein frühes Stadium der Krebsentstehung überprüft werden, um dann später auf 
natürlich und ektopisch exprimierende Zelllinien überzugehen, die aus verschiedenen Krebstumoren isoliert worden sind.

Der EAG-Kanal besitzt prinzipiell zwei funktionelle Teile, die Auswirkungen auf die Zellphysiologie haben können, seine $\mathrm{K}+$-durchlässige Pore und einen langen $\mathrm{C}$-Terminus mit zahlreichen putativen Bindungsstellen für Signaltransduktionskomponenten. Um Hinweise darauf $\mathrm{zu}$ finden, welchen Einfluss die Fähigkeit von hEAG1a, Kaliumionen zu transportieren, auf die physiologische Auswirkungen der EAG1-Expression in Zellen hat, wurde paralell eine Mutante von EAG1a mit einer Punktmutation (G440S), die keine Kaliumionen transportiert, überprüft.

HEK293-Zellen wurden mit dem hEAG1a- oder G440S-Konstrukt im pTracer-oder pcDNA3Vektor oder den Vektoren allein polyklonal oder monoklonal transfiziert und die korrekte Expression der Sequenz auf mehreren Ebenen verifiziert. Mittels PCR wurden diejenigen Klone identifiziert, die die größten RNA-Mengen für das jeweilige Konstrukt exprimierten (Abb. 11A-C). Dabei stellte sich heraus, dass alle pcDNA3-Vektorkonstrukte eine konstant um das 10-fache geringere Expression der Konstrukte als die pTracer-Vektorkonstrukte aufwiesen (Abb. 11B, C). Es wurden daher ausschließlich pTracer-Konstrukte weiter untersucht. Die Entscheidung fiel auf HEK-pTracer Polyklon 2, HEK-pTracer-hEAG1aPolyklon 2, HEK-pTracer-hEAG1a-Monoklon und HEK-pTracer-G440S-Polyklon 2, im weiteren nur noch als HEK-pTracer, HEK-hEAG1a, HEK-hEAG1a-Monoklon und HEKhG440S bezeichnet. Weiterhin konnten bei Sequenzierung sowohl des Konstruktes vor der Transfektion als auch der in den Zellen exprimierten mRNA-Sequenz keine Mutationen zu den Zielsequenzen entdeckt werden. Die letzteren drei Klone stellten vergleichbare Mengen des korrekt glykosylierten hEAG1a und G440S her, während in HEK-pTracer-Zellen und untransfizierten HEK-Zellen kein hEAG1 detektiert werden und damit gleichzeitig eine eventuelle endogene Expression von hEAG1 in dieser Zelllinie ausgeschlossen werden konnte (Abb. 11D). 
A

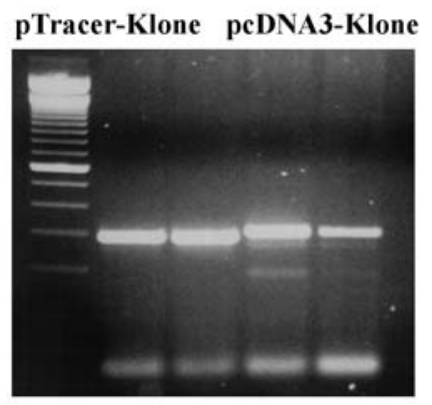

$\begin{array}{lllll}M & 1 & 2 & 3 & 4\end{array}$

B

C pcDNA3-Klone
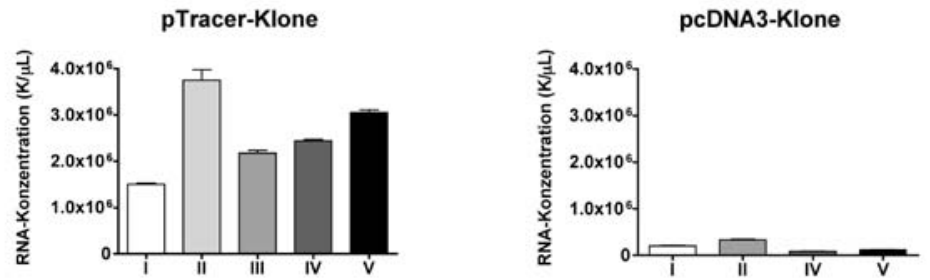

D

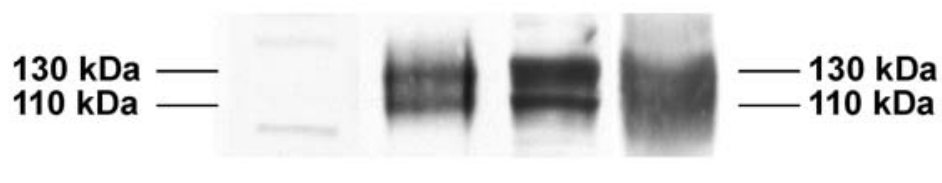

2 I $\quad$ III $\quad$ V

Abb. 11: Überprüfung der transfizierten HEK293-Zellen. A: PCR mit pTracer- bzw. pcDNA3spezifischen Primern. M: 100 bp-Leiter, 1: HEK-pTracer-Polyklon 1, 2: HEK-pTracer-Polyklon 2; 3: HEK-pcDNA3-Polylon 1, 4: HEK-pcDNA3-Polyklon 2. B und C: Real-Time-PCR mit EAG1aspezifischen Primern und Sonden in HEK-pTracer- und pcDNA3-Klonen. Linke Seite: pTracerKlone und rechte Seite: pcDNA3-Klone: I: HEK-hEAG1a-Polyklon 1, II: HEK-hEAG1a-Polyklon 2, III: HEK-pTracer-hEAG1a-Monoklon, IV: HEK-G440S-Polyklon 1, V: HEK-G440S-Polyklon 2. D: Western Blot der transfizierten Zellen mit EAG1a-spezifischem polyklonalem Antikörper. Die Banden zeigen das charakteristische Molekulargewicht von 110 und $130 \mathrm{kDa}$. 2: HEK-pTracerPolyklon 2, I: HEK-pTracer-hEAG1a-Polyklon 2, III: HEK-pTracer-hEAG1a-Monoklon, V: HEKpTracer-G440S-Polyklon 2.

Die Zellmembranlokalisation und korrekte Assemblierung konnte mittels Aktivitätsmessungen des Ionenkanals elektrophysiologisch nachgewiesen werden. Diese Messungen wurden von Dr. Francisco Monje, Dr. Luis Pardo und Bryan E. Downie durchgeführt. Im Falle der HEK-hEAG1a-Zellen wurde der typische Cole-Moore-Shift beobachtet und im Falle der HEK-G440S-Zellen, bei denen keine Ionenströme messbar sind, die gating-Ströme (Daten nicht gezeigt). 
Diese aufgeführten Kontrollexperimente zeigen, dass die Transfektion mit den korrekten Sequenzen erfolgreich war, Protein in großen Mengen korrekt glykosiliert exprimiert und in der Membran lokalisiert war und der Kanal dort in seiner natürlichen tetrameren Assemblierung aktiv vorlag. Außerdem wurde eine Veränderung des Phänotyps der hEAG1a und G440S-transfizierten Zellen im Vergleich zu den Vektor-transfizierten bemerkt. Die Vektor-transfizierten Zellen wuchsen ausgebreitet und schienen fest auf dem Boden der Kulturflasche angehaftet zu sein, während die HEK-hEAG1a-Zellen ein zusammengedrängtes Wachstumsbild zeigten (Abb. 12A, B). Der Grund dafür könnte möglicherweise eine verminderte Anhaftung kombiniert mit einer verringerten Kontaktinhibierung sein.

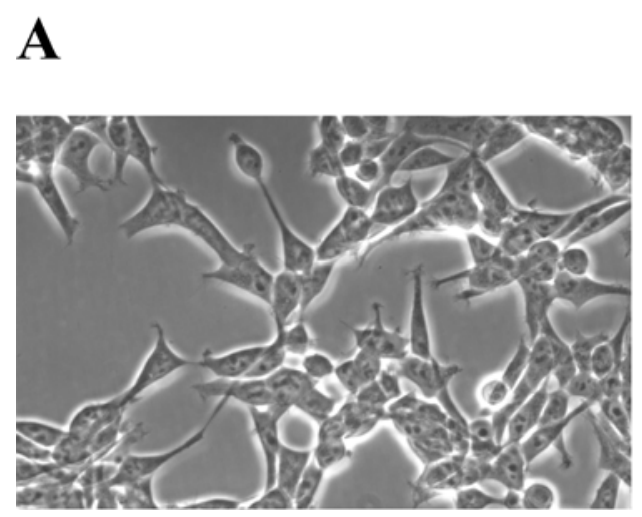

B

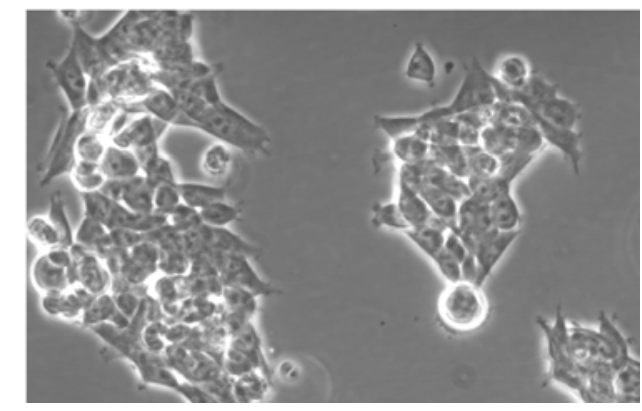

Abb. 12: Lichtmikroskopische Aufnahmen des Phänotyps der HEK-pTracer- (A) und der HEKhEAG1a-Zellen (B).

\subsubsection{Proliferationsassay}

Der Proliferationsassay jedoch zeigte einen überraschenden Verlauf. Untransfizierte HEKZellen wuchsen im Allgemeinen deutlich schneller als alle drei transfizierten Zelllinien, da sie ohne Selektionsantibiotikum kultiviert wurden (Daten nicht gezeigt). Sowohl die hEAG1a als auch die G440S-exprimierenden Zellen wuchsen langsamer als die pTracer-transfizierten Zellen (Abb. 13), obwohl alle drei Zelllinien gleichartig kultiviert wurden (gleiches Medium und gleiche Selektionsantibiotika-Konzentration). Andererseits konnte die Proliferation von HEK-hEAG1a-Monoklon-Zellen und den HEK-hEAG1a-Zellen (Daten nicht gezeigt) wie in natürlich exprimierenden Zellen spezifisch mit Anti-hEAG1-siRNAs gehemmt werden (Abb. 40) und man kann daher von einer die Proliferation aktivierenden Rolle von hEAG1a ausgehen. Möglicherweise war der Expressionsvektor für die unerwarteten Effekte auf die Proliferationsrate verantwortlich. Eine Klärung dieser Beobachtung war bis jetzt nicht möglich. 


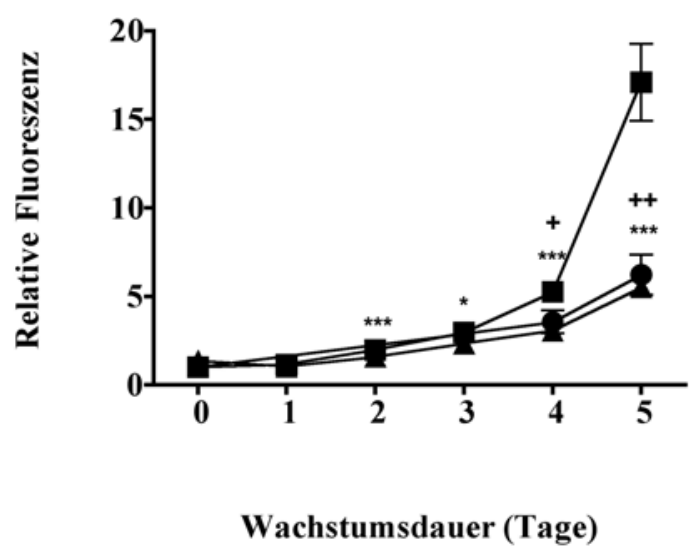

Abb. 13: Proliferationsassay der transfizierten Zellen. Die HEK-pTracer-Zellen (Quadrate) wuchsen schneller als die HEK-hEAG1a-Zellen (Dreiecke) und die HEK-G440S-Zellen (Kreise). * = $\mathrm{p}<0.05, * * *=\mathrm{p}<0.001$, Vergleich HEK-pTracer-Zellen mit HEK-hEAG1a-Zellen. $+=p<0.05$, $+++=\mathrm{p}<0.001$, Vergleich HEK-pTracer -Zellen mit HEK-G440S-Zellen.

\subsection{Differentielle Genexpression}

Um zu untersuchen, ob die beobachteten Änderungen in der Proliferation durch Änderungen in der Expression von Genen hervorgerufen wurden, wurde in dieser Arbeit das Genexpressionprofil der hEAG1a-transfizierten HEK-Zellen und natürlich hEAG1exprimierenden Zellen (MDA-MB435S-Zellen) erstellt. Daher wurden in dieser Arbeit verschiedene Strategien angewendet. Es wurde einerseits hEAG1a in Zellen, die keines exprimieren, hineingebracht und andererseits vorhandenens hEAG1 in natürlich exprimierenden Zellen gehemmt. Zum einen wurde die Genexpression im heterologen Transfektionsystem in HEK-Zellen mittels Pfad-spezifischen cDNA-Arrays und subtraktiver Hybridisierung untersucht, zum anderen in einer natürlich hEAG1-exprimierenden Zelllinie durch Inhibierung von hEAG1 mit Astemizol mittels Mikroarrays.

\subsubsection{Differentielle Expression in transfizierten HEK-Zellen}

RNA aus untransfizierten und hEAG1a-transfizierten HEK-Zellen wurde auf ihre Integrität überprüft (Daten nicht gezeigt), in markierte cDNA umgeschrieben und mit vier verschiedenen pfadspezifischen Arrays hybridisiert, dem Cancer/Oncogenesis-II, dem Cancer/Metastasis-I, dem Cancer/Angiogenesis-II und dem Integrin GEArray der Firma SuperArray Inc. mit jeweils 23 pfadspezifischen Genen. Als Kandidaten für differentielle 
Expression in untransfizierten im Vergleich zu hEAG1a-transfizierten HEK-Zellen wurden solche Gene ausgewählt, die nach Standardisierung auf das Haushaltsgen GAPDH einen signifikanten Unterschied von $>1.5$ bei hoher Expression (starkem Signal) und $>2.0$ bei niedriger Expression (schwachem Signal) ergaben. Kandidaten waren demnach autotaxin, bFGF, c-SRC, BLK, c-ETS2, c-MYB, CSF-1, PAI-1, Integrin $\alpha 2 b$, Integrin $\alpha 3$ und Integrin a4 (Abb. 14). Von diesen Kandidaten wurden die zelluläre Rezeptor-assoziierte Tyrosinkinase c-SRC, die Rezeptor-assoziierte B-Lymphozyten-spezifische Tyrosinkinase BLK und der endogene Proteaseinhibitor Plasminogenaktivator-Inhibitor (PAI-1) näher mit Real-Time-PCR untersucht, da diese Gene eng mit Krebserkrankungen in Verbindung gebracht wurden. c-SRC ist ein seit langem bekanntes Protoonkogen und stellt eine Rezeptorassoziierte Tyrosinkinase dar, die in einer Vielzahl von Krebsarten im Menschen zu einer hohen Prozentzahl überexprimiert wird (Biscardi et al., 1999). Eine weitere zur SRC-Familie gehörende Rezeptor-assoziierte Tyrosinkinase ist BLK, die in B-Lymphozyten entdeckt wurde, aber auch in nicht-lymphoiden Geweben exprimiert wird (Appel et al., 2002). Durch die Expression von konstitutiv aktiven BLK konnte eine maligne Transformation von B-ZellVorläufern induziert werden, was für eine Beteiligung von BLK an der Kontrolle der B-ZellDifferenzierung und Proliferation spricht (Malek et al., 1998). PAI-1 ist Teil des UrokinaseTyp-Plasminogen-Aktivator-Systems, das aus uPA, uPAR und PAI-1 und-2 besteht und die Degradation von Laminin, Fibronektin und Fibrin und die Aktivierung von Pro-MMPs und Wachstumsfaktoren (TFG $\beta$, bFGF, VEGF) kontrolliert. Dieses proteolytische System fördert die Tumor-Metastasierung über verschiedene Mechanismen und wurde mit schlechter Prognose in Patienten mit Brustkrebs in Verbindung gebracht (Han et al., 2005).

Es konnte keine signifikant differentielle Expression zwischen den verschiedenen Transfektionen festgestellt werden (Abb. 15A-C). Man kann also davon ausgehen, dass die näher untersuchten Gene nicht differentiell zwischen hEAGla-haltigen und -freien Zellen exprimiert werden. 


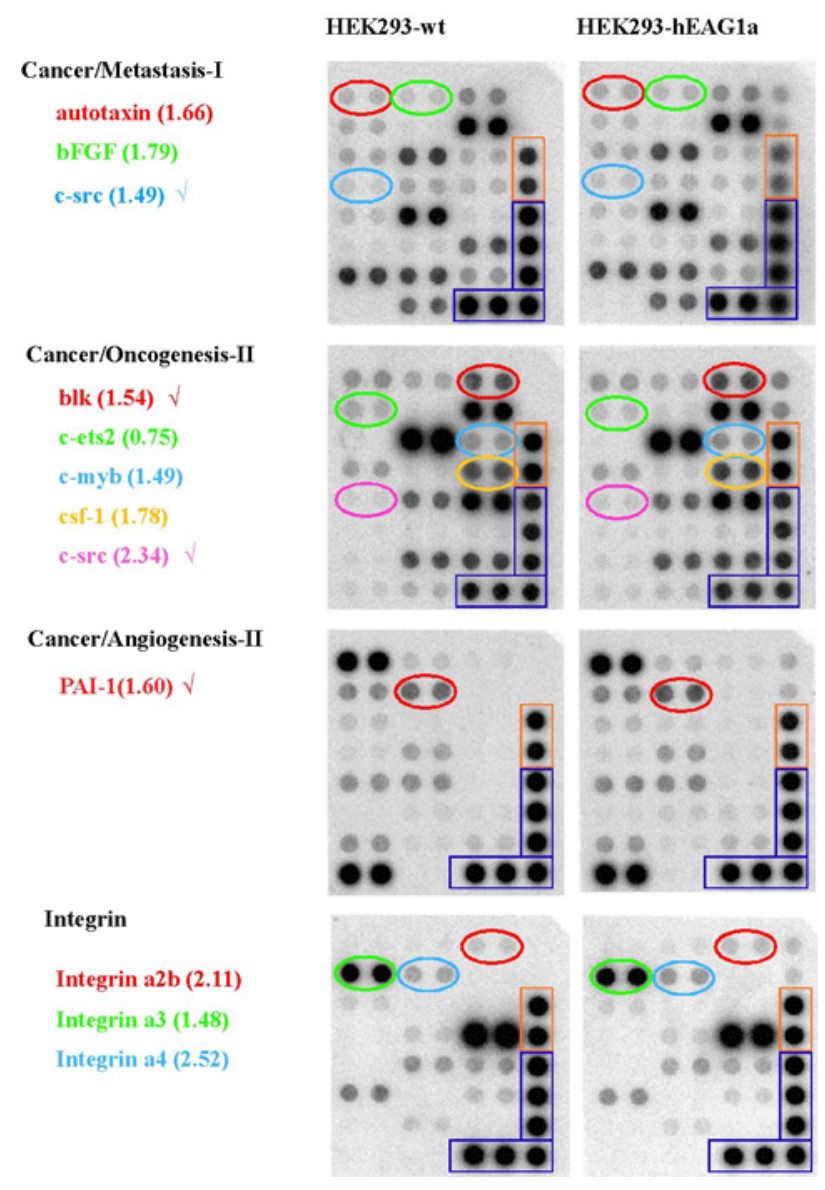

Abb. 14: Hybridisierung von markierter cDNA von untransfizierten und hEAG1a-transfizierten HEK-Zellen mit dem Cancer/Metastasis-I, Cancer/Oncogenesis-II, Cancer/Angiogenesis-II und Integrin GEArray. Die potentiell differentiell exprimierten Gene sind in der Abbildung mit farbigen Elipsen markiert. In Klammern dahinter befindet sich der Faktor des Expressionsunterschieds nach Standardisierung auf das Haushaltsgen GAPDH. Die Spots, die den Haushaltsgenen GAPDH (blau) und $\beta$-Aktin (orange) entsprechen, sind mit farbigen Rechtecken umrandet.

\section{A}

he-SRC

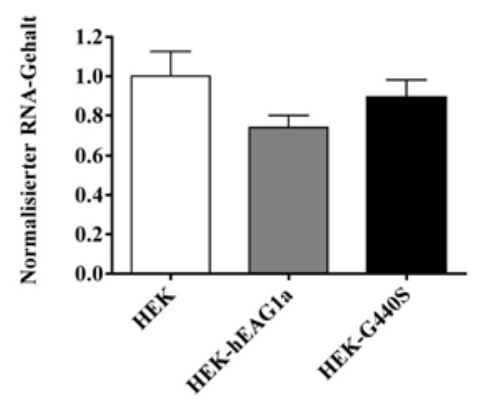

B

hBLK

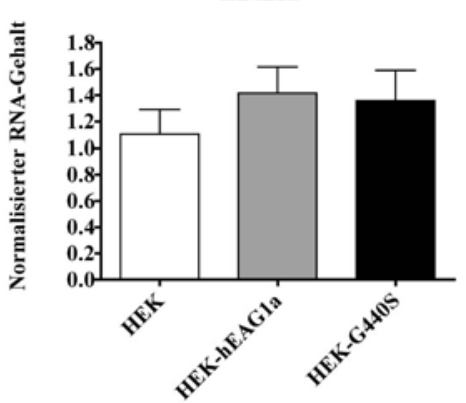

hPAI-1

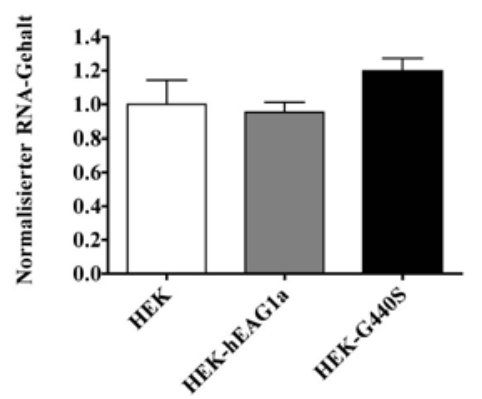

Abb. 15: Analse der potentiell differentiell exprimierten Gene in HEK-Zellen mit Real-TimePCR. Normalisierter RNA-Gehalt der untransfizierten HEK-Zellen, hEAG1a-transfizierten HEKZellen und der G440S-transfizierten HEK-Zellen. A: Normalisierter hc-SRC-RNA-Gehalt, B: Normalisierter hBLK-RNA-Gehalt und C: Normalisierter hPAI-1-RNA-Gehalt. 


\subsubsection{Subtraktive Hybridisierung}

Da die fokussierte Strategie zur Untersuchung der differentiellen Genexpressionkeine großen Änderungen erkennen ließ, wurde daraufhin eine Methode ohne Bias angewendet, die subtraktive Hybridisierung, mit der auch noch gänzlich unbekannte Gene gefunden werden können.
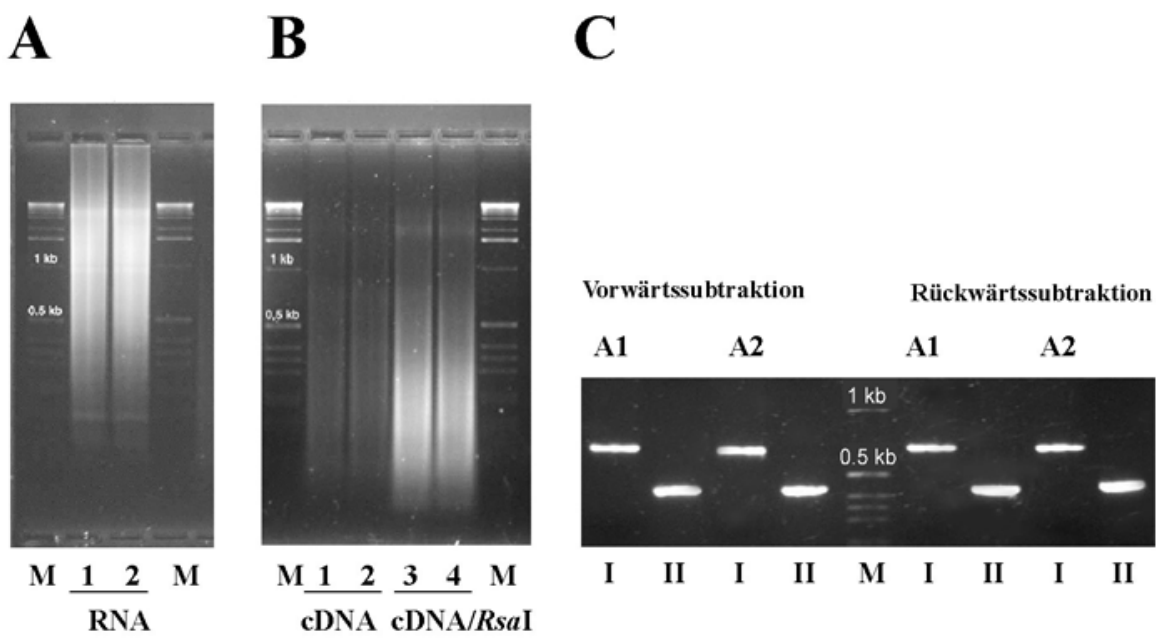

\section{D}

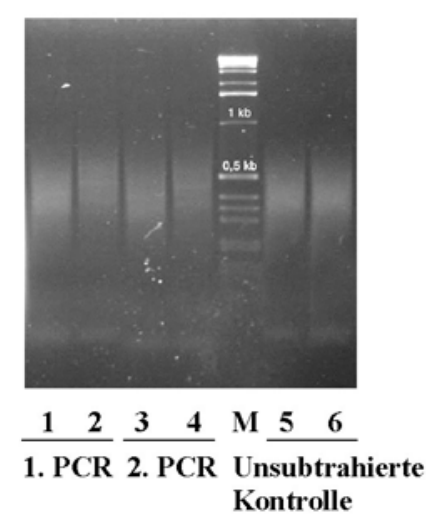

Abb. 16: Qualitätskontrolle der RNA, der cDNA, des RsaI-Verdaus, der Adaptorligation und der PCR-Reaktionen nach der subtraktiven Hybridisierung. M: 1 kb-Leiter. A: RNA-Gel: 1: HEK-hEAG1a, 2: HEK-pTracer. B: Doppelsträngige cDNA vor und nach RsaI-Verdau. 1: HEKhEAG1a-cDNA, 2: HEK-pTracer-cDNA, 3: HEK-hEAG1a-cDNA nach RsaI-Verdau, 2: HEKpTracer-cDNA nach RsaI-Verdau. C: Adaptorligationskontrolle. A1: Adaptor 1, A2: Adaptor 2, Na21: Primer für äußeren Teil der Adaptoren, I: PCR mit Na21-Primer und GAPDH-Primer 3'-Primer, II: PCR mit GAPDH-Primer 5'-Primer und GAPDH-Primer 3'-Primer. D: 1. und 2. PCR-Reaktion nach der Subtraktiven Hybridisierung und cDNA der unsubtrahierten Kontrolle. In der 1. und 2. PCRReaktion wurde im Vergleich zur unsubtrahierten Kontrolle ein Bandenmuster sichtbar, das den angereicherten Genen entsprach. 1: HEK-hEAG1a-PCR 1, 2: HEK-pTracer-PCR 1, 3: HEK-hEAG1aPCR 2, 4: HEK-pTracer-PCR 2. 5: HEK-hEAG1a-Kontrolle, 2: HEK-pTracer-Kontrolle.

mRNA wurde aus EAG1a-transfizierten (HEK-hEAG1a-Zellen) und Vektor-transfizierten (HEK-pTracer-Zellen) HEK-Zellen isoliert, ihre Qualität überprüft (Abb 16A) und die 
Subtraktion unter Verwendung des Kits für subtraktive Hybridisierung (BD PCR-Select ${ }^{T M}$ cDNA Subtraction Kit; BD Biosciences-Clontech), gefolgt vom Kit für differentielles Screening (PCR-Select Differential Screening Kit; BD Biosciences-Clontech) durchgeführt. Die Kontrollen für den erfolgreichen RsaI-Verdau (Abb. 16B), für die Adaptorligation (Abb. 16C) und die PCR-Reaktionen (Abb. 16D) deuten auf eine gelungene Subtraktionsprozedur hin, die Größenverschiebung nach dem Verdau ist deutlich zu erkennen, die Adaptorligation war sehr effizient und in der ersten, bzw. deutlicher in der zweiten PCR, wurden schwache Banden der angereicherten Gene sichtbar.

\subsubsection{1 hGAPDH ist in hEAG1a-und pTracer-transfizierten HEK-Zellen differentiell exprimiert}

Die Kontrolle der Subtraktionseffizienz zeigte ein überraschendes Ergebnis. Für diese Kontrolle wurde in einer PCR mit Produkt aus der 2. PCR-Reaktion der subtrahierten und unsubtrahierten Proben die Menge an hGAPDH überprüft, die im Falle einer gelungenen Subtraktion sowohl in der Vorwärts- als auch in der Rückwärtssubtraktion in dem subtrahierten Ansatz geringer sein sollte, d. h. erst bei höherer Zyklenzahl der PCR detektierbar sein sollte. Die Auftrennung im Agarose/Ethidiumbromid-Gel zeigte jedoch in der Rückwärtssubtraktion, dass dies nicht geschehen war. Es waren ungefähr die gleichen Mengen an Produkt in der unsubtrahierten und der subtrahierten Probe aus der Rückwärtssubtraktion vorhanden, während die Vorwärtssubtraktion dem Erwarteten entsprach. Nachdem jedoch die gleiche Prozedur mit hTFR1 durchgefürt worden war und eine drastische Verringerung der TFR-Menge in beiden Subtraktionsrichtungen sichtbar war, wurde deutlich, das die Menge an hGAPDH in den Ausgangs-RNAs differentiell exprimiert, d. h. in pTracer-transfizierten HEK-Zellen stärker exprimiert sein musste (Abb 17A, B). 
A Subtraktionseffizienzkontrolle (hTFR)
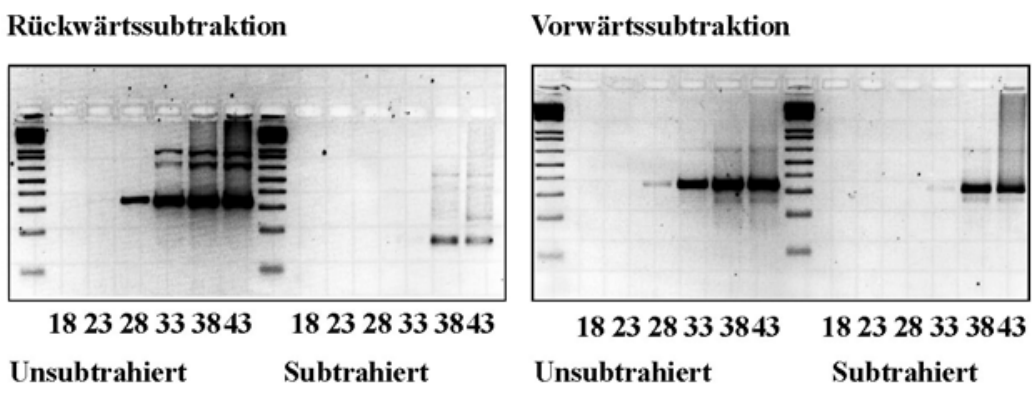

B Subtraktionseffizienzkontrolle (GAPDH) Rückwärtssubtraktion
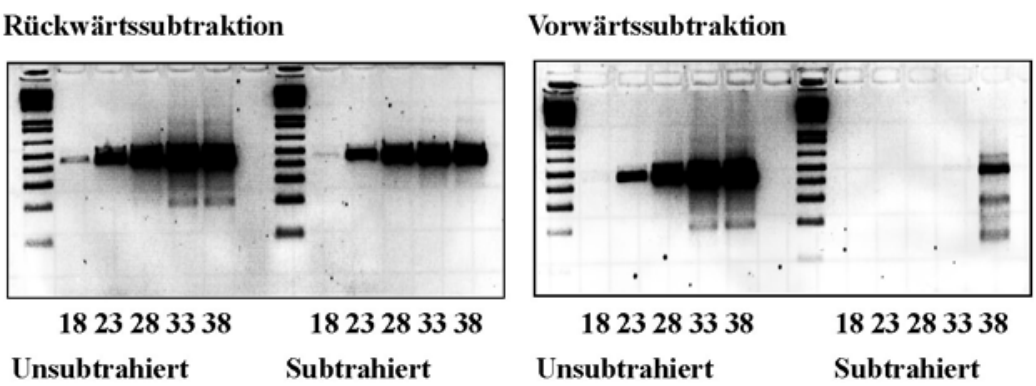

Abb. 17: Subtraktionseffizienzkontrolle. Subtraktionseffizienzkontrolle von hTFR (A) und GAPDH (B). 18, 23, 28, 33, 38, und 43 PCR-Zyklen wurden durchgeführt

Das Haushaltsgen Transferrin-Rezeptor Typ 1 (TFR1) war durch die Prozedur sowohl in der Vorwärts- als auch in der Rückwärtssubtraktion mit hoher Effizienz heraussubtrahiert worden. Dabei konnte hTFR1 in der Rückwärtsreaktion effizienter unterdrückt werden als in der Vorwärtsreaktion, was auf eine leicht erhöhte hTFR1-RNA-Menge in den hEAG1atransfizierten Zellen hinweist, die später auch mit Real-Time-PCR bestätigt wurden. Die differentielle Expression von hGAPDH wurde später ebenfalls durch Real-Time-PCR mit GAPDH-Primern und die Detektion von einem GAPDH-Klon in der Rückwärtssubtraktion im differentiellen Screening bestätigt. Die Effekte auf die hTFR1- und hGAPDHSubtraktionseffizienz waren gegenläufig, was die Hypothese bestärkt, dass es sich hierbei tatsächlich um Expressionunterschiede handelt.

\subsubsection{Differentielles Screening der Klone aus der Vorwärts- und Rückwärtssubtraktion}

Durch die spezielle Anwendung der subtraktiven Hybridisierung in transfizierten Zellen ergab sich die Notwendigkeit, die Klone der Vorwärtssubtraktion nicht nur mit Sonden aus der Vorwärts- und Rückwärtssubtraktion sondern auch mit einer hEAG1a-Sonde hybridisieren zu müssen, um von vorn herein die Klone für die Sequenzierung auszuschließen, die hEAG1a entsprachen (Abb 18-19). 
Durch das differentielle Screening wurden 14 putativ differentiell exprimierte Klone in der Vorwärtssubtraktion und 47 putativ differentiell exprimierte Klone in der Rückwärtssubtraktion gefunden, von denen in dieser Arbeit 2 bzw. 9 Klone mit Real-TimePCR näher untersucht wurden. Es handelte sich bei den Klonen aus der Vorwärtssubtraktion um VAP-C (vesicle-associated membrane protein-associated protein C) und CUTL1 (CCAAT-displacement protein) (Abb. 20A, B), bei denen aus der Rückwärtsreaktion um zweimal MAZ (myc-associated zinc finger protein), zweimal RACK1 (receptor for activated protein kinase C), PIK3R3 (phospatidylinositol 3 kinase, regulatory subunit 3), BRCA1 (breast cancer 1), UBE1 (ubiquitin-activating enzyme 1), EEF1A (eukariotic translation elongation factor 1) und GAPDH (glycerin-aldehyd-3-phosphat dehydrogenase) (Abb. 21AG). Alle Klone, bis auf BRCA1 (96\%), wiesen eine Homolgie von 99-100 \% zu den Sequenzen in der Gendatenbank auf. Da im Laufe dieser Arbeit ersichtlich wurde, dass die Oberflächenexpression von hEAG1 reguliert ist (siRNA-Studien), wurde u.a. das VAP-C-Gen zur Weiteruntersuchung ausgewählt, obwohl es noch nicht mit Krebserkrankungen in Verbindung gebracht wurde. Die anderen Kandidatengene wurden schon in vorangegangenen Studien mit Krebs assoziert.

Die Real-Time-PCR von HEK-pTracer im Vergleich zu hEAG1a- und G440S-transfizierten HEK-Zellen zeigte außer für GAPDH (EAG1a: $36.26 \pm 10.85 \%$ bzw. G440S: $37.41 \pm 11.21$ \%) (Abb. $21 \mathrm{C}$ ) nur für MAZ (EAG1a: $16.19 \pm 5.39 \%$ bzw. G440S: $17.88 \pm 4.63 \%$ ) (Abb. 21A) und RACK1 (EAG1a: $9.27 \pm 3.09$ \% bzw. G440S: $5.12 \pm 2.76 \%$ ) (Abb.21B) signifikante, jedoch geringe Expressionsunterschiede. Da die Kanal-transfizierten Zellen geringere Mengen an GAPDH, MAZ und RACK1 exprimieren, könnte dies der Grund für die unerwartete Senkung der Proliferation in Kanal-transfizierten HEK293-Zellen sein. 


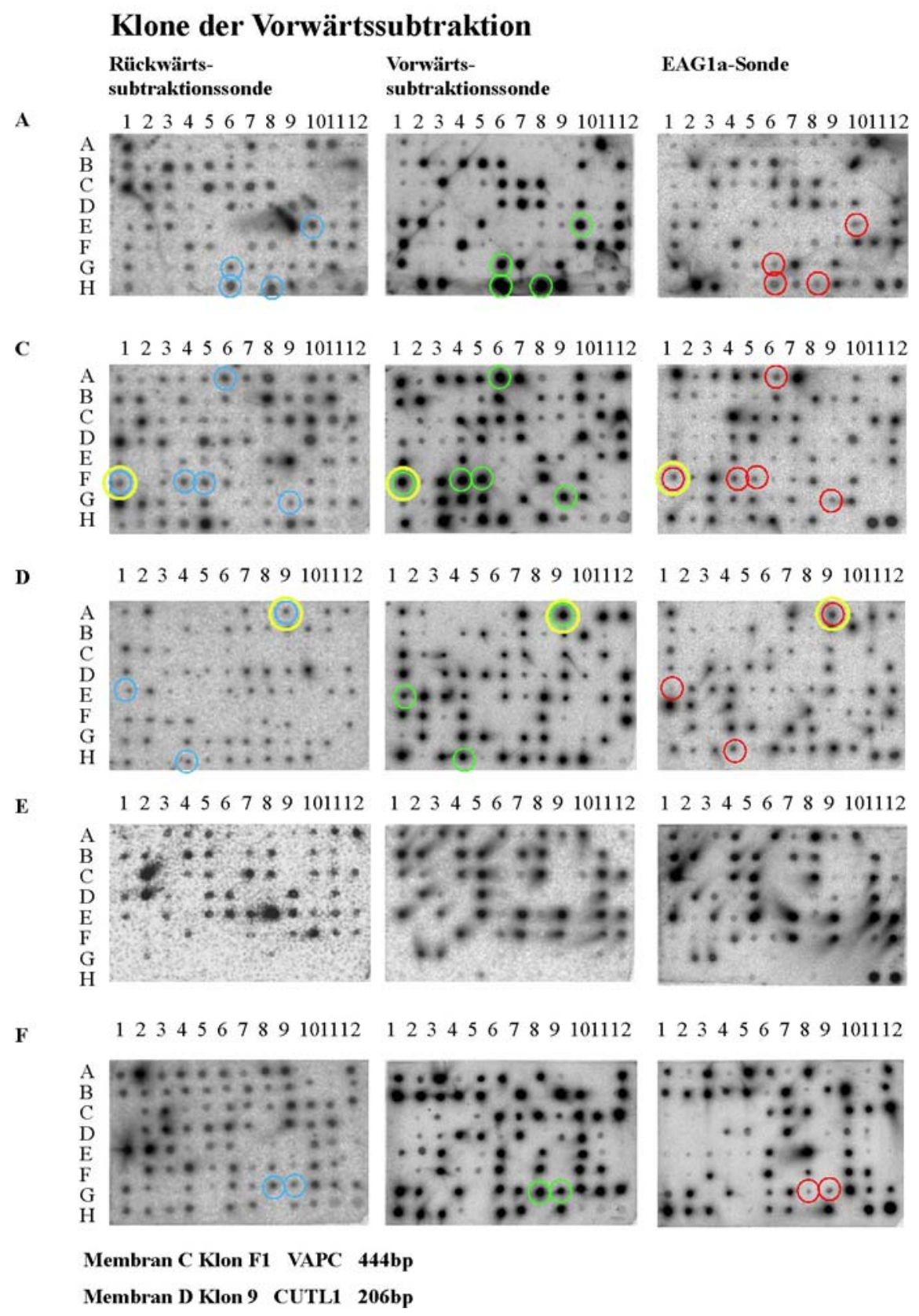

Abb. 18: Hybridisierung (A-F) der Klone aus der Vorwärtssubtraktion mit den markierten Sonden aus der Rückwärtssubtraktion (linke Spalte), der Vorwärtssubtraktion (mittlere Spalte) und der EAG1a-Sonde (rechte Spalte). Potentiell differentiell exprimierte Klone zeigten ein positives Signal in der Hybridisierung mit der Sonde der Vorwärtssubtraktion und gleichzeitig negative Signale in der Hybridisierung mit der Sonde der Rückwärtssubtraktion und der hEAG1aSonde. Die Klone C61 und D9 (gelb umrandet) wurden durch Sequenzierung als VAPC und CUTL1 identifiziert und mit Real-Time-PCR überprüft. Die Angaben hinter dem Gennamen in bp entsprechen der gefundenen und sequenzierten Insert-Größe. 
A

B

C

D

E

F

G

E

(a)
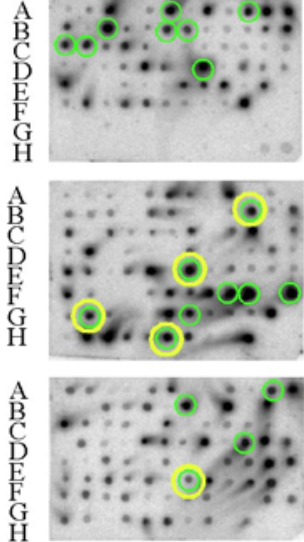

H
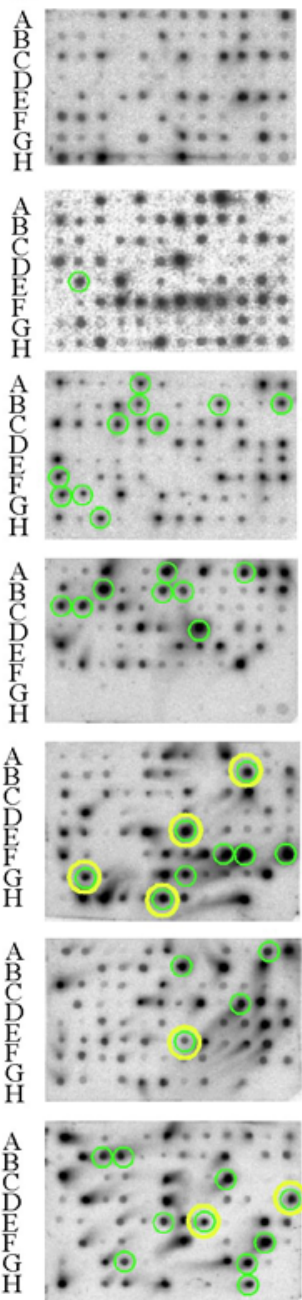

Klone der Rückwärtssubtraktion

\section{Rückwärts- Vorwärts-}

subtraktionssonde subtraktionssonde
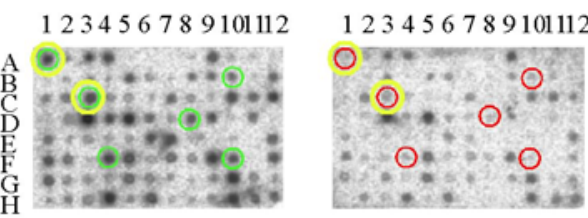

MembranA Klon A1 MAZ 315bp

Membran A Klon C3 RACK1 218bp
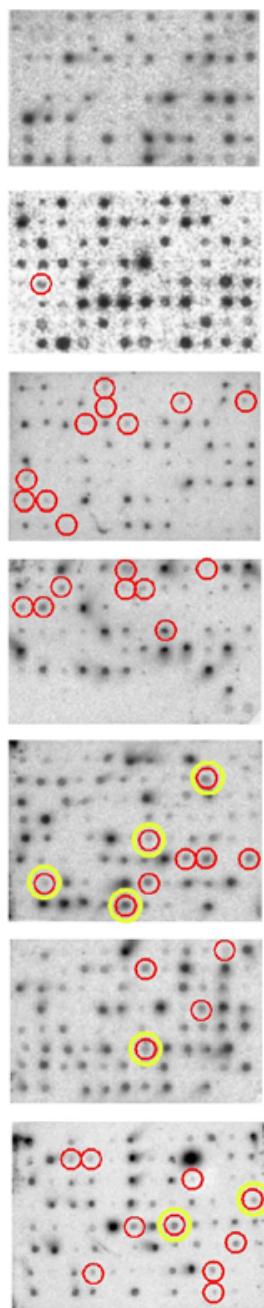

Membran F Klon B22 RACK1 321bp

Membran F Klon E7 UBE1 205

Membran F Klon G2 PIK3R3 170bp

Membran F Klon H6 GAPDH 442bp

Membran G Klon F7 BRCA1 265bp

Membran H Klon D12 MAZ 326bp

Membran H Klon E8 EEF1A 750bp

Abb. 19: Hybridisierung (A-H) der Klone aus der Rückwärtssubtraktion mit den markierten Sonden aus der Rückwärtssubtraktion (linke Spalte) und der Vorwärtssubtraktion (rechte Spalte). Potentiell differentiell exprimierte Klone zeigten ein positives Signal in der Hybridisierung mit der Sonde der Rückwärtssubtraktion und gleichzeitig ein negatives Signal in der Hybridisierung mit der Sonde der Vorwärtssubtraktion. Die durch Sequenzierung identifizierten und mit Real-TimePCR überprüften Klone sind gelb umrandet. Die Angaben hinter dem Gennamen in bp entsprechen der gefundenen und sequenzierten Insert-Größe. 
A

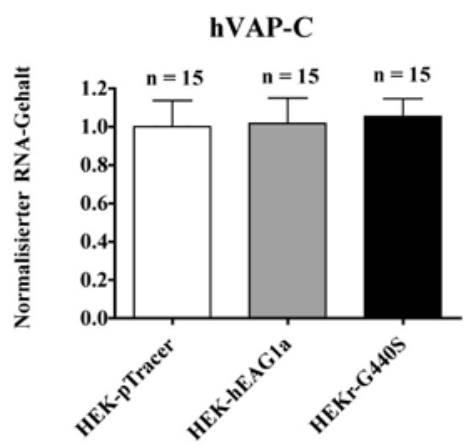

B

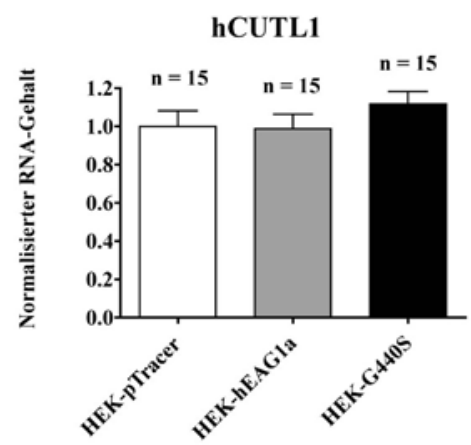

Abb. 20: Real-Time PCR der potentiell positiven Klone aus der Vorwärtssubtraktion. HVAPC (A) und hCUTL1 (B) zeigten keine differentielle Expression zwischen den untersuchten Zelllinien.

$\mathbf{A}$

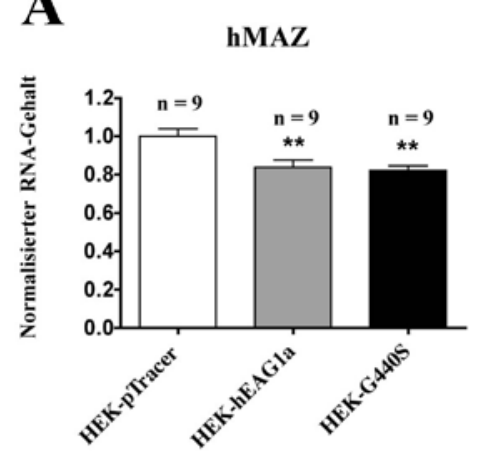

D

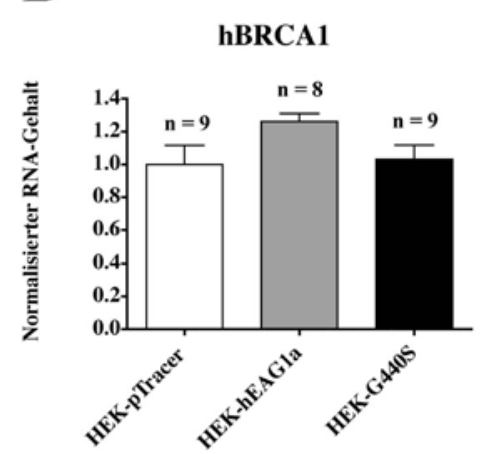

G

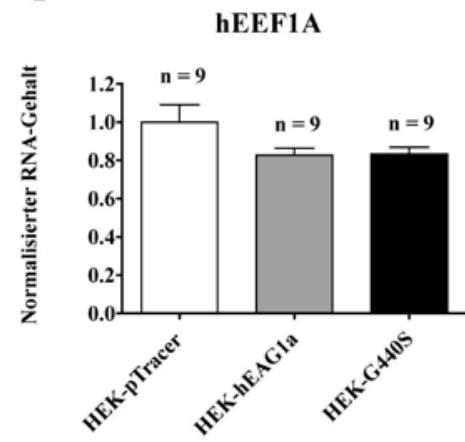

B

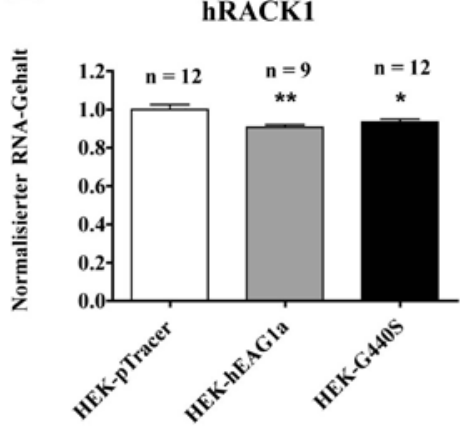

$\mathbf{E}$

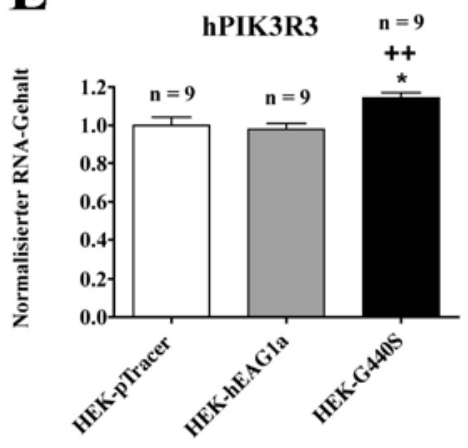

C

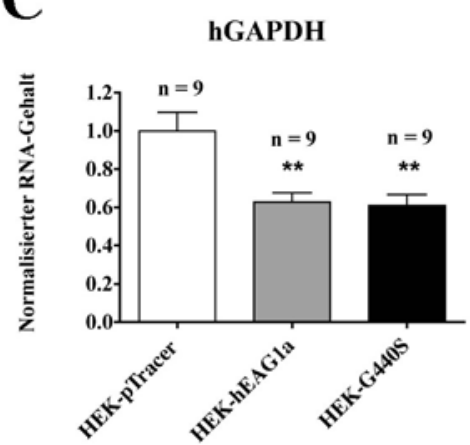

$\mathbf{F}$

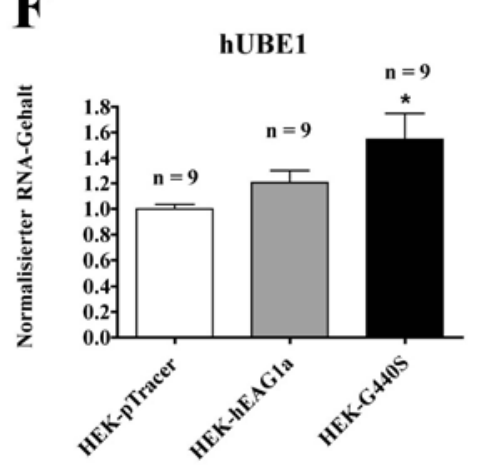

Abb. 21: Real-Time PCR der potentiell positiven Klone aus der Rückwärtssubtraktion. Die Gene hMAZ, hRACK1 und hGAPDH (A-C) waren tatsächlich zwischen den HEK-pTracer- und HEKhEAG1a-Zellen differentiell exprimiert $(*=\mathrm{p}<0.05, * *=\mathrm{p}<0.01$ zwischen HEK-pTracer und HEK-hEAG1a bzw. HEK-G440S, $++=<0.01$ zwischen HEK-hEAG1a und HEK-G440S), während 
die Gene hBRCA1, hPIK3R3, hUBE1 und hEEF1A (D-G) keine differentielle Expression zwischen diesen beiden Zelllinien zeigten.

\subsubsection{Genexpressionsstudien mit Mikroarrays}

\subsubsection{Behandlung von natürlich exprimierenden Krebszelllinien mit Astemizol verringert die Proliferation der Zellen}

Bei der Verwendung von heterologen Expressionssystemen zur Untersuchung der Genexpression besteht die Gefahr, dass in den verwendeten Zelllinien bestimmte Komponenten der Signaltransduktionswege, die in natürlich exprimierenden Zellen durch das heterolog hergestellte Protein angesteuert werden, nicht oder nur in geringem Maße vorhanden sind. Daher wurde als nächstes das Genexpressionsprofil von natürlich hEAG1exprimierenden Zellen durch Hemmung der hEAG1-Funktion (Aktivität als $\mathrm{K}^{+}$-Kanal) untersucht. Ein Problem stellte dabei anfänglich das Fehlen eines spezifischen Hemmstoffes für hEAG1 dar, da weder das trizyklische Anti-Depressivum Imipramin noch das AntiHistamin Astemizol spezifische Blocker für hEAG1 darstellen. Imipramin blockiert sowohl viele Natrium, Kalzium und Kaliumkanäle im Herz und im Gehirn als auch EGL2-Kanäle, während Astemizol der paradigmatische Inhibitor für hERG-Kanäle ist (García-Ferreiro et al., 2004). Unglücklicherweise konnte eine breite Koexpression dieser anderen Kanäle mit hEAG1 sowohl in natürlich exprimierenden Zelllinien als auch in Krebsgweben in unserem Labor festgestellt werden, die vermutlich die Ursache für die schweren therapeutische Nebenwirkungen darstellt, die in klinischen Studien mit diesen Therapeutika beobachtet wurden (Zhou et al., 1999). Daher wurde in dieser Studie mit dem Inhibitor Astemizol die Zelllinie MDA-MB-435S verwendet, die kein hERG und nur sehr wenig hEAG2 exprimiert. Verglichen wurde das Expressionsprofil der Astemizol-behandelten Zellen mit Zellen, die mit Norastemizol oder Lösungsmittel (DMSO) in der korrespondierenden Verdünnung inkubiert wurden. Der $\mathrm{IC}_{50}$-Wert für die Blockierung von hEAG1 mit Astemizol im heterologen Expressionssystem beträgt $196 \mathrm{nM}$, während mit $100 \mu \mathrm{M}$ Norastemizol nur $10 \%$ Inhibierung erreicht werden kann (García-Ferreiro et al., 2004) Die Wirkung von Norastemizol auf z.B. den Histamin Rezeptor Typ 1 bewegt sich dagegen in ähnlicher Größenordnung wie die Wirkung von Astemizol (Bachmann, 2000), sodass Unterschiede zwischen den Astemizolund Norastemizol-behandelten Zellen die Inhibierung von hEAG1 reflektieren sollten. 
Zur Auswahl einer geeigneten Zelllinie wurde die Proliferation von IPC298-, IGR-39- und MDA-MB435S-Zellen unter Astemizol- und Norastemizolbehandlung überprüft. Alle Zelllinien zeigten signifikannte Unterschiede in der Proliferation unter FCS-reduzierten Bedingungen. Nur die MDA-MB435S-Zelllinie zeigte in FCS-haltigem Medium eine signifikante Inhibierung der Proliferation durch Astemizol um $45.98 \pm 1.33 \%$ ( $<<0.001)$. Unter FCS-Mangelbedingungen konnte nach einer anfänglichen Proliferationsphase bei den MDA-MB435S-Zellen und den IPC298-Zellen eine Stagnation bzw. ein Rückgang der Proliferation beobachtet werden. Die IGR-39-Zellen zeigten unter FCS-Mangel noch Proliferation, die in den Astemizol-behandelten im Vergleich zu Norastemizol-behandelten Zellen einen um $52.43 \pm 16.35 \%$ reduzierten Wert aufwies (Abb. 22A-C).

\section{A}
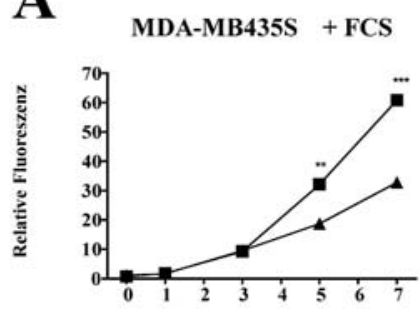

Wachstumsdauer (Tage)

B
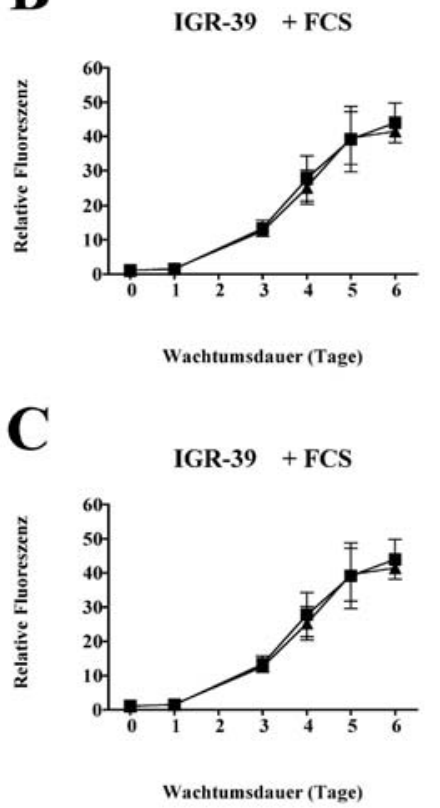

MDA-MB435S - FCS

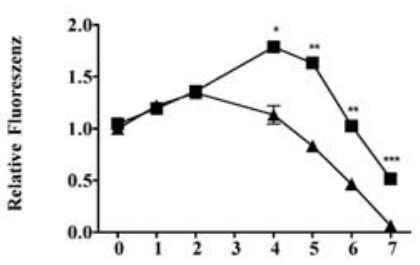

Wachstumsdauer (Tage)

IGR-39 - FCS

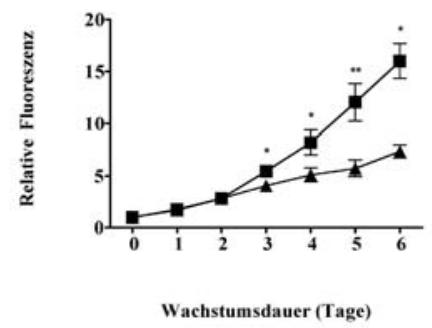

IPC -FCS

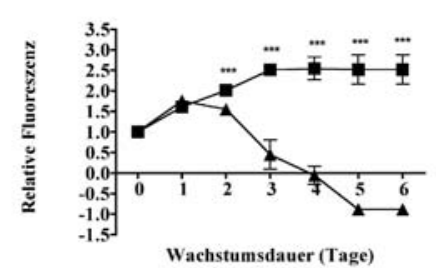

Abb. 22: Proliferation der Zelllinien MDA-MB435S (A), IGR-39 (B) und IPC298 (C) unter FCShaltigen (linke Spalte) und FCS-reduzierten Bedingunger (rechte Spalte). Die Zellen wurden mit $500 \mathrm{nM}$ Astemizol (Dreiecke) oder Norastemizol (Quadrate) behandelt. 


\subsubsection{Differentielle Genexpression in Astemizol, Norastemizol und DMSO behandelten MDA-MB435S-Zellen}

Die Mikroarrays wurden in Zusammenarbeit mit der Abteilung für die Analyse des Vertebratengenoms des Max-Planck-Instituts für molekulare Genetik in Berlin durchgeführt. Für seine Durchführung wurde die MDA-MB435S-Zelllinie ausgewählt, da diese eine signifikannte Reduktion der Proliferation auch unter FCS-haltigen Bedingungen zeigte, was die in vivo-Bedingungen im Säugetiergewebe widerspiegelt. Diese Zelllinie exprimiert nur eine geringe hEAG2-Menge und kein hERG (unpublizierte Daten unseres Labors). Die verwendeten Arrays enthielten 15657 verschiedene Gene.

Vor der Durchführung der Array-Experimente wurde die Qualität der RNA überprüft (Daten nicht gezeigt). Die erhaltenen Werte für drei Versuchswiederholungen (drei verschiedene Kultivierungen der Zellen mit den Reagenzien) wurden, wie unter Material und Methoden beschrieben, normalisiert, statistisch ausgewertet und in vier Klassen eingeteilt. Die Tabelle 4 stellt die Auflistung der am wahrscheinlichsten Kandidaten für eine differentielle Expression zwischen Astemizol-, Norastemizol- und DMSO-behandelten MDA-MB435S-Zellen dar (Tab. 4). Es wurden hauptsächlich die schon bekannten Gene weiteruntersucht, da dies in der Laborpraxis schneller und unkomplizierter möglich war (Inhibitoren und Antikörper waren kommerziell erhältlich für den Fall, dass die differentielle mRNA-Expression bestätigt wurde).

\begin{tabular}{ll}
\hline Abkürzung des Gens & Name des Gens \\
\hline Klasse 1 (A > N = D; A < N = D) & PC2 (positive cofactor 2, multiprotein complex) glutamine/Q- \\
PCQAP & rich-associated protein \\
& $?$ \\
novel_ENSMBL_AA916508 & Pleckstrin homology domain interacting protein \\
PHIP & Keratin 23 (histone deacetylase inducible) \\
KRT23 & TBC1 domain family, member 22B \\
FLJ20337; TBC1D22B & Chromosome 15 open reading frame 33 \\
FLJ32800 & Chromosome 9 open reading frame 80 (C9orf80) \\
HSPC043 & Catenin (cadherin-associated protein), alpha 1 \\
CTNNA1 & Zinc finger protein 236 \\
ZNF236 & Melanocyte 2NbHM Homo sapiens cDNA clone \\
novel_ENSMBL_N24038 & Vasodilator-stimulated phosphoprotein \\
VASP & Ets variant gene 1 \\
ETV1 &
\end{tabular}




\begin{tabular}{|c|c|}
\hline HSD17B7 & 17 $\beta$-hydroxysteroid dehydrogenase type 7 \\
\hline \multicolumn{2}{|c|}{ Klasse $2(A>D>N ; A<D<N)$} \\
\hline FLJ10901 & cDNA FLJ10901 fis, clone NT2RP5003524 \\
\hline DKFZP434N014; DFNB31 & Deafness, autosomal recessive 31 \\
\hline KIAA0367; BMCC1 & $\begin{array}{l}\text { Novel proapoptotic gene with the BNIP2 and Cdc42GAP } \\
\text { homology }(\mathrm{BCH}) \text { domain }\end{array}$ \\
\hline FLJ31795; CCDC43 & Coiled-coil domain containing 43 \\
\hline AMPD2 & Adenosine monophosphate deaminase 2 \\
\hline LOC90353 & Fetal brain $m R N A$ \\
\hline SIGLEC8 & Sialic acid binding Ig-like lectin 8 \\
\hline \multicolumn{2}{|l|}{ Klasse $3(\mathbf{A}>\mathbf{N}>\mathbf{D} ; \mathbf{A}<\mathbf{N}<\mathbf{D})$} \\
\hline NT5C & Cytosolic 5'(3')-deoxyribonucleotidase \\
\hline PPARD & Peroxisome proliferative activated receptor \\
\hline BRIP1 & BRCA1 interacting protein C-terminal helicase 1 \\
\hline MYBPC3 & Myosin binding protein $C$ \\
\hline FLJ14624, TMTC4 & Transmembrane and tetratricopeptide repeat containing 4 \\
\hline BIRC4 & Baculoviral IAP repeat-containing 4 \\
\hline WBP4 & WW domain binding protein 4 (formin binding protein 21 ) \\
\hline JAZ & Double-stranded RNA-binding zinc finger protein \\
\hline novel_ENSMBL_AA054543 & CDNA clone from pregnant uterus \\
\hline SLC27A4 & Solute carrier family 27 (fatty acid transporter), member 4 \\
\hline HOXA11 & Homeo box A11 \\
\hline CCL28 & Chemokine (C-C motif) ligand 28 \\
\hline TRC8 & Translocation in renal carcinoma on chromosome 8 \\
\hline FLJ20752; ASNSD1 & Asparagine synthetase domain containing 1 \\
\hline MGC4399; BMSC-MCP & PNC1 protein \\
\hline $\mathrm{XRCC} 4$ & $\begin{array}{l}X \text {-ray repair complementing defective repair in Chinese } \\
\text { hamster cells } 4\end{array}$ \\
\hline DKFZP434H0820 & Chromosome 9 open reading frame 88 \\
\hline APPBP1 & Amyloid beta precursor protein binding protein 1 \\
\hline LCN7 & Lipocalin 7 \\
\hline novel_ENSMBL_AA405044 & ? \\
\hline
\end{tabular}

Tab. 4: Potentiell differentiell exprimierte Gene aus dem Mikroarray: A: Astemizol, N: Norastemizol und D: DMSO. Da hEAG1-Hemmung als URsache für geänderte Genexpression nur für die Gene aus Klasse 1- 3 in Frage kommt, wurden die Gene aus der Klasse 4 nicht in dieser Tabelle aufgeführt.

Acht Gene aus der Klasse 1 (PCQAP, KRT23, FLJ20337, FLJ32800, CTNNA1, ZNF236, VASP, HSD17B7) und vier Gene aus der Klasse 2 (FLJ10901,FLJ31795, AMPD2, SIGLEC8) wurden mit Real-Time-PCR weiter untersucht, wobei SIGLEC8 so gering 
exprimiert war, dass es nicht mit PCR gemessen werden konnte. Eine signifikant differentielle Expression dieser Gene zwischen Astemizol- und Norastemizol-behandelten Zellen konnte nicht bestätigt werden (Abb. 23A-H, 24A-C).

A

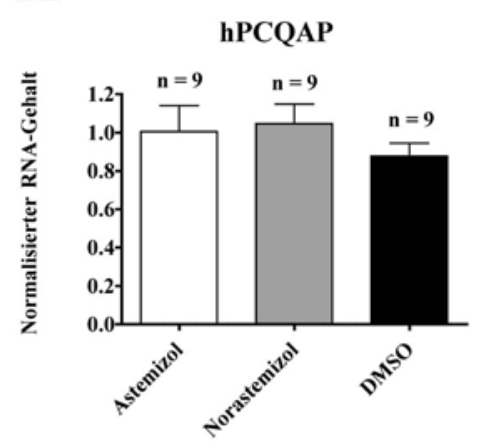

D

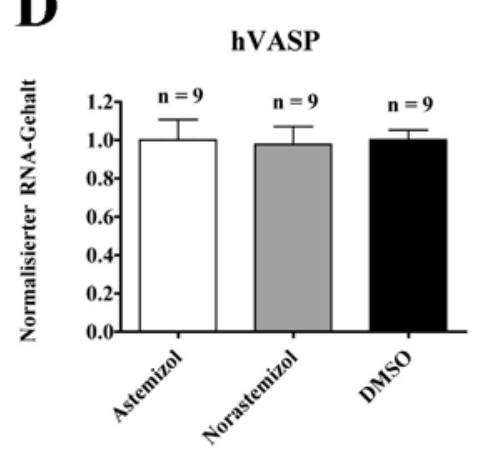

G

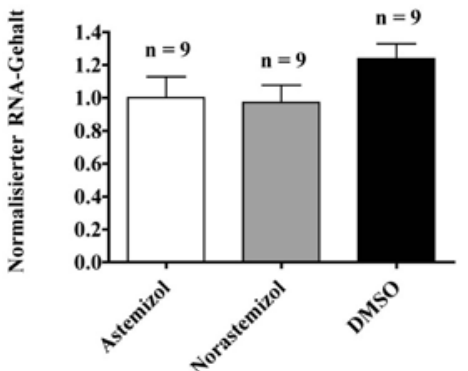

B

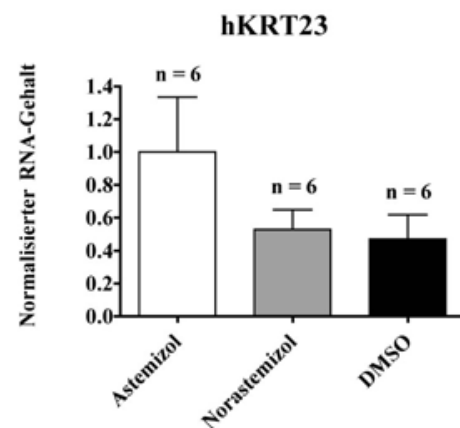

$\mathbf{E}$

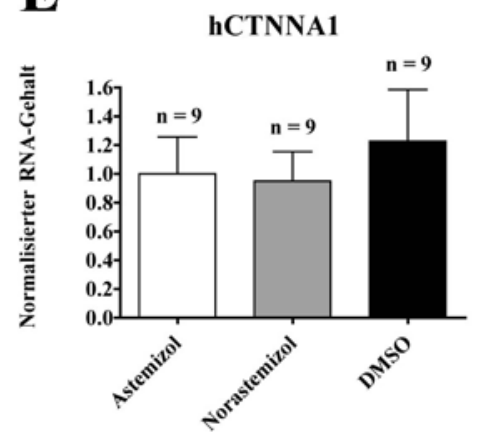

$\mathbf{H}$

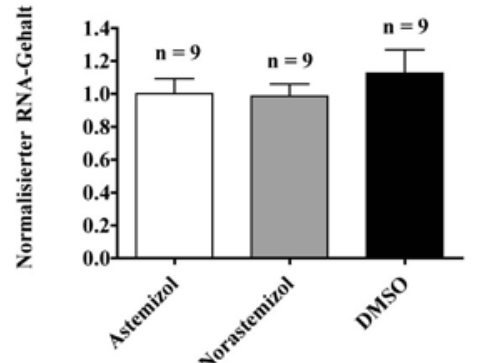

C

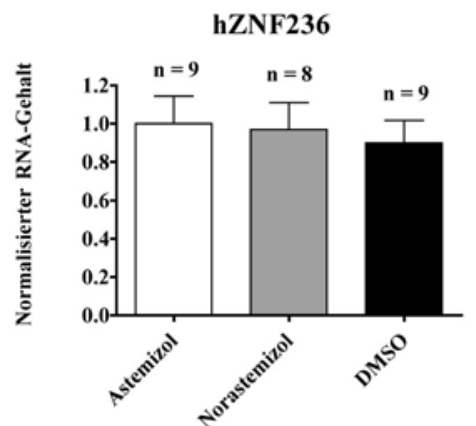

$\mathbf{F}$

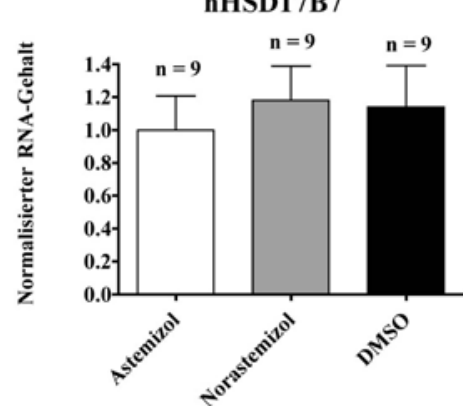

Abb. 23: Normalisierter RNA-Gehalt der Kanditatengene aus der Klasse 1. A: PCQAP, B: KRT23, C: ZNF236, D: hVASP, E: CTNNA1, F: HSD17B7, G: FLJ20337 und H: FLJ32800. 


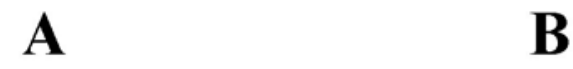

hAMPD2

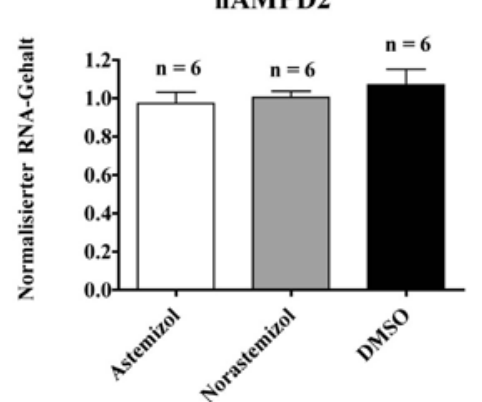

B

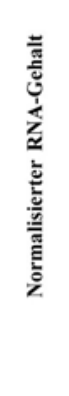

hFLJ10901

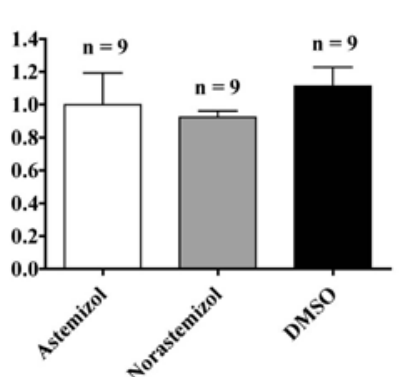

hFLJ31795

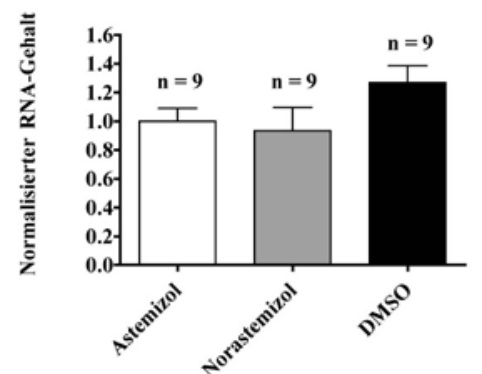

Abb. 24: Normalisierter RNA-Gehalt der Kanditatengene aus der Klasse 2. A: AMPD2, B: FLJ10901, C: FLJ31795.

\subsubsection{Expression einiger in Krebs involvierter Gene unter Astemizolbehandlung}

Krebstumore sind immer eine Folge einer Über- oder Unterexpression von Genen, die im weitesten Sinn bei der Zellproliferation eine aktivierende oder hemmende Rolle spielen. Eines dieser Gene ist z. B. GADD45a (growth arrest-and DNA damage-inducible gene GADD45 $\alpha$ ), das in der Lage ist, den Eintritt in die S-Phase zu verhindern und damit die Proliferation hemmt (Smith et al., 1994). Auch das PKA-Gen, das für die Protein Kinase A kodiert, und sprouty homolog 2 (Spry2) übernehmen hemmende Funktionen bei der Proliferationsregulation (Gross et al., 2001; Stork und Schmitt, 2002). Alle drei Gene wurden mittels Mikroarrays beim Vergleich von Rhabdomyosarkomagewebe mit entsprechendem gesunden Gewebe als differentiell exprimiert identifiziert (Kappler et al., 2003). Daher wurde die Expression dieser Gene in Astemizol-, Norastemizol- und DMSO-behandelten MDAMB435S-Zellen mit Real-Time-PCR überprüft. Es wurde keine differentielle Expression beobachtet (Abb. 25A-C).
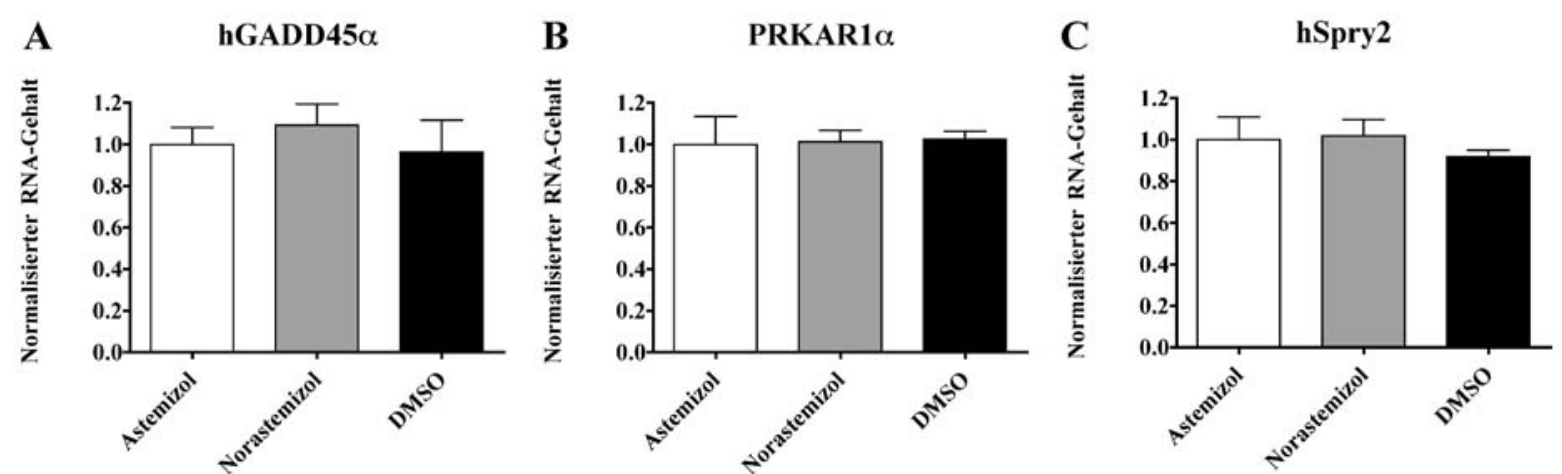

Abb. 25: Relative Expressionsmengen bekannter Krebsgene in Astemizol-, Norastemizol- und DMSO-behandelten MDA-MB435S-Zellen. A: GADD45 $\alpha$, B: PRKAR1 $\alpha$, C: Spry2. Dargestellt ist der normalisierte RNA-Gehalt für diese Gene. 


\subsubsection{Mutationen in der hEAG1-Sequenz}

Fast allen Arten von Krebs liegt eine Änderung der Sequenz eines Gens zu Grunde, dabei wird entweder ein stimulatorisches Gen (Proto-Onkogen) hyperaktiv oder ein inhibitorisches Gen (Tumorsuppressor-Gen) inaktiviert (Lynch et al., 2004; Sordella et al., 2004; Tracy et al., 2004). Teilweise werden auch verschiedene Spleißvarianten des gleichen Gens in Krebsgewebe und normalem Gewebe exprimiert (Agrawal und Eng, 2006). Bei der Charakterisierung der Beteiligung von hEAG1 an der Tumorigenese wurde bisher nur ein kleiner Teil der Sequenz aus MCF-7-Zellen überprüft (400 bp) und keine Änderung zu der Sequenz aus dem Gehirn gefunden (Pardo et al., 1999). Daher wurde in dieser Arbeit überprüft, ob in den verschiedenen in dieser Studie verwendeten Zelllinien Punktmutationen und/oder Deletionen in der EAG-Sequenz vorkamen oder Tumor-spezifische Spleißvarianten exprimiert wurden. Da es sich bei dem EAG-Kanal um ein tetrameres Protein handelt, können auch kleine Mengen an veränderten Untereinheiten, die neben der normalen Form exprimiert werden und mit dieser als Heteromere assemblieren, große physiologische Veränderungen zur Folge haben (Crociani et al., 2003).

Aus diesem Grunde wurde in dieser Arbeit zunächst eine Sequenzierung durchgeführt, indem kleine überlappende Stücke der Gesamtsequenz amplifiziert, kloniert und sequenziert wurden, und nicht, wie sonst üblich, die gesamte Sequenz amplifiziert und sequenziert. Bei der letzteren Methode würden z. B. Varianten, die einen verkürzten N- oder C-Terminus haben, nicht detektiert werden. Es wurden neun verschiedene Primerpaare (1 - 9) verwendet, die sich teilweise überlappten und 451 bp lange Fragmente amplifizierten. Im Gehirn, wo die bekannten Varianten hEAGla und hEAG1b vorkommen, konnten alle Fragmente mit den Primern detektiert werden (Abb. 26A). Ebenso zeigte die PCR mit hEAG1a-transfizierten HEK- und CHO-Zellen die erwarteten Banden, hier konnte PCR-Fragment 1 nicht amplifiziert werden, da der Vorwärtsprimer im untranslatierten Bereich bindet, der nicht im Transfektionskonstrukt enthalten war (Abb. 26C, E). Im weiteren Verlauf der Studie wurden in der PCR fünf verschiedene hEAG1-Sequenztypen ersichtlich. Die Zelllinien IGR-39 (Melanom-Zelllinie), DU-145 (Prostatakrebs-Zelllinie) und HT-1080 (Fibrosarkom-Zelllinie) exprimierten die gesamte Länge der hEAG1a-Sequenz (PCR-Fragmente 1 - 9) (Abb. 26D, I, $\mathrm{K}$ ), während in den Zelllinien MCF-7 (Brustkrebs-Zelllinie) und Hs633t (FibrosarkomZelllinie) nur die PCR-Fragmente 1 - 8 amplifiziert werden konnten (Abb. 26H, M). In den Zelllinien IPC298 (Melanom-Zelllinie) und TE671 (Rhabdomyosarkom-Zelllinie) wurden nur die Fragmente 2 - 8 (Abb. 26B, J) und in den Zelllinien MDA-MB435S (Brustkrebs-Zelllinie) 
und A204 (Rhabdomyosarkom-Zelllinie) nur die Fragmente 2 - 9 in der PCR vervielfältigt (Abb. 26F, L). In LNCaP-Zellen (Prostatakrebs-Zelllinie), konnten Fragmente 5 - 9 amplifiziert werden (Abb. 26G).
A hBrain
B $\quad$ IPC298
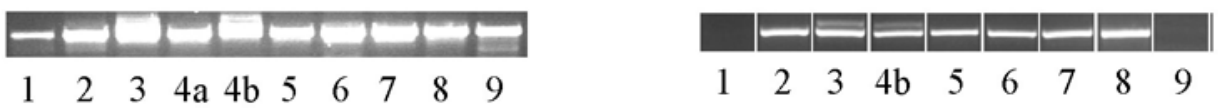
C HEK-hEAGla
D IGR-39
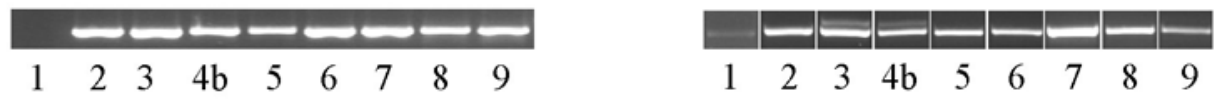
E CHO-hEAGla
F MDA-MB435S
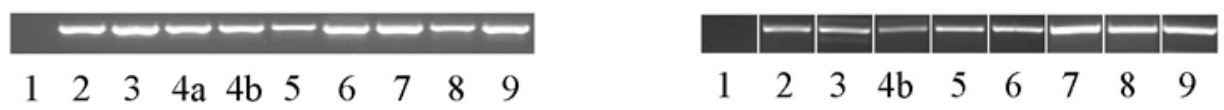
G LNCAP
H $\quad$ MCF-7
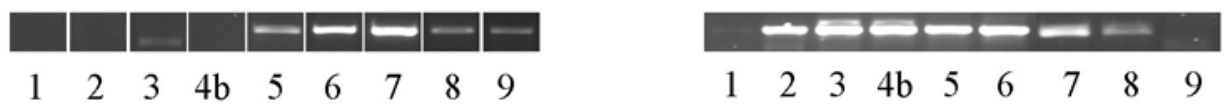
I DU-145
J TE-671
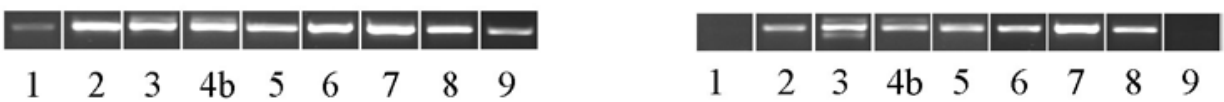
K HT1080
L A204
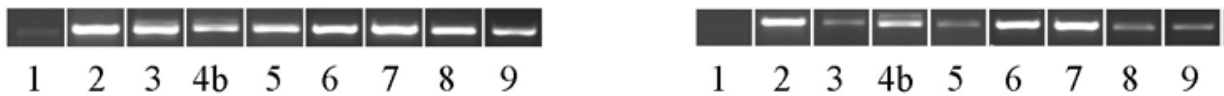

M Hs633t

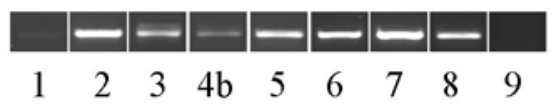

Abb. 26: PCR-Reaktionen unter Einsatz von cDNA aus: Gehirn (A), hEAG1a-transfizierten HEK(C) und CHO-Zellen (E), und den Zelllinien IPC298 (B), IGR-39 (D), MDA-MB435S (F), LNCaP (G), MCF-7 (H), DU-145 (I), TE-671 (J), HT1080 (K), A204 (L) und Hs633t (M) mit den über die Sequenz von EAG1 verteilten Primerpaaren (1-9). M: 100 bp-Leiter. Die deutlich sichtbare mittlere Markerbande entspricht einer Größe von 600 bp. Die hEAG1a-spezifischen Banden sind 451 bp groß.

Diese Beobachtungen deuten darauf hin, dass in den Zelllinien verschiedene Teile der hEAG1-Sequenz entweder fehlen oder Mutationen enthalten, die die Primerbindung verhinderten. Daher wurden die PCR-Fragmente 1 - 9 von 3 der Zelllinien, sofern vorhanden, kloniert und sequenziert. Bei Verwendung der Primer $4 \mathrm{~b}$ wurde die kleinere Bande, die hEAG1a entsprach, kloniert. Dabei stellte sich heraus, dass die Sequenz aus der IGR-39 
Zelllinie die stillen Mutationen T1187G und T2225C (SNP single nucleotide polymorphism) enthielt, während die MDA-MB435S-Zelllinie neben der normalen Sequenz noch eine Variante besaß, die eine Deletion von 32 Nukleotiden ( $\Delta 1043-1074)$ hatte und daher ein verkürztes Protein (Aminosäuren 1-295), dessen letzte drei Aminosäuren nicht KTW sondern FAI lauteten, herstellte.
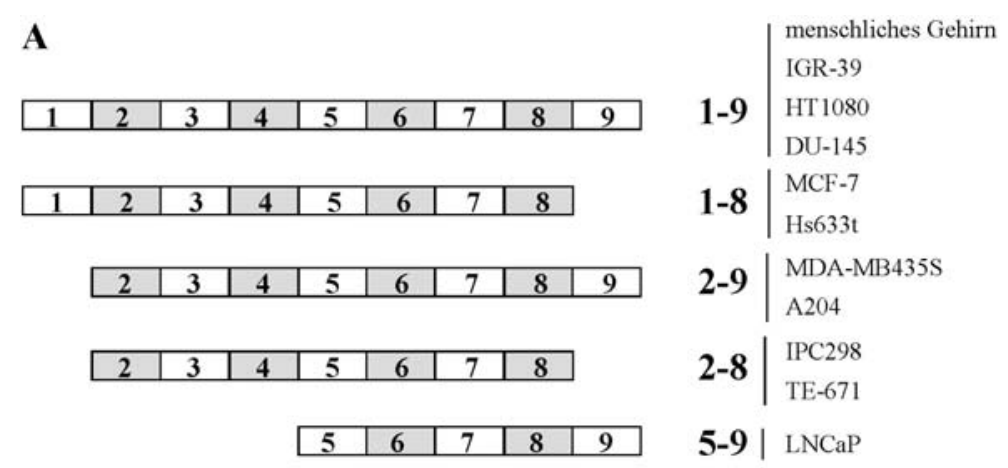

B

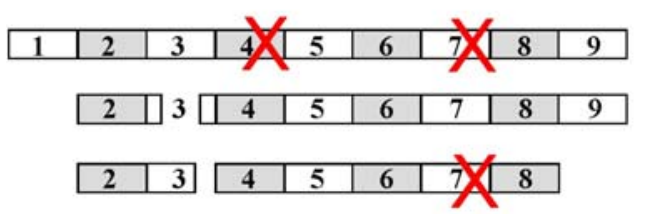

1-9 IGR-39

2-9 MDA-MB435S

2-8 IPC298

Abb. 27: Schematische Darstellung der verschiedenen hypothetischen hEAG1-Sequenztypen. A: 1-9: Fragmente, die mit PCR amplifiziert wurden. B: Die amplifizierten Fragmente mit den Deletionen und Punktmutationen. (Rotes Kreuze, SNPs: Single nucleotide polymorphisms).

Die IPC298-Zelllinie beinhaltete zwei Varianten, zum einen die normale Sequenz mit einer stillen Punktmutation (T2225C) zum anderen eine Deletion (A1201-1216) zusammen mit der stillen Punktmutation (T2225C) und stellte vermutlich ein verkürztes Protein her, das von Aminosäure 1-343 der normalen Sequenz entsprach und der 46 (AA344-389; LLCWSCWCVCLGWLHTGWPASGTALGTMRSLTRTPRQSATTAGCTN) Aminosäuren mit anderer Sequenz folgten (Abb. 27).

\subsubsection{HEK-hEAG1a- und hG440S-Zellen zeigen einen veränderten Phänotyp}

Es konnte beobachtet werden, dass die HEK-hEAG1a- und HEK-hG440S-Zellen weniger ausgebreitet wuchsen und eher eine kompaktere Form als die pTracer- und Wildtypzellen einnahmen (Abb. 12A-B). Das deutet auf ein verändertes Anhaftungs- und Ausbreitungsverhalten hin. Daher wurde die Anhaftung näher untersucht, und es konnte in Anhaftungsassays auf Plastik beobachtet werden, dass die Wildtypzellen $2.5 \pm 0.6$ mal und 
die pTracer-tranfizierten Zellen $2.8 \pm 0.03$ mal so stark wie die kanalhaltigen Zellen auf Plastik hafteten (Abb. 28A) Diese Unterschiede waren hochsignifikant.

\subsubsection{HEK-hEAG1a- und HEK-hG440S-Zellen weisen ein geringeres Haftungsvermögen auf verschiedenen extrazellulären Matrixproteinen auf}

Im Verlaufe der Metastasierung von Krebstumoren und der Einwanderung der Zellen in Blutoder Lymphgefäße müssen sie sich von der Basalmembran lösen, diese und anderes Bindegewebe durchdringen und auf der anderen Seite wieder ablösen. Die Basalmembran und das Bindegewebe sind aus extrazellulären Matrixproteinen aufgebaut. In der Basalmembran findet man unter anderem KollagenIVund Laminin, während in Bindegewebe Fibronektin verbreitet ist und dort zelladhäsive Funktion ausübt. Gelatine ist denaturiertes Kollagen. PolyL-Lysin und Protamin sind kationische Peptide, die Integrin-unabhängige Anhaftung vermitteln (El-Aneed, 2004). Die kanalhaltigen Zellen zeigten auf allen Beschichtungsproteinen signifikant verminderte Haftung.

A

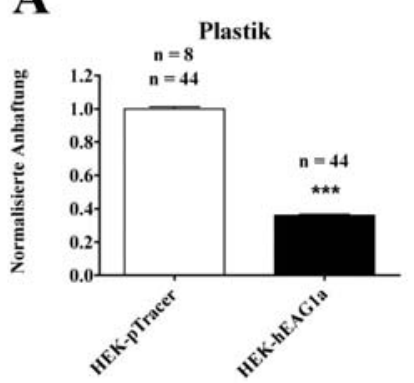

D

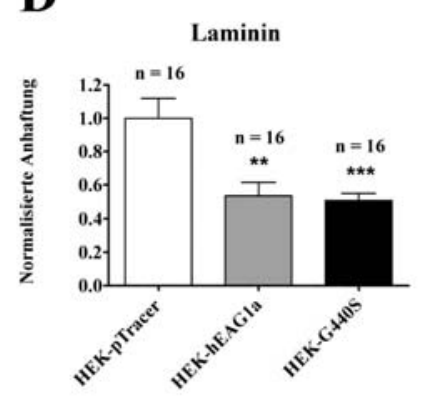

G

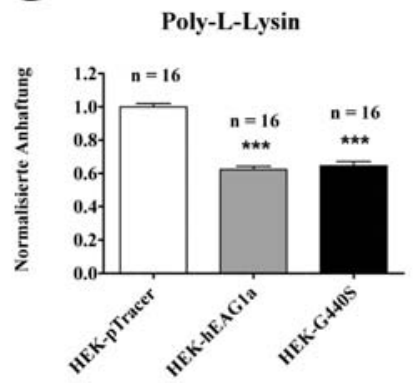

B

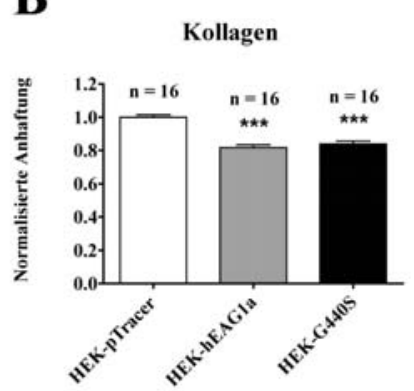

E

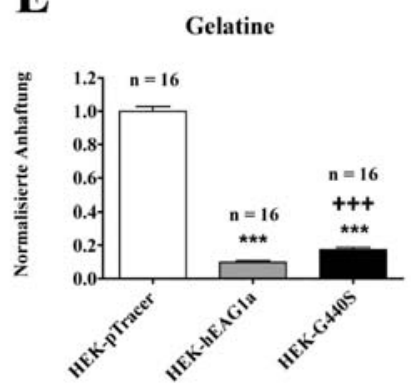

C

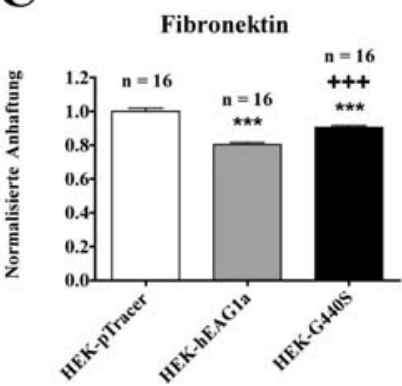

F

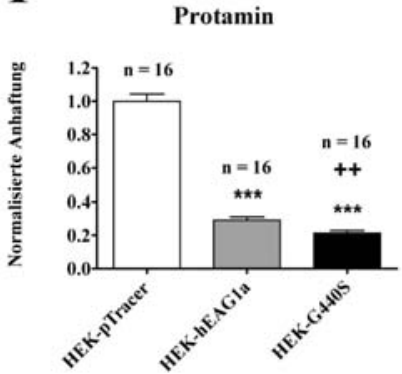


Abb. 28: Anhaftung der hEAG1a- bzw. G440S-transfizierten und untransfizierten HEK-Zellen auf Plastik und verschiedenen Extrazellulärer Matrix-Proteinen. A und B: Plastik, C: Kollagen IV, D: Fibronektin, E: Laminin, F: Gelatine, G: Protamin und H: Poly-L-Lysin $(* *=p<0.01, * * *=p$ $<0.001$ zwischen HEK-pTracer und HEK-hEAG1a bzw. HEK-G440S, $++\mathrm{p}=<0.01,+++=\mathrm{p}<$ 0.001 zwischen HEK-hEAG1a und HEK-G440S).

Die Anhaftung von HEK-hEAG1a- und hG440S-Zellen auf Kollagen war im Vergleich zu HEK-pTracer-Zellen um 18.3 $\pm 2.4 \%$ bzw. 16.0 $\pm 2.3 \%$ reduziert (Abb. 28B), während die Anhaftung an seinem Denaturierungsprodukt Gelatine mit $90.2 \pm 3.1 \%$ bzw. $82.6 \pm 3.2 \%$ noch wesentlich stärker vermindert war (Abb.28E). Auf Laminin hafteten die HEK-hEAG1aund hG440S-Zellen um $46.7 \pm 14.5 \%$ bzw. $49.4 \pm 12.7 \%$ weniger an (Abb. 28D), auf Fibronektin um $19.6 \pm 2.5 \%$ bzw. $9.5 \pm 2.4 \%$ (Abb. 28C). Die Bindung an die bisher genannten Proteine erfolgte vermutlich über die Integrine der Zellen, während die Anhaftung an die kationischen Peptide Poly-L-Lysin und Protamin unspezifisch durch ionische Wechselwirkungen bewirkt wurde. Auch auf Poly-L-Lysin war eine Reduktion um $37.7 \pm 2.8$ \% bzw. $35.5 \pm 3.4 \%$ (Abb. 28G) und auf Protamin um $70.9 \pm 4.9 \%$ bzw. $78.7 \pm 4.7 \%$ zu beobachten (Abb. 28F).

\subsubsection{Die Integrin $\beta 1$-Untereinheit ist in den kanalhaltigen Zellen nicht differentiell exprimiert}

Die spezifische Bindung der Zellen an extrazelluläre Matrixproteine wird von heterodimeren Oberflächenrezeptoren, den Integrinen, vermittelt, die aus einer $\alpha$ - und einer $\beta$-Untereinheit bestehen, wobei die letzte die Verbindung zum Zytoskelett herstellt. Die $\beta 1$-Untereinheit ist diejenige $\beta$-Untereinheit, die in Kollagen IV-, Lamin- und Fibronektin-bindenden Integrinen die Anhaftung vermittelt und die in den meisten anderen Integrinen vorkommt (Brancaccio et al., 2006). Daher wurde die mRNA-Herstellung für Integrin $\beta 1$ untransfizierten und hEAG1atransfizierten HEK-Zellen überprüft, jedoch kein Unterschied zwischen den Zelllinien gefunden (Abb. 29). 


\section{Integrin $\beta 1$}

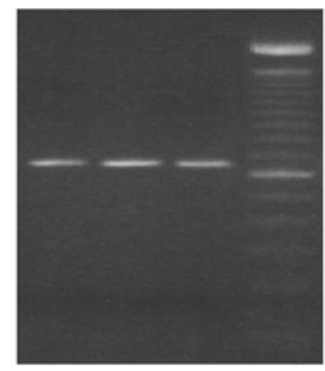

\section{$\begin{array}{llll}1 & 2 & 3 & M\end{array}$}

Abb. 29: Integrinß1-PCR von cDNA aus HEK-pTracer (1), HEK-hEAG1a (2) und HEK-G440S (3).

\subsubsection{Differentielle Expression von Fibronektin}

Da die Zellen auch selber zu der verfügbaren Menge an ECM-Proteinen durch Sekretion beitragen können, wurde mit PCR und Real-Time-PCR überprüft, ob die Zellen unterschiedlich viel Kollagen IV oder Fibronektin exprimieren. Eine Änderung der mRNAMenge für Kollagen IV konnte nicht beobachet werden (Abb. 30A), die Fibronektin-RNAProduktion jedoch war signifikant um $45.5 \pm 9.0 \%$ erhöht bzw. um $27.5 \pm 6.7 \%$ verringert (Abb. 30B). An dieser Stelle bleibt natürlich unklar, ob es auf Protein- und/oder Aktivitätsebene geschieht.

A

KollagenIV $\alpha 1$

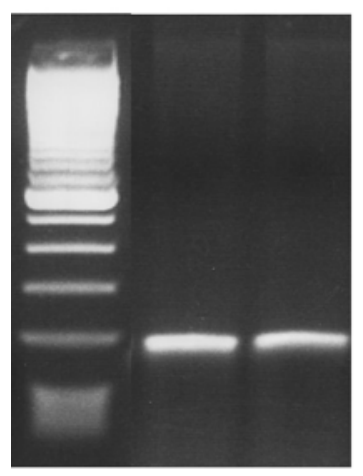

M 12
B

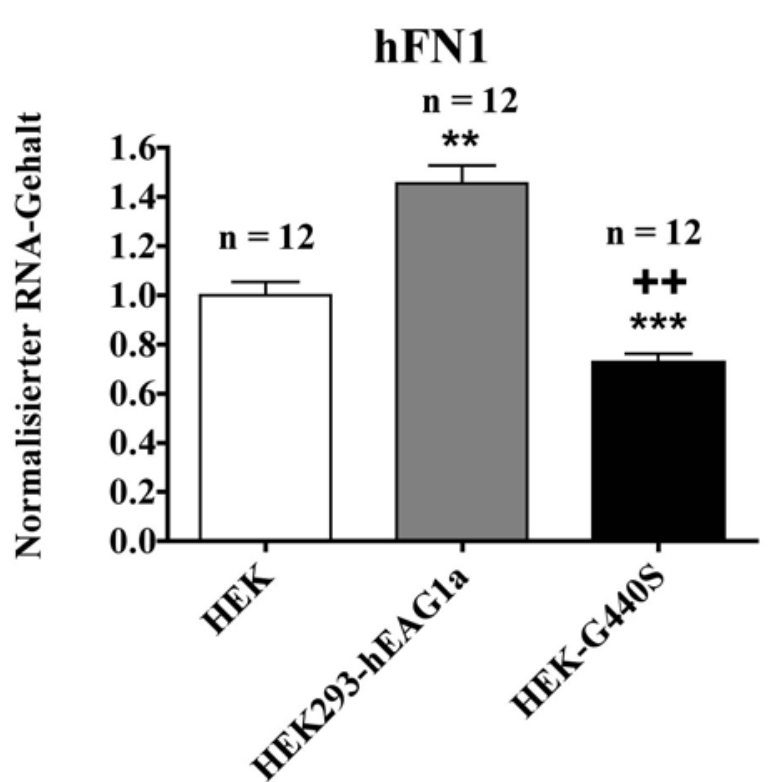

Abb. 30: Expression von ECM-Proteinen. A: KollagenIV $\alpha 1-P C R$ von cDNA aus untransfizierten (1) und hEAG1a-transfizierten HEK-Zellen (2). B: Real-Time-PCR mit Fibronektin-spezifischen Primern mit cDNA aus HEK-pTracer, HEK-hEAG1a und HEK-G440S. 


\subsubsection{4 hEAG1a-haltige HEK-Zellen produzieren weniger MMP2-RNA und scheiden weniger MMP2-Protein aus}

Eine weitere Klasse von Proteinen ist an der Metastasierung beteiligt, die Proteasen. Insbesondere die Matrixmetalloproteinasen sind eingehend auf ihre Beteiligung an der Progression von Krebserkrankungen untersucht worden (Mook et al., 2004). Sie sorgen dafür, dass die entarteten Zellen die Basalmembran durchdringen können, indem sie bestimmte extrazelluläre Matrix-Proteine abbauen. MMP-2 und MMP-9 spalten Kollagen IV und sein Abbauprodukt Gelatine und werden daher Gelatinasen genannt (Folgueras et al., 2004; Overall und Kleifeld, 2006). Ihre Funktion wird sowohl auf transkriptioneller als auch auf posttranslationeller Ebene durch Sekretion und Aktivitätsmodulation reguliert (Folgueras et al., 2004; Overall und Kleifeld, 2006).

Die Real-Time-PCR zeigte, dass HEK-hEAG1a- und HEK-G440S-Zellen um $72.2 \pm 20.6 \%$ bzw. $76.8 \pm 23.8 \%$ weniger hMMP-2-RNA als Wildtypzellen besaßen, während die hMMP9-RNA-Menge sehr gering und nicht signifikant unterschiedlich war (Abb. 31A, B). Mittels eines MMP-2-Aktivitätsassays wurde überprüft, ob die Regulation auf der Aktivitätsebene geschah. Es wurde beobachtet, dass die endogene Proteaseaktivität der kanalhaltigen Zellen sehr gering und im Vergleich zu den Wildtypzellen nicht verändert war. Nach künstlicher Aktivierung durch p-Aminophenylmercuric acetate (APMA) konnte ein signifikanter Unterschied festgestellt werden, die Aktivität der hEAG1a-haltigen HEK-Zellen war um 60.6 $\pm 25.6 \%$ reduziert (Abb. 31C). Dieser Befund wurde weiterhin mit Zymographie verifiziert, bei der die ausgeschiedenen Proteasen im Laufe der Auftrennung in einer SDSPolyacrylamid-Gelelektrophorese in einem mit Gelatine kopolymerisierten Gel künstlich aktiviert wurden (Daten nicht gezeigt). Aus den oben genannten Beobachtungen kann man schließen, dass möglicherweise ein weiterer Stimulus, der in vitro nicht vorhanden war, nötig ist, um die differentielle Expression von hMMP2 in differentielle Proteaseaktivität umzuwandeln. 
A

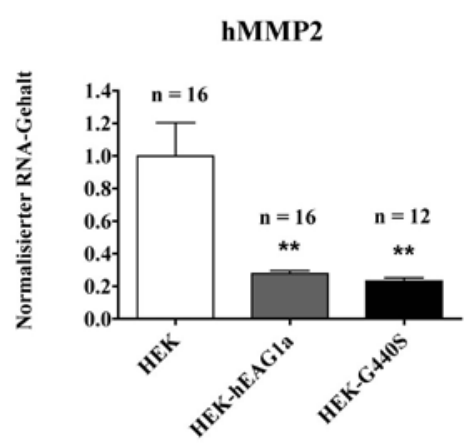

C

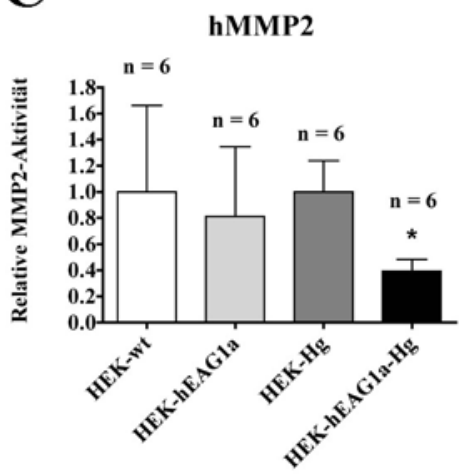

B

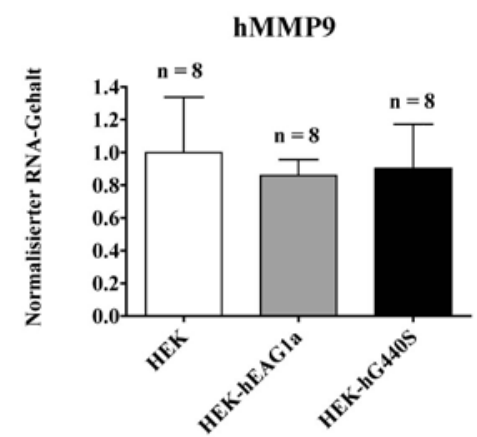

Abb. 31: MMP2 und MMP9-RNA und Enzymgehalt der untransfizierten und hEAG1atransfizierten HEK-Zellen. A: Normalisierter hMMP2-RNA-Gehalt, B: Normalisierter hMMP9RNA-Gehalt, C: Relative hMMP2-Aktivität.

\subsection{RNA-Interferenz (RNAi)}

Bis zu dieser Arbeit gab es keinen spezifischen Inhibitor für hEAG1, da weder das trizyklische Anti-Depressivum Imipramin noch das Anti-Histamin Astemizol spezifische Blocker für hEAG1 darstellen. Daher wurde in dieser Studie nach anderen Möglichkeiten gesucht, hEAG1 zu hemmen. Mit der RNA-Interferenz wurde eine neue, hochspezifische und effektive Methode gefunden, die die Expression von hEAG1 unterbindet und die sich insbesondere für die Charakterisierung von hEAG1 in vitro als sehr geeignet erwies.

\subsubsection{Spezifische siRNAs reduzieren hEAG1 mRNA-Mengen}

Es wurden drei Zelllinien ausgesucht, um die Auswirkungen der Stilllegung des menschlichen EAG1-Kanals mittels siRNAs zu beobachten. hEAG1a-transfizierte HEK-Zellen (HEKhEAG1a-Monoklon-Zellen) wurden als heterologes Expressionsystem ausgewählt, während 
zwei weitere Zelllinien mit endogener hEAG1-Expression als Modelle für die "normale" (Daoy-Zellen aus Gehirn isoliert) oder ektopische Expression (MDA-MB435S aus Brustkrebs isoliert) des Kanals dienten.

Als Positivkontrolle für die Transfektionseffizienz wurde gegen die menschliche Glyzerinaldehyd-3-Phosphat-Dehydrogenase (hGAPDH) gerichtete siRNA verwendet. Da es sich bei der GAPDH um ein Schlüsselenzym der Glykolyse handelt, sollte sich eine Verminderung des Proteins als eine Reduktion in der metabolischen Aktivität der siRNAtransfizierten Zellen offenbaren. Wie erwartet reduzierte hGAPDH-siRNA-Behandlung die Mengen an hGAPDH-RNA in allen drei Zelllinien (Abb. 32A-C), die metabolische Aktivität sofort und das Wachstum der Zellen einige Tage nach der Transfektion (Abb. 32D).
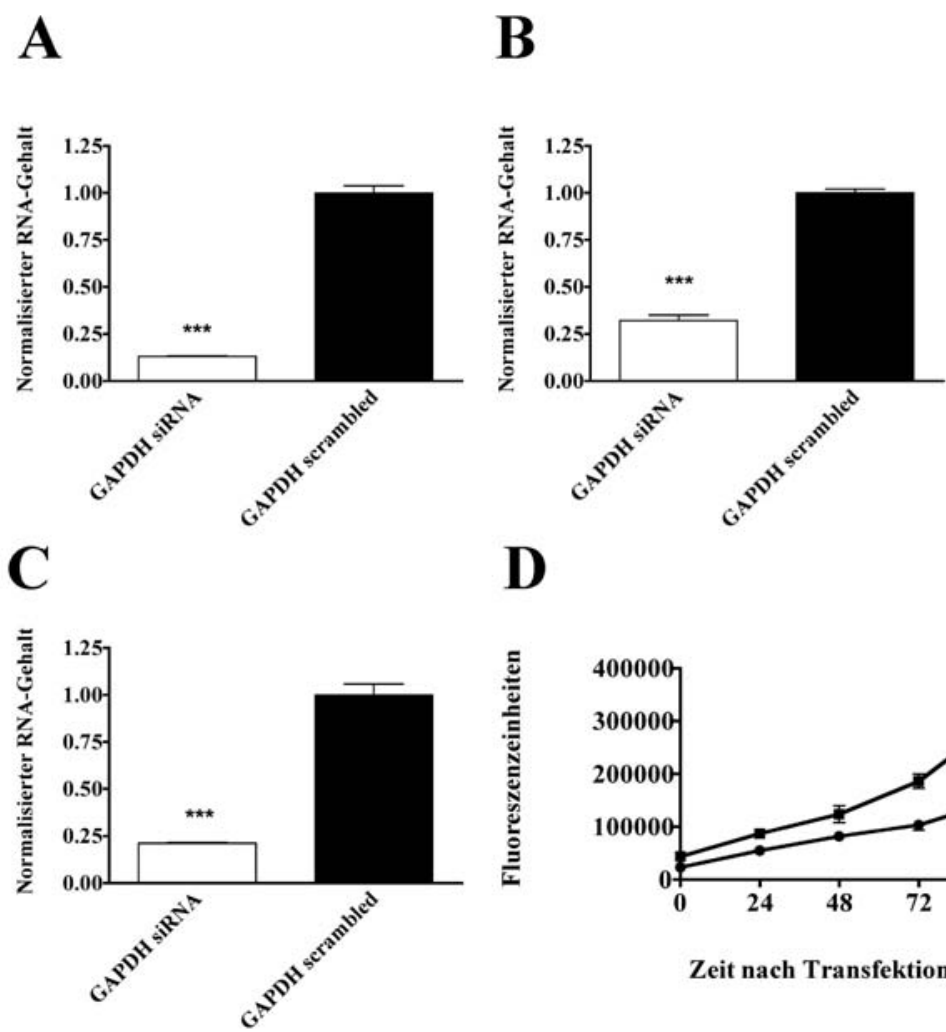

Abb. 32: Effektive siRNA-Transfektion in drei Modelzelllinien. Reduktion der hGAPDH-mRNA durch Behandlung der hEAG1a-transfizierten HEK-Zellen (A), der MDA-MB435S-Zellen (B) und der Daoy-Zellen (C) mit hGAPDH-siRNA (Weiße Säulen) im Vergleich mit der siRNA-Negativkontrolle 1 (Negative Control \# 1) (Schwarze Säulen). ${ }^{* * *}=\mathrm{p}<0.001$. D: Metabolische Aktivität der DaoyZellen nach der Behandlung mit GAPDH-siRNA (Kreise) und der Negativkontrolle (Negative Control \#1 ) (Quadrate).

Die Verwendung von mehreren funktionalen siRNAs erlaubt die unabhängige Bestätigung der phänotypischen Effekte (Huppi et al., 2005). Die Hemmung mit mehreren verschiedenen siRNAs, die gegen das gleiche Gen gerichtet sind, ist nötig, da die siRNAs oft unterschiedlich effektiv sind. Dieses Verhalten ist bedingt durch die unterschiedlichen thermodynamischen 
Eigenschaften, Stabilitäten und Positionierung sowohl der siRNAs selber als auch der Zielsequenz auf dem Gen (Eckstein, 2005). Daher wurden in dieser Arbeit vier verschiedene gegen hEAG1 gerichtete siRNAs getestet, die als Kv10.1-1 - Kv10.1-4 bezeichnet wurden, um sie von dem Kanal zu unterscheiden. Diese siRNAs erkennen bestimmte Zielsequenzen auf der hEAG1-mRNA und unterschieden sich in ihrer Effizienz der Genstilllegung in sowohl hEAG1a-transfizierten HEK-Zellen als auch in den endogen exprimierenden Zellen (Abb. $33 \mathrm{~A}-\mathrm{C})$.

A

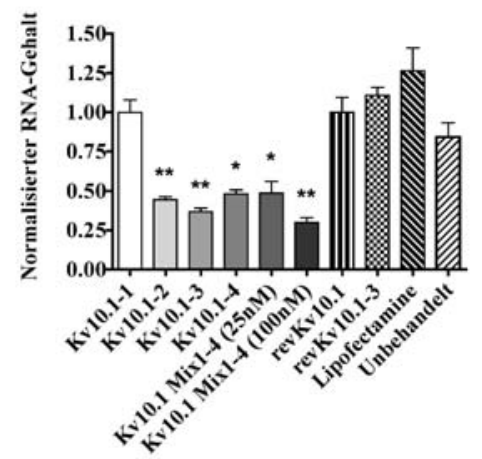

\section{B}

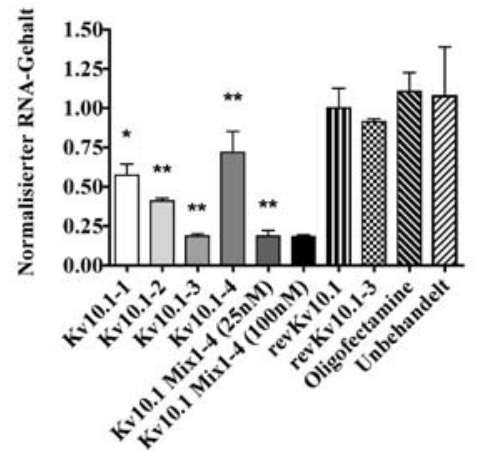

C

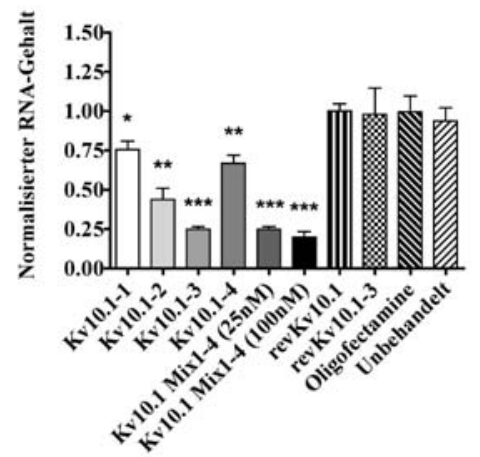

Abb. 33: Reduktion der hEAG1a-RNA-Menge durch siRNA. Dargestellt ist der normalisierte hEAG1a-RNA-Gehalt in Zellen, die mit $25 \mathrm{nM}$ der vier verschiedenen siRNAs (Kv10.1-1 Kv10.1-4), einer Mischung aus je 6.25 nM Kv10.1-1 - Kv10.1-4 (25 nM), einer Mischung aus je 25 nM Kv10.1-1 - Kv10.1-4 (100 nM), 25 nM revKv10.1, 25 nM revKv10.1-3, Oligofectamine bzw. Lipofectamine behandelt wurden oder unbehandelt waren. A: hEAG1a-transfizierte HEKZellen, B: MDA-MB435S-Zellen und C: Daoy-Zellen $(*=\mathrm{p}<0.05, * *=\mathrm{p}<0.01, * * *=p<0.001)$. In der Analyse wurden in allen Proben drei biologische Replikate zusammengefaßt, mit Ausnahme der Proben revKv10.1 Mix 1-4 in B und revKv10.1 Mix 1-4 in C.

Kv10.1-1 war nicht in der Lage, die Mengen von hEAG1a-RNA in den EAG1-transfizierten HEK-Zellen signifikant zu reduzieren (Abb. 33A), während in den natürlich exprimierenden Zellen alle vier siRNA-Spezies die Mengen an hEAG1a-mRNA verringern konnten (Abb. 33B, C). In allen Zelllinien stellte sich Kv10.1-3 als die effektivste siRNA heraus, da sie den hEAG1a-RNA-Gehalt um $63.2 \pm 9.7 \%$ (HEK-hEAG1a-Zellen, Abb. 33A), $81.3 \pm 12.7 \%$ (MDA-MB435S-Zellen, Abb. 33B) und 75.1 $\pm 4.9 \%$ (Daoy-Zellen, Abb. 33C) vermindern konnte. 


\subsubsection{Die Reduktion von hEAG1a durch EAG-siRNAs ist spezifisch}

Nebeneffekte und unspezifische Effekte sind die Hauptprobleme bei der Interpretation der durch siRNA induzierten Phänotypen. Um dieses Problem zu umgehen, wurden in dieser Arbeit mehrere unabhängige Lösungsansätze verwendet. Erstens wurde die minimale effektive Konzentration jeder EAG1-siRNA bestimmt und nachfolgend konsequent für alle Experimente verwendet. Außerdem wurden sowohl kommerzielle nonsense siRNAs (Negative Control \#1) eingesetzt, die erwiesenermaßen keinen erkennbaren Phänotyp induzieren, wie auch zwei speziell für diese Arbeit entworfene Negativkontrollen. Diese Negativkontrollen bestanden jeweils aus den umgekehrten, aber nicht komplementären Sequenzen der entsprechenden aktiven Ziel-siRNAs, die gegen zwei verschiedene Regionen in der hEAG1-Sequenz gerichtet waren. So wurde erreicht, dass die Negativkontrollen nicht nur die gleichen Nukleotide, sondern auch die gleiche Abfolge der Nukleotide wie die gegen hEAG1-gerichteten siRNAs enthielten. Keine dieser Kontroll-siRNAs bewirkte signifikante Änderungen in den gemessenen Parametern in allen Experimenten (Abb. 32A-C, 33A-C, 35A-C). Außerdem konnte mit siRNAs, die gegen den nahen Verwandten hEAG2 gerichtet waren, keine Reduktion der hEAG1a-mRNA-Menge bewirkt werden und umgekehrt änderte hEAG1-siRNA nicht den Gehalt an hEAG2-mRNA, was zeigt, dass es sich hierbei um einen hochspezifischen Effekt auf die entsprechende Zielsequenz handelt. (Abb. 34A, B).

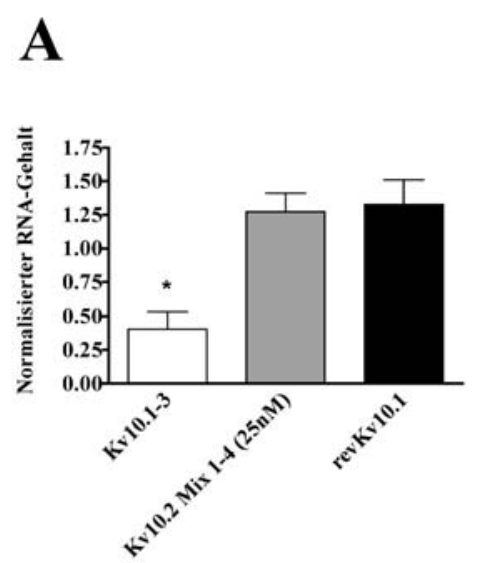

B

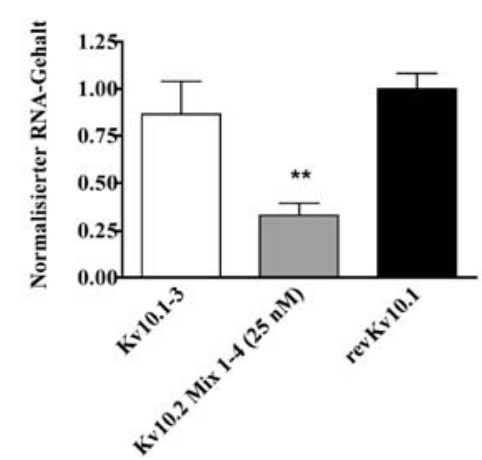

Abb. 34: EAG1-siRNA beeinflußt nicht die hEAG2-RNA-Menge und umgekehrt. A: Normalisierter hEAG1a-RNA-Gehalt von Zellen behandelt mit Kv10.1-3 (weiße Säulen), ein Gemisch aus 6.25 nM Kv10.2-1 - Kv10.2-4 (25 nM) (graue Säulen) und revKv10.1 (schwarze Säulen). B: Normalisierter hEAG2-RNA-Gehalt von Zellen behandelt mit Kv10.1-3 (weiße Säulen), ein Gemisch aus 6.25 nM Kv10.2-1 - Kv10.2-4 (25 nM) (graue Säulen) und revKv10.1 (schwarze Säulen). Die Daten stammen aus einer RNA-Isolation, die Real-Time-PCR wurde in Triplikaten durchgeführt $*^{*}=$ $\mathrm{p}<0.05, * *=\mathrm{p}<0.01)$ 


\subsection{3 hEAG1-siRNAs lösen keine unspezifischen Antworten der Zelle aus}

Die Interferonantwort stellt eine Verteidigung gegen virale RNA während einer Infektion dar und bewirkt in Immun-(Sledz und Williams, 2004) und Nichtimmunzellen (Benveniste, 1992; Persengiev et al., 2004) eine globale nicht-spezifische Unterdrückung der Genexpression.

Während synthetische siRNA-Duplices die Interferonantwort nicht auszulösen vermögen (Elbashir et al., 2001; Minks et al., 1979), können jedoch durch siRNA-Behandlung Gene induziert werden, die keine Rolle in der Interferonantwort spielen, wie zum Beispiel das Pyruvatedehydrogenasekinase Isoenzym 1 (PDK1) (Persengiev et al., 2004). PDK1 ist Bestandteil des mitochondrialen Pyruvatdehydrogenase-Multienzymkomplexes, der die oxidative Dekarboxylierung von Pyruvat katalysiert und den für die Homöostase des Kohlenhydratstoffwechsels in Säugetieren wichtigsten Enzymkomplex darstellt (Gudi et al., 1995). Es ist zu beachten, dass es sich bei der in dieser Arbeit verwendeten hPDK1 nicht um die 3-Phosphoinositid-abhängige Proteinkinase 1 handelt, die genauso abgekürzt wird. Keine der spezifischen siRNAs, die in dieser Arbeit benutzt wurden, induzierte Veränderungen in der Expression von hPDK1. Daraus kann man schließen, dass die beobachteten phänotypischen Effekte nicht auf unspezifische, durch doppelsträngige RNA hervorgerufene Antworten zurückzuführen sind (Abb. 35A-C, 36B).
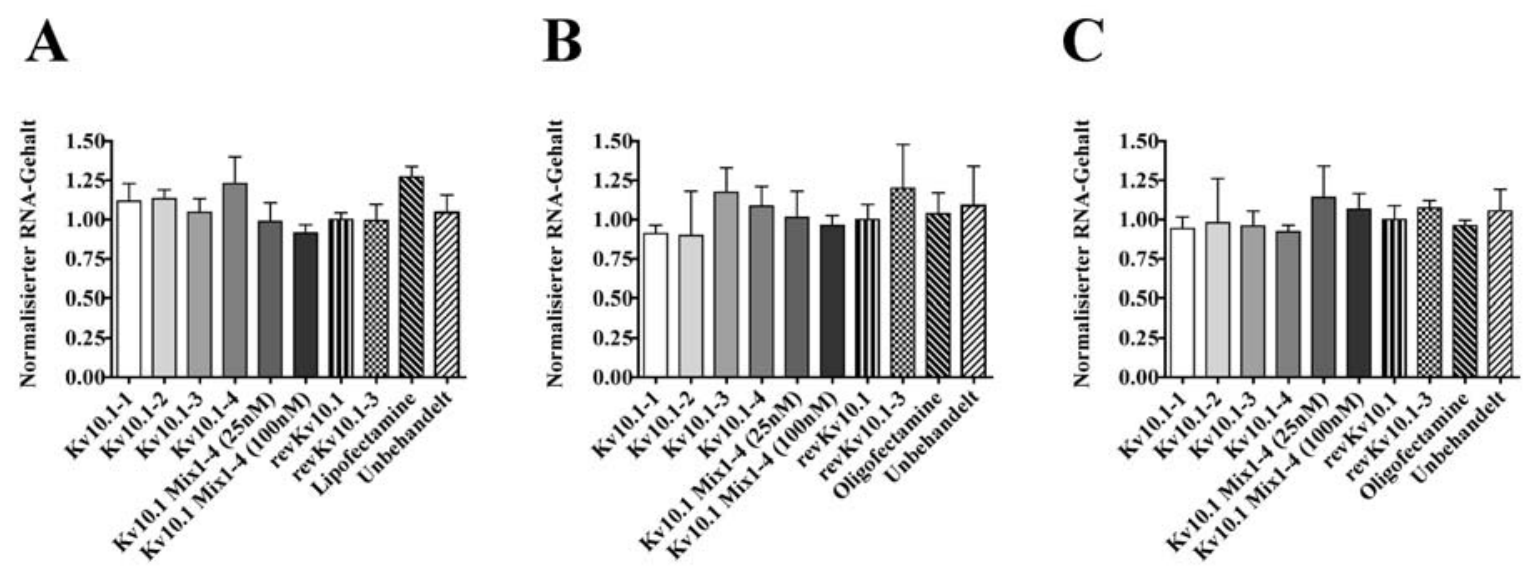

Abb. 35: Der normalisierte hPDK1-mRNA-Gehalt wurde durch hEAG1-siRNA-Behandlung nicht verändert. Normalisierte hPDK1-RNA-Gehalt in Zellen, die mit $25 \mathrm{nM}$ der vier verschiedenen siRNAs (Kv10.1-1 - Kv10.1-4), einer Mischung aus je $6.25 \mathrm{nM} \mathrm{Kv10.1-1} \mathrm{-} \mathrm{Kv10.1-4} \mathrm{(25} \mathrm{nM),} \mathrm{einer}$ Mischung aus je $25 \mathrm{nM} \mathrm{Kv10.1-1} \mathrm{-} \mathrm{Kv10.1-4} \mathrm{(100} \mathrm{nM),} 25 \mathrm{nM}$ revKv10.1, $25 \mathrm{nM}$ revKv10.1-3, Oligofectamine bzw. Lipofectamine behandelt wurden oder unbehandelt waren. A: hEAG1atransfizierte HEK-Zellen, B: MDA-MB435S-Zellen und C: Daoy-Zelle. In der Analyse wurden in allen Proben drei biologische Replikate zusammengefaßt. 


\subsubsection{Dauer der Transfektion}

Da lange Expositionen der Zellen mit der Mischung aus Transfektionsreagenz und siRNA eventuell zu unspezifischen Reaktionen führen können, wurde die Transfektionsdauer variiert, um die optimale Zeit zu bestimmen. Normalerweise wird eine Transfektionsdauer von $4 \mathrm{~h}$ empfohlen, aber die optimale Zeit ist stark abhängig vom verwendeten System. Die Zellen wurden mit dem äquilibrierten siRNA-Transfektionsreagenzgemisch für 4 h, 8 h, 12 h und 24 $\mathrm{h}$ inkubiert und die relative Reduktion von hEAG1a-RNA durch Kv10.1-3 mit Real-TimePCR verfolgt. Zusätzlich wurde der hPDK1-RNA-Gehalt gemessen, um eventuell auftretende unspezifische Effekte auszuschließen. Optimale hEAG1a-Reduktion wurde nach 8-stündiger Inkubation mit siRNA in hEAG1a-transfizierten HEK-Zellen beobachtet, während längere Inkubationszeiten nicht-signifikante Änderungen im PDK1-RNA-Gehalt hervorriefen. Daher wurden alle nachfolgenden Experimente mit 8-stündiger Transfektion durchgeführt (Abb. 36A, B).
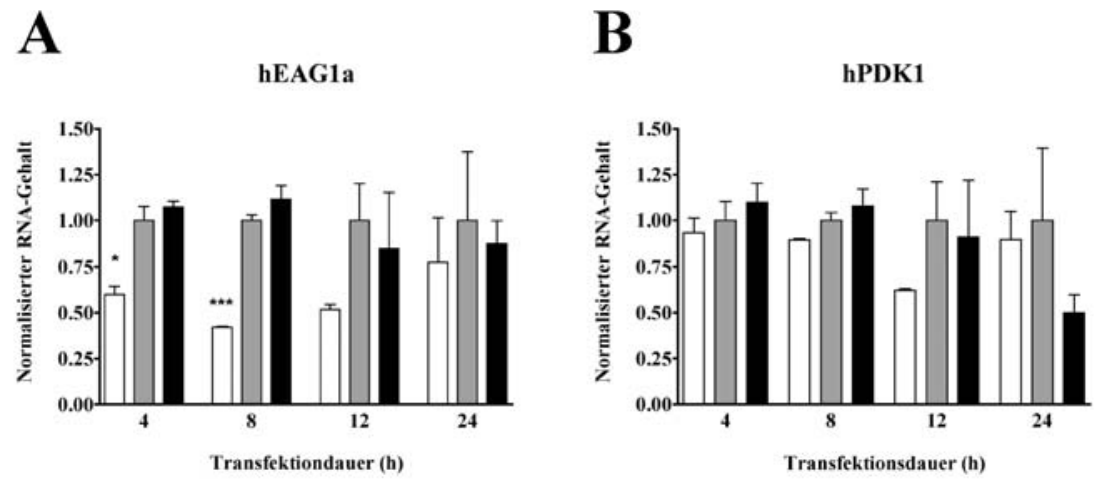

Abb. 36: Einfluß der Transfektionsdauer auf die Effizienz der Inhibierung der hEAG1a-und hPDK1-Transkription durch hEAG1-siRNAs. hEAG1a-transfizierte HEK-Zellen wurden $4 \mathrm{~h}$, 8h (n $=3), 12 \mathrm{~h}$ und $24 \mathrm{~h}(\mathrm{n}=1)$ mit Kv10.1-3 (weiße Säulen), revKv10.1 (graue Säulen) in Lipofectamine und nur Lipofectamine (Schwarze Säulen) behandelt. A: Normalisierter hEAG1a-RNA-Gehalt, B: Normalisierter hPDK1-RNA-Gehalt $(*=\mathrm{p}<0.05, * * *=\mathrm{p}<0.001)$.

\subsubsection{Dosis-Abhängigkeit der hEAG1-Inhibierung}

Um sowohl die nicht-spezifischen Effekte auf andere Gene als auch jegliche unspezifischen Effekte zu minimieren, sollte die Minimalkonzentration der siRNAs, die den maximalen Effekt hervorruft, bestimmt werden (Editorial, 2003). Daher wurde die Dosis-Abhängigkeit der hEAG1-siRNA-vermittelten Inhibierung sowohl in hEAGla-transfizierten als auch in natürlich exprimierenden Zellen ermittelt. Die $\mathrm{IC}_{50}$-Werte lagen im $10^{-8}$ Molar-Bereich (19.56 
$\pm 36 \mathrm{nM}$ (HEK-hEAG1a), $11.77 \pm 9 \mathrm{nM}($ MDA-MB435S) und $10.43 \pm 10 \mathrm{nM}$ (Daoy)) und eine unspezifische Antwort konnte nicht beobachtet werden. Basierend auf dieser Information wurde $25 \mathrm{nM}$ in allen nachfolgenden Experimente verwendet (Abb. 37A-C).

A

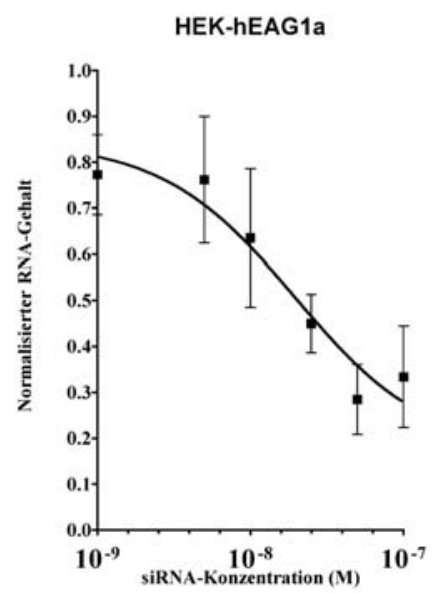

B

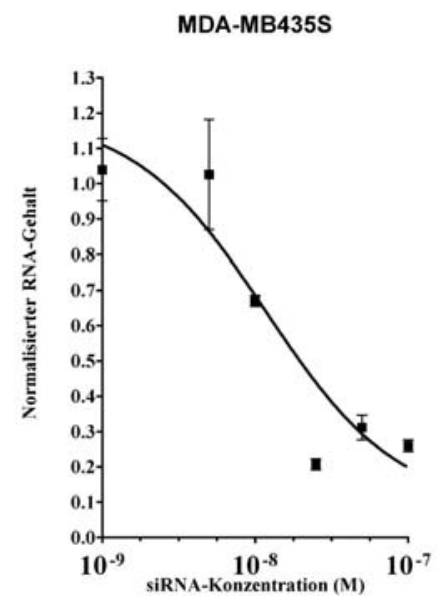

C

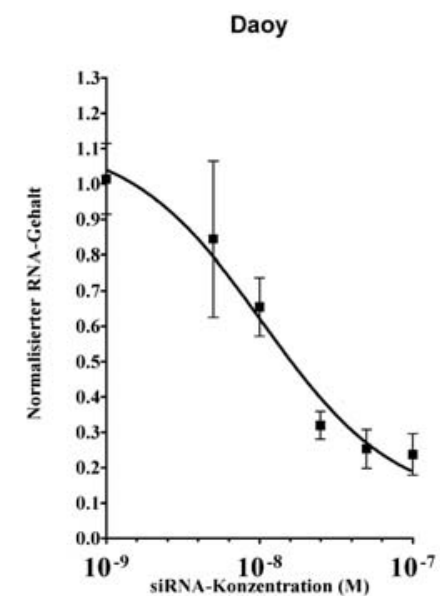

Abb. 37: Dosis-Antwort-Abhängigkeit der hEAG1-Inhibierung durch siRNAs. hEAG1atransfizierte HEK-Zellen (A), MDA-MB435S-Zellen (B) und Daoy-Zellen (C) wurden mit Kv10.1-3 behandelt. Die Linie repräsentiert die Anpassung einer Hill-Gleichung an die Daten.

\subsubsection{Zeitverlauf des siRNA-Effektes}

Es gibt viele Veröffentlichungen, in denen der Zeitverlauf der siRNA-Aktivität für verschiedene Zielgene auf RNA, Protein und funktionaler Ebene untersucht wurde (Bantounas et al., 2004; Choi et al., 2005; Tulac et al., 2004).
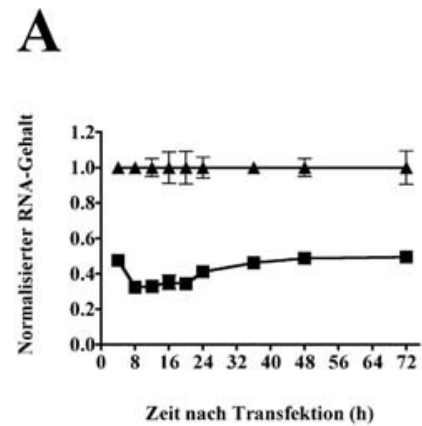
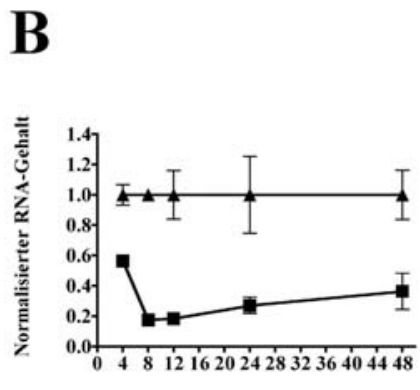

Zeit nach Transfektion (h)
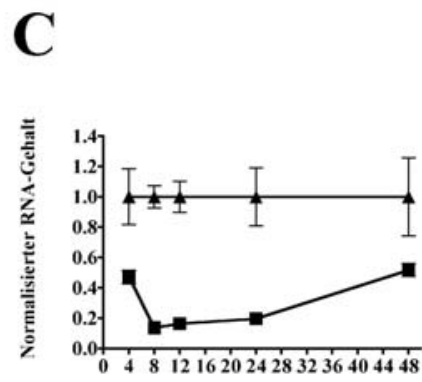

Zeit nachTransfektion (h)

Abb. 38: Zeitverlauf nach Behandlung der hEAG1a-transfizierten HEK-Zellen (A), der MDAMB435S-Zellen (B) und der Daoy-Zellen (C) mit Kv10.1-3 (Quadrate) und revKv10.1 (Dreiecke). Es wurden in allen Zelllinien drei biologische Replikate durchgeführt bis auf A: $16 \mathrm{~h}: \mathrm{n}=$ $1,72 \mathrm{~h}: \mathrm{n}=2$ und B: $48 \mathrm{~h}: \mathrm{n}=2$.

Die maximale Inhibierung wurde in diesen Veröffentlichungen nach $24 \mathrm{~h}$ oder sogar später beobachtet. Der Zeitverlauf für die hEAG1-Inhibierung wurde in dieser Arbeit bestimmt und 
ein überraschend schneller Effekt bemerkt. Eine Reduktion der hEAG1a RNA-Menge konnte schon nach $4 \mathrm{~h}$ beobachtet werden und sie erreichte ihr Minimum nach $8 \mathrm{~h}$. Erst nach $72 \mathrm{~h}$ stieg die RNA-Menge wieder an (Abb. 38A-C).

Daher waren auch auf der Protein- und Funktionsebene schnellere Effekte als die in der Literatur beschriebenen zu erwarten. Western Blots (Abb. 39A) und FACS-Messungen (Abb. 39B) zeigten eine signifikante Reduktion der Proteinmenge für hEAG1a, die schon nach $8 \mathrm{~h}$ sichtbar und am geringsten 48 h nach Start der Transfektion war. Nach 144 h wurden die Kontrollwerte wieder erreicht. Die FACS-Messungen wurden von Fernanda Mello de Queiroz durchgeführt

$\mathbf{A}$

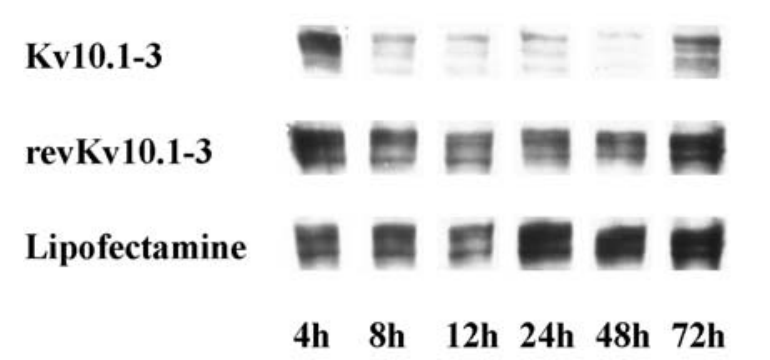

4h $\quad 8 h \quad 12 h \quad 24 h \quad 48 h \quad 72 h$
B

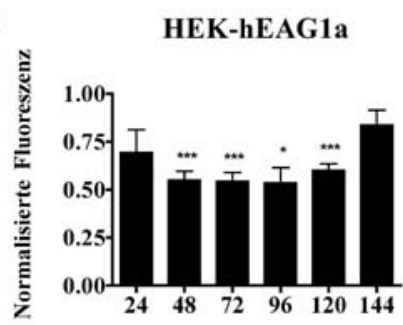

Zeit nach Transfektion (h)

C

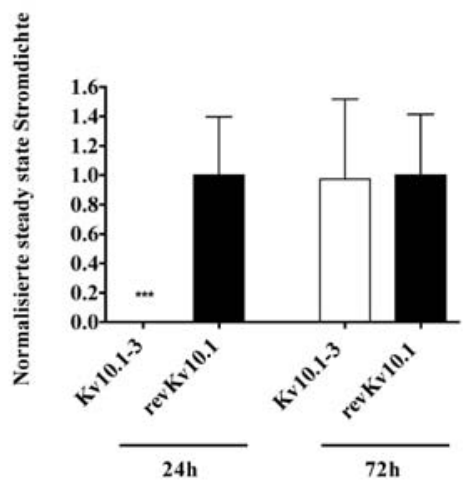

Abb. 39: si-RNA-Behandlung reduzierte hEAG1a effizient sowohl auf Protein- als auch auf Funktionsebene. A: Western Blot-Analyse des Zeitverlaufs der Behandlung der hEAG1atransfizierten HEK-Zellen mit Kv10.1-3, revKv10.1-3 und Lipofectamine. Es wurden $30 \mu \mathrm{g}$ Gesamtprotein pro Spur geladen. Die Doppelbanden bei 110 und $130 \mathrm{kDa}$ entsprechen den zwei Glykosylierungszuständen von hEAG1a. B: Flußzytometrische Analyse des Zeitverlaufs der Kv10.13-Behandlung (normalisiert auf revKv10.1-Behandlung) der hEAG1a-transfizierten HEK-Zellen. C: Elektrophysiologische Messungen $24 \mathrm{~h}$ und $72 \mathrm{~h}$ nach Behandlung der hEAG1a-transfizierten HEKZellen mit Kv10.1-3 (weiße Säulen; $n=12$ für $24 \mathrm{~h}, \mathrm{n}=17$ für $72 \mathrm{~h}$ ) und revKv10.1 (schwarze Säulen; $\mathrm{n}=12$ für $24 \mathrm{~h}, \mathrm{n}=11$ für $72 \mathrm{~h}$ ). Dargestellt wurde die stationäre Stromdichte von Kv10.1-3behandelten Zellen normalisiert auf die stationäre Stromdichte von revKv10.1-behandelten Zellen $(* * *=\mathrm{p}<0.001)$.

Auf der Funktionsebene waren die hEAGla-Ströme nach $24 \mathrm{~h}$ komplett gehemmt und erholten sich nach $72 \mathrm{~h}$ völlig (Abb. 39C). Die elektrophysiologische Charakterisierung wurde durchgeführt von Bryan R. Downie. Das scheint im Gegensatz zu der Proteinmenge zu stehen, die zu diesen Zeitpunkten noch reduziert war (Abb. 39A, B). Es wird vermutet, dass 
hEAG1 wichtig für das Zellwachstum in mehreren Zelllinien ist (Gavrilova-Ruch et al., 2002; Ouadid-Ahidouch et al., 2001; Pardo et al., 1999). Daher wurde in dieser Arbeit der mögliche Effekt der Stilllegung der hEAG1-Expression auf die Proliferation der Zellen untersucht. Da die maximale Reduktion der Proteinmenge nach $48 \mathrm{~h}$ gemessen werden konnte, wurde eine Auswirkung auf die Proliferation relativ spät nach der Transfektion erwartet. Spezifische Anti-hEAG1-siRNA reduzierte die Proliferation der drei Modellzelllinien über eine überprüfte Zeitspanne von 96 h. Zu diesem Zeitpunkt war die Proliferation um $57.2 \pm 4.8 \%$ (HEK-hEAG1a), $44.9 \pm 3.7 \%$ (MDA-MB435S) und $31.9 \pm 1.6 \%$ (Daoy) reduziert (Abb. 40A-D).

A

HEK-pTracer

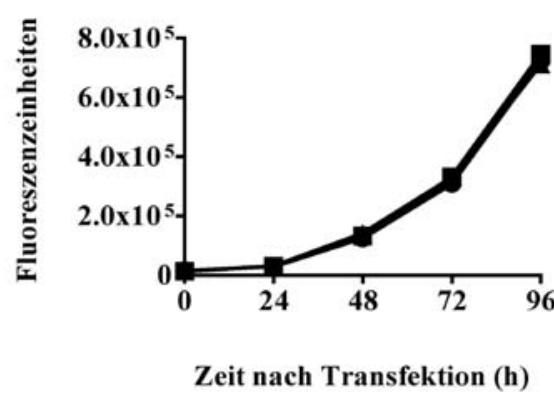

C

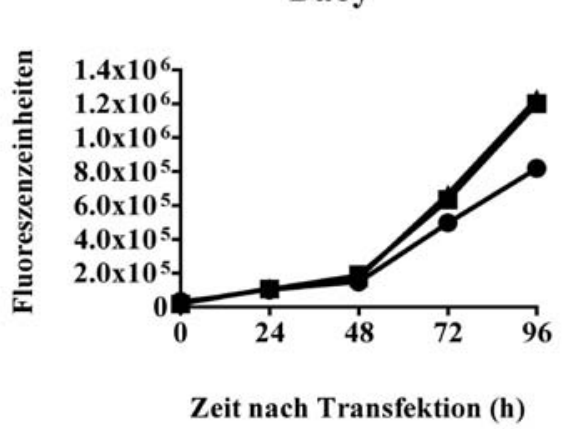

B

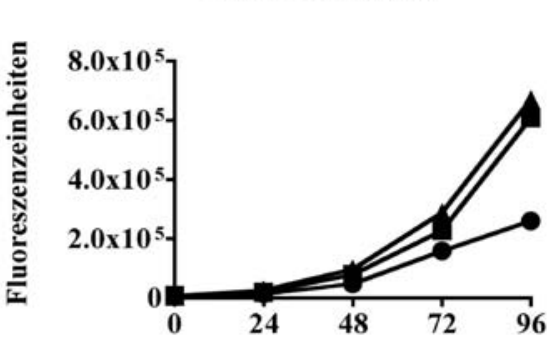

Zeit nach Transfektion (h)

D

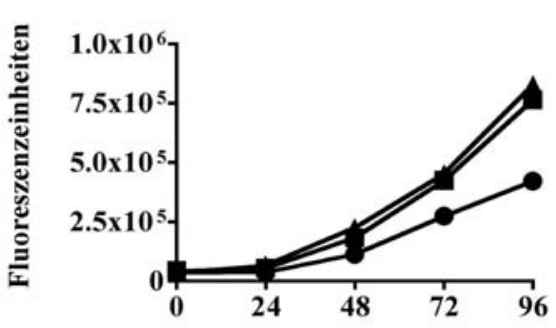

Zeit nach Transfektion (h)

Abb. 40: hEAG1-Stilllegung reduzierte die Proliferation. Proliferation von Vektor-transfizierten HEK-Zellen (HEK-pTracer-Zellen) (A), hEAG1a-transfizierten HEK-Zellen (B), MDA-MB435SZellen (C) und Daoy-Zellen (D) behandelt mit Kv10.1-3 (Kreise), revKv10.1 (Quadrate) und Lipofectamine (HEK-Zellen) bzw. Oligofectamine (MDA-MB435S- und Daoy-Zellen) (Dreiecke).

\subsubsection{Die Stilllegung von hEAG1 mit siRNAs reduziert die Proliferation von Tumorzelllinien}

Nach der Optimierung und Charakterisierung der Effekte, die hEAG1-siRNA auf die Modellzelllinien ausübte, wurden die Untersuchungen auf zahlreiche andere Zelllinien 
ausgeweitet, die aus den Haupttypen von Krebsgeschwüren isoliert wurden. Es wurden Zelllinien überprüft, die von Sarkomen (HT-1080, A-204, Hs633t, TE-671), von Brustkarzinomen (MDA-MB435S, MCF-7), von Melanomen (IGR-39, IPC298), von Cervixkarzinomen (HeLa), von Neuroblastomen (SHSY-5Y) und von Medulloblastomen (Daoy) abstammen. Dabei wurde beobachtet, dass die Behandlung der Zellen mit hEAG1siRNAs in allen Fällen die RNA-Mengen reduzierte und dass die Proliferation in fast allen Zelllinien gehemmt wurde, allerdings in unterschiedlichem Maße (Tab. 5).

\begin{tabular}{|c|c|c|c|c|}
\hline Zelllinie (Ursprung) & Reduktion der & $p$-Wert & Reduktion der & $p$-Wert \\
\hline & RNA-Menge (\%) & & Proliferation (\%) & \\
\hline HEK293-pTracer (Transfizierte & n.b. & -- & $3.0 \pm 3.4$ & 0.4 \\
\hline \multicolumn{5}{|l|}{ Zellen) } \\
\hline HEK293-hEAG1a (Transfizierte & $63.2 \pm 10.0$ & 0.003 & $57.2 \pm 4.8$ & $<0.0001$ \\
\hline \multicolumn{5}{|l|}{ Zellen) } \\
\hline MDA-MB435S ( Brustkrebs) & $82.4 \pm 3.7$ & $<0.0001$ & $44.9 \pm 3.7$ & $<0.0001$ \\
\hline MCF-7 (Brustkrebs) & $56.2 \pm 7.6$ & 0.002 & n.b. & n.d. \\
\hline Daoy (Zerebelläres Medulloblastom) & $86.3 \pm 7.5$ & 0.0003 & $31.9 \pm 1.6$ & $<0.0001$ \\
\hline IGR39 (Melanom) & $88.3 \pm 16.5$ & 0.006 & n.b. & -- \\
\hline IPC298 (Melanom) & $75.5 \pm 7.0$ & 0.0004 & n.b. & -- \\
\hline HT1080 (Fibrosarkom) & $82.3 \pm 2.6$ & $<0.0001$ & $36.3 \pm 8.1$ & 0.01 \\
\hline Hs633t (Fibrosarkom) & $70.5 \pm 13.0 *$ & $<0.005$ & $54.1 \pm 19.6 *$ & 0.05 \\
\hline TE-671 (Rhabdomyosarkom) & $75.2 \pm 3.6$ & $<0.0001$ & $43.5 \pm 8.8$ & 0.4 \\
\hline A204 (Rhabdomyosarkom) & $75.0 \pm 8.8$ & 0.01 & $83.8 \pm 3.2$ & 0.001 \\
\hline SH-SY5Y (Neuroblastom) & $91.5 \pm 16.2$ & 0.01 & n.b. & -- \\
\hline HeLa (Zervixkarzinom) & $49.4 \pm 14.7$ & 0.03 & n.b. & -- \\
\hline
\end{tabular}

$*=\mathrm{Kv} 10.1-4$

Tabelle 5: Maximale Reduktion der hEAG1a-RNA-Menge und der Proliferation in verschiedenen Zelllinien als Prozent der Kontrolle nach Behandlung mit Eag1-siRNA. n.b., nicht bestimmt. Die maximale Reduktion wurde, falls nicht anders angegeben, mit Kv10.1-3 bestimmt. Die Experimente zur Inhibierung des hEAG1-Kanals durch siRNAs in den Sarkomzelllinien wurden von Fernanda Mello de Queiroz durchgeführt.

\subsubsection{Behandlung der transfizierten HEK-, MDA-MB435S- und Daoy-Zellen mit hEAG1-siRNAs erhöht die RNA-Menge des Zinkfingertranskriptions- faktors MAZ}


Die in dieser Arbeit optimierte RNAi-Methode wurde nachfolgend zur Identifikation von Genen angewendet, deren Expression durch hEAG1-Expression moduliert wurde. Da Faktoren, die sich flussabwärts von den geänderten Zielgenen befinden, entsprechend später beeinflusst werden, wurde für die Untersuchung der zwei geringfügig differentiell exprimierten Gene hRACK1 und hMAZ aus der subtraktiven Hybridisierung ein nach späteren Zeitpunkten verschobener Zeitverlauf postuliert, der in den RNAi-Experimenten mit den drei Modellzelllinien (HEK-hEAG1a-, MDA-MB-435S- und Daoy-Zellen) nachgewiesen werden konnte. In allen drei Zelllinien konnte nach $24 \mathrm{~h}$ eine signifikante Erhöhung der hMAZ-mRNA-Menge nach Kv10.1-3-Transfektion beobachtet werden, die ein Maximum bei $48 \mathrm{~h}$ aufwies (HEK-hEAG1a-Zellen: $82.82 \pm 15.86 \%$, MDA-MB435S: $238.9 \pm 21.8 \%$, Daoy: $97.24 \pm 23.53 \%$ ) und sich danach wieder den Kontrollwerten annäherte. Die maximale Erhöhung war mit $70.49 \pm 6.44 \%$ in den MDA-MB435S-Zellen am größten (Abb. 41A-C). Mit dem zweiten differentiell exprimierten Gen, hRACK1, konnte kein solcher Zeitverlauf in transfizierten HEK-Zellen beobachtet werden (Daten nicht gezeigt), daher kann ein globaler unspezifischer Effekt der siRNAs auf die hMAZ-Expression ausgeschlossen werden.

$\mathbf{A}$

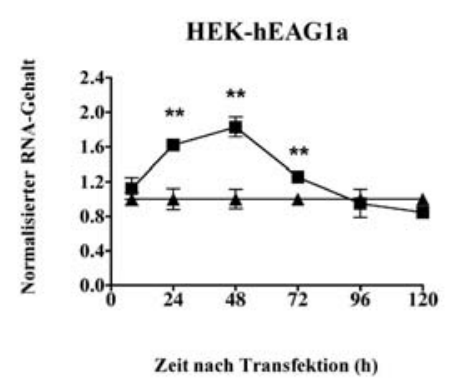

B

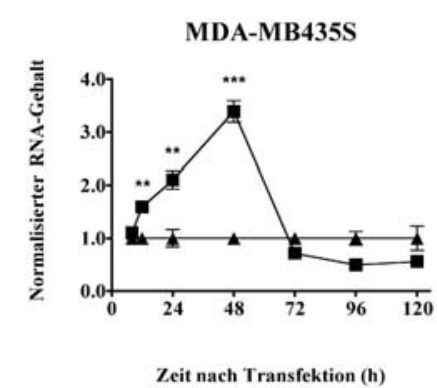

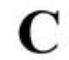

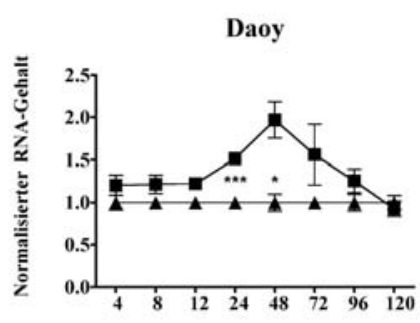

Zeit nach Transfektion (h)

Abb. 41: Zeitverlauf der Veränderung der MAZ-RNA-Menge nach Behandlung der hEAG1atransfizierten HEK293-Zellen (A), der MDA-MB435S-Zellen (B) und der Daoy-Zellen (C) mit Kv10.1-3 (Quadrate) und revKv10.1 (Dreiecke). Es wurden in allen Zelllinien mindestens drei Versuchswiederholungen durchgeführt.

MAZ (Myc-associated zink fingerprotein) ist ein 477-Aminosäuren langer ZinkfingerTranskriptionsfaktor vom $\mathrm{Cys}_{2} \mathrm{His}_{2}$-Typ. Er fungiert im Menschen-, Maus- und HamsterZellen als Aktivator, Initiator (Bossone et al., 1992) und Terminator (Ashfield et al., 1994) der Transkription. Er besitz die Fähigkeit, an den Promotor vom c-Myc-Gen zu binden und ihn zu aktivieren (Bossone et al., 1992). Im Promotor der reversen Transkriptase (hTERT) der menschlichen Telomerase, deren Aktivität in etwa $90 \%$ von Tumorproben erhöht war und 
das Potential für die Immortalisierung vieler Zelltypen hatte (Cong et al., 2002), wurden Bindungsstellen für hMAZ gefunden.

\subsubsection{Die Transkription der durch hMAZ regulierten Protoonkogene hc-Myc und hTERT wird durch hEAG1-siRNA-Behandlung inhibiert.}

Bindungsstellen für MAZ kommen in den Promotoren mehrerer mit Krebs in Verbindung gebrachter Gene wie dem c-Myc- (Kabilova et al., 2006) und hTERT-Gen (Cong et al., 2002) vor und regulieren dort die Genexpression. Daher wurden auch Zeitverläufe von diesen beiden hMAZ-Zielgenen nach Stilllegung von hEAG mit RNAi aufgenommen und eine signifikante maximale Reduktion der RNA-Menge 48-96 h nach Transfektion in den siRNAbehandelten Zellen beobachtet (Abb. 42).

A

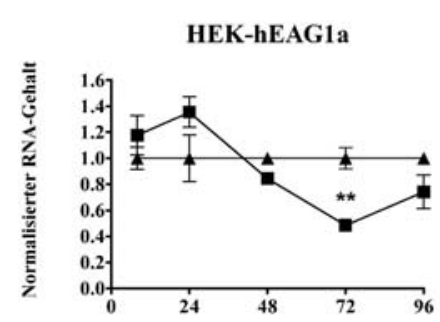

Zeit nach Transfektion (h)

D

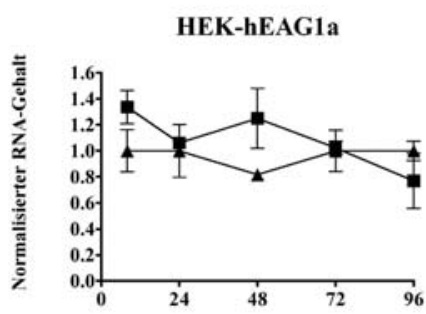

Zeit nach Transfektion (h)
B

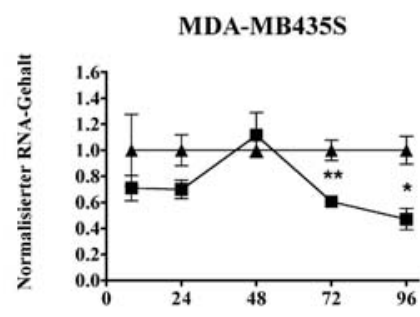

Zeit nach Transfektion (b)

\section{$\mathbf{E}$}

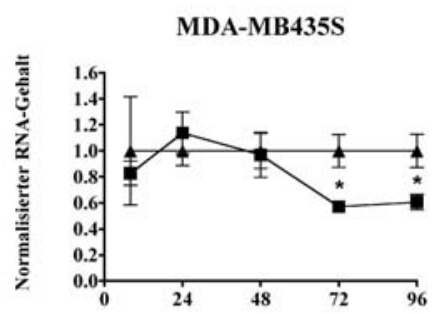

Zeit nach Transfektion (h)
C

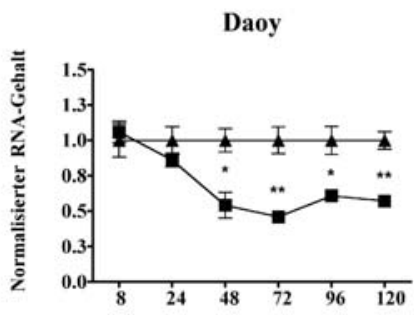

Zeit nach Transfektion (h)

$\mathbf{F}$

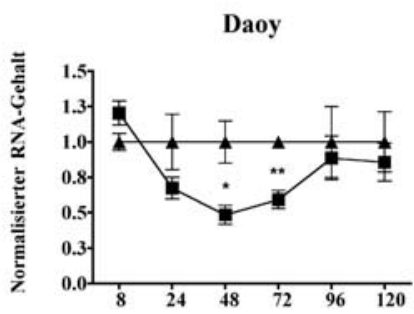

Zeit nach Transfektion (h)

Abb. 42: Zeitverlauf der Veränderung der hc-Myc- (A-C) und hTERT-RNA-Menge (D-F) nach Behandlung der hEAG1a-transfizierten HEK-Zellen (A), der MDA-MB435S-Zellen (B) und der Daoy-Zellen (C) mit Kv10.1-3 (Quadrate) und revKv10.1 (Dreiecke). Es wurden in allen Zelllinien mindestens drei Versuchswiederholungen durchgeführt.

Die c-Myc-RNA-Menge war in den HEK-hEAG1a-Zellen maximal nach $72 \mathrm{~h}$ um $51.4 \pm 8.8$ $\%$, in den MDA-MB435S-Zellen nach 96 h um 90.2 $\pm 15.7 \%$ und in den Daoy-Zellen nach $72 \mathrm{~h}$ um $54.1 \pm 9.6 \%$ reduziert (Abb. 42A-C). Die hTERT-RNA-Menge war in den MDAMB435S-Zellen nach $72 \mathrm{~h}$ um $42.9 \pm 12.8 \%$ und in den Daoy-Zellen nach $48 \mathrm{~h}$ um $51.4 \pm$ $16.2 \%$ vermindert (Abb. 42E, F). Lediglich in den transfizierten HEK-Zellen konnte keine 
signifikante Änderung der hTERT-mRNA-Menge gefunden werden (Abb. 42D). Im Gegensatz zur maximalen hMAZ-RNA-Erhöhung bei 24-48 h zeigte die c-Myc-RNAReduktion ein Maximum bei 72-96 h. Dies deutet darauf hin, dass die Regulation dieses Gens durch hEAG1 möglicherweise über den Transkriptionsfaktor hMAZ verläuft. Im Gegensatz dazu ist die hTERT-RNA-Menge wie die hMAZ-RNA-Menge in Daoy-Zellen schon nach 48 h maximal reduziert, so dass es sich hierbei eventuell um einen direkten Effekt von hEAG1 auf die Expression von hTERT in dieser Zelllinie handeln könnte. Der gegenläufige Einfluss der Anti-hEAG1-siRNA-Behandlung auf die RNA-Menge von hMAZ im Vergleich zu hcMyc und hTERT bekräftigt noch mal, dass es sich um hEAG1-spezifische Effekte handelt. Das c-Myc-Protoonkogen spielt eine Schlüsselrolle bei der Zellproliferation, Differenzierung und Apoptose (Coller et al., 2000). Es ist eines der typischen, schon lange bekannten Protoonkogene und kodiert für ein nukleäres Phosphoprotein, das in die maligne Tumorgenese involviert ist (Kabilova et al., 2006). Es besitzt eine basische Helix-LoopHelix/Leucin-Zipper Domäne, die die Dimerisierung mit seinem Bindungspartner MAX (Myc-associated Factor $X$ ) vermittelt, die für seine Funktion sowohl als Aktivator als auch Repressor der Transkription nötig ist (Secombe et al., 2004). Cong et al. haben herausgefunden, dass die Aktivität der reversen Transkriptase (hTERT) der menschlichen Telomerase in etwa $90 \%$ von Tumorproben erhöht ist und sie das Potential für die Immortalisierung vieler Zelltypen besitzt (Cong et al., 2002). 


\section{Diskussion}

\subsection{Expression von EAG}

In dieser Arbeit wird der EAG1-Kanal sowohl auf seine Expression als auch auf die Konsequenzen seiner Expression hin untersucht. Der erste Teil der Arbeit befasst sich mit der natürlichen und heterologen Expression von EAG1.

\subsubsection{Expression von EAG in Ratten und Mäusen}

Im Menschen findet man den EAG1-Kanal außer in reproduktivem Gewebe (Hoden, Gebärmutter), in Myoblasten kurz vor der Fusion und in Krebsgewebe ausschließlich im Gehirn (Occhiodoro et al., 1998; Patt et al., 2004). Dot Blot-Experimente zeigten im Cortex, im Cerebellum, Hippocampus, Nucleus caudatus, Putamen, in der Amygdala sowie im frontalen, occipitalen und temporalen Lappen ein positives Signal für EAG1, während der Thalamus, die Substantia nigra und Medulla oblongata wie auch Herz, Leber, Niere, Lunge, Milz und Thymus negativ waren (Pardo et al., 1999).

Die zwei EAG-Gene, EAG1 und EAG2 sind in vielen Regionen des Rattenhirns exprimiert. Es war dort eine ausgeprägte Expression von EAG1 im Cortex, Hippocampus, Cerebellum, Nucleus caudatus, Putamen, Amygdala, Hypothalamus und dem Bulbus olfactorius detektierbar. Im Gegensatz dazu war die Expression von EAG2 etwas begrenzter; so konnten größere Mengen ausschließlich im Cortex, Hippocampus (Ludwig et al., 2000), Thalamus, Mittelhirn und Stammhirn mittels in situ Hybridisierung gefunden werden, wo EAG2 in Gliazellen detektiert wurde (Saganich et al., 2001). Milz, Leber, Lunge, Nieren und Herz waren in der Ratte EAG1- und EA2- negativ (Ludwig et al., 1994; Ludwig et al., 2000).

Die neurophysiologische Aufgabe dieser Kanäle in diesen Regionen blieb jedoch lange unklar. Die ersten Hinweise wurden 2005 von Jeng et al. gefunden, die eine differentielle Expression von EAG1 und EAG2 in hippocampalen Neuronen der Ratte beobachteten. Dabei wurde der rEAG1-Kanal in der somatodendritischen Region in Synaptophysin- und Densinexprimierenden Zellen lokalisiert, was auf eine mögliche Beteiligung dieses Kanals an der Modulation der postsynaptischen Reizweiterleitung in glutaminergen Synapsen hindeutet (Jeng et al., 2005). Weiterhin wurde rEAG1-und rEAG2-Expression in Nervenzellen der peripheren sympathischen Ganglien der Ratte gefunden. rEAG1 konnte im paravertebralen 
Ganglion, dem oberen zervikalen Ganglion, und zwei prävertebralen Ganglien, dem Bauchhöhlenganglion und dem oberen mesenterischen Ganglion, detektiert werden, während rEAG2 nur in den beiden prävertebralen Ganglien vorkam (Shi et al., 1998).

Die vorliegende Arbeit konnte zeigen, dass in der Ratte auch in Hoden, Lunge, Milz, Nieren und Thymusdrüse signifikante Mengen an rEAG1-mRNA vorhanden sind, während Lebergewebe negativ für rEAG1 war. Moderate Mengen rEAG2-RNA wurden nur in Hoden, Nieren und Thymusdrüse beobachtet. Dies steht im Gegensatz zu der Veröffentlichung von Ludwig, der kein rEAG1 in Milz, Leber, Lunge, Nieren, Hoden und Herz und kein rEAG2 in Nieren der Ratte gefunden hatte (Ludwig et al., 1997; Ludwig et al., 1994). Diese Diskrepanz kann dadurch erklärt werden, dass diese Forschergruppe Sprague-Dawley-Ratten verwendet hat, während in dieser Arbeit Wistar-Ratten benutzt wurden. In der Literatur sind große Unterschiede innerhalb der Stämme von Ratten und Mäusen sowohl physiologischer als auch verhaltensbiologischer Natur beschrieben (Gomez-Serrano et al., 2001). Außerdem stellt die Real-Time-PCR, so wie sie in dieser Arbeit durchgeführt wurde, eine sensitivere Methode als die in situ-Hybridisierung und normale RT-PCR dar. Als Referenz für die positive Expression von EAG wurden Kopienzahlen von Zelllinien genommen, die als positiv bewertet worden sind (> 500-1000 Kopien/ $\mu$ l).

In der Maus konnten in dieser Studie hohe bis moderate Mengen von mEAG1-RNA im Hippocampus, Hypothalamus, Bulbus olfactorius, Hoden, Lunge, Milz und Thymus beobachtet werden, während im Herz geringe, aber detektierbare mEAG1-RNA-Mengen aufgefunden wurden. mEAG2 wurde nur im Hypothalamus und nicht in Herz und Bulbus olfactorius exprimiert.

Das Vorhandensein von EAG1-RNA im Mäuseherz war eher überraschend, da weder für die Ratte noch für den Menschen eine EAG1-Expression im Herz beschrieben wurde (Ludwig et al., 1994; Pardo et al., 1999). Das Fehlen der EAG2-Expression im Mäuse-Herz ist im Einklang mit Veröffentlichungen des Vorkommens dieser Kanäle in der Ratte (Ludwig et al., 2000). Im Bulbus olfactorius der Maus konnte in dieser Arbeit keine EAG2-Expression detektiert werden, während die Literatur diese in Ratten beschreibt (Ludwig et al., 2000; Saganich et al., 2001). Ob es sich in der Maus bei den detektierten EAG-Formen um die exakte Sequenz der schon bekannten EAG-Kanäle handelt und in welchen Strukturen der EAG1-positiven Organen und in welchen Zelltypen EAG exprimiert wird, kann nun Gegenstand von weiterführenden Studien werden. 


\subsubsection{Induktion oder Repression von EAG durch Auslösung einer sterilen Entzündung mit LPS}

In der Vergangenheit wurde für viele Rezeptoren und Ionenkanäle festgestellt, dass sie durch Stress moduliert werden und diese Modulation über ähnliche Wege wie die Modulation durch Entzündungsmediatoren erfolgt (Gerth et al., 2005; Nishiyama et al., 1995; Radulovic et al., 1999; Radulovic et al., 2000; Rivest et al., 1995). Dabei sind häufig die HypothalamusHypophysen-Nebennierenachse (HPA-Achse), das autonome Nervensystem mit seinen Mediatoren Adrenalin und Noradrenalin und/oder eine Ausschüttung von Immunmodulatoren involviert (Gerth et al., 2005; Radulovic et al., 2000; Singh und Jiang, 2004). BK-Kanäle z. B. werden durch Glukokortikoide sowohl auf transkriptionell-translationeller wie auch auf Aktivitäts-Ebene reguliert (Lovell et al., 2004). In der Literatur wurde beschrieben, dass der EAG-verwandte hERG-Kanal durch $\alpha$ - als auch $\beta$-adrenerge System aktiviert und durch adrenerge Antagonisten gehemmt werden konnte (Thomas et al., 2004a; Thomas et al., 2004b).

Lipopolysaccharide sind Komponenten der äußeren Membran von gramnegativen Bakterien, die, wenn sie in den Körper von Säugetieren gelangen, über eine Aktivierung des angeborenen Teils des Immunsystems zur Zytokinproduktion und als Überreaktion zum tödlichen septischen Schock führen (Triantafilou und Triantafilou, 2002). Das Signal, das LPS bei Bindung an seine Rezeptoren, dem membrangebundenen (CD14) und dem löslichen (sCD14) Rezeptor, auslöst, wird vom toll-like Rezeptor 4 (TLR4) in die Zelle weitergeleitet, da die LPS-Rezeptoren keine Transmembran- und Intrazellulärdomänen besitzen. Durch seine Aktivierung wird eine Induktion von Zyto- und Chemokinen, Rezeptoren, Enzymen, Transkriptionsfaktoren (Guha und Mackman, 2002) und Komplementkomponenten (Blatteis et al., 2004) bewirkt. Im Verlauf der Tumorbildung treten bedingt durch die Aktivierung des Immunsystems oft entzündliche Reaktionen auf, die sich auch auf die örtliche Expression von Genen und auf die Expression von Genen im Gehirn auswirken können (Smyth et al., 2004). Eine wachsende Anzahl an Referenzen beschreibt eine Regulation von Ionenkanälen, darunter viele Kaliumkanäle (Yakubovich et al., 2001), durch LPS und seine Mediatoren (Jou et al., 1998; Pyo et al., 1997).

In dieser Arbeit wurden die Auswirkungen von LPS auf den gesamten Organismus der Maus durch intraperitoneale Injektion untersucht. In Herz und Thymus konnte eine signifikante Steigerung der EAG1 und im Thymus auch der EAG2-Menge beobachtet werden, während EAG1 in der Milz herunterreguliert war. 
Beim Effekt, den LPS auf Gewebe außerhalb des Zentralnervensystems ausübt, könnte es sich sowohl um eine direkte Auswirkung ihrer Bindung an die LPS-Rezeptoren (CD14, CD14s) oder um eine indirekte Wirkung über Mediatoren des aktivierten Immunsystems oder der Stressachsenmediatoren handeln (Gerth et al., 2005; Radulovic et al., 1999; Radulovic et al., 2000; Singh und Jiang, 2004).

LPS vermag die Blut-Hirn-Schranke nicht zu durchdringen (Singh und Jiang, 2004). Da es aber über seine Mediatoren wie Interleukin $1 \beta$ auch im Gehirn seine Wirkung entfaltet, wurde gleichzeitig die die RNA-Menge für Interleukin $1 \beta$ in den verschiedenen Organen und Gehirnregionen überprüft. In allen Gehirnteilen und Organen konnte, wie in der Literatur beschrieben, eine signifikante Erhöhung der Interleukin1 $\beta$-RNA-Menge notiert werden (Yao et al., 2005). Die Blut-Hirn-Schranken-durchgängigen Mediatoren von LPS waren also aktiv im Gehirn. Dass sich dennoch die EAG1-Expression nicht veränderte, spricht dafür, dass die Modulation der EAG1-Expression in der Peripherie über die LPS-Rezeptoren direkt erfolgt. Diese Hypothese wird unterstützt durch die beobachtete Verringerung der EAG1-Menge bei Behandlung von Zelllinien mit LPS in vitro.

\subsection{Heterologe EAG-Expression}

Der EAG1-Kanal wurde in mehreren Krebszellinien entdeckt, die ursprünglich aus Geweben isoliert wurden, die negativ für EAG sind (Pardo et al., 1999). Daraufhin wurde eine Vielzahl von Krebstumoren verschiedenen histologischen Ursprungs untersucht und eine EAG1Proteinexpression in $75 \%$ der Fälle entdeckt, während das entsprechende normale Gewebe bis auf seltene Ausnahmen kein EAG1 exprimierte (Queiroz et al., 2006; Hemmerlein et al., 2006).

In bisher veröffentlichten Studien zur physiologischen Auswirkung des EAG-Kanals wurde die heterologe Expression von hEAG1 in CHO-Zellen (Hamster) untersucht (Pardo et al., 1999). In dieser Arbeit wurde nun das Verhalten des menschlichen EAG1-Kanals in menschlichen Zelllinien (HEK) beobachtet. HEK-Zellen wurden nicht aus Tumorgewebe isoliert und dienen daher in dieser Studie als Modell für ein frühes Stadium der Krebsentstehung mit moderatem Phänotyp. Außerdem ist diese Zelllinie weitläufig für die heterologe Expression von Genen und speziell Ionenkanälen und nachfolgende funktionelle Studien etabliert, da sie große Mengen Protein korrekt glykosyliert herstellt und sie für elektrophysiologische Messungen sehr geeignet ist (García-Ferreiro et al., 2004). 


\subsection{1 hEAG1a-haltige HEK-Zellen zeigten eine verminderte Proliferation}

EAGla-transfizierte CHO-Zellen zeigten sowohl in vitro als auch in vivo eine erhöhte Proliferationrate (Pardo et al., 1999). Daher wurde zunächst erwartet, dass auch EAG1atransfizierte HEK-Zellen diese erhöhte Wachstumsrate aufweisen. Überraschenderweise war genau das Gegenteil der Fall, sowohl die hEAG1a- wie auch die G440S-haltige Zelllinie proliferierte signifikant langsamer als die Wildtyp- oder die Vektor-transfizierten HEKKontrollzellen. Da sich sowohl die EAG1a-haltigen wie auch die G440S-haltigen Zellen im Proliferationsassay gleich verhielten, kann man davon ausgehen, dass die Fähigkeit, $\mathrm{K}^{+} \mathrm{zu}$ transportieren, dafür nicht verantwortlich ist. Ein Entzug von Selektionsantibiotika über mehrere Passagen (bis zu 30 Tagen) konnte das beobachtete Wachstumsverhalten der HEKZellen nicht umkehren. Auch die metabolische Aktivität war in allen Proben vergleichbar, denn am Tag der Ausplattierung konnten keine Unterschiede in den Messwerten des Assays festgestellt werden. Die Ursache für das Verhalten lag weder im Verlust der kanalhaltigen Zellen durch verminderte Anhaftung zum Zeitpunkt der Messung noch am Verlust der EAG1Expression. In allen Proben konnten gleich viele Zellen im Überstand beobachtet werden, und das unterschiedliche Anhaftungsverhalten wirkte sich nur in der 1-stündigen Anfangsphase nach dem Aussäen aus. In der Literatur werden Fälle von Onkogenen beschrieben, die anstatt einer Proliferationsverstärkung eine Stagnation bzw. einen Wachstumsarrest, eine Differenzierung der Zellen oder Apoptose bewirken (Trost et al., 2005). Das Protoonkogen ras, welches die Zellen im hyperaktiven Zustand mit konstitutiven Wachstumssignalen versorgt und die Zellproliferation beschleunigt, induziert einen permanenten Zellzyklusarrest in menschlichen Primärkultur-Fibroblasten. Dieses Phänomen wird als vorzeitige Alterung (premature senescence) bezeichnet (Deng et al., 2004). Einige Veröffentlichungen beschreiben das Phänomen der vorzeitigen Alterung als Folge der Exposition von Zellen mit subzytotoxischem Stress (SIPS, stress-induced premature senescence). In Krebstumoren und in der Zellkultur sind die transformierten Zellen Stressfaktoren wie zeitweise wechselnder Sauerstoff- und Nährstoffzufuhr und unterschiedlichen Mengen an toxischen Stoffwechselendprodukten ausgesetzt, wenn die Wachstumsrate eines Tumors die Geschwindigkeit der Neovaskularisation übersteigt, bzw. wenn in Kultur die Zellen sich der stationären Phase annähern.

Ein anderer Erklärungsansatz des unerwarteten Proliferationsverhaltens wäre die Annahme, dass durch die initialen Anhaftungsunterschiede eine lag-Phase in der Anfangsphase der Zellteilung der kanalhaltigen Zellen entstanden sein könnte. Bei den kommerziell erhältlichen 
Proliferationsassays wird gewöhnlich die metabolische Aktivität der Zellen gemessen, die üblicherweise proportional zur Zellzahl ist. Nicht anhaftende Zellen können sich normalerweise nicht teilen, wohl aber metabolisch aktiv sein. Der Proliferationsassay mit heterolog EAG-exprimierenden HEK-Zellen im Vergleich zu Vektor-transfizierten Zellen scheint daher nicht die geeignete Messmethode für die phänotypischen Veränderungen nach heterologer EAG1-Expression $\mathrm{zu}$ sein, da es offensichtlich eine Beschleunigung des Wachstums unbekannter Ursache mit dem pTracer-Vektor ohne EAG in den HEK-Zellen gab. Daher wurde im Folgenden die Proliferation von EAG1a-transfizierten HEK-Zellen spezifisch mit EAG1-siRNAs inhibiert, um eine geeignete Kontrolle zum Vergleich zu haben. Die Proliferation von EAGla-transfizierten HEK-Zellen konnte mit dieser Methode mit geringen Mengen an Anti-EAG1-siRNAs spezifisch gehemmt werden, wie es auch für natürlich exprimierende Zellen möglich war. Man kann daher davon ausgehen, dass EAG1 die Proliferation der transfizierten Zellen erhöht. Im weiteren Verlauf dieser Arbeit wurden die Auswirkungen der EAG-Expression im heterologen Expressionssystem deshalb mit zusätzlichen Methoden wie Enzymaktivitätsassays, Anhaftungsassays und differentielle Genexpressionsstudien untersucht.

\subsubsection{Differentielle Matrix-Metalloproteinaseproduktion der hEAG1a-haltigen Zellen}

Die meisten Veröffentlichungen beschreiben eine positive Korrelation zwischen der Menge an aktiven MMP-2 und MMP-9 und der Aggressivität von Tumorzellen sowie ihrer Fähigkeit Metastasen zu bilden (Mook et al., BBA, 2004). MMP-2 und MMP-9 spalten Kollagen IV und sein Abbauprodukt Gelatine und werden daher Gelatinasen genannt. Sie sind dafür verantwortlich, dass metastasierende Zellen die Basalmembran durchdringen können, die zum großen Teil aus Kollagen IV und Laminin besteht (Folgueras et al., 2004; Overall und Kleifeld, 2006). Ihre Funktion wird sowohl auf transkriptioneller als auch auf posttranslationeller Weise durch Sekretion und Aktivitätsmodulation reguliert (Folgueras et al., 2004). In dieser Arbeit wurde beobachtet, dass die verglichenen Zelllinien verschiedene Mengen an Pro-MMP-2 exprimierten und ausschieden, wobei die hEAG1a-haltigen Zellen weniger MMP-2 als die Kontrollzellen herstellten. Nach künstlicher Aktivierung der Proteasen konnte eine verringerte Aktivität von MMP-2 in konditioniertem, FCS-freien Medium der hEAG1a-haltigen Zellen beobachtet werden. Vor der Aktivierung konnte nur eine sehr geringe, nicht differentielle MMP-2-Aktivität gemessen werden. In vivo sind eine 
Vielzahl von Signalen vorhanden, die eine Aktivierung von Pro-MMP-2 bewirken (z. B. bereitgestellt durch Zytokine und Wachstumsfaktoren) und in der Literatur beschrieben (BarEli, 1999). Daher ist es möglich, dass in vitro Signale fehlten, die die in dieser Arbeit beobachtete differentielle MMP-2-Expression in differentielle MMP-2-Aktivität umwandeln konnten. Da es sich bei dem Prozess der Metastasierung um einen sehr komplexen Vorgang mit streng zeitlich und örtlich regulierten Anhaftungs- und Ablösungsprozessen und proteolytischen Vorgängen handelt (Folgueras et al., 2004), ist es schwierig, das beobachtete Verhalten der transfizierten Zellen zu interpretieren oder gar einem Metastasestadium zuzuordnen.

\subsection{3 hEAG1a-haltige HEK-Zellen haften schlechter auf Plastik und extrazellulären Matrix-Proteinen}

Die hEAG1a-haltigen Zellen hafteten schlechter auf allen verwendeten Proteinen sowie auf Plastik, wobei die Effekte am ausgeprägtesten auf Laminin und Gelatine, vermittelt durch spezifische Bindung von Integrinen, sowie unspezifisch auf den kationischen Proteinen PolyL-Lysin und Protamin waren. Bei dem Prozess der Metastasierung handelt es sich um einen sehr komplexen Vorgang mit streng zeitlich und örtlich regulierten Anhaftungs- und Ablösungsprozessen (Folgueras et al., 2004). Das beobachtete verminderte Anhaftungsverhalten der kanaltransfizierten Zellen könnte einem Ablösungsstadium bei der Extravasion aus dem Ursprungsgewebe in die Blutgefäße nach dem Durchdringen der Basalmembran entsprechen. Zellen können selber extrazelluläre Matrixproteine ausscheiden und damit ihre Anhaftung an Oberflächen fördern. In den hEAG1a-transfizierten HEK-Zellen war die Fibronektin-RNA-Menge signifikant erhöht. Da in den G440S-Mutanten die Expression geringer als in den Wildtypen war, spielt für die Fibronektinexpression offensichtlich der $\mathrm{K}^{+}$-Ionentransport eine Rolle. In der Literatur wurde beschrieben, dass erhöhte Fibronektinexpression mit einer erhöhten Sterblichkeit der Krebspatienten, der Invasionstiefe und dem Auftreten von Lymphknotenmetastasen korreliert (Ioachim et al., 2002). 


\subsection{Mutationen}

Fast allen Arten von Krebs liegt eine Änderung der Sequenz eines Gens zu Grunde, dabei wird entweder ein stimulatorisches Gen (Protoonkogen) hyperaktiv (Onkogen) oder ein inhibitorisches Gen (Tumorsuppressorgen) inaktiviert. Dies geschieht meist durch Mutationen oder Deletionen bzw. Insertionen in dem Gen. Für den EGF-Rezeptor z. B. wurde von mehreren Forschergruppen gezeigt, dass die Tyrosinkinasedomäne eine Missensemutation und Deletion aufweist, die die Kinaseaktivität auf Stimulation mit EGF hin steigert und damit die Proliferation erhöht (Lynch et al., 2004; Sordella et al., 2004). Gelegentlich werden auch unterschiedliche Spleißvarianten des gleichen Gens in Krebsgewebe und normalem Gewebe exprimiert (Agrawal und Eng, 2006).

Die Zellinien IPC298 und IGR-39 verhielten sich in dieser Arbeit im Proliferationsassay unter Inhibierung mit Astemizol verschieden. In der Literatur ist beschrieben, dass IGR-39Zellen weder mRNA für EAG1 exprimieren noch konnten in ihnen EAG1-spezifische Ströme gemessen werden (Meyer et al., 1999). Die im Rahmen dieser Arbeit durchgeführten PCRAmplifikationsversuche zeigten jedoch eine starke Expression von EAG1 in den IGR-39Zellen, d.h. eine unterschiedliche EAG-Expression konnte nicht der Grund für das unterschiedliche Wachstumsverhalten sein. Bei der Charakterisierung der Beteiligung von hEAG1 an der Tumorigenese Bis jetzt wurde nur ein sehr kleiner Teil der Sequenz aus MCF7-Zellen überprüft und keine Änderung zu der Sequenz aus dem Gehirn gefunden (Pardo et al., 1999).

Daher wurde in dieser Arbeit untersucht, ob in den verschiedenen, in dieser Studie verwendeten natürlich EAG1-exprimierenden Zelllinien Punktmutationen und/oder Deletionen in der EAG-Sequenz vorkamen. Da es sich bei dem EAG-Kanal um ein tetrameres Protein handelt, können auch kleine Mengen an veränderten Untereinheiten, die neben der normalen Form exprimiert werden und mit dieser als Heteromere assemblieren, große physiologische Veränderungen zur Folge haben. Diese Veränderungen könnten, wie für andere Kanäle beschrieben, durch Heteromerisierung (Crociani et al., 2003) oder Veränderungen in Transport oder Halbwertszeit der Kanäle hervorgerufen werden (Soldovieri et al., 2006).

Es konnte in dieser Arbeit gezeigt werden, dass die Melanom-Zelllinie IPC298 und die Brustkrebszelllinie MDA-MB435S neben der normalen Form Varianten von EAG1 exprimieren, die Deletionen aufweisen. Durch die daraus resultierende Leserasterverschiebung könnten verkürzte Proteine mit veränderten C-Termini hergestellt 
werden. Außerdem können die beiden Zelllinien weitere Mutationen im 5'-untranslatierten Bereich oder im Anfang des translatierten Bereichs (MDA-MB435S und IPC298) und im 3'translatierten Bereich (IPC298) enthalten, da diese Stücke nicht mit PCR amplifiziert werden konnten. Es wäre möglich, dass diese Mutationen das Leseraster durch ein alternatives Startkodon oder Deletionen bzw. Insertionen wieder herstellen, trotdem wäre aber die Sequenz zwischen den beiden Mutationsstellen geändert.

Im weiteren Verlauf der Studie wurden in 10 verschiedenen Zelllinien (IPC298, IGR-39, MDA-MB435S， MCF-7， HT1080， Hs633t， TE-671， A204， LNCAP， DU-145) unterschiedlichen Ursprungs (Melanom, Brustkrebs, Fibrosarkom, Rhabdomyosarkom und Prostatakrebs) in der PCR 5 verschiedene EAG1-Sequenztypen ersichtlich. Nur drei davon (IGR-39-, HT1080- und DU-145-Zellen) exprimieren vermutlich den EAG1-Kanal in der Form, in der er im Gehirn vorkommt, während bei den anderen entweder im N-terminalen und/oder im C-terminalen Bereich Mutationen oder Deletionen vorkommen. $\mathrm{Zu}$ diesem Zeitpunkt kann natürlich keine Aussage darüber gemacht werden, ob diese mutierten Sequenzen wirklich translatiert, normal glykosyliert und zur Membran transportiert und als Kanaluntereinheiten korrekt assembliert werden. In der Literatur wurden für andere Kaliumkanalmutationen Veränderungen in diesen Eigenschaften gefunden (Persson et al., 2005), z. B. für den hERG-Kanal, der wie der EAG-Kanal zu der EAG-Familie gehört (Gong et al., 2004). Eine fehlerhafte Glykosylierung oder die Bildung von nicht-funktionellen Tetrameren könnte bei manchen der in dieser Arbeit untersuchten natürlich exprimierenden Zelllinien erfolgen. Da der molekulare Mechanismus der transformierenden Eigenschaften von EAG und der Wirkungsort in der Zelle noch nicht geklärt werden konnten, ist eine Interpretation der Beobachtungen an dieser Stelle nicht möglich. Genauere Studien über diese ersten Hinweise auf Mutationen werden Aufschluss darüber geben.

\subsection{Identifikation differentiell exprimierter Gene in transfizierten HEK- Zellen}

In den letzten Jahren wurden große Fortschritte bei der Sequenzierung vollständiger Genome wie das des Menschen und der Aufklärung der Funktion von Genen erzielt. Unerlässlich für die Aufklärung des komplexen Zusammenspiels von Genen und den Proteinen, die sie kodieren, war dabei die Analyse des Transkriptoms von Zellen, die bestimmten Bedingungen ausgesetzt waren. Diese Analyse kann prinzipiell unter Verwendung verschiedener Methoden 
wie Mikroarrays, subtraktiver Hybridisierung oder differenzielles Display durchgeführt werden. In dieser Arbeit wurden sowohl Mikroarrays als auch die subtraktive Hybridisierung als methodische Ansätze zur Aufklärung der zellphysiologischen Veränderungen nach Transfektion von hEAG1a in Zellen und nach der Hemmung von hEAG1 in natürlich exprimierenden Zellen gewählt. Zunächst wurde das Verhalten des menschlichen hEAG1aKanals in menschlichen Zelllinien (HEK293) beobachtet, die als Modell für das Verhalten von EAG1 in einem frühen Stadium der Krebsentstehung gelten können.

Diese Arbeit stellt damit die erste darauf ausgerichtete Studie dar, Hinweise auf die Funktion von hEAG1 über das Genexpressionsprofil der Zellen zu finden. Zunächst wurden hEAG1atransfizierte HEK mit Wildtyp- oder Vektor-transfizierten Zellen mit pfadspezifischen Arrays mit geringer Gendichte (23 Gene pro Array) verglichen. Mit Hilfe dieser pfadspezifischen Arrays sollten erste Hinweise auf die involvierten Gen-Familien und Signaltransduktionswege erhalten werden. Diese Methode hat sich laut Literatur als erfolgreich erwiesen (Van 't Veer et al., 2002). Anstatt ein Genom-weites Expressionsprofil als Ganzes zu erstellen, beinhaltet ein fokussierter cDNA-Array Gene, deren Beziehungen $\mathrm{zu}$ physiologischen oder pathophysiologischen Zuständen vorher schon etabliert oder zumindest vermutet werden, da für die meisten physiologischen Vorgänge eine charakteristische differentielle Expression von nur ca. 100 verschiedenen Genen beobachtet wird (Van 't Veer et al., 2002). Wie bei allen Arrays wurden für die Auswahl der Kandidatengene, die weiter mit anderen Methoden untersucht werden sollten, spezielle Kriterien angewendet, die zahlreich in der Literatur beschrieben sind. Hierzu zählen die Höhe der Expressionsänderung und der Basalexpression sowie Reproduzierbarkeit, Signifikanz und Kontext (Hu et al., 2006). 11 Gene aus vier verschiedenen Krebs-spezifischen Arrays erfüllten die genannten Kriterien. Von diesen wurden drei mit Real-Time-PCR weiter untersucht, nämlich die Rezeptor-assoziierten Tyrosinkinasen c-SRC und BLK und der endogene Proteaseinhibitor PlasminogenaktivatorInhibitor PAI-1. Die Real-Time-PCR zeigte jedoch, dass die Gene zwischen den kanalhaltigen Zellen und den Kontrollzellen nicht differentiell exprimiert werden. Man kann daher davon ausgehen, dass die Gene, die durch EAG1-Expression verändert werden, in diesen pfadspezifischen Arrays nicht enthalten sind. Es sind möglicherweise andere, bisher nicht so direkt mit Krebs in Verbindung gebrachte Gene verändert.

\subsubsection{Mikroarray}


In den bisher diskutierten heterologen Expressionssystemen wurden die Auswirkungen des Einbringens von EAG1 in Zellen untersucht. Hierbei besteht die Gefahr, dass bestimmte interagierende Faktoren fehlen oder der Kanal anormal prozessiert wird, da es sich um ein artifizielles System handelt. Weiterhin birgt dieses System die Gefahr, dass durch die Einführung des pTracer-Plasmids in den Zellen physiologische Veränderungen, möglicherweise Genexpressionsänderungen hervorgerufen werden, die nicht auf EAG1Expression zurückzuführen sind. Daher wurde in dieser Arbeit als nächstes die Expression von EAG1 in natürlich exprimierenden Zellen, die von Krebstumoren abstammen (Cailleau et al., 1978), untersucht. Mit diesem Ansatz war es möglich, zu beobachten, welche Gene bei Inhibierung vom natürlich exprimierten Kanal in den verschiedenen Zellen hoch- oder herunterreguliert wurden. Mikroarrays werden routinemäßig für Transkriptomanalysen im großen Maßstab durchgeführt, sind erfolgreich für die simultane Überprüfung der Expression einer fast unbegrenzten Anzahl von Genen angewendet worden und stellen somit die Basis für die Identifikation differentiell exprimierter Gene in verschiedenen Zelltypen, Entwicklungsund Krankheitsstadien und Behandlungen mit Reagenzien dar (Schena et al., 1995). Diese Eigenschaft ist besonders wertvoll für die Entschlüsselung komplexer Krankheiten wie Krebs. Seit 1999, dem Jahr, in dem die ausgereifte Mikroarray-Technologie erhältlich wurde, wurde dieses Werkzeug in zahlreichen Krebsforschungsstudien angewendet und mit ihm neue Einsichten in die biologischen Prozesse, die dem Krebs zu Grunde liegen, erworben.

Die in dieser Arbeit besonders hervorgetretenen acht Gene aus der Klasse 1 (PCQAP, KRT23, FLJ20337, FLJ32800, CTNNA1, ZNF236, VASP, HSD17B7) und vier Gene aus der Klasse 2 (FLJ10901,FLJ31795, AMPD2, SIGLEC8) wurden mit Real-Time-PCR weiter untersucht, wobei SIGLEC8 so gering exprimiert war, dass es nicht mit PCR gemessen werden konnte. Die differentielle Expression der Kandidatengene aus den drei Klassen konnte nicht mit Real-Time-PCR bestätigt werden.

Da das Genexpressionsprofil nach 7-tägiger Inkubation mit den Reagenzien bestimmt wurde, wäre es möglich, dass die Blockierung von EAG1 durch Astemizol die EAG-haltigen Zellen unterdrückt hat und daher eine Selektion von weiterhin proliferierenden Zellen erfolgte, die das gleiche Expressionsprofil wie unbehandelte Zellen aufwiesen.

Krebstumore sind meist eine Folge einer gestörten Regulation von Genen, die im weitesten Sinn bei der Zellproliferation eine aktivierende oder hemmende Rolle spielen. Eines dieser Gene ist z.B. GADD45 $\alpha$ (growth arrest- and DNA damage- inducible gene GADD45 $\alpha$ ), das in der Lage ist, den Eintritt in die S-Phase zu verhindern und damit die Proliferation hemmt 
(Smith et al., 1994). Auch das PKA-Gen, das für die Protein Kinase A kodiert, und sprouty homolog 2 (Spry2) übernehmen inhibierende Funktionen bei der Proliferationsregulation (Gross et al., 2001; Stork und Schmitt, 2002). Diese drei Gene wurden mittels Mikroarrays beim Vergleich von Rhabdomyosarkomgewebe mit entsprechendem gesunden Gewebe als differentiell exprimiert identifiziert (Kappler et al., 2003). Die Expression dieser Gene wurde daher besonders überprüft, es konnte keine differentielle Expression in den Zelllinien beobachtet werden.

\subsubsection{Subtraktive Hybridisierung}

Da die fokussierte Strategie zur Untersuchung der differentiellen Genexpressionkeine großen Änderungen erkennen ließ, wurde daraufhin eine Methode ohne Bias angewendet, die subtraktive Hybridisierung, mit der auch noch gänzlich unbekannte Gene gefunden werden können. Mit Methoden wie der subtraktiven Hybridisierung können nur Fragmente von Genen gefunden werden, eine Tatsache, die durch die vollständige Sequenzierung des menschlichen Genoms keinen großen Nachteil mehr darstellt. Durch die spezielle Anwendung der subtraktiven Hybridisierung zum Vergleich von transfizierten Zellen wurden in dieser Arbeit einige Modifikationen zum Protokoll des Herstellers nötig. Zum einen wurden andere Adaptoren verwendet, da die Adaptoren des Herstellers T7Promotorsequenzen beinhalteten, die sowohl im Transfektionsvektor (pTracer) als auch im Sequenziervektor (pGEM-T) vorkamen und zu Problemen während der Subtraktion und der Sequenzierung geführt hätten. Zum anderen musste der jeweilige Driver-Ansatz mit TesterPlasmid versetzt werden, um das Auftreten von EAG1- und eventuell GFP-Klonen zu unterdrücken, die natürlich hochdifferentiell zwischen den $\mathrm{zu}$ vergleichenden Zellen exprimiert werden. Die Kontrollen zeigten, dass die Subtraktion korrekt und effizient funktioniert hatte. Das Haushaltsgen Transferrin-Rezeptor Typ 1 (TFR1) war durch die Prozedur sowohl in der Vorwärts- als auch in der Rückwärtssubtraktion mit hoher Effizienz heraussubtrahiert worden. Dabei konnte der Transferrin-Rezeptor in der Rückwärtsreaktion effizienter unterdrückt werden als in der Vorwärtsreaktion, was auf nicht signifikant größere hTFR-RNA-Mengen in den hEAG1a-transfizierten Zellen hinweist, die später auch mit RealTime-PCR bestätigt wurden. Nach dem Ausschluß der hEAGla-Klone wurden durch das differentielle Screening 14 putativ differentiell exprimierte Klone in der Vorwärtssubtraktion und 47 putativ differentiell exprimierte Klone in der Rückwärtssubtraktion gefunden, von denen in dieser Arbeit 11 mit Real-Time-PCR näher untersucht wurden. Es handelte sich bei 
den Klonen aus der Vorwärtssubtraktion um VAP-C (vesicle-associated membrane proteinassociated protein C) und CUTL1 (CCAAT-displacement protein), bei denen aus der Rückwärtsreaktion um zwei Klone MAZ (myc-associated zinc finger protein), zwei Klone RACK1 (receptor for activated protein kinase C), PIK3R3 (phospatidylinositol 3 kinase, regulatory subunit 3), BRCA1 (breast cancer 1), UBE1 (ubiquitin-activating enzyme 1), EEF1 $\alpha$ (eukariotic translation elongation Factor 1) und GAPDH (glycerin-aldehyd-3phosphat dehydrogenase). Da im Laufe dieser Arbeit ersichtlich wurde, dass die Oberflächenexpression von hEAG1 streng reguliert ist (siRNA-Experimente), wurde das VAP-C-Gen zur Weiteruntersuchung ausgewählt, obwohl es noch nicht mit Krebserkrankungen in Verbindung gebracht wurde. VAP-C interagiert mit Vesikelassoziierten Proteinen, die intrazelluläre Membranproteine darstellen, die mit Mikrotubuli assoziieren und eine Funktion bei Membrantransport und -fusion übernehmen (Bock und Scheller, 1997). Da es sich bei der subtraktiven Hybridisierung um eine Methode ohne Bias handelt, die im Gegensatz zu den Pfad-spezifischen Arrays in keiner Weise Krebsgene bevorzugt, ist das gehäufte Auffinden von Krebs- und Proliferations-verwandten Genen besonders bemerkenswert. So wurden reduzierte CUTL1 mRNA-Mengen in 8 von 13 Leiomyom-Tumoren gefunden. Es wird vermutet, dass CUTL1 als Tumorsuppressorgen agiert, dessen Inaktivierung von pathologischer Relevanz in der Ethiologie von GebärmutterLeiomyomen sein könnte (Zeng et al., 1997). Veränderte Expression des Translationselongationsfaktors $\quad 1 \alpha \quad($ EEF $1 \alpha), \quad$ einem $\quad$ Kernbestandteil der Proteinsynthesemaschinerie, wurde durch mehrere unabhängige Studien in Verbindung mit einem transformierten Phänotyp gebracht (Gopalkrishnan et al., 1999). BRCA1 repräsentiert das paradigmatische Brustkrebs-Tumorsuppressorgen (Yoshida und Miki, 2004). UBE1 ist ein Bestandteil der Ubiquitinierungsenzymkaskade, die eng mit Krebs assoziiert wurde (Sherr, 2004). PIK3R3 wurde 1998 mit Tumorentstehung im Säugetier in Verbindung gebracht (Jimenez et al., 1998).

In der Überprüfung durch Real-Time-PCR stellten sich drei von diesen acht verschiedenen Genen aus dem differentiellen Screening nach der subtraktiven Hybridisierung als geringfügig, aber signifikant differentiell exprimiert heraus. Dabei handelte es sich um GAPDH, RACK1 und MAZ.

\subsubsection{Das Haushaltsgen GAPDH war in den verglichenen Zelllinien differentiell exprimiert}


Es konnte in dieser Arbeit beobachtet werden, dass das Haushaltsgen GAPDH in den verglichenen Zellen unterschiedlich stark exprimiert worden sein musste, da es im Experiment nicht heraus subtrahiert wurde. Dieses Ergebnis wurde durch Real-time-PCR und Identifizierung eines Klons aus der Rückwärtssubtraktion als GAPDH im differentiellen Screening verifiziert. GAPDH ist ein Schlüsselenzym aus der Glykolyse und setzt Glyzerinaldehyd-3-phosphat in 1, 3-Bisphoshoglyzerat um. Es wird allgemein als konstantes Haushaltsgen betrachtet und als solches als Kontrolle für differentielle RNA-und ProteinProduktion in Northern Blotting, Real-Time-PCR und Western Blot verwendet. Neuere Studien jedoch machen deutlich, dass auch Haushaltsgene unter bestimmten Bedingungen differentiell exprimiert sein können. Die differentielle Expression von „nicht-differentiellen“ Haushaltsgenen in der Embryonalentwicklung ist beschrieben (Prime et al., 2000). Außerdem wurde beobachtet, dass die mRNA-Expression in einigen Tumorproben, in malignen Mauszellinien und menschlichem Prostatakrebs verändert war (Valenti et al., 2006).

In dieser Arbeit konnte durch Inhibierung dieses Enzyms mit siRNA eine Erniedrigung der Proliferation und der metabolischen Aktivität beobachtet werden. Da die hEAG1a- und G440S-transfizierten Zellen geringere Mengen an GAPDH exprimietren, könnte dies der Grund für die unerwartete Verringerung der Proliferation in diesen Zellen sein. Die Umsetzung des Substrats zu Produkt durch das Enzym ist eine limitierende und streng regulierte Schlüsselreaktion in der Glykolyse, die die Ausgangsprodukte für den Zitratzyklus und die nachfolgende oxidative Phosphorylierung zur Energiegewinnung bereitstellt. Ein genereller Mangel an GAPDH, bzw. seiner Aktivität ist möglicherweise in der Lage, alle Stoffwechselvorgänge langsamer ablaufen zu lassen, da weniger Energie für den Stoffwechsel bereit steht, wodurch die in dieser Arbeit beobachtete Verlangsamung der Proliferation teilweise erklären ließe.

\subsubsection{Zwei Gene, RACK1 und MAZ, sind in kanalhaltigen Zellen differentiell exprimiert}

In der subtraktiven Hybridisierung wurden jeweils zwei verschiedene Klone von RACK1 und MAZ gefunden, ein starker Hinweis darauf, dass diese Gene tatsächlich differentiell exprimiert sind. RACK1 ist der Rezeptor für aktivierte Proteinkinase $C$ ( $\beta$ IIPKC) und daher ein Bestandteil der PKC-Signaltransduktionskaskade. Er wurde als intrazelluläres AdapterProtein aus der Tryptophan-Aspartat(WD)-Familie und als $36 \mathrm{kDa}$ Homolog der $\beta$ Untereinheiten trimerer G-Proteine identifiziert (Iniguez-Lluhi et al., 1993; Neer et al., 1994). 
Viele Studien lieferten Hinweise darauf, dass RACK1 eine Rolle bei der PKC-vermittelten Signaltransduktion in Krebsgeweben übernimmt. Im menschlichen großzelligen Lungenkrebs und im Darmkrebs z. B. ist die Expression von RACK-1 im Vergleich zum entsprechenden normalen Gewebe erhöht (Schechtman und Mochly-Rosen, 2001). Eine andere Forschergruppe berichtet, dass RACK1 durch Suppression von SRC das Wachstum von NIH 3T3- und HEK-Zellen verlangsamt, indem es den Übergang von der G1 zur S-Phase des Zellzyklusses hemmt, und es damit einen Tumorsuppressor darstellen könnte (Mamidipudi et al., 2004). Die Beobachtung dieser Arbeit, dass die Expression von RACK1 in den EAGhaltigen Zellen, die eine verringerte Proliferation aufwiesen, vermindert war, würde eher für die positive Beeinflussung des Wachstums durch RACK-1 sprechen.

Das zweite differentielle Gen, MAZ (myc-associated zink finger protein), ist ein 477Aminosäuren langer Zinkfinger-Transkriptionsfaktor vom $\mathrm{Cys}_{2} \mathrm{His}_{2}-\mathrm{Typ}$. Er fungiert in Menschen-, Maus- und Hamster-Zellen als Aktivator, Initiator (Bossone et al., 1992) und Terminator (Ashfield et al., 1994) der Transkription. In dieser Arbeit wurde eine verminderte Expression von RACK1 und MAZ in heterolog exprimierenden kanalhaltigen Zellen beobachtet, die möglicherweise an der beobachteten Verminderung der Proliferation in HEKZellen beteiligt sein könnte.

\section{5 hEAG1 wird effizient und hochspezifisch durch Anti-EAG1-siRNAs gehemmt}

Um den schon am Anfang dieser Arbeit erwähnten Einfluss des Transfektionsplasmids pTracer auf die Physiologie der Zellen auszuschließen, wurde nachfolgend die Inhibierung von hEAG1 mit RNAi in HEK-Zellen und natürlich exprimierenden Zellen etabliert und optimiert, um danach diese Methode zur genaueren Untersuchung der potentiell differentiell exprimierten Gene zu verwenden. Bis zu dieser Arbeit gab es keinen spezifischen Inhibitor für EAG1, da weder das trizyklische Anti-Depressivum Imipramin noch das AntiHistaminikum Astemizol spezifische Blocker für EAG1 darstellen. Imipramin blockiert sowohl viele $\mathrm{Na}^{+}-, \mathrm{Ca}^{2+}$ - und $\mathrm{K}^{+}$-Kanäle im Herzen und im Gehirn als auch EGL2-Kanäle, während Astemizol der paradigmatische Inhibitor für hERG-Kanäle ist (García-Ferreiro et al., 2004). Unglücklicherweise konnte eine breite Koexpression dieser anderen Kanäle mit EAG1 sowohl in natürlich exprimierenden Zelllinien als auch in Krebsgeweben und schwere therapeutische Nebeneffekte festgestellt werden (Zhou et al., 1999). Einen spezifischen 
Blocker für EAG zu finden, ist für die Aufklärung der physiologischen Rolle des Kanals im Gehirn als auch seiner pathophysiologischen Relevanz in Tumorzellen und für eine mögliche Therapeutische Anwendung notwendig.

Mit der neuen und hochspezifischen RNA-Interferenz-Methode wurde eine effektive Methode gefunden, die Expression von hEAG1 zu unterbinden. Diese Methode erwies sich insbesondere für die Charakterisierung von EAG in vitro als sehr geeignet. siRNAs repräsentieren eine geeignete Alternative zu Blockern der Kanalaktivität. Sie haben sich als wertvoll und spezifisch bei der Inhibierung von verschiedenen Proteinen einschließlich Ionenkanälen, z. B. TASK-1 (Gurney und Hunter, 2005), erwiesen und stellen einen vielversprechenden methodischen Ansatz für die Krebstherapie dar (Izquierdo, 2005).

Der wichtigste Faktor für die erfolgreiche Anwendung von siRNAs ist die Auswahl eines geeigneten Segmentes der mRNA. Mehrere Bedingungen müssen dabei berücksichtigt werden (Eckstein, 2005), auf die in dieser Arbeit besonders eingegangen wurde. Für das Design der siRNAs wurde der HiPerformance siRNA Design Algorithm von Qiagen verwendet, der die thermodynamischen Eigenschaften und die vorausgesagten Spezifitäten der siRNAs berücksichtigt, aber letztendlich können nur Experimente Einblick in die tatsächlichen Effizienzen und Spezifitäten einer bestimmten siRNA geben.

Kontrollexperimente sollten die Verwendung von mindestens zwei unabhängigen spezifischen siRNAs wie auch mismatch siRNAs oder srambled siRNAs beinhalten (Editorial, 2003). In dieser Arbeit wurden vier unabhängige hEAG1-Sequenzen getestet und jeweils verschieden starke Reduktionen der hEAG1-Expression beobachtet. Mit der effektivsten Sequenz wurde gezeigt, dass mit geringen Konzentrationen siRNA die hEAG1Expression in mehreren Zelllinien auf der mRNA, Protein und funktionellen Ebene gehemmt werden konnte. Dieses Ergebnis wurde nicht mit kommerziell erhältlichen unspezifischen siRNAs, einer Mischung aus vier unabhängigen Anti-hEAG2-siRNAs oder reversen, nicht komplementären siRNAs beobachtet. In dieser Arbeit wurden zum ersten Mal reverse, nichtkomplementäre siRNAs als zusätzliche Kontrolle verwendet. Sie weisen die gleiche Nukleotidzusammensetzung und die ähnlichste Struktur zu der spezifischen siRNA auf und besitzen daher das Potential, die meisten nicht-spezifischen Effekte von siRNAs auszulösen. Weitere Kontrollexperimente, in denen die RNA-Mengen des nahe verwandten hEAG2-Gens und eines nicht-spezifischen Gens (PDK1) überprüft wurden, deuten an, dass die verwendeten hEAG1-siRNAs sehr spezifisch auf ihre Zielsequenzen wirken.

Hohe siRNA-Konzentrationen können unspezifische Effekte hervorrufen. Die Menge an siRNA, die für den maximalen Abbau der Ziel-RNA nötig ist, kann abhängig von der 
Expressionsmenge des Zielgens sein (Daude et al., 2003). Daher wurde in dieser Arbeit die Dosis-Abhängigkeit der hEAG1-siRNA in transfizierten und natürlich exprimierenden Zellen bestimmt. Der $\mathrm{IC}_{50}$-Wert lag in allen Fällen im $10 \mathrm{nM}$-Bereich und deutete an, dass unspezifische Effekte durch zu hohe siRNA-Konzentrationen unwahrscheinlich waren.

Nach neuestem Erkenntnisstand haben auch siRNAs das Potential, eine Interferonantwort (Sledz und Williams, 2004) und damit eine globale nicht-spezifische Unterdrückung der Genexpression auszulösen (Bantounas et al., 2004; Persengiev et al., 2004). Außerdem gibt es Hinweise darauf, dass 21-mer siRNAs nicht nur eine Auslösung der Interferonantwort bewirken sondern auch die Expression von gänzlich unverwandten Genen beeinflussen können. Um Falschinterpretationen dieser unspezifischen Effekte zu vermeiden, wird empfohlen, dem Zielgen verwandte und nicht verwandte Gene parallel zu überprüfen, die minimale noch effektive siRNA-Konzentration und mehrere scrambled und spezifische siRNAs einzeln oder in Kombination zu verwenden und die Expositionszeiten zu optimieren (Editorial, 2003). In dieser Arbeit deutet keines der Kontrollexperimente auf eine unspezifische Wirkungsweise oder auf ungewollte Effekte auf andere Gene hin. Daher kann man daraus schließen, dass die in dieser Arbeit beobachteten phänotypischen Veränderungen durch die Stilllegung der hEAG1-Expression hervorgerufen wurden.

Da es bei der Interpretation von siRNA-Experimenten wichtig ist, nicht nur die Sequenz und die Umsetzung der siRNA selbst, sondern auch Zelllinien-bedingte Faktoren zu berücksichtigen (Choi et al., 2005), wurden für diese Arbeit drei Zelllinien unterschiedlichen Ursprungs verwendet, die sich in ihren RNA-Expressionsmengen und möglicherweise im Durchsatz von hEAG1 und der Anwesenheit oder Abwesenheit von Interaktionspartnern unterscheiden.

hEAG1a-transfizierte HEK-Zellen wurden als heterologes Expressionssystem benutzt, in dem hEAG1a-Ströme gut gemessen werden können und große hEAG1a-RNA- $\left(1-5 \times 10^{6}\right.$ Kopien/ $\mu 1)$ und Protein-Mengen verfügbar sind. Diese Zelllinie stammt jedoch nicht von einem Tumor $a b$, sondern wurde durch Infektion mit einem Adenovirus immortalisiert (Graham et al., 1977) und repräsentiert daher ein artifizielles System, in dem möglicherweise interagierende Faktoren fehlen oder der Kanal anormal prozessiert wird.

Die Medulloblastom-Zelllinie Daoy wurde als ZNS-abgeleitetes Modell verwendet. Das Medulloblastom ist der häufigste maligne Gehirntumortyp in Kindern, der vermutlich von undifferenzierten Zellen der granulären Schicht des Kleinhirns abstammt. Die Daoy-Zelllinie besitzt neuronale und gliale Charakteristiken (Peyrl et al., 2003) und exprimiert eine moderate 
Menge an endogenem hEAG1 (10000-50000 Kopien/ $\mu 1)$. Außerdem exprimiert sie natürlicherweise hEAG2, was eine gute interne Kontrolle darstellt.

Die dritte Zelllinie, die MDA-MB435S, stammt von einem Brustkrebstumor ab, obwohl Genarrayexperimente eher darauf hindeuten, dass sie mit Melanomzellen verwandt ist (Ross et al., 2000; Sellappan et al., 2004). Sie exprimiert eine geringe hEAG1-Menge (1000-5000 Kopien/ $\mu$ l) und eine sehr kleine hEAG2-Menge. Diese zwei Zelllinien sind daher gute Kandidaten dafür, Faktoren zu besitzen, die für die Interaktion mit hEAG in Krebszellen nötig sind.

Die Behandlung der Zellen mit hEAG1-siRNA ergab fast identische phänotypische Veränderungen in allen drei Zelllinien, die als Reduktion der Proliferation interpretiert werden können. Daher wurden nachfolgend die Auswirkungen der hEAG1-Stilllegung durch siRNAs auf die Proliferation in weiteren Krebszelllinien aus verschiedenen Tumorarten wie Rhabdomyosarkomen, Fibrosarkomen, Brustkrebs, Melanomen, Zervixkarzinomen, Neuroblastomen und Medulloblastomen untersucht. In dieser Arbeit wurde eine konsistente Reduktion der Wachstumsgeschwindigkeit in den meisten Zelllinien beobachtet. Diese Beobachtungen unterstreichen die Beteiligung von hEAG1 an der Tumorproliferation und bestärken die Hypothese, dass hEAG1 ein geeignetes Zielprotein für die Krebstherapie darstellt.

Der Zeitverlauf der Reduktion von hEAG1-RNA, Protein und Aktivität nach Behandlung mit siRNAs war ungewöhnlich schnell und deutet daher auf einen schnellen Umsatz dieses Moleküls auf allen Ebenen hin. Normalerweise werden zwei bis vier Tage benötigt, um eine Reduktion von Protein nach der Exposition mit siRNAs detektieren zu können (Gurney und Hunter, 2005; Tulac et al., 2004). In dieser Arbeit konnte nicht nur eine Reduktion des hEAG1a-Proteins nach weniger als $8 \mathrm{~h}$ nach der Transfektion, sondern auch eine komplette Inhibierung der hEAG1a-Leitfähigkeit nach $24 \mathrm{~h}$ beobachtet werden. Dass die RNA-Mengen sich erst nach $72 \mathrm{~h}$ erholten, einem Zeitpunkt, an dem die elektrophysiologische Aktivität schon wieder komplett hergestellt war, deutet auf das Vorhandensein eines intrazellulären Vorrats an hEAG1a-Protein hin. Der Hintergründe dafür und die Folgen dieses rapiden Durchsatzes werden zur Zeit untersucht.

\subsection{Die Expression von MAZ und zwei seiner Zielgene werden durch hEAG1 moduliert}


Da Faktoren, die sich flussabwärts von den geänderten Zielgenen befinden, entsprechend später beeinflusst werden, wird für die Regulation der zwei geringfügig differentiell exprimierten Gene hRACK1 und hMAZ aus der subtraktiven Hybridisierung ein nach späteren Zeitpunkten verschobener Zeitverlauf postuliert, der in den Experimenten mit den drei Modellzelllinien (hEAG1a-transfizierte HEK-, MDA-MB-435S- und Daoy-Zellen) nachgewiesen werden konnte. In allen drei mit Anti-EAG1-siRNA-behandelten Zelllinien konnte nach 24 h eine signifikante Erhöhung der hMAZ-mRNA-Menge mit einem Maximum bei 48 h, beobachtet werden, dass sich später wieder Kontrollwerten annäherte. Die maximale Erhöhung war mit $70.49 \pm 6.44 \%$ in den MDA-MB435S-Zellen am größten. Mit dem zweiten differentiell exprimierten Gen aus der subtraktiven Hybridisierung, hRACK1, konnte kein solcher Zeitverlauf in transfizierten HEK-Zellen wie für hMAZ beobachtet werden, daher kann ein globaler unspezifischer Effekt der siRNAs auf die hMAZ-Expression ausgeschlossen werden. Dieser 477-Aminosäuren lange Zinkfinger-Transkriptionsfaktor vom $\mathrm{Cys}_{2} \mathrm{His}_{2}$-Typ fungiert in Menschen-, Maus- und Hamster-Zellen als Aktivator, Initiator und Terminator der Transkription (Ugai et al., 2001). Vier Bindungsstellen für hMAZ wurden im Promotor des Serotonin 1a Rezeptors (HT1a-Rezeptor) gefunden. Im Transient TransfectionAssay-Experiment konnte in drei menschlichen Zelllinien die Expression von HT1a-Rezeptor durch hMAZ erhöht werden (Parks und Shenk, 1996). Auch der Promotor des N-Methyl-DAspartat-Rezeptor (NMDA) 1 (NR1) beinhaltet Sequenzen, an die hMAZ binden und die Promotoraktivität erhöhen kann (Okamoto et al., 2002). Eine Forschergruppe hat herausgefunden, dass ein Pankreas-spezifisches MAZ-Transkript in 5 bis 10-fach höheren Mengen in Inselzellkarzinomen als in normalen Inselzellen exprimiert wird und die transkriptionelle Aktivität des c-MYC-Gens verstärkt (Tsutsui et al., 1996). Im Yeast-TwoHybrid-Assay war 2001 gezeigt worden, dass MAZ mit dem putativen Tumorsuppressor DCC (deleted in colorectal cancer) assoziert und dadurch seine Bindung an den c-MYCPromotor und die Expression von c-MYC vermindert wird (Ugai et al., 2001). Bindungsstellen für hMAZ kommen auch in dem Promotoren des hc-MYC-Gens selbst sowie im Promotor von Gen der reversen Transkriptase der Telomerase (hTERT) vor (Cong et al., 2002; Kabilova et al., 2006) vor und regulieren dort die Genexpression.

Das c-MYC-Protoonkogen ist eines der typischen, schon lange bekannten Protoonkogene und kodiert für ein nukleäres Phosphoprotein, das in die maligne Tumorigenese involviert ist (Kabilova et al., 2006). Es besitzt eine basische Helix-Loop-Helix/Leucin-Zipper Domäne, die die Dimerisierung mit seinem Bindungspartner MAX (Myc-assciated Factor $X$ ) vermittelt, die für seine Funktion als sowohl Aktivator als auch Repressor der Transkription 
nötig ist (Secombe et al., 2004). Es spielt eine Schlüsselrolle bei der Zellproliferation, Differenzierung und Apoptose und induziert oder reprimiert eine Vielzahl der für diese Funktionen zuständigen Gene (Coller et al., 2000). Die Aktivität der reversen Transkriptase (hTERT) der menschlichen Telomerase war in etwa $90 \%$ von Tumorproben erhöht und sie besitzt das Potential für die Immortalisierung vieler Zelltypen (Cong et al., 2002). Auf Grund dieser Beobachtungen wurden in dieser Arbeit auch Zeitverläufe dieser beiden hMAZZielgene nach Stilllegung von EAG mit RNAi aufgenommen. Es konnten eine signifikante maximale Reduktion der RNA-Menge 48-92 h nach Transfektion der siRNAs in die Zellen beobachtet werden. Der gegenläufige Einfluss der Anti-EAG1-siRNA-Behandlung auf die Transkription von hMAZ im Vergleich zu hc-MYC und hTERT bekräftigt nochmals, dass die dokumentierten Effekte EAG1-spezifisch sind.

Durch Verminderung der hEAG1-RNA-Menge durch siRNAs konnte in dieser Arbeit hMAZ induziert werden. hMAZ kann kontextabhängig als Aktivator oder Repressor agieren (Secombe et al., 2004). Die Beobachtung dieser Arbeit könnte darauf hin deuten, dass hMAZ in diesem System als Repressor am hc-MYC-Promotor die Transkription von hc-MYC unterbindet und die Zellen dadurch langsamer wachsen. Ist hEAG1 in großen Mengen vorhanden, wird hMAZ nur geringfügig exprimiert und kann die hc-MYC-Transkription nicht mehr hemmen. Die hc-MYC-Expression und die Proliferationsrate werden erhöht. In den hEAG1a-transfizierten HEK-Zellen konnte in der subtraktiven Hybridisierung ebenfalls eine geringere hMAZ-RNA-Menge beobachtet werden als in Vektor-transfizierten Zellen. Die Erhöhung der hTERT-Expression könnte eine Folge der hc-MYC-Expression sein, da im hTERT-Promotor Bindungsstellen für diesen Transkriptionsfaktor vorkommen und schon gezeigt wurde, dass hTERT durch hMYC induziert wird (Cong et al., 2002). Der in dieser Arbeit beobachtete gleichgerichtete Effekt auf die hc-MYC und hTERT-Expression in ektopisch exprimierenden Krebszelllinien macht Sinn, wenn man bedenkt, dass während des normalen Zellwachstums die Telomeraseaktivität entsprechend den Proliferationsanforderungen der spezifischen zellulären Funktionen streng reguliert wird. Sie hält damit proliferative Grenzen (Senszenz) gegen die Zellentartung aufrecht (Cong et al., 2002). Bei Disregulation ihrer Expression kann daher entweder ein Zellzyklusarrest auftreten (bei verminderter Expression) oder der Zellzyklus ungehemmt durchlaufen werden (bei erhöhter Expression). (Harley, 2002). Die in dieser Arbeit bei Anwesenheit von hEAG1 beobachtete simultane Erhöhung der hTERT-Expression garantiert den Krebszelllinien eine freie Passage durch den Zellzyklus. Die hTERT-Expression in der Adenovirusimmortalisierten HEK-Zelllinie wird offensichtlich nicht durch hEAG1, hMAZ oder hc-MYC 
reguliert. Die Untersuchung der Unterschiede dieser Zelllinie zu den anderen beiden in dieser Arbeit verwendeten Krebszellinien wird Hinweise auf den zugrundeliedenden Mechanismus liefern.

In dieser Arbeit wurde mit der RNA-Interferenz eine Methode gefunden und optimiert, mit der hEAG1 auf allen Ebenen seiner Expression und Aktivität inhibiert werden kann. Die dafür entworfenen siRNAs konnten in der vorliegenden Arbeit erfolgreich für die Beeinflussung und Untersuchung der flussabwärts liegenden Zielgene von hEAG1 hMAZ, hc-MYC und hTERT, die in engem Zusammenhang mit Krebserkrankungen stehen, angewendet werden. Diese siRNAs können in Zukunft als Werkzeug benutzt werden, um sowohl die physiologische als auch pathophysiologische Funktion und die Wirkungsmechanismen dieser interessanten Proteine weiter aufzudecken.

\subsection{Zusammenfassung und abschließende Betrachtung}

1) In dieser Arbeit wurde zum ersten Mal mit der RNA-Interferenz-Methode eine hochspezifische Möglichkeit gefunden, den hEAG1-Kanal sowohl auf RNA-, Proteinund Aktivitätsebene als auch auf Funktionsebene (Proliferation, Expressionsmodulation von Zielgenen) zu hemmen und somit eine Grundlage für die Entwicklung einer EAG1-spezifischen Krebstherapie geschaffen. Für andere in Krebs involvierte Gene wurde der erfolgreiche Einsatz von siRNAs in vorklinischen Studien beschrieben (Izquierdo, 2005). Es gelang in der vorliegenden Arbeit mit zwei unabhängigen Methoden, der Inhibierung von EAG mit siRNAs und der subtraktiven Hybridisierung, den Zinkfinger-Transkriptionsfaktor MAZ als flussabwärts liegendes Zielgen von hEAG1 $\mathrm{zu}$ identifizieren. In den drei Modellzelllinien konnte ein defininierter Induktionszeitverlauf von MAZ durch Stilllegung von EAG1 beobachtet werden, der eine maximale Induktion $48 \mathrm{~h}$ nach siRNA-Transfektion zeigte. Bindungsstellen für diesen Transkriptionsfaktor kommen in den Promotoren mehrerer mit Krebs in Verbindung gebrachter Gene wie dem c-MYC- (Kabilova et al., 2006) und TERT-Gen (Cong et al., 2002) vor und regulieren dort die Genexpression. Daher wurden auch Zeitverläufe von diesen beiden MAZ-Zielgenen nach Stilllegung von EAG mit RNAi aufgenommen und eine signifikante maximale Repression der RNAMenge 48-96 h nach Transfektion in den siRNA-behandelten Zellen beobachtet. In Zukunft kann diese nun optimierte Methode als Werkzeug benutzt werden, um sowohl 
die physiologische als auch pathophysiologische Funktion dieser interessanten Proteine weiter aufzudecken.

2) Es konnte durch die Optimierungsstrategie und das Design von neuen Kontrollen ein signifikanter allgemeiner Beitrag zum neuen Forschungsfeld der RNA-Interferenz geleistet werden.

3) Weitere Gene, die für die physiologische Funktion der EAG1-Expression in menschlichen Zelllinien und Krebszelllinien verantwortlich sein könnten, konnten mit der subtraktiven Hybridisierung gefunden und mit quantitativer Real-Time-PCR verifiziert werden. Es konnte gezeigt werden, dass der mRNA-Gehalt von RACK1, MMP2, Fibronektin und des Haushaltsgens GAPDH durch Transfektion von hEAG1a in HEK-Zellen signifikant verändert wurde.

4) Es wurden durch die Sequenzierung von hEAG1 aus Krebszelllinien erste Hinweise darauf gefunden, dass EAG1 in unterschiedlichen Formen in Krebszellen vorkommt, deren Sequenzen von der hEAG1-Sequenz im Gehirn abweichen. Die Expression von Varianten mit Mutationen, Deletionen oder Insertionen von Onkogenen oder Tumorsuppressorgenen wurde vielfach beobachtet (Huang et al., 2004; Lynch et al., 2004; Sordella et al., 2004; Tracy et al., 2004).

5) Es wurde in dieser Arbeit erstmals das Vorkommen von EAG-Kanälen außerhalb des Gehirns in mehreren Organen der Maus beschrieben. Bisher wurde nur die Ratte auf Verteilung der EAG-Expression im Gehirn und peripheren Organen untersucht (Ludwig et al., 1994; Napp, 2003).

6) In weiterführenden Experimenten konnte erstmals die EAG-mRNA-Expression in Mäusen durch die Auslösung einer sterilen Entzündung durch intraperitoneale Injektion von Lipopolysacchariden außerhalb des Gehirns induziert oder reprimiert werden, während sie im Gehirn unverändert blieb. Ein wachsende Anzahl an Referenzen beschreibt eine Regulation von Ionenkanälen durch LPS und seine Mediatoren (Jou et al., 1998; Pyo et al., 1997; Yakubovich et al., 2001). 


\section{Literaturverzeichnis}

Abdul, M., and Hoosein, N. (2002a). Expression and activity of potassium ion channels in human prostate cancer. Cancer Lett 186, 99-105.

Abdul, M., and Hoosein, N. (2002b). Voltage-gated potassium ion channels in colon cancer. Oncol Rep 9, 961-964.

Adjaye, J., Herwig, R., Herrmann, D., Wruck, W. Benkahla, A., Brink, T. C, Nowak, M., Carnwath, J. W., Hultschig, C., Niemann, H., and Lehrach, H. (2004). Cross-species hybridisation of human and bovine orthologous genes on high density cDNA microarrays. BMC Genomics 5, 83 .

Agrawal, S., and Eng, C. (2006). Differential expression of novel naturally occurring splice variants of PTEN and their functional consequences in Cowden syndrome and sporadic breast cancer. Hum Mol Genet 15, 777-787.

Appel, S., Filter, M., Reis, A., Hennies, H.C., Bergheim, A., Ogilvie, E., Arndt, S., Simmons, A., Lovett, M., Hide, W., Ramsay, M., Reichwald, K., Zimmermann, W., and Rosenthal, A. (2002). Physical and transcriptional map of the critical region for keratolytic winter erythema (KWE) on chromosome 8p22-p23 between D8S550 and D8S1759. Eur J Hum Genet 10, 17-25.

Ashfield, R., Patel, A.J., Bossone, S.A., Brown, H., Campbell, R.D., Marcu, K.B., and Proudfoot, N.J. (1994). MAZ-dependent termination between closely spaced human complement genes. Embo J 13, $5656-5667$.

Bachmann, K.A. (2000). Norastemizole Sepracor. Curr Opin Investig Drugs 1, 219-226.

Bantounas, I., Phylactou, L.A., and Uney, J.B. (2004). RNA interference and the use of small interfering RNA to study gene function in mammalian systems. J Mol Endocrinol 33, 545-557.

Bar-Eli, M. (1999). Role of interleukin-8 in tumor growth and metastasis of human melanoma. Pathobiology 67, 12-18.

Bashyam, M.D. (2002). Understanding cancer metastasis: an urgent need for using differential gene expression analysis. Cancer 94, 1821-1829. 
Benveniste, E.N. (1992). Inflammatory cytokines within the central nervous system: sources, function, and mechanism of action. Am J Physiol 263, C1-16.

Bianchi, L., Wible, B., Arcangeli, A., Taglialatela, M., Morra, F., Castaldo, P., Crociani, O., Rosati, B., Faravelli, L., Olivotto, M., and Wanke, E. (1998). herg encodes a K+ current highly conserved in tumors of different histogenesis: a selective advantage for cancer cells? Cancer Res 58, 815-822.

Birnboim, H.C., and Doly, J. (1979). A rapid alkaline extraction procedure for screening recombinant plasmid DNA. Nucleic Acids Res 7, 1513-1523.

Biscardi, J.S., Tice, D.A., and Parsons, S.J. (1999). c-Src, receptor tyrosine kinases, and human cancer. Adv Cancer Res 76, 61-119.

Blatteis, C.M., Li, S., Li, Z., Perlik, V., and Feleder, C. (2004). Signaling the brain in systemic inflammation: the role of complement. Front Biosci 9, 915-931.

Bock, J.B., and Scheller, R.H. (1997). Protein transport. A fusion of new ideas. Nature 387, 133-135.

Bossone, S.A., Asselin, C., Patel, A.J., and Marcu, K.B. (1992). MAZ, a zinc finger protein, binds to $\mathrm{c}-\mathrm{MYC}$ and $\mathrm{C} 2$ gene sequences regulating transcriptional initiation and termination. Proc Natl Acad Sci U S A 89, 7452-7456.

Brancaccio, M., Hirsch, E., Notte, A., Selvetella, G., Lembo, G., and Tarone, G. (2006). Integrin signalling: The tug-of-war in heart hypertrophy. Cardiovasc Res 70, 422-433.

Brüggemann, A., Stühmer, W., and Pardo, L.A. (1997). Mitosis-promoting factor-mediated suppression of a cloned delayed rectifier potassium channel expressed in Xenopus oocytes. Proc Natl Acad Sci U S A 94, 537-542.

Cailleau, R., Olive, M., and Cruciger, Q.V. (1978). Long-term human breast carcinoma cell lines of metastatic origin: preliminary characterization. In Vitro 14, 911-915.

Camacho, J., Sánchez, A., Stühmer, W., and Pardo, L.A. (2000). Cytoskeletal interactions determine the electrophysiological properties of human EAG potassium channels. Pflügers Arch 441, 167-174.

Cherubini, A., Taddei, G.L., Crociani, O., Paglierani, M., Buccoliero, A.M., Fontana, L., Noci, I., Borri, P., Borrani, E., Giachi, M., Becchetti, A., Rosati, B., Wanke, E., Olivotto, M., and Arcangeli, A. 
(2000). HERG potassium channels are more frequently expressed in human endometrial cancer as compared to non-cancerous endometrium. Br J Cancer 83, 1722-1729.

Chittajallu, R., Chen, Y., Wang, H., Yuan, X., Ghiani, C.A., Heckman, T., Mcbain, C.J., and Gallo, V. (2002). Regulation of Kv1 subunit expression in oligodendrocyte progenitor cells and their role in G1/S phase progression of the cell cycle. Proc Natl Acad Sci U S A 99, 2350-2355.

Choi, I., Cho, B.R., Kim, D., Miyagawa, S., Kubo, T., Kim, J.Y., Park, C.G., Hwang, W.S., Lee, J.S., and Ahn, C. (2005). Choice of the adequate detection time for the accurate evaluation of the efficiency of siRNA-induced gene silencing. J Biotechnol 120, 251-261.

Coetzee, W.A., Amarillo, Y., Chiu, J., Chow, A., Lau, D., Mccormack, T., Moreno, H., Nadal, M.S., Ozaita, A., Pountney, D., Saganich, M., Vega-Saenz De Miera, E., and Rudy, B. (1999). Molecular diversity of K+ channels. Ann N Y Acad Sci 868, 233-285.

Coller, H.A., Grandori, C., Tamayo, P., Colbert, T., Lander, E.S., Eisenman, R.N., and Golub, T.R. (2000). Expression analysis with oligonucleotide microarrays reveals that MYC regulates genes involved in growth, cell cycle, signaling, and adhesion. Proc Natl Acad Sci U S A 97, 3260-3265.

Cong, Y.S., Wright, W.E., and Shay, J.W. (2002). Human telomerase and its regulation. Microbiol Mol Biol Rev 66, 407-425, table of contents.

Crociani, O., Guasti, L., Balzi, M., Becchetti, A., Wanke, E., Olivotto, M., Wymore, R.S., and Arcangeli, A. (2003). Cell cycle-dependent expression of HERG1 and HERG1B isoforms in tumor cells. J Biol Chem 278, 2947-2955.

Daude, N., Marella, M., and Chabry, J. (2003). Specific inhibition of pathological prion protein accumulation by small interfering RNAs. J Cell Sci 116, 2775-2779.

Deng, Q., Liao, R., Wu, B.L., and Sun, P. (2004). High intensity ras signaling induces premature senescence by activating p38 pathway in primary human fibroblasts. J Biol Chem 279, 1050-1059.

Eckstein, F. (2005). Small non-coding RNAs as magic bullets. Trends Biochem Sci 30, 445-452.

Editorial (2003). Whither RNAi? Nat Cell Biol 5, 489-490. 
El-Aneed, A. (2004). An overview of current delivery systems in cancer gene therapy. J Control Release 94, 1-14

Elbashir, S.M., Harborth, J., Lendeckel, W., Yalcin, A., Weber, K., and Tuschl, T. (2001). Duplexes of 21-nucleotide RNAs mediate RNA interference in cultured mammalian cells. Nature 411, 494-498.

Folgueras, A.R., Pendas, A.M., Sanchez, L.M., and Lopez-Otin, C. (2004). Matrix metalloproteinases in cancer: from new functions to improved inhibition strategies. Int J Dev Biol 48, 411-424.

Fraser, S.P., Grimes, J.A., Diss, J.K., Stewart, D., Dolly, J.O., and Djamgoz, M.B. (2003). Predominant expression of Kv1.3 voltage-gated $\mathrm{K}+$ channel subunit in rat prostate cancer cell lines: electrophysiological, pharmacological and molecular characterisation. Pflügers Arch 446, 559-571.

García-Ferreiro, R.E., Kerschensteiner, D., Major, F., Monje, F., Stühmer, W., and Pardo, L.A. (2004). Mechanism of Block of hEag1 K ${ }^{+}$Channels by Imipramine and Astemizole. J Gen Physiol 124, 301317.

Gavrilova-Ruch, O., Schonherr, K., Gessner, G., Schonherr, R., Klapperstuck, T., Wohlrab, W., and Heinemann, S.H. (2002). Effects of imipramine on ion channels and proliferation of IGR1 melanoma cells. J Membr Biol 188, 137-149.

Gerth, A., Grosche, J., Nieber, K., and Hauschildt, S. (2005). Intracellular LPS inhibits the activity of potassium channels and fails to activate NFkappaB in human macrophages. J Cell Physiol 202, 442452.

Gomez-Serrano, M., Tonelli, L., Listwak, S., Sternberg, E., and Riley, A.L. (2001). Effects of cross fostering on open-field behavior, acoustic startle, lipopolysaccharide-induced corticosterone release, and body weight in Lewis and Fischer rats. Behav Genet 31, 427-436.

Gong, Q., Keeney, D.R., Robinson, J.C., and Zhou, Z. (2004). Defective assembly and trafficking of mutant HERG channels with C-terminal truncations in long QT syndrome. J Mol Cell Cardiol 37, 1225-1233.

Gopalkrishnan, R.V., Su, Z.Z., Goldstein, N.I., and Fisher, P.B. (1999). Translational infidelity and human cancer: role of the PTI-1 oncogene. Int J Biochem Cell Biol 31, 151-162. 
Graham, F.L., Smiley, J., Russell, W.C., and Nairn, R. (1977). Characteristics of a human cell line transformed by DNA from human adenovirus type 5. J Gen Virol 36, 59-74.

Gross, I., Bassit, B., Benezra, M., and Licht, J.D. (2001). Mammalian sprouty proteins inhibit cell growth and differentiation by preventing ras activation. J Biol Chem 276, 46460-46468.

Gudi, R., Bowker-Kinley, M.M., Kedishvili, N.Y., Zhao, Y., and Popov, K.M. (1995). Diversity of the pyruvate dehydrogenase kinase gene family in humans. J Biol Chem 270, 28989-28994.

Guha, M., and Mackman, N. (2002). The phosphatidylinositol 3-kinase-Akt pathway limits lipopolysaccharide activation of signaling pathways and expression of inflammatory mediators in human monocytic cells. J Biol Chem 277, 32124-32132.

Gurney, A.M., and Hunter, E. (2005). The use of small interfering RNA to elucidate the activity and function of ion channel genes in an intact tissue. J Pharmacol Toxicol Methods 51, 253-262.

Hahn, W.C., and Weinberg, R.A. (2002). Modelling the molecular circuitry of cancer. Nat Rev Cancer 2, 331-341.

Hamill, O.P., Marty, A., Neher, E., Sakmann, B., and Sigworth, F.J. (1981). Improved patch-clamp techniques for high-resolution current recording from cells and cell-free membrane patches. Pflügers Archiv European Journal of Physiology 391, 85-100.

Han, B., Nakamura, M., Mori, I., Nakamura, Y., and Kakudo, K. (2005). Urokinase-type plasminogen activator system and breast cancer (Review). Oncol Rep 14, 105-112.

Harley, C.B. (2002). Telomerase is not an oncogene. Oncogene 21, 494-502.

Hemmerlein, B., Weseloh , R.M., Queiroz, F.M., Knötgen, H., Sánchez, A., Rubio, M.E., Martin, S., Schliephacke, T., Jenke, M., Radzun, H.J., Stühmer, W., and Pardo, L.A. (2006). Frequent overexpression of Eag1 potassium channels in clinical tumour specimens. Cancer Cell Biol, submitted.

Holen, T., and Mobbs, C.V. (2004). Lobotomy of genes: use of RNA interference in neuroscience. Neuroscience 126, 1-7. 
Hoshi, N., Takahashi, H., Shahidullah, M., Yokoyama, S., and Higashida, H. (1998). KCR1, a membrane protein that facilitates functional expression of non-inactivating $\mathrm{K}+$ currents associates with rat EAG voltage-dependent K+ channels. J Biol Chem 273, 23080-23085.

Hu, Y., Uttamchandani, M., and Yao, S.Q. (2006). Microarray: a versatile platform for highthroughput functional proteomics. Comb Chem High Throughput Screen 9, 203-212.

Huang, S., Armstrong, E.A., Benavente, S., Chinnaiyan, P., and Harari, P.M. (2004). Dual-agent molecular targeting of the epidermal growth factor receptor (EGFR): combining anti-EGFR antibody with tyrosine kinase inhibitor. Cancer Res 64, 5355-5362.

Huesken, D., Lange, J., Mickanin, C., Weiler, J., Asselbergs, F., Warner, J., Meloon, B., Engel, S., Rosenberg, A., Cohen, D., Labow, M., Reinhardt, M., Natt, F., and Hall, J. (2005). Design of a genome-wide siRNA library using an artificial neural network. Nat Biotechnol 23, 995-1001.

Huppi, K., Martin, S.E., and Caplen, N.J. (2005). Defining and assaying RNAi in mammalian cells. Mol Cell 17, 1-10.

Hutvagner, G., and Zamore, P.D. (2002). A microRNA in a multiple-turnover RNAi enzyme complex. Science 297, 2056-2060.

Iniguez-Lluhi, J., Kleuss, C., and Gilman, A.G. (1993). The importance of G-protein beta lambda subunits. Trends Cell Biol 3, 230-236.

Ioachim, E., Charchanti, A., Briasoulis, E., Karavasilis, V., Tsanou, H., Arvanitis, D.L., Agnantis, N.J., and Pavlidis, N. (2002). Immunohistochemical expression of extracellular matrix components tenascin, fibronectin, collagen type IV and laminin in breast cancer: their prognostic value and role in tumour invasion and progression. Eur J Cancer 38, 2362-2370.

Izquierdo, M. (2005). Short interfering RNAs as a tool for cancer gene therapy. Cancer Gene Ther 12, 217-227.

Jeng, C.J., Chang, C.C., and Tang, C.Y. (2005). Differential localization of rat Eag1 and Eag2 K+ channels in hippocampal neurons. Neuroreport 16, 229-233.

Jenke, M., Sánchez, A., Monje, F., Stühmer, W., Weseloh, R.M., and Pardo, L.A. (2003). C-terminal domains implicated in the functional surface expression of potassium channels. Embo J 22, 395-403. 
Jimenez, C., Jones, D.R., Rodriguez-Viciana, P., Gonzalez-Garcia, A., Leonardo, E., Wennstrom, S., Von Kobbe, C., Toran, J.L., L, R.B., Calvo, V., Copin, S.G., Albar, J.P., Gaspar, M.L., Diez, E., Marcos, M.A., Downward, J., Martinez, A.C., Merida, I., and Carrera, A.C. (1998). Identification and characterization of a new oncogene derived from the regulatory subunit of phosphoinositide 3-kinase. Embo J 17, 743-753.

Jou, I., Pyo, H., Chung, S., Jung, S.Y., Gwag, B.J., and Joe, E.H. (1998). Expression of Kv1.5 K+ channels in activated microglia in vivo. Glia 24, 408-414.

Ju, M., and Wray, D. (2006). Molecular regions responsible for differences in activation between heag channels. Biochem Biophys Res Commun 342, 1088-1097.

Kabilova, T.O., Chernolovskaya, E.L., Vladimirova, A.V., and Vlassov, V.V. (2006). Inhibition of human carcinoma and neuroblastoma cell proliferation by anti-c-myc siRNA. Oligonucleotides 16, 1525 .

Kaplan, W.D., and Trout, W.E., 3rd (1969). The behavior of four neurological mutants of Drosophila. Genetics 61, 399-409.

Kappler, R., Calzada-Wack, J., Schnitzbauer, U., Koleva, M., Herwig, A., Piontek, G., Graedler, F., Adamski, J., Heinzmann, U., Schlegel, J., Hemmerlein, B., Quintanilla-Martinez, L., and Hahn, H. (2003). Molecular characterization of Patched-associated rhabdomyosarcoma. J Pathol 200, 348-356.

Kupershmidt, S., Yang, T., Chanthaphaychith, S., Wang, Z., Towbin, J.A., and Roden, D.M. (2002). Defective human Ether-a-go-go-related gene trafficking linked to an endoplasmic reticulum retention signal in the C terminus. J Biol Chem 277, 27442-27448.

Lovell, P.V., King, J.T., and Mccobb, D.P. (2004). Acute modulation of adrenal chromaffin cell BK channel gating and cell excitability by glucocorticoids. J Neurophysiol 91, 561-570.

Ludwig, J., Owen, D., and Pongs, O. (1997). Carboxy-terminal domain mediates assembly of the voltage-gated rat ether-a-go-go potassium channel. Embo J 16, 6337-6345.

Ludwig, J., Terlau, H., Wunder, F., Brüggemann, A., Pardo, L.A., Marquardt, A., Stühmer, W., and Pongs, O. (1994). Functional expression of a rat homologue of the voltage gated either a go-go potassium channel reveals differences in selectivity and activation kinetics between the Drosophila channel and its mammalian counterpart. EMBO Journal 13, 4451-4458. 
Ludwig, J., Weseloh, R., Karschin, C., Liu, Q., Netzer, R., Engeland, B., Stansfeld, C., and Pongs, O. (2000). Cloning and functional expression of rat eag2, a new member of the ether-a-go-go family of potassium channels and comparison of its distribution with that of eag1. Mol Cell Neurosci 16, 59-70.

Ludwig, T., Puttmann, S., Bertram, H., Tatenhorst, L., Paulus, W., Oberleithner, H., and Senner, V. (2005). Functional measurement of local proteolytic activity in living cells of invasive and noninvasive tumors. J Cell Physiol 202, 690-697.

Lynch, T.J., Bell, D.W., Sordella, R., Gurubhagavatula, S., Okimoto, R.A., Brannigan, B.W., Harris, P.L., Haserlat, S.M., Supko, J.G., Haluska, F.G., Louis, D.N., Christiani, D.C., Settleman, J., and Haber, D.A. (2004). Activating mutations in the epidermal growth factor receptor underlying responsiveness of non-small-cell lung cancer to gefitinib. N Engl J Med 350, 2129-2139.

Malek, S.N., Dordai, D.I., Reim, J., Dintzis, H., and Desiderio, S. (1998). Malignant transformation of early lymphoid progenitors in mice expressing an activated Blk tyrosine kinase. Proc Natl Acad Sci U S A 95, 7351-7356.

Mamidipudi, V., Zhang, J., Lee, K.C., and Cartwright, C.A. (2004). RACK1 regulates G1/S progression by suppressing Src kinase activity. Mol Cell Biol 24, 6788-6798.

Mansi, J.A., Rivest, S., and Drolet, G. (1998). Effect of immobilization stress on transcriptional activity of inducible immediate-early genes, corticotropin-releasing factor, its type 1 receptor, and enkephalin in the hypothalamus of borderline hypertensive rats. J Neurochem 70, 1556-1566.

Marrion, N.V. (1997). Does r-EAG contribute to the M-current? Trends Neurosci 20, 243-244.

Mathie, A., and Watkins, C.S. (1997). Is EAG the answer to the M-current? Trends Neurosci 20, 14.

McCaffrey, A.P., Meuse, L., Pham, T.T., Conklin, D.S., Hannon, G.J., and Kay, M.A. (2002). RNA interference in adult mice. Nature 418, 38-39.

Meyer, R., Schonherr, R., Gavrilova-Ruch, O., Wohlrab, W., and Heinemann, S.H. (1999). Identification of ether a go-go and calcium-activated potassium channels in human melanoma cells. J Membr Biol 171, 107-115.

Miller, C. (2000). An overview of the potassium channel family. Genome Biol 1, REVIEWS0004. 
Minks, M.A., West, D.K., Benvin, S., and Baglioni, C. (1979). Structural requirements of doublestranded RNA for the activation of 2',5'-oligo(A) polymerase and protein kinase of interferon-treated HeLa cells. J Biol Chem 254, 10180-10183.

Mook, O.R., Frederiks, W.M., and Van Noorden, C.J. (2004). The role of gelatinases in colorectal cancer progression and metastasis. Biochim Biophys Acta 1705, 69-89.

Morais Cabral, J.H., Lee, A., Cohen, S.L., Chait, B.T., Li, M., and Mackinnon, R. (1998). Crystal structure and functional analysis of the HERG potassium channel $\mathrm{N}$ terminus: a eukaryotic PAS domain. Cell 95, 649-655.

Mu, D., Chen, L., Zhang, X., See, L.H., Koch, C.M., Yen, C., Tong, J.J., Spiegel, L., Nguyen, K.C., Servoss, A., Peng, Y., Pei, L., Marks, J.R., Lowe, S., Hoey, T., Jan, L.Y., Mccombie, W.R., Wigler, M.H., and Powers, S. (2003). Genomic amplification and oncogenic properties of the KCNK9 potassium channel gene. Cancer Cell 3, 297-302.

Mullis, K.B., and Faloona, F.A. (1987). Specific synthesis of DNA in vitro via a polymerase-catalyzed chain reaction. Methods Enzymol 155, 335-350.

Napp, J. (2003). N-linked glycosylation if ether à-go-go potassium channels: effects on cell surface expression and functional properties. PhD-Thesis, Georg-August University Göttingen.

Napp, J., Monje, F., Stühmer, W., and Pardo, L.A. (2005). Glycosylation of Eag1 (Kv10.1) potassium channels: intracellular trafficking and functional consequences. J Biol Chem 280, 29506-29512.

Neer, E.J., Denker, B.M., Thomas, T.C., and Schmidt, C.J. (1994). Analysis of G-protein alpha and beta gamma subunits by in vitro translation. Methods Enzymol 237, 226-239.

Nilsson, J.A., and Cleveland, J.L. (2003). Myc pathways provoking cell suicide and cancer. Oncogene 22, 9007-9021.

Nishiyama, A., Kambe, F., Kamiya, K., Kurokouchi, K., Kanda, K., Murata, Y., Toyama, J., and Seo, H. (1995). Effects of stress on Kv1.5 K+ channel gene expression in the left ventricle of rat hearts. Environ Med 39, 141-144.

Novina, C.D., and Sharp, P.A. (2004). The RNAi revolution. Nature 430, 161-164. 
Occhiodoro, T., Bernheim, L., Liu, J.H., Bijlenga, P., Sinnreich, M., Bader, C.R., and FischerLougheed, J. (1998). Cloning of a human ether-a-go-go potassium channel expressed in myoblasts at the onset of fusion. FEBS Lett 434, 177-182.

Okamoto, S., Sherman, K., Bai, G., and Lipton, S.A. (2002). Effect of the ubiquitous transcription factors, SP1 and MAZ, on NMDA receptor subunit type 1 (NR1) expression during neuronal differentiation. Brain Res Mol Brain Res 107, 89-96.

Ouadid-Ahidouch, H., Le Bourhis, X., Roudbaraki, M., Toillon, R.A., Delcourt, P., and Prevarskaya, N. (2001). Changes in the K+ current-density of MCF-7 cells during progression through the cell cycle: possible involvement of a h-ether.a-gogo K+ channel. Receptors Channels 7, 345-356.

Overall, C.M., and Kleifeld, O. (2006). Tumour microenvironment - opinion: validating matrix metalloproteinases as drug targets and anti-targets for cancer therapy. Nat Rev Cancer 6, 227-239.

Pardo, L.A., Del Camino, D., Sánchez, A., Alves, F., Brüggemann, A., Beckh, S., and Stühmer, W. (1999). Oncogenic potential of EAG K ${ }^{+}$channels. Embo J 18, 5540-5547.

Parks, C.L., and Shenk, T. (1996). The serotonin 1a receptor gene contains a TATA-less promoter that responds to MAZ and Sp1. J Biol Chem 271, 4417-4430.

Patt, S., Preussat, K., Beetz, C., Kraft, R., Schrey, M., Kalff, R., Schönherr, K., and Heinemann, S.H. (2004). Expression of ether a go-go potassium channels in human gliomas. Neurosci Lett 368, 249253.

Pei, L., Wiser, O., Slavin, A., Mu, D., Powers, S., Jan, L.Y., and Hoey, T. (2003). Oncogenic potential of TASK3 (Kcnk9) depends on K+ channel function. Proc Natl Acad Sci U S A 100, 7803-7807.

Persengiev, S.P., Zhu, X., and Green, M.R. (2004). Nonspecific, concentration-dependent stimulation and repression of mammalian gene expression by small interfering RNAs (siRNAs). Rna 10, 12-18.

Persson, A.S., Klement, G., Almgren, M., Sahlholm, K., Nilsson, J., Petersson, S., Arhem, P., Schalling, M., and Lavebratt, C. (2005). A truncated Kv1.1 protein in the brain of the megencephaly mouse: expression and interaction. BMC Neurosci 6, 65. 
Peyrl, A., Krapfenbauer, K., Slavc, I., Yang, J.W., Strobel, T., and Lubec, G. (2003). Protein profiles of medulloblastoma cell lines DAOY and D283: identification of tumor-related proteins and principles. Proteomics 3, 1781-1800.

Piros, E.T., Shen, L., and Huang, X.Y. (1999). Purification of an EH domain-binding protein from rat brain that modulates the gating of the rat ether-a-go-go channel. J Biol Chem 274, 33677-33683.

Preussat, K., Beetz, C., Schrey, M., Kraft, R., Wolfl, S., Kalff, R., and Patt, S. (2003). Expression of voltage-gated potassium channels Kv1.3 and Kv1.5 in human gliomas. Neurosci Lett 346, 33-36.

Prime, G., Horn, G., and Sutor, B. (2000). Time-related changes in connexin mRNA abundance in the rat neocortex during postnatal development. Brain Res Dev Brain Res 119, 111-125.

Pyo, H., Chung, S., Jou, I., Gwag, B., and Joe, E.H. (1997). Expression and function of outward K+ channels induced by lipopolysaccharide in microglia. Mol Cells 7, 610-614.

Queiroz, F.M., Suarez-Kurtz, G., Stühmer, W., and Pardo, L.A. (2006). Ether a go-go potassium channel expression in soft tissue sarcoma patients. Int J Cancer, submitted.

Radulovic, M., Dautzenberg, F.M., Sydow, S., Radulovic, J., and Spiess, J. (1999). Corticotropinreleasing factor receptor 1 in mouse spleen: expression after immune stimulation and identification of receptor-bearing cells. J Immunol 162, 3013-3021.

Radulovic, M., Weber, C., and Spiess, J. (2000). The effect of acute immobilization stress on the abundance of corticotropin-releasing factor receptor in lymphoid organs. J Neuroimmunol 103, 153164.

Razin, S., Yogev, D., and Naot, Y. (1998). Molecular biology and pathogenicity of mycoplasmas. Microbiol Mol Biol Rev 62, 1094-1156.

Rivest, S., Laflamme, N., and Nappi, R.E. (1995). Immune challenge and immobilization stress induce transcription of the gene encoding the CRF receptor in selective nuclei of the rat hypothalamus. $\mathrm{J}$ Neurosci 15, 2680-2695.

Ross, D.T., Scherf, U., Eisen, M.B., Perou, C.M., Rees, C., Spellman, P., Iyer, V., Jeffrey, S.S., Van De Rijn, M., Waltham, M., Pergamenschikov, A., Lee, J.C., Lashkari, D., Shalon, D., Myers, T.G., 
Weinstein, J.N., Botstein, D., and Brown, P.O. (2000). Systematic variation in gene expression patterns in human cancer cell lines. Nat Genet 24, 227-235.

Rubinson, D.A., Dillon, C.P., Kwiatkowski, A.V., Sievers, C., Yang, L., Kopinja, J., Rooney, D.L., Ihrig, M.M., Mcmanus, M.T., Gertler, F.B., Scott, M.L., and Van Parijs, L. (2003). A lentivirus-based system to functionally silence genes in primary mammalian cells, stem cells and transgenic mice by RNA interference. Nat Genet 33, 401-406.

Russo, J., Yang, X., Hu, Y.F., Bove, B.A., Huang, Y., Silva, I.D., Tahin, Q., Wu, Y., Higgy, N., Zekri, A., and Russo, I.H. (1998). Biological and molecular basis of human breast cancer. Front Biosci 3, D944-960.

Saganich, M.J., Machado, E., and Rudy, B. (2001). Differential expression of genes encoding subthreshold-operating voltage-gated $\mathrm{k}+$ channels in brain. J Neurosci 21, 4609-4624.

Saiki, R.K., Gelfand, D.H., Stoffel, S., Scharf, S.J., Higuchi, R., Horn, G.T., Mullis, K.B., and Erlich, H.A. (1988). Primer-directed enzymatic amplification of DNA with a thermostable DNA polymerase. Science 239, 487-491.

Sands, Z., Grottesi, A., and Sansom, M.S. (2005). Voltage-gated ion channels. Curr Biol 15, R44-47.

Schechtman, D., and Mochly-Rosen, D. (2001). Adaptor proteins in protein kinase C-mediated signal transduction. Oncogene 20, 6339-6347.

Schena, M., Shalon, D., Davis, R.W., and Brown, P.O. (1995). Quantitative monitoring of gene expression patterns with a complementary DNA microarray. Science 270, 467-470.

Schönherr, R., Lober, K., and Heinemann, S.H. (2000). Inhibition of human ether a go-go potassium channels by $\mathrm{Ca}(2+) /$ calmodulin. EMBO Journal 19, 3263-3271.

Schönherr, R., Mannuzzu, L.M., Isacoff, E.Y., and Heinemann, S.H. (2002). Conformational switch between slow and fast gating modes: allosteric regulation of voltage sensor mobility in the EAG K+ channel. Neuron 35, 935-949.

Secombe, J., Pierce, S.B., and Eisenman, R.N. (2004). Myc: a weapon of mass destruction. Cell 117, 153-156. 
Sellappan, S., Grijalva, R., Zhou, X., Yang, W., Eli, M.B., Mills, G.B., and Yu, D. (2004). Lineage infidelity of MDA-MB-435 cells: expression of melanocyte proteins in a breast cancer cell line. Cancer Res 64, 3479-3485.

Sherr, C.J. (2004). Principles of tumor suppression. Cell 116, 235-246.

Shi, W., Wang, H.S., Pan, Z., Wymore, R.S., Cohen, I.S., Mckinnon, D., and Dixon, J.E. (1998). Cloning of a mammalian elk potassium channel gene and EAG mRNA distribution in rat sympathetic ganglia. J Physiol 511 ( Pt 3), 675-682.

Shikano, S., and Li, M. (2003). Membrane receptor trafficking: evidence of proximal and distal zones conferred by two independent endoplasmic reticulum localization signals. Proc Natl Acad Sci U S A $100,5783-5788$.

Singh, A.K., and Jiang, Y. (2004). How does peripheral lipopolysaccharide induce gene expression in the brain of rats? Toxicology 201, 197-207.

Sledz, C.A., and Williams, B.R. (2004). RNA interference and double-stranded-RNA-activated pathways. Biochem Soc Trans 32, 952-956.

Smith, M.L., Chen, I.T., Zhan, Q., Bae, I., Chen, C.Y., Gilmer, T.M., Kastan, M.B., O'connor, P.M., and Fornace, A.J., Jr. (1994). Interaction of the p53-regulated protein Gadd45 with proliferating cell nuclear antigen. Science 266, 1376-1380.

Smyth, M.J., Cretney, E., Kershaw, M.H., and Hayakawa, Y. (2004). Cytokines in cancer immunity and immunotherapy. Immunol Rev 202, 275-293.

Soldovieri, M.V., Castaldo, P., Iodice, L., Miceli, F., Barrese, V., Bellini, G., Miraglia Del Giudice, E., Pascotto, A., Bonatti, S., Annunziato, L., and Taglialatela, M. (2006). Decreased subunit stability as a novel mechanism for potassium current impairment by a KCNQ2 C terminus mutation causing benign familial neonatal convulsions. J Biol Chem 281, 418-428.

Sordella, R., Bell, D.W., Haber, D.A., and Settleman, J. (2004). Gefitinib-sensitizing EGFR mutations in lung cancer activate anti-apoptotic pathways. Science 305, 1163-1167.

Stork, P.J., and Schmitt, J.M. (2002). Crosstalk between cAMP and MAP kinase signaling in the regulation of cell proliferation. Trends Cell Biol 12, 258-266. 
Terlau, H., Ludwig, J., Steffan, R., Pongs, O., Stühmer, W., and Heinemann, S.H. (1996). Extracellular Mg2 + regulates activation of rat eag potassium channel. Pflügers Arch 432, 301-312.

Thomas, D., Wimmer, A.B., Wu, K., Hammerling, B.C., Ficker, E.K., Kuryshev, Y.A., Kiehn, J., Katus, H.A., Schoels, W., and Karle, C.A. (2004a). Inhibition of human ether-a-go-go-related gene potassium channels by alpha 1-adrenoceptor antagonists prazosin, doxazosin, and terazosin. Naunyn Schmiedebergs Arch Pharmacol 369, 462-472.

Thomas, D., Wu, K., Wimmer, A.B., Zitron, E., Hammerling, B.C., Kathofer, S., Lueck, S., Bloehs, R., Kreye, V.A., Kiehn, J., Katus, H.A., Schoels, W., and Karle, C.A. (2004b). Activation of cardiac human ether-a-go-go related gene potassium currents is regulated by alpha(1A)-adrenoceptors. J Mol Med 82, 826-837.

Tracy, S., Mukohara, T., Hansen, M., Meyerson, M., Johnson, B.E., and Janne, P.A. (2004). Gefitinib induces apoptosis in the EGFRL858R non-small-cell lung cancer cell line H3255. Cancer Res 64, $7241-7244$.

Triantafilou, M., and Triantafilou, K. (2002). Lipopolysaccharide recognition: CD14, TLRs and the LPS-activation cluster. Trends Immunol 23, 301-304.

Trimmer, J.S. (1998). Regulation of ion channel expression by cytoplasmic subunits. Curr Opin Neurobiol 8, 370-374.

Trost, T.M., Lausch, E.U., Fees, S.A., Schmitt, S., Enklaar, T., Reutzel, D., Brixel, L.R., Schmidtke, P., Maringer, M., Schiffer, I.B., Heimerdinger, C.K., Hengstler, J.G., Fritz, G., Bockamp, E.O., Prawitt, D., Zabel, B.U., and Spangenberg, C. (2005). Premature senescence is a primary fail-safe mechanism of ERBB2-driven tumorigenesis in breast carcinoma cells. Cancer Res 65, 840-849.

Tsutsui, H., Sakatsume, O., Itakura, K., and Yokoyama, K.K. (1996). Members of the MAZ family: a novel cDNA clone for MAZ from human pancreatic islet cells. Biochem Biophys Res Commun 226, 801-809.

Tulac, S., Dosiou, C., Suchanek, E., and Giudice, L.C. (2004). Silencing lamin A/C in human endometrial stromal cells: a model to investigate endometrial gene function and regulation. Mol Hum Reprod 10, 705-711. 
Ugai, H., Li, H.O., Komatsu, M., Tsutsui, H., Song, J., Shiga, T., Fearon, E., Murata, T., and Yokoyama, K.K. (2001). Interaction of Myc-associated zinc finger protein with DCC, the product of a tumor-suppressor gene, during the neural differentiation of P19 EC cells. Biochem Biophys Res Commun 286, 1087-1097.

Valenti, M.T., Bertoldo, F., Dalle Carbonare, L., Azzarello, G., Zenari, S., Zanatta, M., Balducci, E., Vinante, O., and Lo Cascio, V. (2006). The Effect of Bisphosphonates on gene expression: GAPDH as a housekeeping or a new target gene? BMC Cancer 6, 49.

Van 't Veer, L.J., Dai, H., Van De Vijver, M.J., He, Y.D., Hart, A.A., Mao, M., Peterse, H.L., Van Der Kooy, K., Marton, M.J., Witteveen, A.T., Schreiber, G.J., Kerkhoven, R.M., Roberts, C., Linsley, P.S., Bernards, R., and Friend, S.H. (2002). Gene expression profiling predicts clinical outcome of breast cancer. Nature 415, 530-536.

Van Kuppeveld, F.J., Johansson, K.E., Galama, J.M., Kissing, J., Bolske, G., Hjelm, E., Van Der Logt, J.T., and Melchers, W.J. (1994a). 16S rRNA based polymerase chain reaction compared with culture and serological methods for diagnosis of Mycoplasma pneumoniae infection. Eur J Clin Microbiol Infect Dis 13, 401-405.

Van Kuppeveld, F.J., Johansson, K.E., Galama, J.M., Kissing, J., Bolske, G., Van Der Logt, J.T., and Melchers, W.J. (1994b). Detection of mycoplasma contamination in cell cultures by a mycoplasma group-specific PCR. Appl Environ Microbiol 60, 149-152.

Vickers, T.A., Koo, S., Bennett, C.F., Crooke, S.T., Dean, N.M., and Baker, B.F. (2003). Efficient reduction of target RNAs by small interfering RNA and RNase H-dependent antisense agents. A comparative analysis. J Biol Chem 278, 7108-7118.

Wang, J., and Barr, M.M. (2005). RNA interference in Caenorhabditis elegans. Methods Enzymol 392, 36-55.

Warmke, J.W., and Ganetzki, B. (1994). A family of potassium channel genes related to eag in drosophila and mammals. Proc Natl Acad Sci USA 91, 3438-3442.

Wilson, G.F., Wang, Z., Chouinard, S.W., Griffith, L.C., and Ganetzky, B. (1998). Interaction of the K channel beta subunit, Hyperkinetic, with eag family members. J Biol Chem 273, 6389-6394. 
Yakubovich, N., Eldstrom, J.R., and Mathers, D.A. (2001). Lipopolysaccharide can activate BK channels of arterial smooth muscle in the absence of iNOS expression. Biochim Biophys Acta 1514, 239-252.

Yang, M., Chishima, T., Wang, X., Baranov, E., Shimada, H., Moossa, A.R., and Hoffman, R.M. (1999). Multi-organ metastatic capability of Chinese hamster ovary cells revealed by green fluorescent protein (GFP) expression. Clin Exp Metastasis 17, 417-422.

Yao, C., Li, X., Murdiastuti, K., Kosugi-Tanaka, C., Akamatsu, T., Kanamori, N., and Hosoi, K. (2005). Lipopolysaccharide-induced elevation and secretion of interleukin-1beta in the submandibular gland of male mice. Immunology 116, 213-222.

Yoshida, K., and Miki, Y. (2004). Role of BRCA1 and BRCA2 as regulators of DNA repair, transcription, and cell cycle in response to DNA damage. Cancer Sci 95, 866-871.

Zeng, W.R., Scherer, S.W., Koutsilieris, M., Huizenga, J.J., Filteau, F., Tsui, L.C., and Nepveu, A. (1997). Loss of heterozygosity and reduced expression of the CUTL1 gene in uterine leiomyomas. Oncogene 14, 2355-2365.

Zhou, Z., Vorperian, V.R., Gong, Q., Zhang, S., and January, C.T. (1999). Block of HERG potassium channels by the antihistamine astemizole and its metabolites desmethylastemizole and norastemizole. Journal of Cardiovascular Electrophysiology 10, 836-843. 


\section{......ein grosses Danke an.....}

...Herrn Prof. Dr. Rüdiger Hardeland und Prof. Dr. Andreas Stumpner für ihre freundliche Bereitschaft, die externe Betreuung dieser Dissertation zu übernehmen. Insbesondere Herr Prof. Dr. Hardeland hat mir durch seine kompetenten und konstruktiven Anmerkungen zu meiner Arbeit wieder einmal weitergeholfen.

...Herrn. Prof. Dr. Walter Stühmer für die Überlassung dieses interessanten Themas, für die Möglichkeit, in seinem Labor diese Arbeit anfertigen zu können und seine Hilfsbereitschaft.

...Herrn Dr. Luis Pardo für seine Betreuung und Bereitschaft, stundenlange wissenschaftliche (...und unwissenschaftliche...:-..) Diskussionen zu führen.

...Dr. Joanna Napp, Dr. Synnöve Beckh, Ute Rust, Dr. Sabine Martin und Kerstin Boerst für das fleissige und konstruktive Korrekturlesen dieser Arbeit.

...Herrn Dr. James Adjaye, Dr. Ralf Herwig und Prof. Dr. Lehrach für die freundliche Aufnahme in ihrem Labor während der Zusammenarbeit.

...Ursula Kutzke, Jasmin Djannatian, Dr. Joanna Napp und Dr. Sabine Martin für die Diskussionen über viele kleine Sachen, die einem im Laboralltag extrem weiterhelfen.

...Dr. Fernanda Mello de Queiroz, Bryan E. Downie und Dr. Arnt Suckow für eine erfolgreiche Zusammenarbeit für das siRNA-Paper

...meine Freunde Steffie, Melli, Nette, Tömö, Rüdi, Henni, Carsten, Imke, Dirk und Marianne (und ihre „Jungs“ und mein „Mädchen“), Carmen und Rainer und Karsten, Kurt und Thorsten, die mir in Zeiten der Frustration immer zur Seite gestanden haben, um mich aufzumuntern, jeder auf seine ganz spezielle Weise.....:-; !

Schön, dass es Euch gibt!!!!

...und ein gaaaaaanz, gaaaaaanz riesiges herzliches Dankeschön an meine Eltern, die mich immer in jeglicher Hinsicht unterstützt haben und stets ein aufmunterndes Wort parat hatten. 


\section{Lebenslauf}

$\begin{array}{ll}\text { Name } & \text { Claudia Weber } \\ \text { Geburtsdatum } & 23.11 .1971 \\ \text { Geburtsort } & \text { Wolfenbüttel } \\ \text { Staatsangehörigkeit } & \text { Deutsch }\end{array}$

\section{Schulische Ausbildung}

$\begin{array}{ll}1978-1982 & \text { Grundschule Cranachstraße in Wolfenbüttel } \\ 1982-1984 & \text { Orientierungsstufe Cranachstraße in Wolfenbüttel } \\ 1984-1991 & \text { Gymnasium im Schloß in Wolfenbüttel } \\ 1991 & \text { Erwerb der Allgemeinen Hochschulreife }\end{array}$

\section{Beruflicher Werdegang}

$1991-1993$

1993

$1993-1998$

1998

$1998-1999$

$1999-2001$
Berufsfachschule Chemie und Pharmazie Dr. v. Morgenstern in Braunschweig

Abschluss zur staatlich anerkannten chemisch-technischen Assistentin

Studium der Biologie an der Georg-August Universität Göttingen Mündliche Diplomprüfung in den Fächern Mikrobiologie, Genetik und Organische Chemie

Diplomarbeit in der Abteilung für Molekulare Neuroendokrinologie bei Prof. Dr. Dr. Joachim Spiess am Max-Planck-Institut für experimentelle Medizin in Göttingen. Titel: Induktion von CRF-R1 in Leukozyten der Maus: Auslösung und Zeitverlauf. Wissenschaftliche Tätigkeit in der Abteilung für Molekulare Neuroendokrinologie bei Dr. Marco Radulovic am Max-Planck- 
Institut für experimentelle Medizin in Göttingen zum Thema:

Signaltransduktion des CRF-Rezeptors.

$2001-2003$

Wissenschaftliche Tätigkeit in der Abteilung für Molekulare

Biologie neuronaler Signale am Max-Planck-Institut für

experimentelle Medizin in Göttingen.

Mai 2003 - 2006

Beginn der Arbeiten zur vorliegenden Dissertation in der Abteilung für Molekulare Biologie neuronaler Signale bei Prof. Dr. Walter Stühmer am Max-Planck-Institut für experimentelle Medizin in Göttingen in der Arbeitsgruppe von Dr. Luis Pardo.

\section{Wissenschaftliche Veröffentlichungen}

Radulovic, M., Weber, C., and Spiess, J. (2000). The effect of acute immobilization stress on the abundance of corticotropin-releasing factor receptor in lymphoid organs. J Neuroimmunol 103, 153-164.

Weber, C., Mello De Queiroz, F., Downie, B.R., Suckow, A., Stuhmer, W., and Pardo, L.A. (2006). Silencing the Activity and Proliferative Properties of the Human EagI Potassium Channel by RNA Interference. J Biol Chem 281, 13030-13037. 